\title{
COMUNICACIÓN EN PREVENCIÓN DE EMERGENCIAS PARA EL PÚBLICO INFANTIL Y ADOLESCENTE : HACIA UN NUEVO MODELO DE GESTIÓN
}

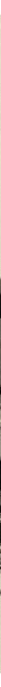

TESIS DOCTORAL $\quad 2015$

Autora: Amanda Vilar Igualada

Dirección: Eva Breva Franch y Magdalena Mut Camacho

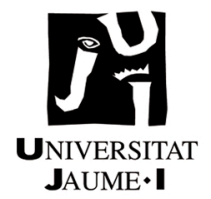

Departamento de Ciencias de la Comunicación

Doctorado en Comunicación Empresarial e Institucional 


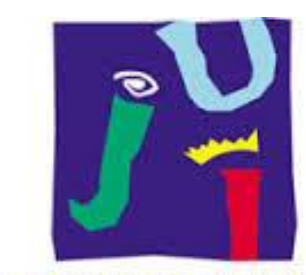

UNIVERSITAT

JAUME•I

Universitat Jaume I de Castelló

Departamento de Ciencias de la Comunicación

Doctorado en Comunicación Empresarial e Institucional

TESIS DOCTORAL

COMUNICACIÓN EN PREVENCIÓN DE EMERGENCIAS PARA EL PÚBLICO

INFANTIL Y ADOLESCENTE:

HACIA UN NUEVO MODELO DE GESTIÓN

Autora: Amanda Vilar Igualada

Dirección: Eva Breva Franch y Magdalena Mut Camacho 


\section{AGRADECIMIENTOS}

La investigación científica nos permite acercarnos a una realidad para tratar de observarla y explicarla, e incluso para intentar predecirla. Desde la formulación de la hipótesis hasta la aplicación de los mecanismos para verificarla se produce un proceso que de alguna forma, se asemeja a un viaje: un viaje que parte de un lugar de origen para tratar de aproximarse a otro lugar que vale la pena conocer.

En ese trayecto, el investigador emprenderá un recorrido para acercarse a ese lugar, a esa realidad, y pondrá en su mochila de viaje libros y teorías, métodos y datos, consultará los mapas que ya otros viajeros realizaron previamente y se esforzará por incorporar nuevos apuntes y dibujos. Incluso, en ocasiones, se verá alentado por la osadía que le llevará a adentrarse por senderos aún no explorados por otros viajeros, para descubrir con suerte algún nuevo camino o, en muchas ocasiones, para tener que desandar cabizbajo esa senda, al comprender que había errado en sus cálculos.

Sí, la investigación es un viaje, y como en todos, hay otras personas que también comparten ese camino. Quisiera agradecer en estas líneas a todas aquellas personas e instituciones que han formado parte de este proceso de investigación. En primer lugar, a las directoras de la tesis, Eva Breva y Magdalena Mut, cuyas indicaciones han resultado muy valiosas para distintos puntos de este recorrido, convirtiéndose en la brújula que siempre apuntaba al Norte.

Quisiera destacar también la participación del Consorcio de Bomberos de Castellón, en la fase empírica de esta investigación, y su generosa y activa colaboración en distintas actividades. Asimismo, gracias al equipo directivo, a la persona encargada del proyecto de riesgos laborales, maestros, personal en general y niños y niñas del Colegio Grangel Mascarós de l'Alcora (Castellón) por su implicación entusiasta que permitió convertir su centro educativo en un motivador espacio de experimentación.

Por otra parte, fue también muy valioso el tiempo que brindaron los distintos organismos públicos, fundaciones y agrupaciones que participaron en la fase de entrevistas en profundidad, porque de ese tiempo y esas conversaciones surgieron numerosos datos y detalles de gran valor para la presente investigación. Colaboraron en dichas entrevistas la Dirección General de Protección Civil y Emergencias (Ministerio del Interior), Dirección General de Prevención, Extinción de Incendios y 
Emergencias (Generalitat Valenciana), Iniciativa para la Educación Escolar en Emergencias, Fundación Fuego y Fundación MAPFRE.

Gracias a la labor del Servicio de Información Audiovisual del Consorcio de Bomberos de Castellón (SIAB) , ya que fue mi participación profesional en este servicio la que me hizo comprender la importancia de la prevención y la necesidad de una mayor investigación en esta temática.

No hubiese podido desarrollar esta investigación sin el apoyo de mi familia, mi pareja y mis amigos. Todos ellos han brindado su energía, interés, cooperación y sus palabras, y han realizado observaciones que sin duda habrán contribuido a un mejor desarrollo de este trabajo. Durante el tiempo de la investigación, además, han tenido que disculpar mi ausencia de numerosas citas, así es que la larga lista de cafés pendientes deberá ser debidamente compensada.

Para finalizar, mi agradecimiento y homenaje a la memoria del catedrático Rafael López Lita, quien me guió en el proyecto de investigación que precedió a esta tesis, dejando útiles enseñanzas para todas las investigaciones posteriores. 


\section{ÍNDICE}

\section{INTRODUCCIÓN (7)}

\section{CAPÍTULO 1. PROBLEMA DE INVESTIGACIÓN (11)}

1.1. Objetivos de la investigación (11)

1.2. Hipótesis y objeto de la investigación (13)

1.3. Ámbito territorial (15)

1.4. Fases de la investigación y metodología (15)

1.5. Fuentes (17)

1.6 Cuadros y gráficos (18)

CAPÍTULO 2. MARCO TEÓRICO (19)

2.1. LA INFORMACIÓN PREVENTIVA EN LAS INSTITUCIONES PÚBLICAS (19)

2.1.1.Glosario (19)

2.1.2. Marco legal de la información preventiva en España (29)

2.1.3. Hacia una cultura mundial de la prevención (40)

2.1.3.1. La cultura mundial de la prevención en el discurso de la ONU (40)

2.1.3.2. Conclusiones (54)

\subsection{EL NIÑO EN EL MAPA DE PÚBLICOS DE LA PREVENCIÓN (58)}

2.2.1. Introducción (58)

2.2.2. Marco social: ¿un entorno concienciado? (59)

2.2.3. Niños y prevención: marco legal (65)

2.2.4. La figura del niño en el discurso internacional (72)

2.2.5. Prevención y currículo escolar. Mejores prácticas (84)

2.2.6. Investigación comunicativa y social en desastres (96)

2.2.6.1. Orígenes (96)

2.2.6.2. Actores (98) 


\subsection{CARACTERÍSTICAS DE LA INFORMACIÓN PREVENTIVA (101)}

2.3.1. Introducción (101)

2.3.2. Las misiones de la información preventiva (102)

2.3.3. El tiempo preventivo (103)

2.3.4. Los actores preventivos (106)

2.3.5. El contenido preventivo (108)

\section{CAPÍTULO 3. MARCO EMPÍRICO (112)}

\subsection{ENTREVISTAS EN PROFUNDIDAD (112)}

3.1.1. Objetivos, método y composición de la muestra (112)

3.1.2. Cuestionario (113)

3.1.3. Análisis de las entrevistas en profundidad (115)

3.1.4. Conclusiones de las entrevistas en profundidad (127)

\subsection{ESTUDIO DE CASO. LA PREVENCIÓN EN LAS WEBS INSTITUCIONALES ESPAÑOLAS (132)}

\subsubsection{Características de la investigación (132)}

3.2.2. Resultados (139)

3.2.3. Análisis de resultados (146)

3.2.3.1. Comparativa de contenidos dirigidos a niños y a adultos (146)

3.2.3.2. Análisis de los formatos más utilizados para infancia y adolescencia (148)

3.2.3.3. Diferencias con los formatos dedicados a un público general (169)

3.2.3.4. Formato de interfaz pedagógica (175)

3.2.3.5. El vídeo como recurso (182)

3.2.4. Resumen de conclusiones (190)

3.2.5. Otros ejemplos: Web de la Agencia Federal para el control de las Emergencias de los Estados Unidos (FEMA) (191)

3.3. ESTUDIO DE CASO. SIMULACROS Y FORMACIÓN PREVENTIVA EN EL COLEGIO GRANGEL MASCARÓS DE L'ALCORA ( CASTELLÓN) (206) 
3.3.1. Justificación de la investigación (206)

3.3.2. Observación de un simulacro de evacuación (207)

3.3.3. Propuesta de modelo de informe comunicativo de simulacro escolar (210)

3.3.4. Intervención en los procesos comunicativos del centro escolar en materia de prevención de emergencias. Propuestas de investigación-acción (223)

3.3.4.1. Introducción (223)

3.3.4.2. Incorporación de documentación y creación de un manual de comunicación en situaciones de emergencia (226)

3.3.4.3. Sesión de trabajo con el personal del centro (244)

3.3.4.4. Actividades con los niños (245)

3.3.4.4.1. Actividades del Ciclo de Infantil (245)

3.3.4.4.2. Actividades de la Semana de la Prevención en el CP Grangel Mascarós (248)

3.3.4.5. Vídeo (257)

3.3.5. Otras actividades (263)

CAPÍTULO 4. CONCLUSIONES Y PROPUESTAS (267)

4.1. Limitaciones y cumplimiento de objetivos (267)

4.2. Conclusiones (269)

4.2.1. El niño en el discurso de la prevención (269)

4.2.2. Formas en que se concreta la adaptación de los contenidos de prevención (271)

4.3. Propuesta de modelo (275)

4.4. Futuras líneas de investigación (279)

4.5. Tendencias de futuro (280)

BIBLIOGRAFÍA (282)

ANEXO (290) 


\section{INTRODUCCIÓN}

Hace algunos años empecé a colaborar como periodista con un servicio de información creado en 2008 y denominado SIAB, cuyas siglas responden a la denominación de Servicio de Información Audiovisual de Bomberos. El cuerpo de bomberos en cuestión es el Consorcio Provincial de Bomberos de Castellón, un ente que da respuesta a las necesidades de 134 municipios en materia de emergencias en las que deban actuar los efectivos de bomberos.

La labor del equipo del SIAB consistía en recopilar imágenes e información de las principales emergencias, para posteriormente distribuir ese material entre los medios de comunicación. Creado en 2008, el servicio tuvo una gran aceptación, convirtiéndose en una fuente oficial de referencia que facilitaba imágenes e información basándose en tres criterios: datos contrastados, material gráfico de calidad, y enfoque centrado en la labor de los bomberos y no en imágenes o datos intrusivos sobre las víctimas. Se distribuyen datos e imágenes de una media de 60 temas cada año. Con el tiempo se han ido diversificando las funciones del SIAB, quien además de ofrecer ese material informativo, también atiende llamadas, gestiona entrevistas o se encarga de publicar en redes sociales, entre otras funciones.

En 2011, y en el marco del Doctorado en Comunicación Empresarial e Institucional, desarrollé un proyecto de investigación centrado en dicho servicio. Partía de la hipótesis de que la información oficial facilitada por los organismos de protección civil en relación a emergencias, así como los mensajes con contenidos sobre prevención o autoprotección difundidos por las mismas fuentes, contribuía a crear una sociedad mejor preparada e informada para afrontar una emergencia. Aquella hipótesis de partida condujo inevitablemente a un mayor ejercicio de autoreflexión en cuanto al papel y las funciones del SIAB, así como a un análisis más profundo de las dinámicas de los medios de comunicación con los que interactuaba cuando desarrollaba mi labor en este servicio. Fruto de dichos análisis surgieron algunas conclusiones y también varios interrogantes. El principal de esos interrogantes se ha convertido con el tiempo 
en el germen de la presente tesis.

El mayor de esos interrogantes tenía que ver con el tipo de contenidos que los medios de comunicación narraban. ¿Por qué algunos de los temas de los que informábamos tenían gran repercusión y otros no? La cobertura que realizábamos de emergencias como incendios, inundaciones o accidentes, tenían una cabida incuestionable en cualquier medio de comunicación. Los medios los consideraban prioritarios para ellos y para sus lectores, oyentes y espectadores, y dedicaban a estos temas numerosas páginas y minutos de información. Sin embargo, no ocurría lo mismo cuando desde el servicio del SIAB tratábamos de suministrar temas de carácter preventivo, relacionados con aspectos tales como qué medidas adoptar para evitar un incendio en una vivienda o consejos para actuar frente a una alerta de lluvias torrenciales que pudiera implicar un riesgo para el ciudadano. Esos temas tenían poca o ninguna repercusión. Esta acentuada diferencia entre la visibilidad mediática entre los temas de emergencia y la que adquirían los temas sobre prevención conducía a preguntarse qué habría detrás de ese fenómeno.

Diversas entrevistas en profundidad a expertos en oficinas de prensa de organismos de emergencias, encuestas a medios de comunicación, y análisis de documentación relativa a la percepción social y conocimiento sobre el riesgo, parecían indicar que lo que había detrás no era uno, sino varios factores. Falta de concienciación social, falta de formación en general en materia de prevención de emergencias, dificultades para que los temas sobre prevención de riesgos y emergencias tuviesen cabida en la inmediatez y los criterios de noticiabilidad de los medios de comunicación, necesidad de una mayor inversión pública en materia de campañas preventivas... Un amplio abanico que influía en el hecho de que los temas preventivos no tuvieran una presencia mediática destacada.

Era evidente que la palabra prevención no estaba en la agenda de los medios de comunicación. Pero lo que parecía más preocupante era que, los propios entrevistados, vinculados a distintas instituciones, expresaban su duda acerca de si la prevención estaba en los primeros puesto de la agenda no sólo mediática, sino de las instituciones y de la sociedad en su conjunto.

Los entrevistados argumentaban diversas razones que bloqueaban una mayor presencia institucional, mediática y social de aquellos temas vinculados a la 
prevención: falta de inversión, falta de delimitación de competencias sobre qué instituciones deberían encargarse de estos temas ... Y un sentimiento generalizado de que se podría hacer más.

Sin embargo, uno de los aspectos en los que todos los expertos parecían coincidir era en que si realmente se quería llegar a alcanzar una sociedad más concienciada sobre cómo evitar riesgos o afrontar emergencias, esa concienciación no debía solo fomentarse desde los medios de comunicación o la información a la ciudadania, sino que debería iniciarse desde la infancia. Un aprendizaje temprano, incluso un aprendizaje a lo largo de la vida que se iniciase en edades tempranes.

La aparente lógica de esta afirmación escondía sin embargo una idea que implicaba un reto de grandes dimensiones: ni más ni menos que el de incluir a los niños y niñas en el mapa de públicos de las instituciones vinculadas a la gestión del riesgo y de las emergencias.

Y parecía ser, a tenor de las respuestas que ofrecían los entrevistados, que la comunicación con estos públicos podía realizarse al margen de campañas globales dirigidas a la ciudadanía en su conjunto (adultos), e independientemente de la presencia o no de estos temas en los medios de comunicación.

En algún momento tuve la sensación de que para alguno de los entrevistados, se confiaba mucho más en la capacidad de aprendizaje de los niños en materia de autoprotección y manejo del riesgo que en la capacidad de cambio y transformación de los adultos de esta sociedad. De alguna forma era como si ya hubiesen dado por perdida una generación y planteasen que los esfuerzos debían centrarse en las siguientes.

Se abría así un nuevo interrogante: ¿incluir a los niños en el mapa de públicos de las instituciones vinculadas a la gestión del riesgo y de las emergencias? El giro estratégico y comunicativo que comportaba esta idea abría nuevos e interesantes interrogantes en el camino investigador.

Se hacía necesario averiguar si en estos momentos, las instituciones vinculadas a la protección civil, estaban desarrollando algún tipo de actividad en este sentido. Por ello, realicé un primer muestreo mediante entrevistas y análisis webs de algunos 
organismos públicos de emergencias que apuntaba a lo siguiente: algunas instituciones públicas vinculadas al ámbito de la protección civil habían empezado a considerar a los niños y adolescentes como uno de sus públicos prioritarios, diseñando específicamente para ellos materiales y actividades enfocadas a aprender cómo evitar y actuar ante un riesgo o una situación de emergencia, y cómo adoptar una actitud preventiva. No parecía ser una práctica dominante, pero sí una tendencia que parecía ir en sentido ascendente y que contaba con ejemplos interesantes que merecía la pena ser investigados. Tal vez esos ejemplos diseminados eran un indicador de que se estuviese produciendo un cambio de concepción mucho mayor.

¿Cómo se estaban comunicando con esos públicos infantiles, con qué medios, canales, formatos y mensajes? ¿Se estaban midiendo los resultados? ¿Se estaba haciendo en España? ¿Eran experiencias semejantes o diferentes entre sí las que se estaban llevando a cabo? ¿Las instituciones vinculadas a la protección civil y las emergencias operaban unilateralmente o contaban con otros actores comunicativos? ¿Había unidireccionalidad o diálogo?

Las preguntas y la búsqueda de sus respuestas excedían los límites de aquel proyecto de investigación cuyos objetivos de análisis eran otros, pero una de las conclusiones que se obtuvieron fue que podían ser el punto de partida para futuras investigaciones.

Fue así como traté de empezar a responder aquellas preguntas. 


\section{CAPÍTULO 1. PROBLEMA DE INVESTIGACIÓN}

\subsection{OBJETIVOS DE LA INVESTIGACIÓN}

Las instituciones del ámbito de la protección civil destinan esfuerzos a dar a conocer a la población los riesgos existentes y cómo pueden evitarlos o hacerles frente y, en buena medida, tratan de llevar a cabo este objetivo a través de la información preventiva.

Este fenómeno y la función de esta información aparecen reflejados en distintos textos legales y son reivindicados por organismos internacionales como la ONU como uno de los principales recursos para reducir el riesgo de desastres en todo el mundo. La utilización de este recurso y la construcción del discurso alrededor de este fenómeno, por parte de los organismos vinculados a la gestión del riesgo y las emergencias, ha ido matizando su inicial unidireccionalidad para tornarse cada vez más un proceso con múltiples actores participantes.

Así se puede observar si atendemos a un análisis de la documentación legal, del discurso de organismos multinacionales, y de una revisión a la literatura científica sobre la comunicación de riesgo. Una triple perspectiva que se verá reflejada en los siguientes capítulos.

Ese devenir desde una antigua unidireccionalidad a una mayor participación ciudadana en los procesos comunicativos ha llevado a las instituciones vinculadas a la gestión de riesgos y emergencias a intentar tener en cuenta las características sociodemográficas y culturales del público para tratar de ajustar sus mensajes a distintos tipos de receptores. Un ajuste que, aún no siendo todavía un fenómeno 
generalizado, está tratando de realizarse cada vez más, contando con la participación de los propios actores implicados, en un trabajo con ellos y no solo para ellos.

De modo aún más reciente, estos cambios en la forma de comunicar se han traducido además en una progresiva adaptación de las formas y contenidos de los mensajes preventivos a las características de públicos especiales muy determinados, y de forma relevante, a la infancia.

Este proceso de construcción de mensajes preventivos orientados a la infancia se está dando de modo simultáneo en numerosos países, impulsado por los cambios sociales, nuevas regulaciones y políticas, y el trabajo conjunto de instituciones vinculadas a la gestión de riesgos y emergencias junto a distintas instancias gubernamentales, organismos internacionales, fundaciones y las propias comunidades destinatarias de las acciones comunicativas.

Todo ello está dando como fruto interesantes prácticas, situación de la que España no es una excepción.

La literatura existente acerca de estos procesos de adaptación de la comunicación en prevención de emergencias al público infantil es relativamente escasa, pese a que las prácticas se encuentren en pleno proceso de expansión.

Por ello la presente investigación parte de este reto inicial, para tratar de abordar un triple objetivo:

a) Describir el panorama actual, y tendencias de futuro, de la información y formación en prevención de emergencias dedicada a la infancia y adolescencia, desde el punto de vista de las organizaciones vinculadas a la gestión de riesgos y emergencias. Interesa detectar, entre otros aspectos, quienes son esas organizaciones, qué relaciones mantienen con el resto de actores y qué tipo de prácticas comunicativas se están generando.

b) Poner en práctica mediante un trabajo de campo las conclusiones más relevantes 
c) A partir del análisis teórico y práctico, el siguiente objetivo es plantear un modelo que resulte de utilidad para aquellas organizaciones vinculadas a las emergencias que quieran incluir a la infancia entre su público prioritario.

\subsection{HIPÓTESIS Y OBJETO DE LA INVESTIGACIÓN}

A partir de los objetivos expuestos, la hipótesis de partida se formula de la siguiente forma:

"Los organismos de protección civil diseminan información destinada a que el ciudadano tome conciencia de los riesgos y emergencias y adquiera conocimientos sobre cómo prepararse ante ellos y, de forma progresiva, han ido incorporando a la infancia y adolescencia entre sus públicos prioritarios. Las prácticas comunicativas generadas están diseñadas teniendo en cuenta las características sociodemográficas y culturales de este público específico, y cuentan con recursos comunicativos diferentes a los utilizados en la comunicación preventiva orientada al público en general".

Por organismos de protección civil hacemos referencia a aquellos organismos vinculados a la gestión de riesgos y emergencias y cuya función está dirigida a la protección de las personas, los bienes y el medio ambiente. En España, el paisaje de los organismos de la protección civil está ampliamente ramificado dado que se trata de una competencia descentralizada que alcanza a distintos niveles de la administración, desde la nacional, a la autonómica, provincial o local.

La reciente Ley 17/2015 del Sistema Nacional de Protección Civil, define en su artículo 1 los objetivos y finalidad de este sistema:

"La protección civil, como instrumento de la política de seguridad pública, es el servicio público que protege a las personas y bienes garantizando una respuesta adecuada ante los distintos tipos de emergencias y catástrofes originadas por causas naturales 0 derivadas de la acción humana, sea ésta accidental o intencionada".

El texto legal señala también el conjunto de organismos que tienen la consideración de servicios públicos o privados de intervención y asistencia en emergencias de protección civil, y entre los que se encuentran, por citar algunos ejemplos, los 
Servicios Técnicos de Protección Civil y Emergencias, los Servicios de Prevención, Extinción de Incendios y Salvamento, los Servicios de Atención Sanitaria en Emergencias o los Servicios de Rescate, entre otros grupos.

Por otra parte, por infancia nos referimos, según la definición de la Real Academia de la Lengua Española al "período de la vida humana desde que se nace hasta la pubertad", mientras que la adolescencia es, también según la RAE, la "edad que sucede a la niñez y que transcurre desde la pubertad hasta el completo desarrollo del organismo".

Estas dos definiciones marcan la separación entre ambos grupos ( infancia y adolescencia) por una cuestión de edad, cuyo límite diferenciador suele situarse en torno a los doce años.

Por otra parte, cabe señalar que si bien algunas de las instituciones analizadas hacen mención a las edades concretas de los niños y niñas a los que van dirigidas sus prácticas comunicativas ( por ejemplo especificando si están diseñadas para niños menores de 6 años, o entre 6-8 años, de 9-11 años, etc.) la gran mayoría no efectúan esa diferenciación. Por ello, nuestras menciones a la "infancia" a lo largo de la presente investigación se referirán genéricamente a los grupos de edad inferiores a 12 años.

Por su parte, por las prácticas comunicativas generadas nos referimos a aquellas que también el propio sistema de protección civil engloba dentro de las denominadas actividades preventivas tales como los "Programas de sensibilización e información preventiva a los ciudadanos" ( artículo 11 de la citada ley), que tienen como objetivo la difusión de contenidos encaminados a que el destinatario conozca datos o adopte actitudes que le ayuden a prevenir riesgos y minimizar daños.

Entre otras cosas, informar al ciudadano tendrá la función, según dicha ley, de, respecto a la relación con los riesgos colectivos, "divulgar las medidas dispuestas para contrarrestarlos, a recomendar conductas para prevenirlos", siendo una información que debe "proporcionarse tanto en caso de emergencia como preventivamente, antes de que las situaciones de peligro lleguen a estar presentes".

La presente investigación pretende analizar el discurso enunciado por las instituciones de protección civil y las prácticas comunicativas generadas, en relación a los 
contenidos sobre prevención de emergencias orientados a la infancia y adolescencia. Por tanto, por una parte, investigaremos quienes son estas organizaciones y qué procesos siguen a la hora de generar dichos contenidos, y por otra, llevaremos a cabo un análisis de los contenidos y formatos producidos.

\section{3. ÁMBITO TERRITORIAL}

El ámbito territorial de la presente investigación es España. Por otra parte, para algunos de los conceptos manejados se han utilizado ejemplos de otros países, muestras que no tienen carácter probabilístico pero sí sirven para ejemplificar tendencias de otros organismos que podrían ser el lugar hacia el que se dirigiese España. Asimismo, se han manejado también datos y documentación que atañen a un ámbito más internacional, en los casos en los que se considera que España está incluida en las tendencias allí reflejadas.

\subsection{FASES DE LA INVESTIGACIÓN Y METODOLOGÍA}

El punto de partida para el diseño metodológico ha sido una exploración de la documentación existente en la literatura científica sobre cómo las organizaciones vinculadas a la prevención de riesgos y emergencias en España tratan de comunicar contenidos sobre prevención de riesgos y emergencias a la infancia y adolescencia en nuestro país.

El resultado de esa inicial fase de exploración ha sido la constatación de la escasa presencia de investigaciones previas dedicadas a esta temática, algo que ha implicado un importante reto para dar inicio al camino investigador.

No existen abundantes precedentes para abordar a estos actores y específicamente a cómo están adaptando sus discursos en prevención de emergencias a un público infantil.

Y sin embargo, se han detectado en esa exploración inicial indicios, unas primeras muestras, de que ese fenómeno de adaptación sí se estaba desarrollando poco a poco en la práctica, y de que había interesantes ejemplos que merecían recopilarse para tratar de ser analizados y poder detectar líneas o tendencias comunes entre las distintas prácticas. 
Finalmente, se ha elaborado un diseño metodológico que tuviera en cuenta el tipo de análisis que se quería realizar, adaptando la metodología a los objetivos concretos. Se describen aquí los pasos seguidos.

\section{Marco teórico: análisis documental}

Como fuentes documentales que ayuden a construir el marco teórico, se ha revisado la literatura existente respecto a la comunicación de riesgo, y concretamente aquellos aspectos dirigidos a analizar cómo las instituciones públicas pueden generar significado y prácticas comunicativas de una forma no unidireccional, sino a partir de la interrelación con varios actores cuyas características sociodemográficas y culturales son tenidas en cuenta.

Asimismo se ha tomado como referencia para desgranar las líneas generales del discurso institucional sobre información preventiva dos tipos de textos: en primer lugar, la legislacion existente en España sobre la materia, tanto aquella que afecta a la ciudadanía en general como a la infancia en particular.

En segundo lugar, la documentación generada por la ONU en relación a las Conferencias Mundiales para la Reducción de Riesgo de Desastres y otros eventos internacionales vinculados a la gestión del riesgo. Las Naciones Unidas aglutinan los puntos de vista de casi 200 países, y tiene entre sus objetivos la creación de una cultura mundial de la prevención, que incluya a la infancia y la adolescencia en el proceso para alcanzar dicha cultura. Por tanto, la documentación generada al respecto es de gran utilidad para la elaboración de nuestro marco y para ver las líneas internacionales que también afectan al caso español.

\section{Marco empírico}

En el marco empírico, se han analizado las prácticas comunicativas generadas por los organismos de protección civil y emergencias así como el tipo de relación entre dichos organismos y otros actores. Se han utilizado técnicas cualitativas y cuantitativas (Del Río, 2011:67-93).

- Se ha realizado un análisis de contenido de 17 páginas web pertenecientes a otras tantos organismos de emergencia autonómicos españoles. Teniendo en cuenta que el Estado Español tiene transferidas las competencias en materia de gestión de emergencias a las autonomías, se trata de una muestra probabilística estadísticamente representativa del panorama web. Tiene un carácter descriptivo y 
también explicativo.

- Para conocer otro tipo de prácticas comunicativas llevadas a cabo por las instituciones vinculadas a la protección civil, en colaboración con otros actores, fundamentalmente del tercer sector, se han realizado una serie de entrevistas en profundidad.

- Para analizar cómo se desarrolla un simulacro escolar en el que participen instituciones vinculadas a la protección civil y otros actores como la comunidad escolar, se ha llevado a cabo un estudio de caso en dos fases.

En primer lugar se ha realizado un estudio etnográfico de como se desarrolla una evacuación en un centro escolar, para a partir de las conclusiones obtenidas llevar a cabo una segunda fase con un carácter más experimental, mediante el método de la investigación- acción participativa (Greenwood, 2000:33).

En esa segunda fase han intervenido el Consorcio Provincial de Bomberos de Castellón y el centro educativo Colegio Público Grangel Mascarós de l'Alcora (Castellón).

Lo que se ha pretendido es tratar de implementar los procesos comunicativos de un simulacro de incendio en un entorno escolar, así como adaptar la información sobre prevención de incendios, mediante distintas actividades, a las edades de un público formado por escolares de infantil y primaria.

Pensamos que la heterogeneidad de las técnicas utilizadas responde a la necesidad de trazar un panorama lo más amplio posible, dado que como hemos comentado anteriormente no existe una extensa literatura al respecto. Por ello la presente tesis se presentaba como una oportunidad para reflejar y describir la variedad de contenidos y relaciones entre actores que giran en torno a la idea de "prevención de emergencias e infancia".

\subsection{FUENTES}

Las fuentes a las que se ha recurrido son tanto de carácter primario como secundario. Entre las primarias econtramos por ejemplo, las fuentes consultadas para las entrevistas en profundidad, y entre las secundarias se hallan, entre otras, los informes de la ONU elaborados tras cada una de las Conferencias Mundiales de Reducción de 
Desastres.

Las fuentes secundarias son originalmente en español, catalán e inglés. Para su citación, durante la investigación han sido traducidas al español.

\subsection{CUADROS Y GRÁFICOS}

Todos los cuadros, gráficos o esquemas que aparecen a lo largo de los diferentes capítulos y apartados de la presente investigación son de elaboración propia. 


\section{CAPÍTULO 2. MARCO TEÓRICO}

\subsection{LA INFORMACIÓN PREVENTIVA EN LAS INSTITUCIONES PÚBLICAS}

\subsubsection{GLOSARIO}

Antes de pasar a profundizar sobre algunos de los conceptos que investigaremos a lo largo de este marco teórico, resulta conveniente la confección de un breve glosario sobre algunos de los términos manejados tanto en los ejemplos de información preventiva y recomendaciones que se analizarán en el apartado empírico, como presentes en algunos de los documentos internacionales y del marco de la comunicación de riesgo que abordaremos en los presentes capítulos. La definición de estos conceptos ha estado sujeta a lo largo de décadas de estudios a constantes debates, reformulaciones y enfoques que han incorporado prismas desde campos muy distintos del saber, desde la física, a la geología, pasando por la psicología, la comunicación o la sociología.

Una revisión a todas las definiciones excede, por extensa y multidisciplinar los límites de la presente investigación por lo que, a modo de ejemplo y con ánimo clarificador expondremos sólo algunos ejemplos de estas definiciones.

\section{Definiciones de la Ley 17/2015}

La ley 17/2015, de 9 de julio, del Sistema Nacional de Protección Civil de España, nos deja en sus artículo 1,2, 8 y 10 sus propias definiciones, indicando que se consideran así "a efectos de esta ley". Las ordenamos aquí alfabéticamente.

Anticipación. La anticipación tiene por objeto determinar los riesgos en un territorio basándose en las condiciones de vulnerabilidad y las posibles amenazas, $y$ comprende los análisis y estudios que permitan obtener información y predicciones sobre situaciones peligrosas.

Amenaza. Situación en la que personas y bienes preservados por la protección civil están expuestos en mayor o menor medida a un peligro inminente o latente. 
Catástrofe. Una situación o acontecimiento que altera o interrumpe sustancialmente el funcionamiento de una comunidad o sociedad por ocasionar gran cantidad de víctimas, daños e impactos materiales, cuya atención supera los medios disponibles de la propia comunidad.

Emergencia de protección civil. Situación de riesgo colectivo sobrevenida por un evento que pone en peligro inminente a personas o bienes y exige una gestión rápida por parte de los poderes públicos para atenderlas y mitigar los daños y tratar de evitar que se convierta en una catástrofe. Se corresponde con otras denominaciones como emergencia extraordinaria, por contraposición a emergencia ordinaria que no tiene afectación colectiva.

Peligro. Potencial de ocasionar daño en determinadas situaciones a colectivos de personas o bienes que deben ser preservados por la protección civil.

Política de prevención. La prevención en protección civil consiste en el conjunto de medidas y acciones encaminadas a evitar o mitigar los posibles impactos adversos de los riesgos y amenazas de emergencia

Protección civil. La protección civil, como instrumento de la política de seguridad pública, es el servicio público que protege a las personas y bienes garantizando una respuesta adecuada ante los distintos tipos de emergencias y catástrofes originadas por causas naturales o derivadas de la acción humana, sea ésta accidental o intencionada.

Riesgo. Es la posibilidad de que una amenaza llegue a afectar a colectivos de personas o a bienes.

Vulnerabilidad. La característica de una colectividad de personas o bienes que los hacen susceptibles de ser afectados en mayor o menor grado por un peligro en determinadas circunstancias. 


\section{Definiciones de la Dirección General de Protección Civil de España}

Por su parte, el organismo de la Dirección General de Protección Civil de España, perteneciente al Ministerio del Interior, nos ofrece también su propio glosario:

Accidente: cuando los individuos afectados por un siniestro, son un segmento de la población de fácil delimitación por una variable nominal: ocupantes de un automóvil, inquilinos de un edificio... En este tipo de situaciones la población queda fuera de los efectos del fenómeno o siniestro, la vida cotidiana de la colectividad no se ve alterada y los sistemas de respuesta y de ayuda a los afectados quedan indemnes y pueden actuar.

Autoprotección conjunto de acciones encaminadas a la protección, realizadas por uno mismo, para sí mismo. Cuando hablamos de Autoprotección estamos hablando de:prevención, control de riesgos así como acciones y medidas a adoptar con objeto de garantizar la protección de los ciudadanos, los bienes y el medio ambiente. Obliga tanto a los ciudadanos como a las Administraciones Públicas.

Calamidad: aquella situación que se alarga en el tiempo, bien por reiteración o prolongación o por sus efectos derivados, como la sequía continuada, los efectos epidemiológicos de un virus recurrente.

Catástrofe: aquella situación en que un fenómeno infausto e imprevisto afecta a una colectividad de forma global, incluidos sus sistema de respuesta institucionales. En la catástrofe, los individuos afectados no podrán contar con ayuda institucional, al menos en los primeros momentos, y tendrá que hacer frente a las consecuencias del fenómeno con sus propias fuerzas.

Crisis: como un estado delicado y conflictivo en el cual, por circunstancias de origen interno o externo, se rompe el equilibrio y la normalidad del sistema y se favorece su desorganización.

Desastre: cuando toda la población de forma indiscriminada, se ve afectada por los hechos infaustos, y la vida social cotidiana se ve alterada. En los desastres los sistemas de respuesta institucionales, públicos y privados, también pueden quedar indemnes y pueden ayudar a la colectividad afectada. 
Emergencia: situación que aparece cuando en la combinación de factores conocidos, surge un fenómeno o suceso que no se esperaba, eventual, inesperado $y$ desagradable por causar o poder causar daños o alteraciones en las personas, los bienes, los servicios o el medio ambiente. La emergencia supone una ruptura de la normalidad del sistema, pero no excede la capacidad de respuesta de la comunidad afectada.

\section{Aproximaciones multidisciplinares}

Por otra parte, haciendo retrospectiva de los análisis y aproximaciones a estos conceptos, hemos de destacar también otras definiciones. Renedo, Gil y Valero (2007) destacan como durante las últimas décadas dichas definiciones han estado en contínuo proceso de revisión desde los distintos campos del saber.

Fritz (1961) definió el desastre como:

"Un evento, concentrado en el tiempo y espacio, en el que una sociedad, o subdivisión de esa sociedad relativamente autosuficiente, sufre un daño severo e incurre en tales pérdidas personales y materiales que se rompe la estructura social y se impide el cumplimiento de todas o de algunas de las funciones [...]".

Posteriormente, las décadas siguientes dejaron diversos enfoques sobre las semejanzas o diferencias de los desastres, accidentes y emergencias. Ha habido numerosos intentos de delimitar aquello que une a los tres fenómenos (Fouce, Hernández-Coronado, Nevado, Martínez, Losada y Lillo: 1998) estableciendo semejanzas. Las distintas definiciones parecían coincidir en aspectos como que todos esos fenómenos eran fuente de destrucción, suponían un riesgo para la vida o la integridad física, causaban desestabilización y requerían de una intervención urgente ante una situación que tenía ciertas dosis de imprevisibilidad (Renedo, Gil, Valero, 2007:28).

Entre las diferencias, para algunos autores se situaban en la tasa de daños personales o materiales cuantificable en cifras, mientras que para otros la diferencia estribaría en el grado de estrés colectivo que generan, un nivel evaluable por el número de personas afectadas, la implicación de éstas con el sistema social impactado o el grado de ruptura del sistema social (Renedo, Gil, Valero, 2007: 29). 


\section{La definición del riesgo}

El riesgo ha sido un concepto ampliamente abordado desde perspectivas muy distintas.

Así, Farré y Fernández (2007:24) señalan que en la literatura anglosajona se distingue entre risk y hazard, refiriéndose a posibilidad de daño y fuente de riesgo respectivamente y añaden que (en catalán en el original) "En su formulación más simple el concepto de riesgo sería una combinación de probabilidad de que se produzca un daño o pérdida no deseado y de la magnitud potencial de dicha pérdida, tal como se ilustra con la siguiente fórmula riesgo = probabilidad $x$ consecuencias".

Y destacan que "Identificar un riesgo en una población exige su reducción o eliminación. Por eso, la definición de riesgo implica, en cierta manera, definir aquello que se considera normal y aquello que no se considera, convirtiéndolo en la anomalia que hay que modificar para volver a la normalidad. Por tanto, más allá de una mera descripción, el riesgo significa emitir un juicio sobre qué es lo que debería hacerse para recuperar la normalidad. Por este motivo, llega a ser un concepto con un enorme potencial de intervención sobre la realidad social, con una importante dimensión política, y convierte los procesos de su definición como verdaderos campos de batalla entre los diferentes agentes sociales implicados”(Farré y Fernández 2007:25).

Por su parte, la Dirección General de Protección Civil y Emergencias, realiza esta reflexión respecto al concepto de riesgo:

"Por riesgo se entiende la probabilidad de que se desencadene un determinado fenómeno o suceso que, como consecuencia de su propia naturaleza o intensidad y la vulnerabilidad de los elementos expuestos puede producir efectos perjudiciales en las personas o pérdidas de bienes.

En el lenguaje común por riesgo cabe también entender el fenómeno, suceso o actividad humana, susceptible de producir daños en personas y/o bienes.

Los riesgos suelen dividirse en naturales y tecnológicos. Al primer grupo corresponden los procesos o fenómenos naturales potencialmente peligrosos. Al segundo grupo los originadas por accidentes tecnológicos o industriales, fallos en infraestructuras 0 determinada actividades humanas". 
La Estrategia Internacional para la Reducción de Desastres de las Naciones Unidas también ha establecido un glosario (2009), y anima a que estas definiciones sean adoptadas por todos los actores implicados, con el fin de crear y utilizar una terminología común. Ofrecemos aquí los que han sido determinados para la lengua española, aunque en algunos casos introducimos entre paréntesis los vocablos utilizados en la versión inglesa de este mismo glosario, cuya comparación lingüística resulta interesante a efectos de comprensión del texto y sus definiciones.

Los apartados señalados como "comentarios" figuran así en los textos originales, y se trata de los comentarios elaborados para cada palabra por los propios redactores del glosario de la EIRD.

Amenaza (hazard) Un fenómeno, sustancia, actividad humana o condición peligrosa que pueden ocasionar la muerte, lesiones $u$ otros impactos a la salud, al igual que daños a la propiedad, la pérdida de medios de sustento y de servicios, trastornos sociales y económicos, o daños ambientales.

Distingue entre distintos tipos de amenaza: biológica, geológica, hidrometeorológica, natural, tecnológica.

En su versión en lengua inglesa, este glosario utiliza por amenaza el término hazard, clasificándolos también por biological hazard, geological hazard, etc.

Riesgo (risk) La combinación de la probabilidad de que se produzca un evento y sus consecuencias negativas.

Comentario: Esta definición es muy similar a la de la Guía 73 de la ISO/IEC. La palabra "riesgo" (risk) tiene dos connotaciones distintas: en el lenguaje popular, por lo general se hace énfasis en el concepto de la probabilidad o la posibilidad de algo (chance of possibility), tal como el "riesgo de un accidente", mientras que en un contexto técnico, con frecuencia se hace más énfasis en las consecuencias, en términos de "pérdidas posibles" (potential losses) relativas a cierta causa, lugar y momento en particular. Se puede observar que la gente no necesariamente comparte las mismas percepciones sobre el significado y las causas subyacentes de los diferentes riesgos 


\section{Las definiciones de la Estrategia Internacional para la Reducción de Desastres para las Naciones Unidas}

Además de las definiciones ya expuestas sobre los conceptos de riesgo y amenaza de la EIRD, introducimos aquí elaboradas por la misma estrategia y resultan de especial interés para los objetivos de la presente investigación.

Se introducen también los comentarios que los propios redactores del glosario de la EIRD han introducido.

Concientización/sensibilización pública (public awareness) El grado de conocimiento común sobre el riesgo de desastres (disaster risks) los factores que conducen a éstos y las acciones que pueden tomarse individual y colectivamente para reducir la exposición y la vulnerabilidad frente a las amenazas (hazards).

Comentario: La concientización pública es un factor fundamental para la reducción eficaz del riesgo de desastres. Su desarrollo se logra, por ejemplo, mediante la elaboración y la diseminación de información a través de los medios de comunicación, campañas educativas (educational channels), establecimiento de centros de información, institución de redes, desarrollo de acciones comunitarias o participativas, al igual que la promoción por parte de funcionarios públicos de alto nivel y líderes comunitarios.

Desastre (disaster) Una seria interrupción en el funcionamiento de una comunidad o sociedad que ocasiona una gran cantidad de muertes al igual que pérdidas e impactos materiales, económicos y ambientales que exceden la capacidad de la comunidad o la sociedad afectada para hacer frente a la situación mediante el uso de sus propios recursos.

Gestión de emergencias (emergency management) La organización y la gestión de los recursos y las responsabilidades para abordar todos los aspectos de las emergencias, especialmente la preparación, la respuesta y los pasos iniciales de la rehabilitación.

Comentario: Una crisis o emergencia es una condición amenazante que requiere de la toma de acciones urgentes. Una acción eficaz de emergencia puede evitar que un evento escale hasta el punto de convertirse en un desastre. La gestión de emergencias incluye planes y disposiciones institucionales para comprometer y guiar los esfuerzos del gobierno, de las organizaciones no gubernamentales, de las entidades voluntarias y de las agencias privadas de forma coordinada e integral para responder a todas las necesidades relativas a una 
emergencia. A veces, la expresión "gestión de desastres" también se utiliza en vez de "gestión de emergencias".

\section{Gestión del riesgo de desastres (Disaster Risk Management) El proceso} sistemático de utilizar directrices administrativas, organizaciones, destrezas y capacidades operativas para ejecutar políticas y fortalecer las capacidades de afrontamiento, con el fin de de reducir el impacto adverso de las amenazas naturales y la posibilidad de que ocurra un desastre.

Comentario: Este término es una ampliación del concepto más general de "gestión del riesgo" para abordar el tema específico del riesgo de desastres. La gestión del riesgo de desastres busca evitar, disminuir o transferir los efectos adversos de las amenazas (hazards) mediante diversas actividades y medidas de prevención, mitigación y preparación (prevention, mitigation and preparedness)

Preparación (Preparedness) El conocimiento y las capacidades que desarrollan los gobiernos, los profesionales, las organizaciones de respuesta y recuperación, las comunidades y las personas para prever, responder, y recuperarse deforma efectiva de los impactos de los eventos o las condiciones probables, inminentes o actuales que se relacionan con una amenaza (imminent or current hazard events or conditions).

Comentario: La preparación es una acción que se lleva a cabo en el contexto de la gestión del riesgo de desastres. Su objetivo principal es desarrollar las capacidades necesarias para gestionar de forma eficaz todos los tipos de emergencia y lograr transiciones metódicas y ordenadas desde la respuesta hasta una recuperación sostenida. La preparación se basa en el análisis sensato del riesgo de desastres y en el establecimiento de vínculos apropiados con los sistemas de alerta temprana. La preparación incluye actividades tales como la planificación de contingencias, la reserva de equipos y suministros, el desarrollo de disposiciones para la coordinación, la evacuación y la información pública, y la capacitacióny los ejercicios de campo correspondientes. Estas actividades deben recibir el apoyo de las capacidadesinstitucionales, jurídicas y presupuestarias formales. El término afín de "prontitud" describe la habilidad deresponder de forma rápida y apropiada cuando así se requiera.

Prevención (prevention) La evasión absoluta de los impactos adversos de las amenazas y de los desastres conexos.

Comentario: La prevención (es decir, la prevención de desastres) expresa el concepto y la intención de evitar por completo los posibles impactos adversos mediante diversas acciones que se toman con anticipación [...] Con mucha frecuencia, no es posible evitar por completo 
laspérdidas y las tareas se transforman en aquellas relativas a la mitigación. Por esta razón, al menos en parte, algunas veces los términos de prevención y de mitigación se utilizan de forma indistinta en su acepción informal.

Reducción del riesgo de desastres (disaster risk reduction) El concepto y la práctica de reducir el riesgo de desastres mediante esfuerzos sistemáticos dirigidos al análisis y a la gestión de los factores causales de los desastres, lo que incluye la reducción del grado de exposición a las amenazas, la disminución de la vulnerabilidad de la población y la propiedad, una gestión sensata de los suelos y del medio ambiente, y el mejoramiento de la preparación ante los eventos adversos

Resiliencia (resilience) La capacidad de un sistema, comunidad o sociedad expuestos a una amenaza para resistir, absorber, adaptarse y recuperarse de sus efectos de manera oportuna y eficaz, lo que incluye la preservación y la restauración de sus estructuras y funciones básicas. 


\section{Conclusiones}

A lo largo de este apartado hemos visto las diferentes definiciones sobre los conceptos vinculados al riesgo, las emergencias y desastres así como a determinadas acciones alrededor de ellos, como la preparación, la prevención o la reducción. Aproximaciones variadas que, a modo de ejemplo, se han extraído de leyes, glosarios de agencias gestoras de emergencias, aproximaciones psicológicas y sociológicas, o la Organización de las Naciones Unidas. Todas ellas son buena muestra del interés por acercarse a estos conceptos desde diferentes disciplinas, y por gestionar las amenazas, riesgos, emergencias o desastres desde la perspectiva de la preparación, la concienciación, la prevención, o la resiliencia.

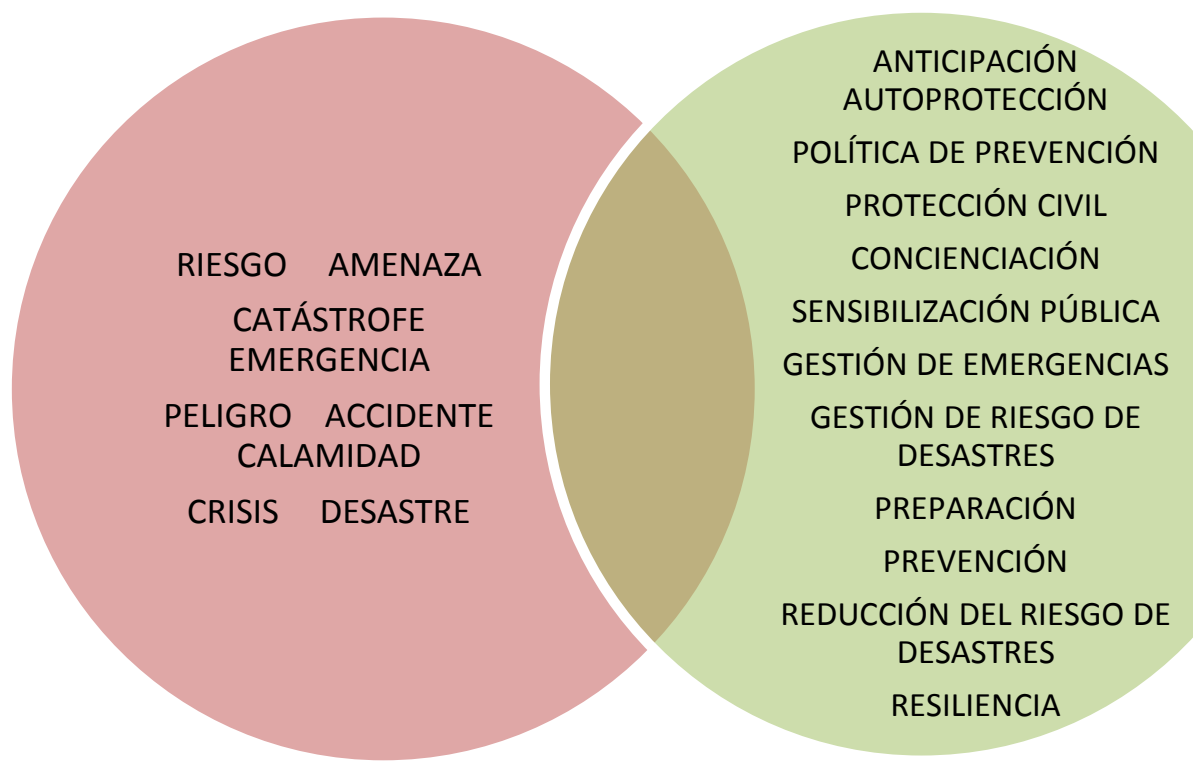

En definitiva, se trata de definiciones pero también de expresiones de las formas en las que las instituciones públicas y los organismos de gestión de emergencias enuncian su discurso en torno a la gestión de riesgos y emergencias, un discurso en el que la prevención, la concienciación, la sensibilización pública o la preparación tienen un peso fundamental.

Se trata de un discurso que expresa también una forma de relación: la relación de la sociedad con los riesgos, amenazas o catástrofes. Una relación que, a tenor de los glosarios y descripciones, quiere ser moldeada por parte de los actores públicos desde un proceso consciente de toma de decisiones que afectan e implican al conjunto de la sociedad. 


\subsubsection{MARCO LEGAL DE LA INFORMACIÓN PREVENTIVA EN ESPAÑA}

Para tratar de determinar cómo las instituciones públicas adaptan su discurso en prevención de emergencias a un público infantil, revisaremos en primer lugar la base misma de ese fenómeno, esto es, el hecho de que las instituciones ofrezcan a la ciudadanía en general información y recomendaciones sobre cómo manejar los riesgos o adoptar pautas de autoprotección.

Para referirnos al tema objeto de estudio, utilizaremos con frecuencia los conceptos de "información preventiva" y "recomendaciones".

Por una parte, del concepto de "información preventiva" hace uso la propia ley 17/2015, de 9 de julio, del Sistema Nacional de Protección Civil, tal como se ha explicado en el capítulo anterior y que aparecía reflejado en el artículo 11 de dicha ley al indicar que dentro de sus actividades se incluyen los "Programas de sensibilización e información preventiva a los ciudadanos".

Por otra parte, durante el transcurso de nuestro análisis del panorama web, correspondiente al marco empírico se detectó que las instituciones analizadas (los diecisiete organismos de gestión de emergencias de las diecisete comunidades autónomas) tendían a utilizar los conceptos de "información preventiva" y "recomendaciones" en mayor medida que otros afines como "consejos de autoprotección", "prevención de emergencias", "prevención de riesgos" etc. Por otra parte, aquello de lo que se intentaba prevenir siempre era denominado en las páginas web, "riesgo".

Por tanto, de lo que se tratará en el presente apartado es de investigar como, sobre un marco legal, las instituciones públicas españolas han elaborado un discurso en torno a la conveniencia de ofrecer "información preventiva" y "recomendaciones" a la población para evitar "riesgos".

Los textos legales tienen la capacidad de describir y al mismo tiempo moldear la realidad. La redacción de una ley o una norma tiene poder performativo ya que al marcar cómo ha de ser la realidad, nos invita a cambiarla si esta no coincide con lo expuesto. Si existen las normas es porque sabemos que el mundo real puede estar muy alejado de lo que ellas dictan, de lo contrario, el objetivo regulador resultaría innecesario. Nos hacen examinarnos a nosotros mismos para saber cómo debemos actuar ante determinadas situaciones, y conceden al ciudadano el poder de exigir a sus gobernantes que la gestión y las decisiones públicas se ajusten a lo dictado en el 
texto. Las leyes y las normas nos cuentan cómo ha de ser el mundo en el que nos movemos, y en el caso que nos ocupa, también en materia de protección civil.

Los poderes públicos y las instituciones vinculadas a la gestión de riesgos y emergencias, tienen entre sus obligaciones la difusión entre la población de los riesgos existentes y cómo prevenirlos o minimizar sus consecuencias. Las leyes de protección civil en España, así como distintas normas básicas, o los distintos Planes Especiales, así han puesto de manifiesto este papel desde que la ley 2/1985 de Protección Civil marcase hace tres décadas el camino a seguir.

En las leyes españolas, el sistema de protección civil y los distintos organismos que lo conforman, tiene un papel central a la hora de promocionar una conciencia social entre la ciudadanía en torno a los distintos riesgos y al fomento de una cultura general de prevención.

Y lo han de hacer, según estos textos legales, a través de la sensibilización, la información, y la promoción de la concienciación respecto a determinadas actitudes.

El panorama aquí trazado, nos muestra por una parte unas instituciones que tienen la labor de promocionar una cultura preventiva, y por otra, una ciudadanía con su propio papel en el proceso de autoprotección y beneficiaria del derecho a recibir la información que le ayude en ese proceso de autoprotección.

Así viene reflejado en los distintos textos legales, empezando por la primera Ley 2/1985 de 21 de enero, sobre Protección Civil, y finalizando en la aprobada 30 años después, la Ley 17/ 2015, de 9 de julio, del Sistema Nacional de Protección Civil.

Un examen minucioso a los distintos capítulos y artículos de estos textos legales pone de manifiesto lo que se espera de los poderes públicos y de los ciudadanos, delimita el ámbito de actuación de actuación de cada uno de estos actores, y refleja un mundo en el que la gestión del riesgo no depende del azar o la fortuna como en siglos precedentes, sino de los procesos de toma de decisiones y de la adopción de medidas protectoras, así como del fomento y la adopción de una cultura preventiva. 


\section{Ley 2/1985, de 21 de enero, de Protección Civil}

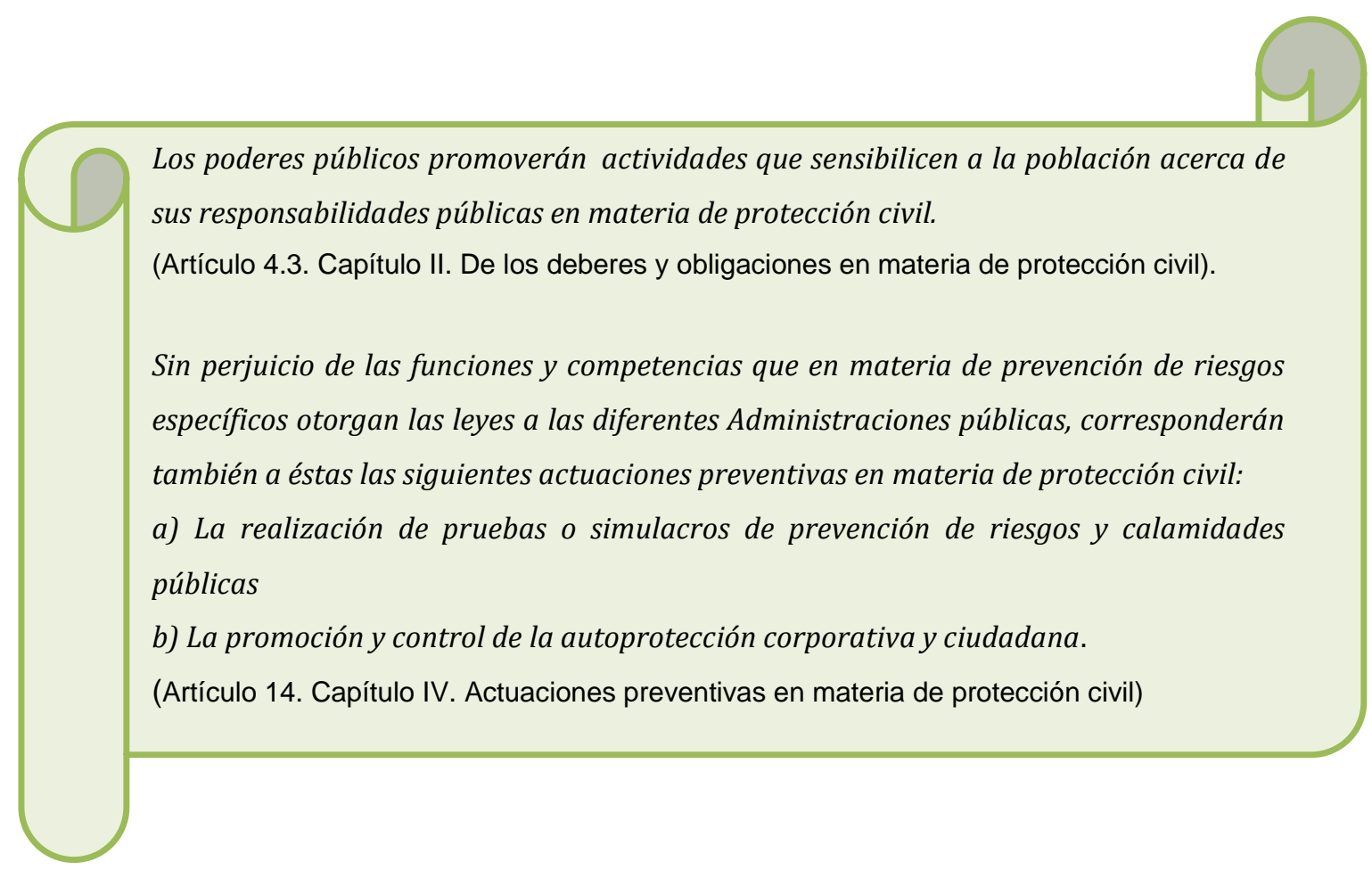

Como se observa en el extracto anterior, esta promoción de una cultura preventiva la encontramos originalmente en esta primera ley de protección civil, para a partir de ahí estar presente en las décadas siguientes en reales decretos, normas, leyes del ámbito laboral, o leyes de emergencias del nivel autonómico.

Se recopilan aquí una serie de ejemplos que muestran cómo la legislación en su conjunto, introduce en sus motivos y artículos referencias a la necesidad de la creación y fomento de la cultura preventiva por parte de los poderes públicos.

\section{Ley 31/1995 de 8 de noviembre, de Prevención de Riesgos Laborales}

"Pero tratándose de una Ley que persigue ante todo la prevención, su articulación no puede descansar exclusivamente en la ordenación de las obligaciones y responsabilidades de los actores directamente relacionados con el hecho laboral. El propósito de fomentar una auténtica cultura preventiva, mediante la promoción de la mejora de la educación en dicha materia en todos los niveles educativos, involucra a la sociedad en su conjunto y constituye uno de los objetivos básicos y de efectos quizá más transcendentes para el futuro de los perseguidos por la presente Ley". 
Real Decreto 967/2002, de 20 de septiembre, por el que se regula la composición y régimen de funcionamiento de la Comisión Nacional de Protección Civil

b) Promover iniciativas de las diferentes Administraciones públicas y de las entidades privadas, para la realización de actuaciones que contribuyan a la mejora de la prevención y mitigación de riesgos de carácter catastrófico.

c) Promover el desarrollo de una cultura social preventiva en relación con los riesgos catastróficos.

(Artículo 2. Funciones)

Ley 13/2010, de 23 noviembre, de la Generalitat Valenciana, de Protección Civil y Gestión de Emergencias

La actuación de las administraciones públicas en la Comunitat Valenciana en materia de protección civil y gestión de emergencias tendrá como objetivos fundamentales los siguientes:

Promover la autoprotección mediante la información y sensibilización de los ciudadanos, empresas e instituciones.

(Artículo 2.3. Acción pública en materia de protección civil y gestión de emergencias. Capítulo Unico. De la protección civil y la gestión de emergencias)

A la Conselleria que tenga atribuida la competencia en materia de protección civil y gestión de emergencias, le corresponde:

e) Establecer los medios para fomentar actuaciones que contribuyan a la prevención de siniestros, a la atenuación de sus efectos, y en general a la toma de conciencia y sensibilización de los ciudadanos de la importancia de la protección civil.

(Artículo 12. Conselleria competente en materia de protección civil y gestión de emergencias. Capítulo único) 
Por otra parte, este papel central de las instituciones como promotoras de una cultura de la prevención se ve complementado por el rol que a su vez se le otorga a la ciudadanía en general y que es un rol basado en la capacidad individual y comunitaria de autoprotección. Pese a que los estamentos públicos y las distintas instituciones vinculadas a las emergencias tienen la obligación de proteger, los ciudadanos también tienen la capacidad y la responsabilidad de autoprotección, que será fundamental durante los primeros momentos de una situación de emergencia. Las distintas leyes y normativas también hacen referencia a este aspecto, dado que los poderes públicos deben colaborar a que los ciudadanos alcancen este objetivo.

\section{Ley 2/1985, de 21 de enero}

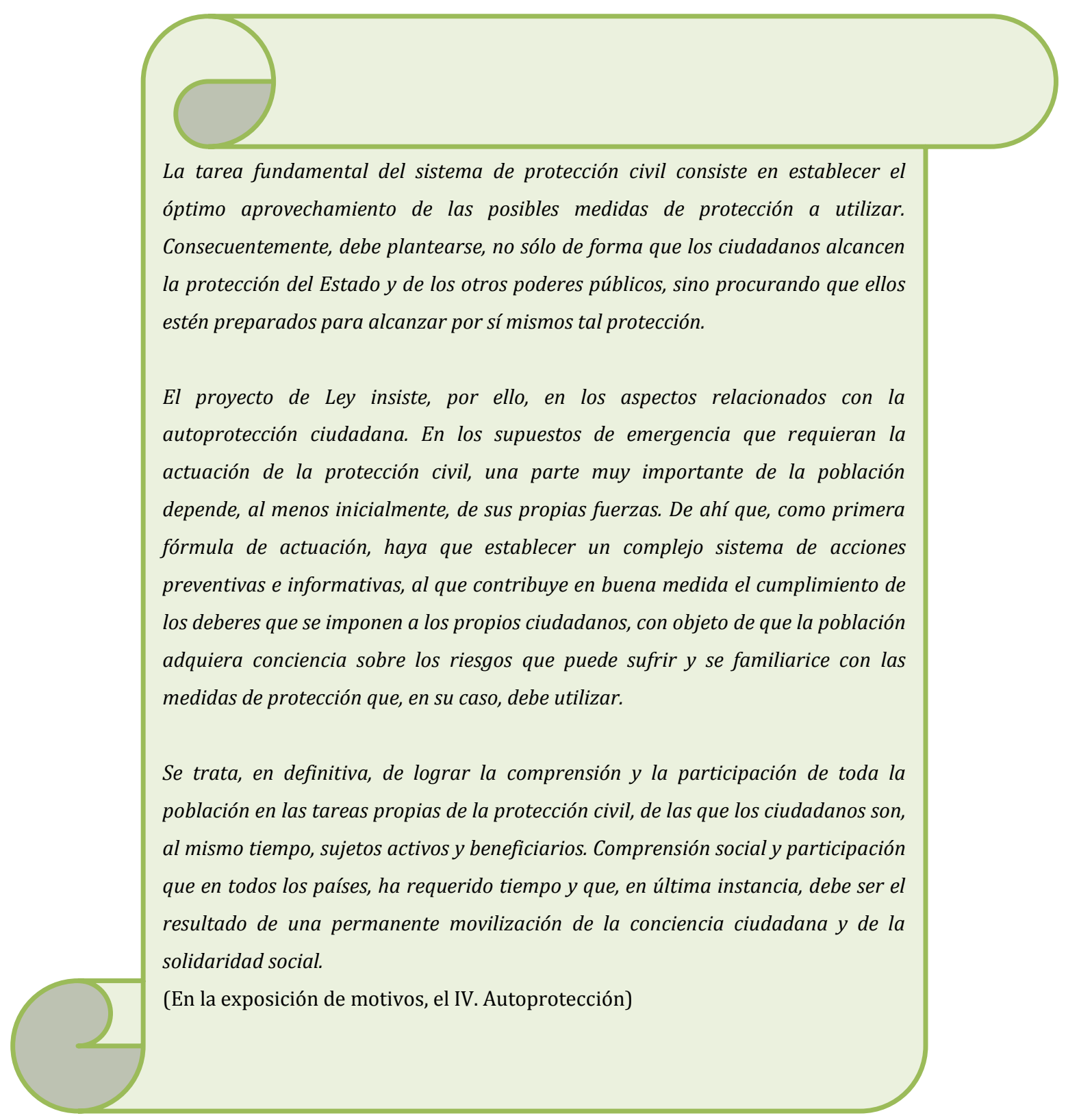


Real Decreto 393/2007, de 23 de marzo, por el que se aprueba la Norma Básica de autoprotección de los centros, establecimientos y dependencias dedicados a actividades que puedan dar origen a una situación de emergencia

Las distintas Administraciones Públicas, en el marco de sus competencias, promoverán de forma coordinada la Autoprotección, estableciendo los medios y recursos necesarios mediante el desarrollo de actuaciones orientadas a la información y sensibilización de los ciudadanos, empresas e instituciones en materia de prevención y control de riesgos, así como en materia de preparación y respuesta en situaciones de emergencia.

(Artículo 7. Promoción y fomento de la autoprotección)

Ley 17/2015, de 9 de julio, del Sistema Nacional de Protección Civil

Los ciudadanos deben tomar las medidas necesarias para evitar la generación de riesgos, así como exponerse a ellos. Una vez sobrevenida una emergencia, deberán actuar conforme a las indicaciones de los agentes de los servicios públicos competentes.

(Artículo 7 ter. 1. Deber de cautela y autoprotección. TíTULO I)

Otro de los pilares de la cultura preventiva, que aparece reflejado a lo largo de los diferentes textos, es la información. Información que puede ayudarnos a actuar frente a un determinado riesgo o emergencia, y contribuir por otra parte a estar más concienciados sobre la importancia que toda la sociedad esté más preparada. Una información que es de obligado cumplimiento para los poderes públicos, y un derecho para los ciudadanos, según viene recogido en las diferentes regulaciones.

A través de las décadas y de las regulaciones, se ha visto como esa referencia a la información se hacía más amplia y detallada, se concretaban sus formas y sus 
contenidos, y finalmente, con la llegada de la Ley 17/2015 del Sistema de Protección Civil, se vinculaba de forma directa la difusión de la información con la contribución a una cultura preventiva.

Por otra parte, la capacidad de difundir información por parte de las instituciones públicas queda ligada en algunos aspectos al papel que también los medios de comunicación pueden jugar en este proceso.

\section{Ley 2/1985, de 21 de enero, de Protección Civil}

En las situaciones de emergencia contempladas en esta Ley, los medios de comunicación social vendrán obligados a colaborar con las autoridades competentes respecto a la divulgación de informaciones dirigidas a la población y relacionadas con dichas situaciones.

Artículo 4.6. Capítulo II. De los deberes y obligaciones en materia de protección civil.

\section{Real Decreto 407/1992, de 24 de abril, por el que se aprueba la Norma Básica de Protección Civil}

p) Determinación de los mecanismos adecuados para la información a la población afectada y al público en general, para que éste pueda adaptar su conducta a la prevista en un Plan de Emergencia.

Los planes especiales se elaborarán para hacer frente a los riesgos específicos cuya naturaleza requiera una metodología técnico-científica adecuada para cada uno de ellos. En su elaboración se tendrán en cuenta:

(...)

f. Características de la información a la población, diferenciando la relativa al conocimiento del riesgo y al conocimiento del Plan.

(Planes Especiales. Artículo 5.1. Disposiciones generales.) 


\section{Ley 13/2010, de 23 de noviembre, de la Generalitat Valenciana de Protección Civil y Gestión de Emergencias}

Elaborar, como fuente de información oficial que es, la información dirigida a la población y a los medios de comunicación sobre los consejos de autoprotección, la evolución y el balance de la emergencia.

Implantar, a decisión del director del plan, centros de atención telefónica para informar a la población y a los afectados sobre la situación de emergencia."

( Art 57 fy 57 i, en referencia a las funciones del Centro de Coordinación de Emergencias)

Serán Infracciones leves ( artículo 76)

2. Denegar a los ciudadanos la información que requieran sobre los riesgos colectivos previstos en los planes y sobre las medidas de protección civil adoptadas.

3. Denegar información a los ciudadanos sobre aspectos de la planificación de protección civil que les afecten de forma directa.

Respecto a los derechos de los ciudadanos (Artículo 4.1.Derechos de los ciudadanos, entidades e instituciones)

Los ciudadanos, entidades, instituciones y organizaciones tienen derecho a que los servicios de intervención frente a emergencias, en sus actuaciones, cumplan los principios de pleno respeto a los derechos fundamentales de los ciudadanos y a las libertades públicas. En particular tienen derecho a:

a) Ser informados sobre los riesgos colectivos graves que pueden afectarles y sobre las actuaciones previstas para hacerles frente.

b) Recibir información e instrucciones sobre las medidas de seguridad a adoptar y la conducta a seguir. 


\section{Ley 17/2015, de 9 de julio, del Sistema Nacional de Protección Civil}

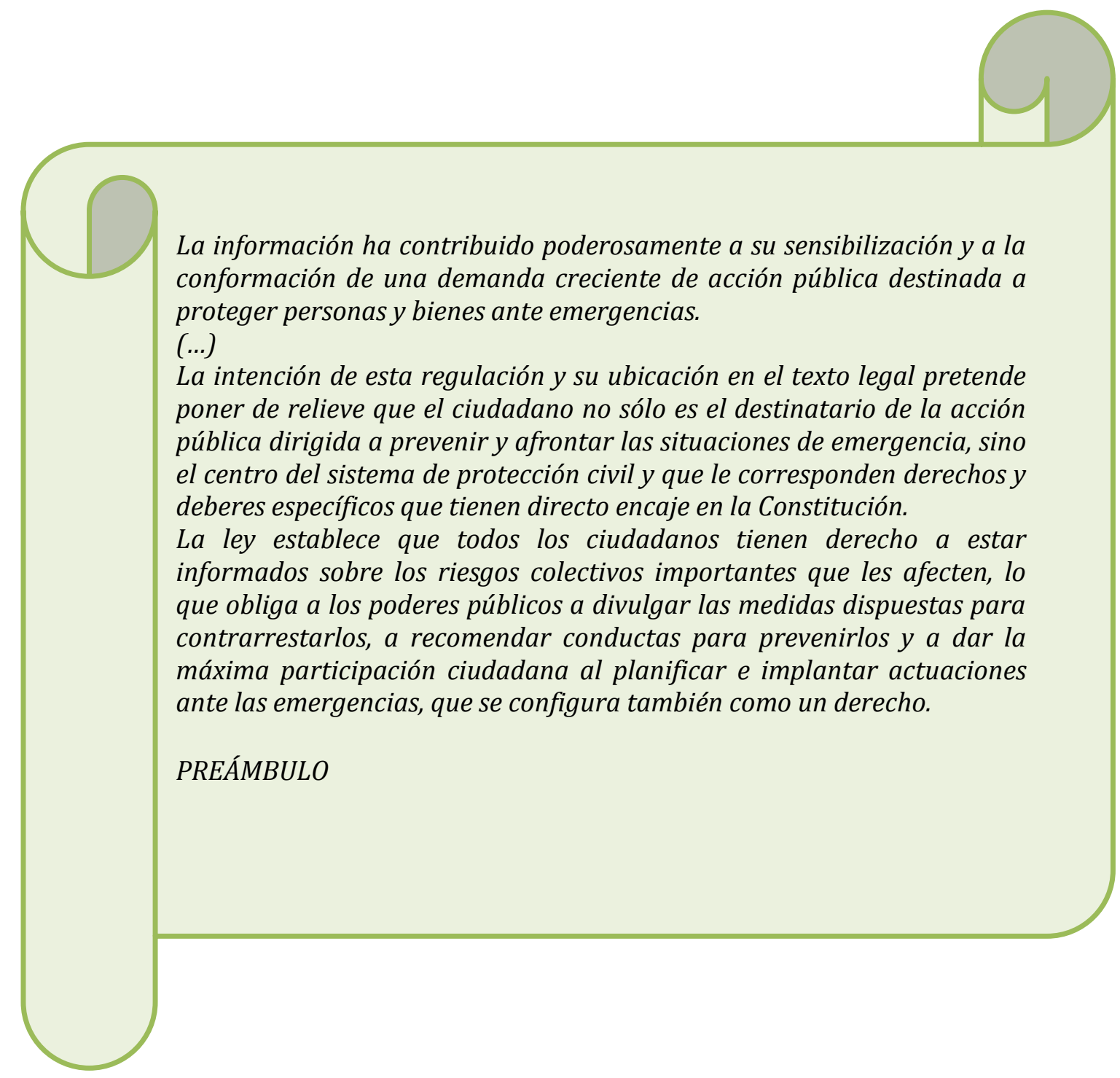

1. Todos tienen derecho a ser informados adecuadamente por los poderes públicos acerca de los riesgos colectivos importantes que les afecten, las medidas previstas y adoptadas para hacerles frente y las conductas que deban seguir para prevenirlos.

2. Dichas informaciones habrán de proporcionarse tanto en caso de emergencia como preventivamente, antes de que las situaciones de peligro lleguen a estar presentes.

(Artículo 6. Derecho a la información. TíTULO I Disposiciones generales) 
Los planes de protección civil previstos en el capítulo III de este título deberán contener programas de información y comunicación preventiva y de alerta que permitan a los ciudadanos adoptar las medidas oportunas para la salvaguarda de personas y bienes, facilitar en todo cuanto sea posible la rápida actuación de los servicios de intervención, y restablecer la normalidad rápidamente después de cualquier emergencia.

(Artículo 10.3. Política de prevención. Capítulo II. Prevención de riesgos de protección civil)

Se crea a través de esta ley el Fondo de Prevención de Emergencias para financiar, las actividades preventivas siguientes, entre otras:

a) Análisis de peligrosidad, vulnerabilidad y riesgos.

b) Mapas de riesgos de protección civil.

c) Programas de sensibilización e información preventiva a los ciudadanos.

(artículo 11.1. Fondo de Prevención de Emergencias)

El Centro Nacional de Seguimiento y Coordinación de Emergencias de Protección Civil ejerce las siguientes funciones

c) Divulgar periódicamente datos y estadísticas sobre emergencias y evaluar la conveniencia y forma de utilización de las redes sociales ante una emergencia de protección civil

(artículo 18. El Centro Nacional de Seguimiento y Coordinación de Emergencias de Protección Civil.) 
Por otra parte, la legislación internacional también ha tenido su peso en el marco español, a través de transposiciones.

Es el caso de las directivas Seveso, que, aún haciendo referencia a un contexto puramente industrial, supusieron un hito en materia informativa al mencionar expresamente la necesidad de informar a la población en caso de accidente grave. Concretamente, sería a través de los Planes de Emergencia Exterior e indicando que las autoridades públicas debían facilitar información a la población en caso de accidente, sobre todo en relación a las medidas a adoptar, y especialmente la evacuación o el confinamiento. La primera Directiva Seveso fue la 82/501/CEE traspuesta a España mediante RD 886/1988, y posteriormente tanto las directivas siguientes como las correspondientes transposiciones se han ido actualizando. 


\subsubsection{HACIA UNA CULTURA MUNDIAL DE LA PREVENCIÓN}

\subsubsection{La cultura mundial de la prevención en el discurso de la ONU}

Como hemos visto en apartados anteriores, la importancia de la prevención y la preparación, la capacidad de los ciudadanos de adoptar medidas de autoprotección, y el derecho a estar informados sobre los riesgos existentes y las medidas a adoptar son tres factores presentes en el sistema de protección civil de España, en los textos que lo regulan, y en las definiciones que lo describen.

Unos factores que también se reproducen en el panorama internacional. También a nivel global, y especialmente a través de la ONU y de sus distintos organismos, la incisión en estos tres aspectos ha sido constante en el discurso de los organismos internacionales en las últimas cuatro décadas, durante prácticamente el mismo periodo que en el caso español.

La revisión de la documentación relativa a este proceso se dibuja como fundamental en la presente investigación dado que se trata de voces autorizadas, cuyos enunciados no producen un impacto únicamente en el ámbito del propio actor internacional, sino que frecuentemente se traducen en medidas regionales, que influyen entre otras cosas, tanto en la difusión de la información preventiva como en el tipo de contenidos o de públicos a quien va dirigida.

Se ha decidido realizar el análisis de forma cronológica de modo que podamos vislumbrar los cambios sociales que les acompañan, y de los que España no es una excepción.

1972

En 1972 se lleva a cabo en Estocolmo (Suecia) la Conferencia de las Naciones Unidas sobre el Medio Humano. La conferencia busca una guía para la preservación del medio ambiente y el equilibrio ecológico, revelando que tanto la industrialización como el subdesarrollo pueden ser fuente de problemas ambientales. El texto también aborda específicamente el tema de los desastres naturales. Recogemos a continuación las principales ideas enunciadas en la Conferencia.

El punto 1 de la declaración indica que "El hombre es a la vez obra y artífice del medio que lo rodea [...]". Se superan así concepciones precedentes existentes sobre los desastres, asociadas a factores como el azar, los dioses o las supersticiones. 
Respecto a cómo acometer la tarea de prevención de desastres a niveles regionales y locales, la ONU se erige como parte actora y guía en todo este proceso, al señalar que las Naciones Unidas prestarán asistencia a los países "cuando estos planifiquen la preparación para casos de desastres" y afirma que "la prevención de los desastres debe considerarse como parte integrante de los programas nacionales presentados al Programa de las Naciones Unidas para el desarrollo".

Por otra parte, la declaración incide en la necesidad de una adecuada comunicación de las alertas sobre desastres, convirtiéndose en un precedente del concepto de alerta temprana que sigue vigente en nuestros días. Así, se recomienda (recomendación número 1 de la Declaración) que se evalúen "los sistemas actuales de comunicación de desastres internacional de alertas contra desastres naturales, con objeto de determinar en qué medida es necesario mejorarlos". Añaden que es necesaria una "difusión generalizada y oportuna de alertas" y que se promueva "un sistema mundial eficaz de alerta contra los desastres naturales en el que se preste especial atención a los ciclones tropicales y los terremotos".

Ya en esta declaración de 1972, la comunidad internacional pone también el acento en la importancia de las acciones educativas, también para los más jóvenes. Se vincula la educación con la responsabilidad y el control que sobre el medio ambiente y los desastres pueden ejercer los ciudadanos, y asimismo se destaca la importancia de la información para fomentar la participación ciudadana.

Así, el Principio 19 indica que "Es indispensable una labor de educación en cuestiones ambientales, dirigida tanto a las generaciones jóvenes como a los adultos y que preste la debida atención al sector de la población menos privilegiado, para ensanchar las bases de una opinión pública bien informada y de una conducta de los individuos, de las empresas y de las colectividades inspirada en el sentido de su responsabilidad $[\ldots]$.

Y finalmente la Recomendación 97 señala la necesidad de "Establecer un programa de información destinada a suscitar el interés de los particulares por el medio humano y a lograr la participación del público en su control. Tal programa recurrirá a los medios de información pública tradicionales y contemporáneos, teniendo en cuenta las peculiaridades nacionales. Además, deberá prever los medios de estimular la participación activa de los ciudadanos y despertar el interés y lograr la contribución de las organizaciones no gubernamentales en la salvaguardia y el mejoramiento del medio". 
En resumen, esta conferencia supuso una primera toma de contacto entre dos mundos, el de los desastres naturales y el de los programas de información para el público.

\section{Resumen:}

1972. Estocolmo (Suecia) Conferencia de las Naciones Unidas sobre el Medio Humano

La prevención de los desastres debe formar parte de los programas para el desarrollo

Es necesario:

-Difundir alertas

-Educación ambiental para jóvenes y adultos para lograr una opinión pública bien informada y una conducta responsable

-Programa de información que motive al público a la participacion.

El programa recurrirá a los medios de información tradicionales y contemporáneos y tendrá en cuenta las peculiaridades nacionales

1989. La Asamblea General de la ONU emite la resolución $44 / 236$ de 22 de diciembre, en la que insta a lanzar una campaña mundial durante el decenio de 1990 para salvar vidas humanas y reducir los efectos de los desastres naturales.

1991. La Asamblea General de la ONU emite la resolución 46/182, de 19 de diciembre, decidiendo adoptar un criterio integrado para el manejo de los desastres en todos sus aspectos e iniciar un proceso de creación de una cultura mundial de la prevención.

1992

En junio de 1992 se adopta la Declaración de Río sobre el Medio Ambiente y el Desarrollo, durante la correspondiente Conferencia de Naciones Unidas. Su objetivo es desarrollar más profundamente la conferencia de Estocolmo de hacía 20 años. 
La declaración de Río señala en el Principio 1 que "Los seres humanos constituyen el centro de las preocupaciones relacionadas con el desarrollo sostenible. Tienen derecho a una vida saludable y productiva en armonía con la naturaleza".

Avanzando en la Declaración, encontramos aspectos que refuerzan el concepto de participación que ya se enunciaba dos décadas antes, ahora de una forma más explícita. Así en el Principio ํo10 se señala que "El mejor modo de tratar las cuestiones ambientales es con la participación de todos los ciudadanos interesados, en el nivel que corresponda. En el plano nacional, toda persona deberá tener acceso adecuado a la información sobre el medio ambiente de que dispongan las autoridades públicas incluida la información sobre los materiales y las actividades que encierran peligro en sus comunidades [...]".

También en Río encontramos referencias a la comunicación en situaciones de desastre y emergencia, en este caso para aquellas situaciones susceptibles de causar daños medioambientales. La obligación de facilitar la información pertinente viene recogida en los Principios 18 y 19: "Los Estados deberán notificar inmediatamente a otros Estados de los desastres naturales u otras situaciones de emergencia que puedan producir efectos nocivos súbitos en el medio ambiente de esos Estados [...]". "Los Estados deberán proporcionar la información pertinente y notificar previamente y en forma oportuna, a los Estados que posiblemente resulten afectados por actividades que puedan tener considerables efectos ambientales transfronterizos adversos [...]".

\section{Resumen:}

\section{Declaración de Río sobre el Medio Ambiente y el Desarrollo}

Se requiere la participación ciudadana para abordar cuestiones ambientales

Los ciudadanos han de tener acceso a información medioambiental de que dispongan las autoridades, incluida la información sobre materiales y actividades peligrosas

Los Estados también deben proporcionar información a otros estados sobre desastres y emergencias que puedan causar efectos transfronterizos 
1990-1999. DIRDN. La ONU fija el Decenio Internacional para la Reducción de los Desastres Naturales.

1994. Primera conferencia Mundial sobre la Reducción de los Desastres. Yokohama, Japón, 23 al 27 de mayo de 1994.

A mediados del Decenio Internacional para la Reducción de los Desastres Naturales (decenio fijado para el periodo 1990-2000) se lleva a cabo la primera conferencia Mundial sobre la Reducción de los Desastres. De dicha conferencia se aprueba la Estrategia de Yokohama para un mundo más seguro y su Plan de Acción.

La conferencia fija claramente en su texto quienes son sus precedentes, al señalar como referentes las resoluciones de la ONU de 1989 y 1991, el Programa 21 aprobado en la Conferencia de las Naciones Unidas sobre el Medio Ambiente y la Declaración de Río sobre el Medio Ambiente y el Desarrollo. Así, se reafirma una vez más y de forma expresa que el desarrollo sostenible y el desarrollo económico no son posibles si no se toman medidas para reducir las pérdidas causadas por los desastres. De nuevo, este actor internacional vincula en su enunciado directamente el concepto de desastre al de otros conceptos como el desarrollo sostenible o las políticas medio ambientales. Es decir, el concepto de desastre nunca figura como algo aislado de otros factores, sino íntimamente conectado a ellos.

Teniendo como base estos puntos de partida, sin embargo, la conferencia va más allá, introduciendo nuevos prismas que en ocasiones son auténticos pasos de gigante.

La centralidad del ser humano en los desastres sigue figurando como en los textos precedentes, pero en este caso el objeto de ese control no es el desastre en sí, sino que se apunta hacia la vulnerabilidad y el riesgo como los factores que sí pueden modelarse desde la acción y las decisiones humanas.

Señala como principio que la evaluación del riesgo es indispensable para la adopción de medidas para la reducción de desastres y que la "vulnerabilidad puede reducirse mediante la aplicación de métodos apropiados de diseño y unos modelos de desarrollo orientados a los grupos beneficiarios, mediante el suministro de educación y capacitación adecuadas para toda la comunidad".

Por tanto, viendo el punto de partida, las dificultades y limitaciones existentes, así como la necesidad de un control del riesgo y la vulnerabilidad como nuevas acciones a conseguir, la conferencia de Yokohama diseña una nueva estrategia para ser aplicada 
a partir del año 2000, concretando que se ha de buscar, entre otros, los siguientes puntos:

"Desarrollo de una cultura mundial de prevención como componente esencial de un planteamiento integrado de la reducción de los desastres"

"Enseñanza y formación en materia de prevención de desastres, preparación para casos de desastres y mitigación de sus efectos"

"Mayor toma de conciencia de las comunidades vulnerables mediante un papel más activo y constructivo de los medios de información en lo que respecta a la reducción de los desastres"

"Participación activa de la población en la reducción de los desastres, la prevención y la preparación para casos de desastre, lo que a su vez permitirá un mejor manejo del riesgo"

"Adopción de una política integrada para la prevención, la preparación y la reacción en el contexto de los desastres naturales y otras situaciones de desastre, con inclusión de los riesgos ambiental y tecnológico"

"Integración del sector privado en las actividades de reducción de desastres mediante la promoción de oportunidades de negocios"

Asimismo se vuelve a poner de relevancia, como en otros textos anteriores, el papel de las ONG, en este caso en el manejo de los riesgos naturales, así como la importancia de contar con las comunidades locales para poder aplicar sus conocimientos, prácticas y valores tradicionales en materia de reducción de desastres.

Yokohama establece un Plan de Acción a seguir por todos los países participantes en el que entre otros les exhortan a elaborar y aplicar "programas de enseñanza e información destinados a despertar conciencia en el público en general, y especialmente en los encargados de formular políticas y en los grupos más importantes, a fin de lograr apoyo para los programas de reducción de desastres y garantizar su eficacia", así como a promover "la participación del sector de los medios de información para que contribuya a aumentar la conciencia del público, a educar y a formar una opinión pública que reconozca mejor las posibilidades de salvar vidas y bienes que ofrece la reducción de los desastres".

Como actividades más concretas dentro de los planes regionales y subregionales (para los países de una misma región o subregión que sean vulnerables a los mismos tipos de riesgos), se establece: 
"Reunir y difundir documentación e información para despertar conciencia de los desastres naturales y las posibilidades de reducir sus efectos"

"Establecer o fortalecer los mecanismos de alerta temprana para la reducción de los desastres"

“Conmemorar el Día Internacional para la Reducción de los Desastres Naturales".

Finalmente, el Mensaje de Yokohama recalca que durante mucho tiempo se ha seguido el criterio de reaccionar ante un caso de desastre más que a prevenirlo, pero que ahora son conscientes de que "para el logro de las metas y los objetivos del Decenio, la prevención de desastres, la mitigación de sus efectos y la preparación para casos de desastre son mejores que la reacción una vez ocurrido uno. La reacción ante un caso de desastre no basta por sí sola pues no arroja más que resultados temporales con un costo muy alto."

Respecto a la difusión de información y conocimientos, remarca que puede realizarse a un costo relativamente bajo:

"La información, los conocimientos y parte de la tecnología necesaria para reducir los efectos de los desastres naturales podrían estar disponibles en muchos casos a un costo bajo y es preciso aplicarlos. Hay que poner libremente y en forma oportuna a disposición de todos, particularmente los países en desarrollo, la tecnología y los datos apropiados con la capacitación correspondiente".

Y se fija en la necesidad de "fomentar la participación activa de la comunidad para comprender mejor la interpretación individual y colectiva de las ideas de desarrollo y riesgo y para entender claramente características culturales y de organización de cada sociedad, así como de su comportamiento y su interacción con el medio físico y natural. Este conocimiento reviste suma importancia [...] para encontrar medios eficaces y eficientes de reducir los efectos de los desastres". 


\section{Resumen:}

1994. Primera conferencia Mundial sobre la Reducción de los Desastres. Yokohama, Japón, 23 al 27 de mayo de 1994. Estrategia de Yokohama para un mundo más seguro y su Plan de Acción

-Referentes : resoluciones de la ONU de 1989 y 1991, el Programa 21 de la Conferencia de las Naciones Unidas sobre el Medio Ambiente, Declaración de Río sobre el Medio Ambiente y el Desarrollo

-La vulnerabilidad puede reducirse mediante la educación y capacitación de la comunidad

Se pretende reducir los desastre mediante:

-Cultura mundial de la prevención

-Enseñanza y formación en prevención y preparación de desastres

-Participación social

- Los medios de comunicación pueden contribuir a tomar conciencia de los desastres

Plan de Acción:

-Programas de enseñanza e información

-Participación de los medios de información

-Para los países de una misma región o subregión"Reunir y difundir documentación e información concienciar sobre los desastres y la posibilidad de reducirlos

-Alerta temprana

-Conmemorar el Día Internacional para la Reducción de los Desastres Naturales

-Prevenir y prepararse ante los desastres es mejor que reaccionar

-Participación activa de la comunidad para comprender sus características culturales, de organización y de interpretación del desarrollo y el riesgo así como de su comportamiento y su interacción con el medio físico y natural 
La ONU adopta la Estrategia Internacional para la Reducción de Desastres (EIRD) y establece la secretaría de la EIRD/ONU. La estrategia insta a los socios a implementar la Reducción de Riesgo de Desastres (RRD), en estrecha colaboración con las instituciones encargadas de gestionar los desastres.

Se denomina reducción de riesgo de desastres (RRD) al "marco conceptual de los elementos que se toman en consideración con el fin de minimizar las vulnerabilidades y los riesgos de desastres en una sociedad, para así evitar (prevención) o limitar (mitigación y preparación) el impacto adverso de las amenazas y facilitar el desarrollo sostenible".

La RRD es vista como un tema transversal en el que deben estar presentes sectores gubernamentales y representantes de la sociedad civil, incluyendo instituciones académicas, medios de comunicación o sector privado.

También en la misma época se insta a los miembros de la ONU mediante resolución 1999/63 a crear Plataformas Nacionales multisectoriales para la RDD.

Entre las tareas a destacar realizadas por la secretaría de la EIRD/ONU se encuentra la coordinación de las Campañas Mundiales para la Reducción de Desastres, que tienen carácter bienal y se dirigen a movilizar acciones de concienciación sobre reducción de desastres.

2005. Informe de la Conferencia Mundial sobre la Reducción de los Desastres. Kobe. Establecimiento del Marco de Acción de Hyogo 2005-2015.

La Conferencia Mundial sobre la Reducción de los Desastres, celebrada en Kobe, supone una revisión de la Estrategia de Yokohama (1994) y un análisis de la situación actual para fijar los nuevos pasos a seguir.

Por una parte, se concluye que los principios de Yokohama siguen manteniendo plena vigencia $y$, por otra, se constata que siguen aumentando las cifras de pérdidas derivadas por desastres, y que por tanto hay que establecer nuevas estrategias a seguir.

¿Cómo conseguir pues esa reducción de los desastres? "Los desastres pueden reducirse considerablemente si la población está bien informada y motivada para asumir una cultura de prevención y de resiliencia ante los desastres[...]", por lo que se fija como una de las prioridades del Marco de Acción para los años 2005-2015 el 
utilizar los conocimientos, las innovaciones y la educación para crear una verdadera cultura de la seguridad y de resiliencia.

Entendiéndose por resiliencia, según indican en el texto la "capacidad de un sistema, comunidad o sociedad potencialmente expuesto a amenazas para adaptarse, resistiendo o cambiando, con el fin de alcanzar o mantener un nivel aceptable en su funcionamiento y estructura. Viene determinada por el grado en que el sistema social es capaz de organizarse para incrementar su capacidad de aprender de los desastres pasados a fin de protegerse mejor en el futuro y mejorar las medidas de reducción de los riesgos".

La difusión de conocimientos y educación contribuye a reducir la vulnerabilidad, pero también los efectos del desastre si este ocurre: "Cuando se produce un desastre, es posible reducir considerablemente su impacto las pérdidas que causa si las autoridades, las personas y las comunidades de las zonas expuestas a las amenazas están bien preparadas y dispuestas a intervenir y disponen de los conocimientos y las capacidades para la gestión eficaz de las situaciones de desastre".

En todos estos procesos se considera que cada país ha de ser el responsable de su propio desarrollo, pero remarcan el papel de organismos internacionales como la ONU para dar alas a este tipo de iniciativas señalando que "un entorno internacional propicio es fundamental para dar estímulo", poniendo en valor el rol prescriptor y de apoyo que dicho organismo está desarrollando desde hace décadas. Ya a nivel estatal, incide en que aquellos países que elaboren sus propios marcos normativos, legislativos e institucionales para la reducción de riesgos de desastre, así como indicadores mensurables de sus progresos, tendrán más capacidad para controlar los riesgos así como para impulsar una mayor participación social.

El marco de Acción de Hyogo supuso la constatación de que el tema de la reducción de desastres consolidaba su presencia en la agenda internacional, fijando un ambicioso plan de acción a seguir.

1. Ejercicios de preparación ante el desastre

En general para toda la sociedad hay que "Promover ejercicios periódicos de preparación para casos de desastre, incluidos ejercicios de evacuación, con miras a lograr una respuesta rápida y eficaz ante situaciones de desastre [...]”. 


\section{Difusión de información}

Se ha de llevar a cabo una mayor difusión de la información sobre los riesgos y la protección que se debe adoptar, por lo que es importante "Proporcionar información clara sobre los riesgos de desastre y las distintas formas de protección, en particular a los ciudadanos de las zonas de alto riesgo [...]".

De forma más concreta, entre las informaciones a difundir se encuentran los mapas de riesgo, los resultados de estudios sobre el impacto social, económico y ambiental de los desastres, así como estadísticas de los desastres acaecidos y los efectos y pérdidas que ocasionan.

Autoridades, ciudadanía y comunidades han de estar conectadas para que esta información se difunda.

\section{La importancia de la alerta temprana}

Se insiste como en años y textos anteriores en el concepto de alerta temprana, para alertar del riesgo a las personas y comunidades expuestas, de forma rápida, coordinada y clara, e indicarles la forma de actuar.

\section{Creación de una terminología común}

Por otra parte, pese a esta adaptación de la información a los factores culturales y sociales de los destinatarios, se reclama asimismo la divulgación de una "terminología internacional normalizada sobre la reducción del riesgo de desastre", para que sea utilizada en los distintos programas, incluidos los de "formación y los de información pública".

(Como se ha visto en los apartados anteriores, en 2009 se editó un documento que incluía esa terminología normalizada).

\section{Compartir la información}

Todos aquellos países que forman parte de la Estrategia Internacional de Reducción de Desastres deben compartir información, difundiendo "las prácticas óptimas, las enseñanzas, las tecnologías y los programas disponibles". El Marco de Acción de Hyogo también pide que se mantenga una plataforma de información mundial y "una cartera de registro en Internet de los programas e iniciativas de reducción de los 
riesgos de desastres adoptados por los Estados y mediante alianzas regionales e internacionales".

7. Participacion del sector privado

Alentar al sector privado a que colabore con el público en las actividades de reducción del riesgo de desastres y a que fomente una cultura de prevención dedicando más recursos a actividades como la evaluación de riesgos y los sistemas de alerta temprana.

8. Participación del voluntariado

Hay que fomentar también la implicación y participación del voluntariado en todas esas tareas.

9. Participación de los medios de comunicación

Se ha de promover la participación de los medios de comunicación en la tarea de concienciación pública, mediante "campañas constantes de educación de la ciudadanía [...]".

\section{Resumen:}

2005. Informe de la Conferencia Mundial sobre la Reducción de los Desastres. Kobe. Establecimiento del Marco de Acción de Hyogo 2005-2015.

Potenciación de los conceptos de Reducción de Riesgo de Desastres y de Resiliencia

El conocimiento y la educación pueden reducir la vulnerabilidad, y crear una cultura de prevención, seguridad y de resiliencia

La ONU sirve para dar estímulo a las organizaciones nacionales. En cada nación, un marco normativo, legislativo e institucional sobre Reducción de Desastre sumado a indicadores mesurables sobre los progresos, favorece la capacidad nacional para controlar los riesgos y lograr la participación ciudadana. 
La ONU sirve para dar estímulo a las organizaciones nacionales. En cada nación, un marco normativo, legislativo e institucional sobre Reducción de Desastre sumado a indicadores mesurables sobre los progresos, favorece la capacidad nacional para controlar los riesgos y lograr la participación ciudadana.

Marco de Acción:

-Realizar ejercicios de preparación incluidos simulacros

-Difundir información sobre riesgos y medidas de protección, incluyendo: mapas de riesgos, estudios estadísticos

-Alerta temprana

-Creación de una terminología común

-Los países de la Estrategia Internacional de Reducción de Desastres compartirán información, incluyendo: buenas prácticas, enseñanzas

-Creación de una plataforma de información mundial para conocer los distintos programas e iniciativas en $R R D$

-Participación del sector privado, voluntarios

-Participación de los medios de comunicación para la difusión de campañas de educación a la ciudadanía

\section{6-2007}

Se lleva a cabo la séptima edición de la Campaña Mundial para la Reducción de Desastres, coordinada desde la secretaría EIRD/ONU y con apoyo de la UNESCO.

2009. Conferencia Mundial de Educación para el Desarrollo Sostenible. UNESCO.

2015. 3a Conferencia mundial sobre la Reducción de Riesgo de Desastres en Sendai, Japón, marzo 2015 
Se adoptó en esta conferencia el Marco de Acción de Sendai para la Reducción del Riesgo de Desastres 2015-2030. Se plantea para 15 años en lugar de para 10 como estaba fijándose hasta el momento.

Como en los casos precedentes esta nueva conferencia mundial supone la revisión del estado de la situación y la adopción de nuevas medidas que contribuyan a los avances para la reducción de desastres y de sus efectos y la consecución de una cultura mundial de la prevención y la resiliencia.

Los objetivos y los planteamientos para alcanzarlos conectan con las conferencias anteriores y se reafirman en distintos puntos como la difusión del conocimiento y la información en torno al riesgo de desastres, y la educación en todos los sectores de la sociedad, buscando:

"(l) Promover la incorporación del conocimiento sobre riesgo de desastres, incluyendo la prevención de desastres, la mitigación, preparación, respuesta, recuperación y rehabilitación, en la educación formal y no formal, así como en la educación de la ciudadanía en todos los niveles, así como en educación profesional”.

También se insiste en el papel de los medios de comunicación, invitándoles a tomar un rol activo e inclusivo en los niveles locales, nacionales, regionales y globales en contribución al incremento de la concienciación pública y en comprender y difundir información cuidada y no sensible sobre riesgo de desastres, incluyendo desastres a pequeñas escala, de una forma sencilla, transparente, accesible $y$ de fácil comprensión, en cooperación cercana con las autoridades nacionales", y también adoptar políticas comunicativas específicas en reducción de riesgo de desastres, apoyar como corresponda los sistemas de alerta temprana y las medidas protectivas que salvan vidas, y estimular una cultura de la prevención y una involucración comunitaria en apoyar campañas de educación pública y consultas públias a todos los niveles de la sociedad, de acuerdo a las prácticas nacionales".

Como cambio significativo respecto a ocasiones anteriores, detectamos una mayor conciencia de tomar en consideración a las distintas tipologías de audiencias y sus distintas necesidades a la hora de preparar y difundir información en torno al riesgo de desastres, en el seno de estrategias nacionales. Así se manifiesta al indicar la necesidad de:

“(m)Promover estrategias nacionales para dirigir educación pública y la concienciación en la reducción de riesgo de desastres, incluyendo la información sobre riesgo de desastres y el conocimiento, mediante campañas, redes sociales y movilización de la 
comunidad, teniendo en cuenta los distintos tipos de audiencias específicas y sus necesidades"

y

“ (a) Promover la recogida, análisis, gestión y uso de datos relevantes e información práctica y asegurar su difusión, tomando en consideracón las necesidades de las diferentes categorías de usuarios".

En este sentido, se celebró una sesión durante la conferencia destinada a una RRD inclusiva para todos los públicos, en la que se planificase "con" y no "para" las distintas comunidades. Además se relataron experiencias desarrolladas con algunas de estas comunidades y se pidió seguir destinando mayores esfuerzos para la educación e información de RRD de carácter inclusivo, abarcando a grupos como personas con discapacidad, pesonas con trastorno de estrés postraumático, esquizofrenia, depresión, personas sordas o ciegas.

\section{Resumen:}

3므 Conferencia mundial sobre la reducción de riesgo de desastres en Sendai, Japón, marzo 2015

Incorporar la Reducción de Riesgos de Desastres (RRD) en la educación formal y no formal

Los medios de comunicación pueden contribuir a la RRD informando de una forma sencilla, transparente y comprensible.

Pueden informar sobre distintos contenidos, incluyendo: desastres de menor magnitud, alertas tempranas, avances en los resultados de la $R R D$

Cada país ha de realizar campañas y utilizar las redes sociales para informar sobre RRD teniendo en cuenta las distintas audiencias y sus necesidades, como las de las personas discapacitadas

\subsubsection{Conclusiones}

Tras la revisión de la documentación emitida por la ONU durante estas cuatro décadas, podemos observar una serie de constantes en el discurso mundial sobre la prevención, así como una evolución y cambios que revelan nuevos enfoques sobre la 
gestión de los riesgos y los desastres y la relación de las instituciones y la sociedad con estos fenómenos.

Por una parte, respecto a las constantes mantenidas durante todo este tiempo, detectamos la importancia concedida al papel de la difusión de la información y la educación para un mejor manejo de los riesgos y los desastres. También la reivindicación de la participación de diversos actores para una mejor implementación de ese manejo: una ciudadanía informada y activa, los medios de comunicación, las ONG's y, apareciendo paulatinamente a lo largo de los años, el sector privado.

Por otra parte, observamos también una evolución durante todas estas décadas, de forma que podemos dividir en dos periodos:

\section{Desde 1972 (Conferencia de las Naciones Unidas sobre el Medio Humano) hasta principios de los años 90}

La prevención de desastres y la planificación de desastres aparecen indisolublemente ligadas al equilibrio medioambiental y al desarrollo.

Respecto al tipo de datos a difundir, se incide en la difusión de alertas, información sobre actividades peligrosas o notificaciones.

\section{4-actualidad (2015)}

Aunque siga reconociéndose la ligazón entre la prevención de desastres y aspectos como el medioambiente y el desarrollo, entre otros factores, la Primera Conferencia Mundial de Reducción de Desastres (Yokohama 1994) y las siguientes (Kobe 2005, Sendai 2015) le otorgaron a la gestión y prevención de los desastres su propia dimensión.

La primera conferencia introdujo cambios conceptuales de gran relevancia, que posteriormente han seguido evolucionando en las siguientes citas mundiales. Resumimos aquí de forma esquemática las principales innovaciones de cada una de las conferencias, innovaciones que los discursos nacionales de las distintos países participantes, incluida España, han asumido como líneas propias fruto del consenso entre los integrantes de la ONU.

\section{Yokohama}

-Reducción de la vulnerabilidad y los desastres mediante la educación y capacitación -Enseñanza y formación para prevención y preparación frente a desastres 
-Desarrollo de una cultura mundial de la prevención

-Si bien las décadas precedentes se centraban más en los desastres naturales, a partir de Yokohama se incide también en los riesgos ambientales y tecnológicos

-La información puede despertar conciencias

-Los medios de comunicación pueden aumentar la concienciación del público

-Hay que fomentar la participación del público para conocer mejor la interpretación individual y colectiva del riesgo

-Se establecerá un Dia Internacional para la Reducción de los Desastres

\section{Kobe}

-Una población bien informada y motivada puede contribuir a una cultura de la prevención y resiliencia ante los desastres

-Se ha de favorecer diálogo entre autoridades y ciudadanos para aumentar la difusión de información

-La información a compartir no sólo han de ser datos o alertas, sino también prácticas óptimas y lecciones aprendidas

-El conocimiento contribuye a una gestión eficaz del desastre

-La resiliencia es el grado en que el sistema puede organizarse para aprender de los desastres pasados para protegerse mejor en el futuro y mejorar las medidas de reducción de riesgo

- Se han de realizar ejercicios periódicos de preparación ante desastres, incluídos evacuaciones

\section{Sendai}

-El conocimiento sobre el riesgo de desastres incluye: prevención, mitigación, preparación, respuesta, recuperación y rehabilitación. Enseñanzas sobre este conocimiento han de incluirse en todos los niveles educativos, desde la infancia a los adultos.

-Se concretan las importantes labores que los medios de comunicación pueden realizar:

*Concienciación

*Facilitar información sencilla y comprensible, en cooperación con las autoridades. Se incluyen los desastres a pequeña escala

*Alerta temprana

*Campañas de educación pública para una cultura de la prevención 
-Las campañas de educación pública deberán tener en cuenta los distintos tipos de audiencias específicas y sus necesidades. Se han de contemplar las diferentes categorías de usuarios, que pueden incluir grupos como personas discapacitadas, o afectadas por trastornos como el estrés postraumático.

En resumen, las conferencias han ido concretando cada vez más el camino mediante el cual lograr una cultura mundial de la prevención, una cultura basada en aspectos como la información, la concienciación y la educación.

Se reivindica el papel de una ciudadanía activa y formada y se concretan las distintas labores a desarrollar por los medios de comunicación. Por último, de forma progresiva se ha incidido en la necesidad de tener en cuenta las interpretaciones individuales y colectivas del riesgo así como las necesidades de los distintos grupos de usuarios, a la hora de diseñar los mensajes y campañas educativas. 


\subsection{EL NIÑO EN EL MAPA DE PÚBLICOS DE LA PREVENCIÓN}

\subsubsection{INTRODUCCIÓN}

La hipótesis de partida de la presente investigación planteaba que los organismos de protección civil dirigían una parte de su comunicación preventiva a informar a los niños y niñas y adolescentes sobre los riesgos existentes y cómo evitarlos. Sostiene, asimismo, que las prácticas comunicativas generadas están diseñadas teniendo en cuenta a este tipo de público, y cuentan con recursos diferentes a los utilizados en la comunicación preventiva orientada al público en general.

Cada organización tiene su propio mapa de públicos (Costa: 1977) y, desde la perspectiva de la presente investigación, la documentación y prácticas analizadas y la información obtenida en el posterior análisis empírico revelan que las instituciones de la protección civil han incluido a la infancia y la adolescencia en ese mapa. Según la clasificación de Costa, entenderíamos a estos nuevos públicos como externos y no tradicionales.

Por su parte, Capriotti (1999, 2009) y Losada (2010: 60-61) indican que hay tres niveles de información sobre los públicos que cada organización puede recopilar.

-Estructura. Incorporación al mapa de los públicos con los que establecer algún tipo de relación.

-Infraestructura: conocer cómo los públicos se informan sobre nuestra organización -Características: conocer la situación de partida de nuestros públicos (demografía, creencias, actidudes) y hábitos de información.

Consideramos que las instituciones de la protección civil en España están tendiendo a incorporar a su mapa de públicos a la infancia y adolescencia, y que para ello realizan previamente un trabajo de análisis para conocer mejor la infraestructura y características de dicho público. Esta incorporación ha venido dada por los siguientes factores, que serán analizados individualmente a lo largo del presente capítulo:

1. Constatación por parte de los organismos de protección civil de que no existe suficiente concienciación por parte del público adulto acerca de los beneficios de informarse y formarse en prevención de emergencias y catástrofes, ni suficiente 
diálogo con los medios de comunicación para que estos se involucren más en la difusión de contenidos en información preventiva.

2. Desarrollo de un marco legal que incorpora al niño como persona a quien formar en aspectos de autoprotección y prevención

3. Reivindicación en el discurso mundial de la prevención del niño como agente de cambio social

4. Análisis de la infraestructura y características del público infantil por parte de organismos internacionales y agencias vinculadas a la gestión de riesgos con el fin de determinar cuáles son las prácticas comunicativas y formativas más adecuadas para estos públicos, muy especialmente desde el ámbito escolar.

5. Esfuerzos desde la teoría de comunicación de riesgo e investigación social de los desastres de remarcar la necesidad de mayor diálogo y participación de todos los actores implicados en la gestión y preparación ante los riesgos y desastres, a través de una comunicación no unidireccional.

Pasaremos a continuación a desglosar cada uno de estos aspectos que, en suma con los demás, han contribuido a ubicar a la infancia y la adolescencia dentro del mapa de público de las organizaciones vinculadas a la protección civil.

\subsubsection{MARCO SOCIAL: ¿UN ENTORNO CONCIENCIADO?}

Incorporar a la infancia y la adolescencia en el mapa de públicos de las organizaciones de protección civil surge, en un parte importante, como reacción a un contexto social que no contribuye por sí mismo a fomentar entre los niños una concienciación en materia de autoprotección.

El entorno en el que estos niños crecen, se educan o se informan todavía no es, pese a las insistencias de los organismos internacionales y los actores legales que hemos visto en capítulos anteriores, un entorno en el que la cultura de la prevención haya arraigado definivitamente, pese a los avances logrados. Precisamente, la contínua insistencia en la importancia de la información y educación ciudadana, a través de los discursos anteriormente analizados, es reveladora de una realidad: si es necesario continuar insistiendo, es porque sigue el nivel de concienciación es insuficiente o todavía no está profundamente enraizado en toda la sociedad.

Así, incorporar a los niños como destinatarios de información y formación sobre aspectos como autoprotección, manejo de riesgos, o actitud preventiva, aparece como 
una manera de paliar ese insuficiente nivel global de concienciación y conocimientos, trabajando por lograr introducir cambios en la raíz del problema..

Hay algunos factores que explican esa dificultad para facilitar la entrada o la difusión de una cultura de la prevención en el público adulto, y que, pese a los avances logrados, siguen siendo una traba para el logro de mayores resultados:

\section{a) Determinadas concepciones sociales sobre el riesgo y nuestra forma de relacionarnos con él}

Las concepciones de la humanidad sobre el riesgo, las amenazas y los desastres han influído la forma en las que las sociedades se relacionan con estos factores. Así, en épocas pasadas se asociaban los desastres a castigos relacionados con los dioses o las fuerzas de la naturaleza o el destino, por lo que las ofrendas o los rituales constituían una forma de tratar de influir en lo sobrenatural (Quarantelli, Lagadec, Boin 2006:18) pero no conducían a una aplicación de criterios científicos.

Hoy en día, siguen existiendo factores psicosociales que influyen en la forma en que concebimos los riesgos, y en la manera en que valoramos tanto su capacidad para afectarnos como la nuestra para protegernos.

Auf de Heide (1989) y Renedo, Gil y Valero (2007:75) mencionan la ilusión de "invulnerabilidad personal" para definir aquella concepción por la cual consideramos que no nos va a pasar nada o negamos la existencia del riesgo. Esto se debe a diversos factores como el fatalismo ( "lo que tenga que suceder sucederá") la negación ("esto no puede suceder aquî"), la baja estimación del riesgo del desastre o un falta de concienciación.

\section{b) La confianza en los sistemas expertos}

Otro de los factores sociales que dificultan la potenciación de una cultura preventiva en la sociedad sería la confianza absoluta en los servicios de emergencia y organismos de protección civil, y las distintas administraciones nacionales, autonómicas, nacionales y locales para gestionar los riesgos y las emergencias, obviando que será la primera respuesta del ciudadano de a pie la que podrá contribuir en los primeros momentos de la emergencia a su adecuada resolución. 
Según un estudio sobre la percepción social del riesgo en España, realizado por el CEISE, el Centro Europeo de Investigación Social de Situaciones de Emergencia (Ministerio del Interior:2008), en nuestro país se ha superado el "riesgo de supervivencia" (hambrunas, guerras, pobreza...) para pasar a un "riesgo de retorno", esto es, derivado de un modo de vida y de un progreso social que sin embargo no ha anulado la existencia de riesgo e inseguridades.

Se ha pasado también de un panorama de "riesgos vividos" a una sociedad de "riesgos percibidos", que son transmitidos y amplificados por los medios de comunicación, extendiéndose la idea de que los riesgos son amenazas universales que pueden afectar a todos (García: 2008:30-34), incluyéndose en este mapa todo tipo de riesgos, desde vendavales, a accidentes de circulación pasando por incendios 0 inundaciones.

Esos riesgos percibidos son difundidos por los medios de comunicación. Pont (2009:26) señala que la percepción del riesgo ha aumentado en las últimas décadas por su divulgación mediática inmediata y Fog $(2002,2004)$ recuerda que la gente tiende a evaluar la probabilidad asociada al riesgo según la cantidad de información que recibe, mediante una cobertura informativa intensa (Walhberg y Sjöberg:2000).

¿Pero aumentar la percepción del riesgo equivale a estar preparado o a tratar de informarse sobre cómo actuar? Parece que no es lo mismo. Para Renedo, Gil, Valero (2007:77) "el hecho de aumentar la percepción del riesgo en una comunidad no implica que la comunidad lleve a cabo medidas preventivas, para ello se hace necesario, una vez aumentada esta percepción del riesgo, dotar a la población de medidas o acciones de cómo actuar en situación de desastre".

El estudio del CEISE parece apuntar en esa misma dirección. Se constataba que la sociedad española ha pasado a ser una sociedad de riesgos percibidos e incluso que para los participantes del estudio muchos de los riesgos admitían estrategias preventivas por considerar que estaban producidos por el hombre (2008:43). Sin embargo, estos datos encerraban una paradoja: pese a esa percepción del riesgo y la constatación generalizada de que la prevención es importante, los participantes tenían un conocimiento prácticamente inexistente sobre emergencias... y casi nadie había intentado nunca corregir esa situación.

Concretamente, el $71,5 \%$ de los participantes indicaba que tenía un conocimiento entre nulo y bajo sobre como comportarse en una situación de emergencia y el $84,1 \%$ nunca había buscado información o tratado de formarse acerca de la prevencion o preparación en caso de catástrofe. El 77,3\% nunca había participado en ningún tipo de simulacro de emergencia. 
De esta forma, encontramos en España, por una parte, una sociedad que tiene una percepción alta de los riesgos y amenazas pero un conocimiento muy bajo sobre como manejar dichos riegos o cómo actuar en una situación de emergencia. Efectivamente, quizá percibamos que vivimos en un mundo de riesgos, pero no parecemos ser conscientes sobre qué significa esto o qué podemos hacer al respecto.

Consideramos que, en buena medida, esto es debido a la confianza social en los sistemas expertos, de los que Pont (2009:22) señala que "se introducen cada vez más en la vida de las personas y crean grandes áreas de seguridad útiles para el mantenimiento de la vida cotidiana, pero al mismo tiempo ejercen una influencia que las personas no pueden controlar"

Los conocimientos que necesitamos para afrontar determinados aspectos de nuestra vida han sido filtrados desde los sistemas expertos o sistemas abstractos. Esa confianza hace que deleguemos en ellos toda actuación relativa a determinados aspectos de nuestra vida cotidiana, y consideramos que también ocurre en materia de atención a emergencias, y por ende, de preparación para ellas.

Giddens indica (1993: 89) que la sociedad tiene un pacto con la modernidad que está gobernado entre otras cosas por "el confort y el miedo". Depositamos nuestra fiabilidad en los sistemas expertos, porque ignoramos: "sólo se exige fiabilidad allí donde existe ignorancia”.

Otra de las consecuencias de ignorar es que vemos el asunto, en este caso los riesgos, como algo insoluble, por lo que incluso conocer la existencia de los riesgos puede tener un efecto aturdidor (Giddens 1993:122).

\section{c) Escasa presencia en los medios de comunicación de la prevención de riesgos} y la preparación frente a emergencias

Como hemos señalado anteriormente, los medios de comunicación pueden amplificar la percepción del riesgo, aunque eso no signifique que ello vaya a hacernos estar más preparados para afrontarlos. Junto a las obstáculos de carácter psicosocial que hemos destacado antes, consideramos que existe otro factor que dificulta el fomento de una cultura mundial de la prevención a través de los medios de comunicaión.

$Y$ es que, si bien los riesgos, las emergencias o los desastres tienen cabida en el discurso mediático, la prevención y preparación ante todos estos fenómenos tiene dificultades para encontrar en él su lugar.

¿Por qué sucede esto? 
El CEISE realizó en el año 1992 un estudio en el colectivo de los responsables de la coordinación y la información de protección civil. Entrevistaron a cerca de cien jefes de prensa de delegaciones gobierno y de unidades de protección civil, y se les pregunto, entre otras cosas, si consideraban que los periodistas estaban interesados en difundir el mensaje preventivo de la protección civil. El $80 \%$ de los entrevistados respondió que sí, aunque de ellos el $42 \%$ matizó su respuesta. Los medios de comunicación estarían interesados sólo si se cumplían dos condiciones o alguna de ellas: que pudieran darle actualidad al mensaje preventivo relacionándolo con la óptica de algún suceso, o si coincidía en aquellos momentos con alguna catástrofe.

Casi veinte años después, en 2011, obtuvimos respuestas similares durante la realización de nuestro proyecto de investigación "Comunicación institucional en emergencias, catástrofes y prevención". Tratábamos de averiguar, como hemos señalado en la introducción, por qué los temas de prevención que trataba de divulgar el Servicio de Información Audiovisual del Consorcio de Bomberos de Castellón (SIAB) tenían menor repercusión mediática que los temas relativos a emergencias de actualidad que distribuía el mismo servicio.

Los doce periodistas entrevistados, de distintos medios de comunicación local, autonómico y nacional, ofrecían respuestas clave para tratar de comprender el fenómeno.

Así, la informacion sobre emergencias acontecidas encajaba en el capítulo de sucesos de los distintos medios, de los que éstos destacaban que se trataba de temas prioritarios que tenían gran interés para sus respectivas audiencias. Sin embargo, respecto a los temas de prevención señalaban que "no son noticia", o "no está consumado el suceso", entre otros aspectos.

$Y$ al igual que veinte años antes, estos medios de comunicación dejaban la puerta abierta a difundir los temas de prevención bajo determinadas circunstancias:

-Si podían ligarse a la actualidad informativa

-Si podían ligarse a sucesos históricos del pasado, a modo de recordatorio

-Si incluían imágenes espectaculares, por ejemplo de grandes simulacros

Los medios de comunicación no se negaban a abordar estos temas, pero era evidente que requerían que las instituciones vinculadas a la protección civil llevasen a cabo un mayor esfuerzo de adaptación de los temas de prevención a la lógica mediática.

En este sentido consideramos que el lenguaje periodístico (López, 1996: 14) tiene una serie de características a las que los temas de prevención deberían ajustarse para 
poder alcanzar mayor visibilidad dentro de los medios de comunicación, encajando con su dinámica y lenguaje.

Nuestro análisis en este sentido es que la prevención, para poder encajar en el discurso mediático debe:

-Relacionarse con el presente y la actualidad.

-Facilitar datos sobre hechos consumados relacionados con el mensaje preventivo que se quiere emitir o sobre el riesgo del que se quiere advertir.

- Mostrar el interés humano, más allá de meras estadísticas o informes

- Ser susceptible de ser contado o mostrado en imágenes.

En resumen, consideramos que la prevención podría encontrar su espacio en la lógica mediática de la información, si las instituciones vinculadas a la protección civil toman en cuenta las necesidades narrativas y formales de los medios de comunicación, y si mantienen con estos un diálogo abierto que invite a la prensa a su importante colaboración en materia de divulgación de una cultura mundial de la prevención. 


\subsubsection{NIÑOS Y PREVENCIÓN: MARCO LEGAL}

Otro de los pilares que ha contribuido a la incorporación de la infancia y la adolescencia en el mapa de públicos de las instituciones vinculadas a la protección civil es la legislación. Basándose en esta, el discurso de dichas instituciones se basa en que las actividades de información, prevención y divulgación en materia de protección civil pueden y deben realizarse desde edades bien tempranas.

De esta forma, se incorpora a los textos legales en España contenido específico sobre la formación en estos temas entre la infancia y la adolescencia. Un nuevo repaso a nuestra legislación nos muestra cómo la figura infantil ha ido incorporándose a lo largo de estos años, como persona que ha de formar parte del proceso de formación en materia de prevención y autoprotección. Así se ha reflejado en determinados artículos legales, de los que hemos extraído algunos ejemplos:

\section{Orden de 13 de noviembre de 1984 sobre evacuación de Centros docentes de Educación General Básica, Bachillerato y Formación Profesional}

Destinada a implantar la realización periódica de ejercicios prácticos de evacuación de emergencia en esos centros docentes, a la espera de aprobarse el Plan General de Emergencia de Centros Docentes.

"(...) parece conveniente regular de una manera provisional, aunque sin prescindir de su carácter general y obligatorio, las prácticas de evacuación de dichos Centros, de forma tal que se conviertan en habituales y sean una actividad más dentro de las tareas escolares. Con ello se pretende conseguir un triple objetivo:

- Enseñar a los alumnos a conducirse en situaciones de emergencia.

- Conocer las condiciones de los edificios en los que se alojan los Centros para conseguir la evacuación de una forma ordenada y sin riesgo para sus ocupantes, ni deterioro de los edificios ni del mobiliario escolar, debiéndose realizar todo ello en el menor tiempo posible.

-Mentalizar a los alumnos, a sus padres y a los profesores de la importancia de los problemas relacionados con la seguridad y emergencia en los Centros escolares." 
"En su virtud, este Ministerio ha dispuesto:

(...)

-Segundo.- Las prácticas de evacuación de edificios que forman parte de los Planes de Seguridad de los Centros docentes deben constituir un componente más de la educación de los alumnos, tanto desde un punto de vista individual como desde un punto de vista social y comunitario."

En el Anexo de la orden, figuran una serie de instrucciones sobre la propia realización de los simulacros. Pese a que ya tienen más de tres décadas, se trata de recomendaciones que hoy en día siguen teniendo plena vigencia tanto para los simulacros con participantes infantiles como para aquellos dirigidos a adultos.

"1.3. (..) este tipo de prácticas no pretende en sí mismo conseguir un resultado óptimo, sino más bien el entrenamiento y la corrección de hábitos de los alumnos, teniendo en cuenta los condicionantes físicos y ambientales de cada edificio."

"3.7. Cada profesor, en su aula, organizará la estrategia de su grupo designando a los alumnos más responsables para realizar funciones concretas como cerrar ventanas, contar a los alumnos, controlar que no lleven objetos personales, etc. Con ello se pretende dar a los alumnos más participación en estos ejercicios."

3.14. "Al comienzo del ejercicio se emitirá una señal de alarma ( timbre, sirena, campana o viva voz) (...)".

3.20. "Por parte del personal del Centro se procurará no incurrir en comportamientos que puedan denotar precipitación o nerviosismo, en evitación de que esta actitud pudiera transmitirse a los alumnos, con las consecuencias negativas que ello llevaría aparejadas." 
4. "Instrucciones orientativas para los alumnos.

4.1. Cada grupo de alumnos deberá actuar siempre de acuerdo con las indicaciones de su profesor y en ningún caso deberá seguir iniciativas propias.

4.2. Los alumnos a los que se haya encomendado por su profesor funciones concretas, se responsabilizarán de cumplirlas y de colaborar con el profesor en mantener el orden del grupo.

(...)

4.7. Los alumnos deberán realizar este ejercicio en silencio y con sentido del orden y ayuda mutua, para evitar atropellos y lesiones, ayudando a los que tengan dificultades o sufran caídas. "

\section{Ley 2/1985, de 21 de enero de Protección Civil}

Capítulo II. De los deberes y obligaciones en materia de protección civil.

"Asimismo, los centros de enseñanza desarrollarán, entre los alumnos, actividades que se encaminen al logro de los fines expuestos en el apartado anterior. Dichas actividades no tendrán la configuración de áreas de conocimiento, ni se computarán a efectos de valoración académica".

(Los fines a los que hace referencia, del apartado anterior, son: la obligación del cumplimiento de las medidas de prevención, las prácticas oportunas y la intervención operativa cuando las circunstancias lo requieran) 
Real Decreto 393/2007, de 23 de marzo, por el que se aprueba la Norma Básica de autoprotección de los centros, establecimientos y dependencias dedicados a actividades que puedan dar origen a una situación de emergencia

Establece la obligación de elaborar Planes de Autoprotección y y determina el contenido mínimo que deben incorporar dichos planes. Asimismo, dispone que se deberá realizar simulacro de emergencia mínimo una vez al año para evaluar la eficacia del plan de autoprotección.

La obligación de los poderes públicos de garantizar el derecho a la vida y a la integridad física, como el más importante de todos los derechos fundamentales, incluido en el artículo 15 de la Constitución Española, debe plantearse no sólo de forma que los ciudadanos alcancen la protección a través de las Administraciones Públicas, sino que se ha de procurar la adopción de medidas destinadas a la prevención y control de riesgos en su origen, así como a la actuación inicial en las situaciones de emergencia que pudieran presentarse

Ley 13/2010, de 23 noviembre, de la Generalitat, de Protección Civil y Gestión de Emergencias

Artículo 8. Autoprotección

"3. Formación escolar.

En los diferentes ciclos formativos de los centros escolares, será obligatorio programar actividades de información, prevención y divulgación en materia de protección civil, realizándose obligatoriamente, al menos una vez al año, un simulacro de evacuación, conforme a las previsiones del plan de autoprotección correspondiente 


\section{Orden 27/2012 de la Consejería de Educación de la Generalitat Valenciana}

Preámbulo

En el entorno escolar, la protección debe desarrollarse desde una vertiente educativa, contando con la colaboración de todos los sectores de la comunidad educativa, y debe tender a fomentar entre el alumnado los hábitos y comportamientos necesarios para las situaciones de riesgo, accidente, peligro o catástrofe, así como educar al discente en materia de autoprotección.

"Artículo 1. Objeto. La presente orden tiene por objeto regular los procedimientos y actuaciones destinadas a la protección de la comunidad educativa mediante la elaboración de los planes de autoprotección y el cumplimiento de las medidas de emergencia".

Define el Plan de Autoprotección (art.4) como "(...) el documento que establece el marco orgánico y funcional previsto para un centro educativo con el objetivo de prevenir y controlar los riesgos sobre las personas y los bienes, dar respuesta adecuada a las posibles situaciones de emergencia, en la zona bajo la responsabilidad del titular de la actividad, y garantizar la integración de estas actuaciones en el sistema público de protección civil".

"Artículo 10. Información. La dirección de cada centro educativo establecerá el procedimiento para informar sobre el plan de autoprotección y que éste sea conocido por todos los sectores de la comunidad educativa" 


\section{Ley 17/2015, de Protección civil}

La planificación, especialmente los planes de autoprotección, la formación del personal perteneciente al sistema de protección civil y singularmente la inclusión en los currículos escolares de contenidos sobre autoprotección y primeros auxilios, son instrumentos poderosísimos de prevención de carácter horizontal que esta ley procura.

Se crea el Fondo Nacional de Prevención de Emergencias como instrumento financiero adecuado para contribuir a dar el impulso necesario a actuaciones de elaboración de análisis y localización de riesgos, campañas de sensibilización e información preventiva a los ciudadanos, programas de educación para la prevención en centros escolares u otra análogas, previéndose para ello la celebración de convenios o acuerdos entre la Administración General del Estado, las Comunidades Autónomas y otra entidades públicas y privadas

\section{CAPÍTULO II}

Prevención de riesgos de protección civil

Artículo 10. Política de prevención.

5. Las Administraciones Públicas promoverán, en el ámbito de sus competencias y con cargo a sus respectivas dotaciones presupuestarias, la realización de programas de sensibilización e información preventiva a los ciudadanos y de educación para la prevención en centros escolares.

Artículo 11. Fondo de Prevención de Emergencias.

1. Se crea el Fondo de Prevención de Emergencias, gestionado por el Ministerio del Interior, dotado con cargo a los créditos que se consignen al efecto en los Presupuestos Generales del Estado, para financiar, en el ámbito de la Administración General del Estado, las actividades preventivas siguientes:

d) Programas de educación para la prevención en centros escolares. 


\section{Conclusiones}

A través de la legislación española, las instituciones vinculadas a la gestión de riesgos y emergencias ponen el foco en la importancia de una formación temprana en materia de prevención y emergencias, destinada a la infancia. Los niños y niñas son personas que pueden recibir información y formación de carácter preventivo, y ello puede redundar en el conjunto de la sociedad.

Estos textos sostienen que las instituciones públicas han de promover entre la ciudadanía actividades que le ayuden a adoptar medidas de "prevención y control de riesgos en su origen, y la actuación inicial en situaciones de emergencia".

Es este marco global es uno de las bases fundamentales sobre el que se sostiene la inclusión directa de la infancia en el discurso de la prevención.

Se destaca que las prácticas de evacuación en los centros escolares resultan un componente formativo clave, en los que se ha de hacer partícipes al alumnado, el profesorado y los padres. Los Planes de Autoprotección han de ser conocidos por toda la comunidad escolar.

Es obligatorio, como parte esencial de una cultura de la autoprotección, programar en el entorno escolar "actividades de información, prevención y divulgación en materia de protección civil"

Este tipo de actividades pretenden fomentar en el alumnado "hábitos $y$ comportamientos necesarios para situaciones de riesgo, accidente, peligro, catástrofe o autoprotección"

La ley más reciente 17/2015 del Sistema Nacional de Protección Civil crea el Fondo de Prevención de Emergencias, que financiará, entre otras actividades preventivas, programas de educación para la prevención en centros escolares.

También esta ley señala que "la inclusión en los currículos escolares de contenidos sobre autoprotección y primeros auxilios, son instrumentos poderosísimos de prevención de carácter horizontal"

Una idea en la que también se redunda de forma especilamente intensa desde diferentes instancias internacionales, tal como veremos en el siguiente apartado. 


\subsubsection{LA FIGURA DEL NIÑO EN EL DISCURSO INTERNACIONAL}

La ONU, a través de las distintas conferencias mundiales, la Estrategia Internacional en Reducción de Desastres, la UNESCO y diferentes iniciativas y estudios relacionados con la infancia y la reducción de desastres, se ha convertido en el principal actor en poner el foco en la formación e información preventiva dirigida a la infancia y adolescencia.

Su reivindicación constante de una cultura mundial de la prevención, que ya vimos en el segundo capítulo de esta investigación, se ha ido materializando cada vez más en la reivindicación de que ese proceso aparezca íntimamente ligado a apoyarse en el valor de los niños como agentes de cambio social.

Dedicaremos este apartado a revisar cuál ha sido la evolución de esta idea en el discurso internacional durante las últimas cuatro décadas.

1972. Conferencia de las Naciones Unidas sobre el Medio Humano, Estocolmo.

Como recordamos, en 1972 se lleva a cabo en Estocolmo (Suecia) la Conferencia de las Naciones Unidas sobre el Medio Humano

Ya en esta declaración de 1972, la comunidad internacional pone también el acento en la importancia de las acciones educativas, también para los más jóvenes. Como hemos señalado anteriormente en el capítulo anterior, la educación sobre el medio ambiente se vinculaba a los factores de responsabilidad y control que los ciudadanos podían ejercer sobre el medio ambiente y los desastres (principio 19: "Es indispensable una labor de educación en cuestiones ambientales, dirigida tanto a las generaciones jóvenes como a los adultos y que preste la debida atención al sector de la población menos privilegiado, para ensanchar las bases de una opinión pública bien informada y de una conducta de los individuos, de las empresas y de las colectividades inspirada en el sentido de su responsabilidad [...]".

En la recomendación número 96, se menciona ya por primera vez y de forma expresa, a la comunidad escolar, al tiempo que se señala la importante labor que en esta materia puede desarrollar la UNESCO, implicando por tanto a esta organización educativa en la preparación ante desastres, una implicación que posteriormente iría consolidándose férreamente con el paso de los años. 
Se recomienda que (...) en particular la Organización de las Naciones Unidas para la Educación, la Ciencia y la Cultura (...) adopten las disposiciones necesarias a fin de establecer un programa internacional de educación sobre el medio, de enfoque interdisciplinario y con carácter escolar y extraescolar, que abarque todos los niveles de la enseñanza y se dirija al público en general, especialmente al ciudadano corriente que vive en las zonas rurales y urbanas, al joven y al adulto indistintamente, con miras a enseñarle las medidas sencillas que, dentro de sus posibilidades, pueda tomar para ordenar y controlar su medio

1992 Declaración de Río sobre el Medio Ambiente y el Desarrollo

Principio 21

“Debería movilizarse la creatividad, los ideales y el valor de los jóvenes del mundo para forjar una alianza mundial orientada a lograr el desarrollo sostenible y asegurar un mejor futuro para todos".

1994. Primera conferencia Mundial sobre la Reducción de los Desastres. Yokohama, Japón, 23 al 27 de mayo de 1994.

Como habíamos visto en las primeras referencias a esta conferencia, uno de sus objetivos es el "Desarrollo de una cultura mundial de prevención como componente esencial de un planteamiento integrado de la reducción de los desastres", y la "Enseñanza y formación en materia de prevención de desastres, preparación para casos de desastres y mitigación de sus efectos".

2000. La ONU adopta la Estrategia Internacional para la Reducción de Desastres (EIRD) y establece la secretaría de la EIRD/ONU. Apelación a implementar la Reducción de Riesgo de Desastres (RRD). 
Entre las tareas realizadas por la secretaría de la EIRD/ONU está la coordinación de las Campañas Mundiales para la Reducción de Desastres, que tienen carácter bienal y se dirigen a movilizar acciones de concienciación sobre reducción de desastres.

En el año 2000 se lanzó la primera campaña, que puso precisamente el foco en la educación y la concienciación de la juventud, en términos de protección medioambiental y de prevención del impacto de desastres. Las jóvenes generaciones son vistas como "los líderes del mañana". La campaña llevó por título: "Prevención de desastres, Educación y Juventud"

\section{Conferencia Mundial sobre la Reducción de los Desastres. Kobe.}

El Marco de Acción de Hyogo indicó la necesidad de promover la inclusión de nociones de reducción de riesgo de desastre en los programas de estudio, poniendo en relación este tratamiento de los programas de estudio con el desarrollo sostenible, una cultura de la prevención y la reducción de los desastres.

Promover la inclusión de nociones de reducción de riesgo de desastre en las secciones pertinentes de los programas de estudio escolares en todos los niveles y la utilización de otros canales formales e informales para transmitir la información a los jóvenes y los niños; promover la incorporación de la reducción del riesgo de desastre como parte integral del Decenio de las Naciones Unidas de la Educación para el Desarrollo Sostenible (2005-2015)

Además de la inclusión de esas nociones de reducción de riesgo de desastre, pide también que se realicen otro tipo de programas: 
"preparación para casos de desastre en las escuelas y las instituciones de enseñanza superior"

"programas y actividades en las escuelas para enseñar la manera de reducir al mínimo los efectos de las amenazas"

Respecto a cómo se ha de facilitar información, detectamos aquí referencias a un proceso de adaptación a las características de los distintos grupos de destinatarios. En este sentido, vemos especialmente interesante la idea de tener en consideración los grupos de edad, una idea que se incluye en los principios generales del Marco de Acción:

Al elaborar los planes para la reducción de los riesgos de desastre se deben tomar debidamente en consideración la diversidad cultural, los diferentes grupos de edad y los grupos vulnerables

Se ha de garantizar la igualdad de los grupos vulnerables en el acceso a la información, considerando como vulnerables entre otros a las mujeres, niños, ancianos, discapacitados y pobres.

Tanto la alerta temprana como la difusión de información sobre el riesgo de desastres en general ha de tener en cuenta en su diseño "las características demográficas, el género, la cultura y el modo de vida de los destinatarios(...)".

y deben "incorporar los conocimientos tradicionales y autóctonos pertinentes y el patrimonio cultural y adaptarse a los distintos tipos de destinatarios, teniendo en cuenta los factores culturales y sociales". 
2006 "Let our children teach us".

Este proyecto coordinado por el profesor Ben Wisner en colaboración con la plataforma del ISDR analiza la incorporación a la educación formal de contenidos relacionados con la reducción de riesgo de desastres, recogiendo datos de 113 países. Las conclusiones resultan de especial relevancia, ya que se han constituido en las base para muchas investigaciones posteriores realizadas por organismos internacionales.

Enumeramos aquí las más importantes:

-Los niños son un agente de cambio que puede introducir auténticas transformaciones sociales en el mundo que les rodea, también en materia de reducción de desastres -Es imprescindible la incorporación de contenidos en reducción de desastres a la educación formal

- Esta incorporación puede producirse integrándose en otros estudios como la historia, la geografía y la ciencia, y puede contribuir a reforzar otras capacidades como la lectura o la escritura.

-La adaptación local en aspectos como la lengua o la cultura es fundamental

- Respecto a cómo educar en materia de reducción de riesgos, la vía más innovadora es el aprendizaje experiencial y concretamente una aproximación child-to-child (pg. 22), que involucre a los niños de forma participativa. Esta formación de niño a niño puede incluir hasta tres variantes: de un niño a otro más pequeño / entre niños de la misma edad / de un niño a su familia o comunidad.

Se defiende este modelo para la educación en riesgo de desastres porque de esta forma el niño relaciona la adquisición de conocimiento con otras facetas de su vida, de forma que conecta el mundo del aula/ con el mundo familiar, lo que aprende/con lo que hace.

-También es útil e importante la utilización de otros recursos como los juegos y los cómics durante el tiempo libre, en los que se introduzcan contenidos sobre la reducción de desastres, aunque siempre supervisando que no acabe convirtiéndose en un aprendizaje pasivo (pg 24). 
“Vemos a los niños como agente de cambio, no como megáfonos para transmitir mensajes de adultos" (pg. 23)

"Los programas más efectivos son los que involucran a los niños en el proceso de toma de decisiones más que usándolos como meros comunicadores de mensajes elaborados por adultos" (pg. 22)

2006-2007 Séptima edición de la Campaña Mundial para la Reducción de Desastres, coordinada desde la secretaría EIRD/ONU y con apoyo de la UNESCO. En esa ocasión vuelve a ponerse el foco en la infancia, tal como se hizo en la primera campaña del año 2000.

La campaña lleva por título "La reducción de los desastres comienza en la escuela".

El objetivo es informar y movilizar a gobiernos, comunidades e individuos para que la reducción de riesgo de desastres se integre plenamente en los planes de estudio, y que los edificios escolares puedan resistir las amenazas naturales. Todo ello especialmente en aquellos países de alto riesgo, aunque no de forma excluyente. Se considera que incluir la RRD en los colegios ayuda a la consecución de los Objetivos del Milenio, entre los que se incluye la reducción de la mortalidad infantil.

Por una parte, se trata de proteger la integridad de aquellos más vulnerables, los niños. Pero por otra, se destaca que también los niños tienen la capacidad de protegerse a sí mismos y a los demás, si están adecuadamente preparados.

La representación que se hace del niño tiene un rol absolutamente activo.

"La inclusión de la educación sobre el riesgo de desastres en los planes de estudio de las escuelas primarias y secundarias promueve la concienciación y una mejor comprensión del entorno inmediato en el que los niños y sus familias viven y trabajan. Con base en experiencias previas, sabemos que los niños que tienen conocimiento sobre los riesgos de las amenazas naturales desempeñan un importante papel cuando se trata de salvar vidas y proteger a los miembros de la comunidad en momentos de crisis". 
“Cuando se produjo el tsunami de diciembre de 2004, la estudiante británica Tilly Smith logró salvar muchas vidas en una playa de Tailandia, puesto que instó a la gente a huir de la costa: sus lecciones de geografía en Gran Bretaña le permitieron reconocer las primeras señales de un tsunami. Al mismo tiempo, Anto, un joven de la isla indonesia de Simeulue había aprendido de su abuelo qué hacer en caso de que se produjera un terremoto. Él y todos los otros isleños huyeron hacia tierras más elevadas antes de que el tsunami azotara la isla, logrando así que todos los miembros de su comunidad, a excepción de ocho, se salvaran".

Por otra parte, en la campaña también se hace mención a casos prácticos ya desarrollados en algunos países donde ya se ha puesto en marcha algún tipo de experiencia en materia de concienciación y educación sobre gestión de riesgo de desastres. El documento de la campaña incide en algunas experiencias prácticas más destacadas (Cuba, Afganistán, Gujarat en India), de las que nosotros extraemos también una serie de conclusiones:

- El primer paso ha de ser capacitar al profesorado: aprender y comprender acerca de la reducción de desastres, para poder trasladáreselo a los escolares

-Es importante involucrar al máximo número de actores, como administraciones locales, comunidad escolar, instituciones educativas.

-Es importante evaluar el conocimiento previo existente sobre prevención y preparación de desastres, para poder orientar las campañas y actividades hacia los objetivos más adecuados y detectar posibles ideas erróneas sobre los desastres

-Adaptarse a las características locales para facilitar la integración de los contenidos en un marco conocido

-Recomendación de combinar herramientas formales y no formales: libros, juegos, demostraciones, ya que se detectó que en aquellos colegios donde el proyecto sólo introdujo una intervención formal a través de libros de texto, no se produjo "el nivel deseable de incidencia en los estudiantes, y los maestros enfrentan dificultades al 
enseñar este nuevo plan de estudios en ausencia de algún tipo de orientación o de capacitación".

2009. Conferencia Mundial de Educación para el Desarrollo Sostenible. UNESCO.

La UNESCO, principal actor de la ONU en materia de Educación, participa activamente en la consecución de los objetivos internacionales en materia de desarrollo sostenible, en este caso desde el ámbito de la educación.

Este rol es fundamental dado que el principio es que "la Educación para el Desarrollo Sostenible contribuye a la Reducción de Riesgo de Desastres, mientras que ésta mejora la calidad y la pertinencia de la educación en zonas expuestas a desastres". Por tanto, ambas, la Educación para el Desarrollo Sostenible y la destinada a la Reducción de Riesgo de Desastres se complementan la una a la otra.

\section{13 de octubre, Día Internacional para la Reducción de los Desastres.}

El mensaje del Secretario General puso ese año el foco en la infancia y juventud como claves para la reducción de los desastres.

"La observancia este año del Día Internacional para la Reducción de los Desastres reconoce el papel vital de los niños y los jóvenes. En Nepal y otros países, se enseña a los niños los elementos básicos de la seguridad en el hogar y en los edificios. Las actividades de reducción de los riesgos y de adaptación al cambio climático en que participan los niños en cuba se están imitando en otras partes del mundo. Últimamente, más de 600 niños y niñas de África, Asia y América Latina elaboraron una Carta de los Niños para la reducción de riesgos de desastres. El mensaje es inequívoco: la reducción de los riesgos de desastres debe pasar a ser, para todos nosotros, una preocupación y una causa permanentes. Invirtamos hoy en un futuro más seguro.

\section{3를 Conferencia mundial sobre la Reducción de Riesgo de Desastres en Sendai. Japón. Marzo 2015}

En la nueva conferencia se incide en incluir un mayor número de participantes a la hora de diseñar políticas y planes, teniendo en cuenta, entre otros factores, una perspectiva de edad e incluyendo entre estos numerosos interlocutores a los niños y los jóvenes. 
Ha de existir un aproximacion preventiva al riesgo de desastres más profunda y más orientada a las personas

Aún reconociendo su rol de líder, regulador y coordinador de este proceso, los Gobiernos deberían involucrarse con otros actores relevantes, incluyendo mujeres, niños y jóvenes, personas con discapacidad, gente sin recursos, inmigrantes, indígenas, voluntarios, (...) y personas mayores, en el diseño y la implementación de políticas, planes y stándards

Una perspectiva de género, de edad, de discapacidad y de cultura debería integrarse en todas las políticas y prácticas, y debería promoverse un liderazgo de la mujer y la juventud. En este contexto, debería ponerse especial atención al apoyo del trabajo voluntario organizado de ciudadanos.

Dentro de las medidas a adoptar hallamos:

(l) Promover la incorporación del conocimiento sobre riesgo de desastres, incluyendo la prevención de desastres, la mitigación, preparación, respuesta, recuperación y rehabilitación, en la educación formal y no formal, así como en la educación de la ciudadanía en todos los niveles, así como en educación profesional"

(m)Promover estrategias nacionales para dirgir educación pública y la concienciación en la reducción de riesgo de desastres, incluyendo la información sobre riesgo de desastres y el conocimiento, mediante campañas, redes sociales y movilización de la comunidad, teniendo en cuenta los distintos tipos de audiencias específicas y sus necesidades"

(ii) La infancia y la juventud son agentes de cambio y debería dárseles el espacio y el tipo de tratamiento que contribuyan a la reducción de riesgo de desastres, de acuerdo a la legislación, las prácticas nacionales y el curriculo educativo. 


\section{Conclusiones}

Durante los últimos cuarenta años se ha incorporado al discurso internacional de la prevención la figura del niño. Detectamos varios momentos que han marcado especialmente el rumbo de esta incorporación:

\section{-Desde 1972 hasta el año 2000}

Durante este tiempo, se ha tenido en consideración la figura del niño como participante del proceso de una cultura mundial de la prevención. En los primeros años se incide en la necesidad de implicar y formar a la comunidad escolar en la preparación ante desastres, incidiendo en que los programas educativos son tan importantes para los adultos como para los jóvenes.

Se destaca la importancia de educar sobre el medio ambiente, para poco a poco ir virando a la educación en prevencion de desastres y mitigación de sus efectos.

\section{-Año 2000-2005}

Año 2000

Se realiza la primera Campaña Mundial para la Reducción de Desastres organizada por la EIRD y el primer foco de atención va a ser la juventud. Con el lema "Prevención de desastres, educación y juventud", toda la atención se dirige a la implicación de un publico muy específico, los jóvenes.

\section{Año 2005}

Segunda Conferencia Mundial de Reducción de Desastres. Kobe.

-Es necesario incluir nociones de reducción de riesgo en los programas de estudios, para lograr una cultura preventiva

-Los planes para la reducción de riesgo de desastres han de tener en cuenta los grupos de edad, y vulnerables, como los niños, así como los factores culturales y sociales y la incorporación de conocimientos y cultura autóctona

\section{-2006 hasta la actualidad ( 2015)}

2006

El estudio "Let Our children teach us" ha ofrecido conclusiones muy interesantes:

-Los niños son un agente de cambio social en la reducción de desastres 
-Hay que incorporar la reducción de desastres a la educación formal

-Es importante la adaptación local

-Formas de educación: experienciales y que involucren al niño como en el sistema child-to-child en el que un niño es capaz de formar a otros y a miembros de su comunidad.

La nueva campaña "La reducción de desastres comienza en la escuela" ha puesto el acento en la infancia:

-La reducción de riesgo de desastres se ha de integrar plenamente en los planes de estudio

-Los niños con conocimientos sobre riesgos naturales desempeñan un papel importante para salvar vidas

-La reducción de riesgo de desastres contribuye a los Objetivos del Milenio

-Para la incorporación a los planes de estudio, se ha de:

*Capacitar al profesorado

* Involucrar al máximo número de actores

*Evaluar conocimiento previo para detectar errores y concretar los objetivos pedagógicos

*Adaptarse a las características locales para facilitar la integración de contenidos

*Combinar herramientas formales y no formales, y evitar utilizar el libro como única herramienta pedagógica

2015 3를 Conferencia Mundial para la Reducción de Riesgo de Desastres. Sendai.

-Es importante incluir a todos los actores para realizar una aproximación preventiva al riesgo de desastres, incluyendo entre esos actores a los niños y los jóvenes

-En todas las políticas y prácticas relacionadas con la reducción de riesgo de desastres, debe integrarse una perspectiva de edad.

-Debe promoverse un liderazgo de la mujer y la juventud

-La infancia y la juventud son agentes de cambio

-En la educación ciudadana, hay que tener en cuenta a las distintas audiencias específicas

En conclusión, se observa en el discurso internacional una creciente presencia de la infancia y la juventud como destinatarios de las políticas y programas vinculadas a la prevención y reducción de riesgos. Desde los primeros años y documentos, ya figura su inclusión, para posteriormente convertirse en un eje clave al que se le otorga un 
papel imprescindible de cambio social, otorgándosele un rol activo en esta transformación. Se demanda tener en cuenta sus características y necesidades a la hora de realizar planes y programas de reducción de riesgos.

A partir de 2006, el discurso adquiere formas cada vez más sofisticadas de concreción de objetivos y métodos, al empezar a basarse en estudios centrados en experiencias prácticas. El último decenio arroja numerosos datos en cuanto a modelos, técnicas y formas de pedagogía útiles para la inclusión de la reducción de riesgo de desastres en el ámbito escolar, tal como veremo en apartados posteriores. 


\subsubsection{PREVENCIÓN Y CURRÍCULO ESCOLAR. MEJORES PRÁCTICAS}

A lo largo de los últimos años hemos visto cómo distintas agencias internacionales han insistido en la inclusión en la educación reglada de los contenidos vinculados a la prevención de riesgos o gestión de desastres. Así se ha manifestado por ejemplo en la sucesivas conclusiones y documentaciones preparadas por la Estrategia Internacioal en Reducción de Desastres o las distintas Conferencias Mundiales vinculadas al medio ambiente o los desastres, tal como hemos visto con anterioridad.

Llegado a este punto, trataremos de ver cómo distintos actores internacionales han abordado la manera de concretar esa inclusión en el currículo escolar de contenidos ligados a la prevención. Para ello hemos realizado un análisis a los principales textos, estudios y revisiones realizadas por estas agencias, que nos permita delimitar las tendencias del discurso internacional a la hora de abordar la presencia de los contenidos de prevención en el currículo escolar. Se trata de líneas importantes, que nos hablan del diálogo entre los diferentes actores, tanto expertos como no expertos, así como del tipo de contenidos y de las formas de aproximar esos contenidos al público infantil y adolescente.

Consideramos, por otra parte, que aunque vayan referidas estas líneas a un contexto escolar, las conclusiones obtenidas pueden trasladarse a otros contextos educativos y otros canales divulgativos en materia de infancia y prevención. Por tanto se trata de una revisión valiosa que nos permite vislumbrar líneas del discurso internacional que pueden servir de guía y contribuir al diseño de las prácticas generadas por las distintas instituciones vinculadas a la protección civil y gestión de emergencias, tanto en España como en el resto del mundo.

Enumeramos a continuación las principales conclusiones obtenidas tras la revisión de estos textos, de los que posteriormente se extraerán algunos ejemplos. Dichos extractos y ejemplos se ofrecerán de modo cronológico para poder ver su evolución.

\section{Aprendizaje a lo largo de la vida y cultura preventiva}

La educación en materia de prevención, desde edades tempranas y mediante el aprendizaje a lo largo de la vida puede ayudar a constituir una cultura preventiva. Las distintas agencias consideran que el aprendizaje adquirido en un contexto escolar y posteriormente en otros como el laboral, repercuten en la actitud y habilidades del individuo a lo largo de la vida. 


\section{Mirar el mundo desde el prisma de la prevención}

La voluntad de contribuir a una cultura mundial de la prevención a través de la educación infantil y adolescente se traduce en distintas áreas: la seguridad y salud en el trabajo, la prevención de riesgos, el medio ambiente o la reducción de riesgo de desastres, entre otros. Se trata de una perspectiva por la cual todos los aspectos que repercuten en la integridad del indivíduo y el desarrollo y bienestar de las sociedades pueden observarse desde el prisma de la cultura preventiva.

\section{Las leyes como impulsoras del cambio social}

Es fundamental una labor reguladora, ya que la legislación puede tener un importante papel como impulsor de la introducción de estas áreas en el currículo escolar. Las leyes pueden resultar motivadoras.

\section{Un diálogo con múltiples actores}

El proceso de incorporación de estos contenidos al currículo escolar es fruto del diálogo de distintos actores y socios, desde expertos en emergencias, a la comunidad escolar, los padres, profesores, alumnos o distintas administraciones. No se trata de un proceso unidireccional sino de un diálogo multilateral que va construyendo significado. Aún así, el papel impulsor del proceso sigue reservándose a las agencias e instituciones vinculadas a la prevención y gestión de riesgos.

\section{Transversal (Cross-curricular) y práctico}

Una de las claves para la incorporación al currículo será un sistema transversal (crosscurricular), y experiencial, con métodos de enseñanza basados en la práctica.

\section{Formar al formador}

Se ha de formar al formador, dotándole de los conocimientos y habilidades necesarios para poder impartir estas enseñanzas.

\section{Los niños aprenden y la sociedad aprende de ellos}

Los niños han de tener un papel activo y participativo durante el proceso de adquisición de este tipo de enseñanzas. El discurso de las distintas agencias pone de 
manifiesto la consideración de los niños como agente transformador de la sociedad de la que forma parte, siendo considerado como un excelente transmisor de conocimientos, tanto a sus iguales como a sus mayores.

\section{Pensar en los targets y diseñar con ellos}

A lo largo de los años se detecta como las distintas agencias insisiten cada vez más en la incorporación de los diferentes targets al proceso de desarrollo de estas actividades y de creación de contenidos. Hay un interés creciente y especialmente reforzado a lo largo de los últimos años en tener en cuenta, en la preparación de estos contenidos, las características demográficas y culturales de los participantes de estas actividades. Se trata de pensar en y con los targets.

A continuación, se expone aquí un compendio de aquellos textos más representativos del estado y mejores prácticas de la incorporación al currículo de los conceptos vinculados a la prevención.

TEXTO: Regional Consultative Committe on Disaster Management, RCC (2007) "Integrating Disaster Risk Reduction into School Curriculum"

Es posible y recomendable incluir la Reducción de Riesgo de Desastres en el currículo, dado el enorme beneficio que produce: los niños son los más vulnerables hacia los desastres pero a la vez se trata de influyentes comunicadores acerca de los desastres, capaces de trasladar las lecciones aprendidas en el colegio a sus propios hogares.

Para incluir la Reducción de Riesgo de Desastres en un estado es necesario:

-Abrir un proceso consultivo que involucre a distintos ministerios, instituciones educativas, organizaciones y técnicos, entre otros.

- Testear mediante prueas la inclusión de la Reducción de Riesgo de Desastres.

-Formar al profesorado

TEXTO: UNESCO (2007) Natural Disaster Preparedness and Education for Sustainable Development. Bangkok.

Este estudio aborda las mejores prácticas desarrolladas en la educación destinada a la preparación de desastres y al desarrollo sostenible. Ofrece conclusiones muy 
interesantes sobre la adaptación a los distintos públicos, incidiendo mucho en la necesidad de integrar los aspectos locales de las distintas comunidades en el proceso.

Es necesario el diálogo y la colaboración con las comunidades indígenas (pg. 53 del estudio), dado que:

-Tienen conocimientos útiles y valiosos sobre los desastres que han pasado de generación en generación. Esa información ha de tenerse en cuenta y documentarse por escrito.

-"Los aspectos religiosos y culturales de los targets necesitaban tenerse en cuenta, ya que pueden ser una fuente significativa de resistencia natural a la preparación ante desastres". El diálogo permitía ver como en algunos casos había prevalencia de explicaciones sobrenaturales sobre otras explicaciones de carácter científico. "Aquel material en preparación ante el riesgo de desastres que no tenga en consideración las creencias prevalentes de las comunidades no será aceptado y y fallará en lograr el efecto deseado. Mediante la participación en los programas de consulta con la comunidad, los equipos eran capaces de identificar estos temas y tenerlos en cuenta en su trabajo".

Es conveniente preparar el material educativo en la lengua de la zona porque aunque encarece los costes y el tiempo para prepararlo "alcanzará a los targets groups de un modo más efectivo".

Por tanto, la experiencia demostraba que el diálogo y la participación con la comunidad permitía por una parte, incorporar el conocimiento autóctono y tradicional que resultaba útil para la gestión del desastre y por otra, contrarrestar aquellas otras ideas preconcebidas que dificultaban la gestión y prevención de los riesgos.

Los equipos encargados de preparar los materiales educativos identificaron la participación y la consulta como un factor de éxito ya que de esta forma pudieron “identificar necesidades locales, integrar estilos locales de aprendizaje en su producto y obtener apoyos para su producto por parte de sus targets de público. La variedad de productos creados subraya las diferentes necesidades que cada grupo encontró en sus respectivos targets de público". (pg 73) 
TEXTO: ISDR International Strategy for Disaster Reduction de la UNESCO (2007). "Towards a Culture of Prevention: Disaster Risk Reduction Begins at School". United Nations.

Tanto el Marco de Hyogo para la Acción 2005-2015 como la Década de la Educación para el Desarrollo Sostenible de las Naciones Unidas 2005-2014 coinciden en que "la educación para la reducción de desastres y para el cambio climático global debe llegar a ser una parte integral de toda estrategia educacional dirigida a promover y crear sociedades prósperas y sostenibles" (pg.5). La campaña global "La reducción de riesgo de desastres comienza en la escuela" anima a incluir la educación en riesgos de desastres en el currículo escolar en los países vulnerables a desastres naturales, para potenciar entre otras cosas una resiliencia en la escuela y a través de la escuela. Como en otros estudios, se hace referencia al necesario diálogo entre los diferentes actores a la hora de participar en este tipo de iniciativas, en los que incluye a los líderes de la comunidad, gestores educativos, padres o maestros.

El estudio analiza distintos países. Destacamos en estas páginas el caso de Francia, ya que resulta reveladora la importancia de un marco normativo como uno de los principales impulsores de los cambios sociales. En este caso este marco fue fruto del diálogo entre los ministerios de Educación, Salud e Interior, que se concretó en la ley n²004-811, del 13 de agosto del 2004 de Modernización de la Seguridad Civil, que en su artículo 5 establece que:

"Todo alumno se beneficia, en el marco de su escolaridad obligatoria, de una sensibilización hacia la prevención de riesgos (...)así como de un aprendizaje de acciones elementales de primeros auxilios".

A lo largo de su escolaridad, los alumnos van cumpliendo con su "libro personal de competencias", entre las que se incluyen aquellas vinculadas a los primeros auxilios, la prevención y el socorro. Además se otorgan a los alumnos certificados de seguridad en carretera, que en el futuro serán necesarios para poder optar a conseguir los respectivos carnets de conducir. El objetivo de todo este proyecto, según aparece reflejado en la ley, es convertir a los propios estudiantes en ciudadanos responsables e informados que de esta forma puedan contribuir de una manera efectiva a la defensa civil. 


\section{TEXTO. International Federation of Red Cross and Red Crescent Societies (2009) "First aid for a safer future. Focus on Europe".}

Se acerca a las iniciativas en formación en primeros auxilios en Europa, detectando que los países nórdicos tienen un porcentaje de ciudadanos formados mucho mayor que en los países del sur, y concluye que se trata por razones reguladoras y culturales.

Por otra parte, considera el conocimiento de primeros auxilios no un mero conocimiento de técnicas sino un acto de humanidad para una ciudadanía que aspira a ser global.

Extraemos aquí las principales conclusiones expuestas en el texto (pgs 3-4).

“Los primeros auxilios no significan una sustitución de los servicios de emergencia; son un paso inicial vital para facilitar una intervención rápida y efectiva que ayude a reducir los daños e incrementar las oportunidades de supervivencia".

Los datos del estudio indican que los países del Norte de Europa normalmente tienen un porcentaje superior de población formada en primeros auxilios: en Noruega se sitúa en un $95 \%$ y en Austria en un $80 \%$. El estudio aduce razones de tipo legal

"tienen leyes que hacen la formación en primeros auxilios obligatoria en el colegio, en el lugar de trabajo, o al obtener una licencia de conducción" y cultural: "En los países Nórdicos y Anglosajones, la gente parece estar más involucrada a nivel individual en los asuntos de su comunidad mientras que los países del sur y el este de Europa, unos estados fuertemente centralizados frecuentemente delegan las emergencias por completo a sus servicios de emergencia".

"La IRFC cree que todas las personas tienen el potencial de salvar vidas. Los primeros auxilios no son sólo técnicas. Son un acto de humanidad y por tanto una responsabilidad clave de la ciudadanía global". 


\section{TEXTO: European Agency for Safety and Health at Work (2009) "OSH in the school curriculum: requirements and activities in the EU Member Estates". Luxembourg: Office for Official Publications of the European Communities.}

La OSH es la Occupational safety and Health (OSH), llamada en español SST: Seguridad y Salud en el Trabajo

Este estudio revisa la forma en la que los Estados Miembros de la Unión Europea están incluyendo en el ámbito educativo los temas de seguridad y salud en el trabajo, y cómo esa educación sobre riesgos puede repercutir en las condiciones y la seguridad de los futuros trabajadores. Entre las competencias que tratan de conseguir en relación a los riesgos están, entre otras, saber pedir ayuda, poder practicar primeros auxilios o saber evaluar riesgos y adoptar medidas para controlarlos.

La educación del riesgo debería en primer lugar advertirles de lo que es peligroso en su entorno (en casa, en el colegio y en el juego) y de quées lo que deberían hacer para convertirles en personas más seguras a ellos y a los que están alrededor. Tal como el niño crece, su conocimiento sobre formación y gestión del riesgo debería desarrollarse. A medida que los jóvenes eligen sus carreras, su educación sobre riesgos debería llegar a ser más especializada para cubrir temas sobre Seguridad y Salud en el Trabajo, incluyendo aquellos aspectos relacionados con sus futuras profesiones. Es importante destacar que la educación sobre riesgos no trata sobre cómo aislar a los niños y jóvenes de todos los riesgos potenciales, sino sobre equiparles para gestionar esas situaciones de un modo seguro (pg.13 del citado estudio).

Tras realizar una revisión de decenas de casos, concluyen que este tipo de contenidos no suele tratarse como una materia independiente sino que la tendencia es incorporarlos a los propios objetivos de aprendizaje de otras materias, ya sean las ciencias o la educación física, entre otros en lo que puede considerarse una incorporación cross-curricular a través de otras asignaturas y a lo largo de los sucesivos cursos y edades del alumnado. El beneficio de una incorporación oficial y regulada al currículo es que lo convierte en algo prioritario para el centro formativo y le permite al profesorado ser sistemático en su aplicación, en lugar de depender del entusiasmo individual de aquellos centros o profesores que tienen interés o formación particular en los temas preventivos. 
El modelo que proponen (pgs 13,14) para una cultura de la prevención, vinculada a la integración de la Seguridad y Salud en el Trabajo incluye, entre otros, la importancia de formar al formador así como de dotar al currículo de un marco legal que sirva de incentivo, ya que "la legislación puede traer cambios en los patrones de conducta".

$Y$ otros dos aspectos muy importantes, el diálogo y la interactividad.

\begin{abstract}
Diálogo y participación de todos los actores involucrados.
"Integrar la Seguridad y Salud en la educación significa integrar un área política (trabajo, seguridad y salud), en otra área, la educación. Eso significa que diferentes sistemas, con diferentes instituciones y diferentes mentalidades, han de comunicarse entre ellos y llevar a cabo una acción conjunta".

"Es importante involucrar a todos los posibles intermediarios como parte del aprendizaje sobre la Seguridad y Salud en el Trabajo considerada como habilidad a lo largo de la vida: los maestros, las empresas, los trabajadores y sus representantes, los padres, los alumnos y los expertos, todos ellos deberían proporcionar apoyo".

Métodos educativos interactivos y fruto del diálogo

A la hora de desarrollar competencias "El foco se ha movido desde enseñar (teaching) conocimientos sobre seguridad y salud mediante un sistema unidireccional (one-waysystem) a un aprendizaje orientado a la experiencia (experience-oriented) basado en el diálogo entre alumnos, profesores y profesionales del ámbito de la seguridad y la salud ".
\end{abstract}

\title{
TEXTO: UNESCO Word Conference on Education for Sustainable Development (2009) Workshop 4. EDS and disaster risk reduction: building disaster-resilient societies. Bonn.
}

La prevención afronta dificultades para estar más presente en la agenda pública, y la principal es que sus resultados no son visibles... hasta pasado un tiempo.

Así lo recordaba, según recoge este estudio, en 1999 el entonces Secretario General de la ONU, Kofi Annan, en el "Introduction to Secretary-General's Annual Report on the Work of the Organization of United Nations" (document A /54/). Pese a que las estrategias de prevención son capaces de ahorrar dinero y salvar vidas, existen reticencias hacia ellas ya que no son visibles: los costes de prevención se pagan en el presente pero sus beneficios llegan en el futuro, y además no son tangibles: "son los desastres que no ocurren". 
Este texto vincula distintos fenómenos: la degradación medioambiental, la gestión indadecuada de los recursos naturales, la presión demográfica, la interacción del hombre con el medio, los desastres... Por ello tiene una visión global de lo que debería ser la educación: La Educación para la Reducción de Riesgo de Desastres (EDRR), como una parte de la Reducción de Riesgo de Desastres (DRR), ha de ser inherente con la Educación para el Desarrollo Sostenible (ESD).

Además educar en estos ámbitos repercute en favorecer la implementación de los derechos del niño reconocido en la Declaración International de los Derechos Humanos, y en la Convención de los Derechos del Niño.

Se concluye que esta educación ha de estar integrada en el sistema formal pero también en el informal al ser un "rápido punto de entrada" para la educación en reducción de riesgo de desastres, además de ser una vía que ofrece formas variadas, divertidas y participativas.

Cuesta tomar conciencia de la importancia de la prevención porque sus beneficios residen en el futuro: son los desastres que no ocurren

En el mundo de la educación, se han de interconectar la Reducción del Riesgo de Desastres y la Educación para un Desarrollo Sostenible

Esta educación favorece la implementación de los Derechos del Niños

Los contenidos han de integrarse en el sistema formal pero también en el informal por ser este una vía de acceso rápida y divertida a los contenidos de prevención

\section{TEXTO: UNICEF-UNISDR (2011). "Children and disasters: building resiliencie through education".}

El estudio lo ha realizado la UNICEF junto a la UNISDR, la United Nations International Strategy for Disaster Reduction, y plasma la situación de educación sobre reducción de riesgos en 23 países, especialmente de Europa del Este. Recuerda que el 
conocimiento y la educación son reconocidos como un componente clave de la reducción de riesgo de desastres en el Marco de Acción de Hyogo 2005-2015.

Señala que integrar en la educación la reducción de riesgos de desastres es "un proceso a largo plazo [...] donde los niños son agentes de cambio" (pg.7) y señala que es necesario integrar la educación en riesgo de desastres y resiliencia en la educación formal y no formal.

El texto hace repaso a documentos de referencia como "Let our children teach us! A review of the role of education and knowledge in disaster risk reduction", la campaña 2006-2007 de UNISDR de "La reducción de desastres comienza en la escuela", así como a distintas iniciativas, como la Década de Educación para el Desarrollo Sostenible de las Naciones Unidas (2005-2014), conducida por la UNESCO, y que llama al desarrollo del concepto de Educación para la Preparación ante Desastres Naturales (ENDP), y la completa integración de la ENDP en todas las estrategias de desarrollo sostenible. Otra de las campañas mencionadas es "My city is getting ready" (UNISDR).

Por su parte la UNICEF lleva desde 1990 ayudando a los países a lograr el objetivo de "Educación para Todos", promoviendo entre otras cosas la preparación ante emergencias, acerca de qué son los desastres, y qué hacer antes, durante y después de que ocurran.

Para hacer el estudio, una de las fuentes que han usado es la herramienta de Índice de Riesgos del Programa de Desarrollo de las Naciones Unidas (UNDP), y las estadísticas del World Bank, y la base de datos EM-DAT sobre información de desastres debidos a riesgos naturales.

Por otra parte, entre las recomendaciones señala la necesidad de que la información sobre riesgo de desastres esté fácilmente disponible tanto para líderes como para ciudadanos especialmente en zonas de alto riesgo, con el fin de reducir el riesgo y aumentar la resiliencia. UNICEF se ofrece como coordinador de fórums de discusión y diálogo sobre la materia (pg 186).

\section{TEXTO: UNESCO \& UNICEF (2012) Disaster Risk Reduction in the School Curricula: Case Studies from Thirty Countries.}

Se trata de un informe sobre los países que han incluido elementos de la reducción de riesgo de desastres en su sistema educativo, con el ánimo de servir de guía para los 
países en proceso de incluirlo. Analiza las mejores prácticas a la hora de integrar la Reducción de Riesgo de Desastres en el currículo escolar.

A lo largo de todo el informe, se pone de relieve que las formas más exitosas de incluir la RRD en el currículo escolar son mediante el proyecto piloto y la simbiosis. Respecto a los métodos pedagógicos, considera más acertados los denominados interactivo, experiencial y activo. Lleva a cabo un minucioso examen de ventajas e inconvenientes de los distintos métodos.

Dado el interés que ofrecen las distintas formas de aproximarse al currícuo y las metodologías pedagógicas empleadas, hemos resumido a continuación las características plasmadas en el informe.

\section{Formas de integrar en el currículo contenidos de reducción de riesgo de desastres}

\footnotetext{
Proyecto piloto:

-Combina materiales multimedia, nuevas pedagogías para la formación, innovación. Se hace en un número limitado de colegios. Pueden estar apoyados por sponsores, pero también ser resultado de la comunicación y trabajo entre ONG's y los gobiernos.

- Ventajas: pueden ser un espacio para la innovación y el entusiasmo. Al estar involucrados distintos actores, como ministerios de educación y emergencias, ONG's o instituciones académicas, tienen la capacidad y recursos financieros para realizar una escala rápida.

- Desventajas: ser una cortina de humo para afrontar cambios más profundos en el currículo.

Simbiosis:

- La DRR se integra en otras asignaturas de forma cross-curricular, como Educación para la Ciudadanía, medioambiente, o educación para el desarrollo sostenible.

- Ventajas: es relativamente fácil incluirlo en otras asignaturas ya desarrolladas y puede añadirle profundidad.

- Desventajas: que los objetivos de la DRR acaben dispersándose, y que falte concreción.
}

El estudio también detectó otros sistemas de integrar la reducción de riesgo de desastres en el currículo, aunque detectó un menor uso y menores niveles de éxito. Se trata los denominados eventos especiales creados de forma esporádica, asignaturas expresamente creadas para estos contenidos y la edición de libros de texto para una difusión centralizada.

Respecto a los libros de texto, aunque utilizarlos aseguraba el tratamiento de los riesgos y los desastres dentro de asignaturas concretas en todos los colegios y era 
fácil de adaptar en aquellos países donde tienen prevalencia los libros de texto, se ha evaluado finalmente como un recurso insuficiente para proporcionar por sí mismo, sin otros apoyos, habilidades y actitudes: "Una cultura basada en el libro de texto promueve la pasividad de los estudiantes e inhibe el aprendizaje interactivo $y$ experiencial, que es el recurso para fomentar una ciudadanía comprometida $y$ participativa".

Respecto a las pedagogías, las que más se usan son: Aprendizaje interactivo, Experiencial, y Activo, que utilizan los siguientes métodos:

\section{Interactivo.}

*Brainstorming

*Discusión por parejas, en pequeños grupos y luego con el grupo completo

* Presentaciones multimedia interactivas y realizadas por estudiantes, profesores y expertos

\section{Experiencial:}

*Realizaciones de video

*Juegos de mesa

*Juegos de rol

* Dramatizaciones (sketches, mimo, marionetas)

* Simulacros

* Reuniones

\section{Acción:}

*Participación de varios actores ( comunidad escolar, expertos locales en riesgos de la comunidad) para concienciar sobre los riesgos, desarrollar mapas de riesgo, y elaborar planes de reducción de riesgo

Por otra parte, tenían menor repercusión y se utilizaban menos otros métodos como el aprendizaje afectivo, interrogativo, y de experiencias de campo: 
-Aprendizaje afectivo: compartir sentimientos sobre amenazas y desastres; ejercicios de empatía basados en los afectados por el desastre.

- Aprendizaje interrogativo: investigación de un estudio de caso, trabajos, etc.

- Aprendizaje mediante experiencias de campo: visitas a servicios de emergencias y desastres, valoración de los mapas de riesgo y de vulnerabilidad, revisión de planes de emergencia, entrevistas a miembros de la comunidad local sobre episodios pasados de amenazas y riesgos. 


\subsubsection{INVESTIGACIÓN COMUNICATIVA Y SOCIAL EN DESASTRES}

\subsubsection{Orígenes}

Los estudios en comunicación de riesgo y la investigación social de los desastres nos ayudarán también a conocer mejor los procesos comunicativos por los que las instituciones gestoras del riesgo, como las vinculadas a la protección civil, preparan, difunden y construyen contenidos en torno a la prevención de riesgos y desastres y cómo han ido incorporando a la infancia y adolescencia en estos procesos.

La aparición de la investigación en comunicación de riesgo se relaciona con diversos factores:

-Surgimiento de la sociedad del riesgo en el último tercio del siglo $X X$ y movimientos ciudadanos y ecologistas de los años 70 (Farré y Gonzalo 2011: 72)

-Necesidad de evitar determinadas prácticas individuales perniciosas para la salud como el tabaquismo (ídem)

-Estudios sobre la percepción social del riesgo tecnológico con la voluntad de reducir la brecha entre los expertos y los ciudadanos, para aminorar las reticencias vinculadas al riesgo tecnológico (Pont, 2009:20, Espluga 2004:147)

- Surgimiento de la investigación social sobre preparación ante desastres, concretamente la preparación de los Estados Unidos a sus ciudadanos para la Guerra Fría y posteriormente la creación hace décadas del Disaster Research Center (DRC) (Quarantelli 2005, Dynes, Quarantelli y Rodríguez 2006: xiii). Estos autores señalan que esa investigación social actualmente se ha expandido hasta los 650 campos de estudio, incluyendo la preparación, la construcción de mensajes o los factores sociales de la reacción ante desastres, entre otros.

Los procesos comunicativos que analizaremos en el marco empírico comparten los objetivos de la comunicación de riesgo (Farré y Fernández, 2007:32-34; Gray et alii, 1999) de informar a la población para mejorar sus conocimientos sobre los riesgos, así como cambiar sus comportamientos para reducir los que sean arriesgados y promover los que resulten apropiados. 


\subsubsection{Actores}

En sus primeras décadas, los procesos de comunicación y preparación ante riesgos y desastres tenían un perfil más unidireccional y basado en la voz de los expertos, mientras que las décadas siguientes el panorama se ha ampliado y se aprecia un proceso interactivo en el que intervienen numerosos actores (Pont, 2009:29, US National Research Council 1989:21).

Además de los expertos también otros actores, como la población, tienen un papel en un proceso interdependiente de informaciones, opiniones e intereses el que se refuerzan los canales de consulta, respuesta y diálogo (Farré y Fernández, 2007).

Así, mientras que en el primer perfil los expertos son los actores principales de una comunicación unidireccional dirigida hacia un público pasivo, en la segunda tendencia la participación ciudadana y la contribución de los no expertos es fundamental (íbidem, 32). Se trata de planear con el ciudadano y no para ellos. (Quarantelli, Lagadec, y Boin, 2006: 38).

En consecuencia, algunas de las tendencias actuales de estas investigaciones que incluyen un amplio abanico de actores, consideran a los ciudadanos ordinarios como "los primeros intervinientes" (first responders, Tierney, 2006:409), destacando cómo se involucran en la respuesta a las emergencias tras un desastre (Drabek 2002, McEntire 2002 y 2006: 174).

Algo que ya la ley 2/1985 de Protección Civil de España señalaba al decir que en los primeros instantes de una emergencia, la población depende inicialmente de sus propias fuerzas.

Por otra parte, esta variedad de actores participantes implicará mayores esfuerzos por parte de los gestores del riesgo y las emergencias a la hora de difundir contenidos e información, ya que ante una variedad de receptores no se puede dar la misma información a todos igual de la misma forma (Casterfors et alii, 2001).

En este sentido, la comunicación de riesgo habrá de tener en cuenta las características tecnológicas, mediáticas, sociodemográficas (Rodriguez, Díaz, Santos, Aguirre 2006:477) porque estas influirán en la respuesta.

Rodríguez, Díaz, Santos y Aguirre (2006:480) proponen un modelo para comunicar riesgos y avisos, con carácter bidireccional, basado en la educación y el entrenamiento y que contemple la división de la población en varios grupos especiales como los ancianos o los las personas discapacitadas. Se trata de un modelo multidireccional, que propone la coordinación entre diferentes usuarios mediante canales formales e informales. 
Según este modelo para que la información sea útil, deberá mostrase de una forma comprensible, manejable y relevante y, por su parte, el usuario final deberá tener la capacidad y los recursos necesarios para que esa información le permita prepararse, responder y recuperarse de un desastre.

En la siguiente figura, que los autores basan en el sistema de avisos integrado de Nigg (1995), podemos apreciar los principales actores y relaciones entre ellos.

Se trata de un modelo muy completo. Sin embargo, desde la perspectiva de nuestra investigación consideramos que también se debería incorporar de forma expresa los actores "infancia y adolescencia", y que también debería concretarse junto a la educación general otra "para la infancia y adolescencia".

Aunque pueda inferirse de otros actores y apartados la presencia de la infancia y la juventud, consideramos que mencionarlos y mostrarlos expresamente contribuyen a darles la visibilidad y presencia comunicativa que requieren.

Dado que distintas instancias nacionales e internacionales reivindican la capacidad y rol transformador de los niños, su presencia específica nos parece necesaria para poner de relieve dichas características. Ubicamos esas modificaciones en letra cursiva. Como se ve en el gráfico que mostramos a continuación, consideramos a la infancia y adolescencia como un actor que debe ocupar su espacio entre los publicos especiales, cuando se requiera, pero también lo ubicamos al mismo nivel que la ciudadanía en general y en diálogo directo con otros actores como las agencias de gestión de emergencias o los líderes políticos.

Lo consideramos un actor con entidad propia y con su propio peso específico, tal como lo han reflejado las leyes, estudios y discursos nacionales e internacionales que hemos visto en apartados y capítulos anteriores 
Modelo de comunicación de amenazas y avisos de Rodríguez et alii, con la incorporación de la infancia y adolescencia

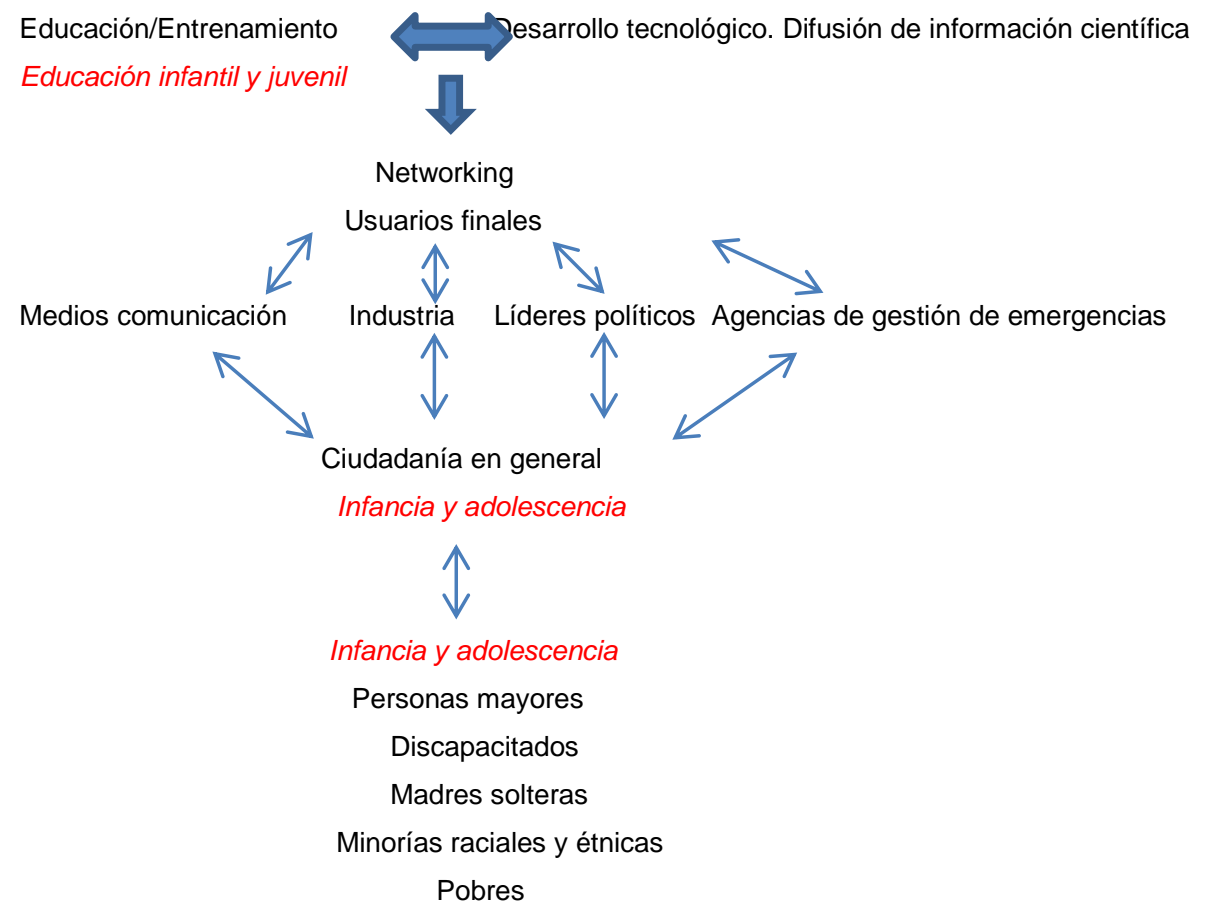

\section{Conclusiones}

En resumen, los estudios de investigación social en desastres y de la comunicación de riesgo han contribuido a analizar desde nuevos prismas el mapa de actores participantes en la preparación ante riesgos, emergencias y desastres. Un mapa progresivamente ampliado, y en el que caben los niños y adolescentes, tal como reinvindican las leyes y organismos internacionales como la ONU.

Las últimas tendencias en estos estudios sociales y comunicativos del riesgo y los desastres revelan la importancia de tener en cuenta las distintas audiencias para lograr que la información que reciban les resulte realmente útil para estar bien preparados, en una progresiva adaptación a sus características concretas. Una adaptación que se ha visto por ejemplo, en la manera de pensar en el currículo escolar, tal como se ha visto en los ejemplos y análisis del apartado anterior. 


\subsection{CARACTERÍSTICAS DE LA INFORMACIÓN PREVENTIVA}

\subsubsection{INTRODUCCIÓN}

El objetivo de la presente tesis es comprobar cómo las instituciones vinculadas a la protección civil adaptan a un público infantil contenidos y formatos destinados a informarse y prepararse en materia de prevención de riesgos y emergencias. Antes de adentrarnos en los estudios de caso y las entrevistas en profundidad llevadas a cabo para explorar esta cuestión, conviene detenernos previamente para trazar un paisaje de las características generales de la información y comunicación preventivas.

Utilizamos esta denominación de "información y comunicación preventivas" porque como hemos señalado al inicio de esta tesis, las regulaciones españolas así lo utilizan al indicar que entre sus actividades deben dirigirse a los "Programas de sensibilización e información preventiva a los ciudadanos" (art.11 ley 17/2015, de 9 de julio, del Sistema Nacional de Protección Civil). Indicábamos también que las webs de instituciones vinculadas a la protección civil en España, que posteriormente analizaremos, hacían sobre todo referencia a "información preventiva" $y$ "recomendaciones", con mayor frecuencia que otras ideas afines como "consejos de autoprotección", "prevención de emergencias", "prevención de riesgos".

Es por ello que en el presente capítulo trataremos de describir sus características haciendo uso de las mismas denominaciones usadas por los estamentos de protección civil.

Se ha tratado de dibujar dichas características a partir de la consulta de distintas fuentes del marco teórico así como de la propia observación derivada de los estudios de caso y las entrevistas en profundidad, ya que aunque en dichos puntos de la investigación se pretendía obtener eminentemente datos relativos a la infancia y la adolescencia, el propio proceso de investigación permitía observar aspectos de carácter más general. Por tanto, antes de pasar a los apartados destinados a los puntos más específicos y dedicados al público infantil y adolescente, nos detendremos en el marco más amplio de la comunicación e información preventivas en general. 


\subsubsection{LAS MISIONES DE LA INFORMACIÓN PREVENTIVA}

La primera característica de la información preventiva, en el contexto de las instituciones de protección civil y gestión de emergencias, es lo que podríamos denominar su "misión protectora".

La información preventiva tiene un papel fundamental, que, en primera instancia, alberga la misión de ayudarnos a protegernos de un hipotético daño. El destinatario de esa información puede, con ella, evitar una amenaza o evento dañino, mejorar la respuesta ante él, mitigar sus efectos o prepararse mejor para futuras repeticiones de esta amenaza.

En este sentido, la información preventiva contribuiría al proceso global de preparación (preparedness), que según definía el glosario de la EIRD se trataba del "conocimiento y las capacidades que desarrollan los gobiernos, los profesionales, las organizaciones de respuesta y recuperación, las comunidades y las personas para prever, responder, y recuperarse de forma efectiva de los impactos de los eventos o las condiciones probables, inminentes o actuales que se relacionan con una amenaza".

La información preventiva, por tanto, contribuiría a la adquisición de ese conocimiento y capacidades para prever, responder y recuperarse de eventos o amenazas.

La segunda misión que consideramos que tiene asignada la información preventiva sería la "misión concienciadora". La información preventiva contribuye a que la sociedad pueda tomar conciencia tanto de la existencia de riesgos y amenazas como de la capacidad del ciudadano de adoptar las medidas necesarias tanto para reducir la exposición al riesgo como para relacionarse con él. En este caso, la información preventiva contribuiría a una cultura mundial de la prevención.

En este sentido, la información preventiva está vinculada con el concepto de concienciación y sensibilización pública (public awareness) que la EIRD define como "el grado de conocimiento común sobre el riesgo de desastres (disaster risks) los factores que conducen a éstos y las acciones que pueden tomarse individual y colectivamente para reducir la exposición y la vulnerabilidad frente a las amenazas (hazards)".

Recordemos que la propia EIRD indicaba que el desarrollo de la concienciación pública se logra, entre otras cosas, mediante la elaboración y diseminación de información a través de los medios de comunicación o canales educativos(...)acciones comunitarias o participativas. 


\subsubsection{EL TIEMPO PREVENTIVO}

El tiempo de la información preventiva, en el contexto de las emergencias y desastres, es un aspecto complejo que trataremos de abordar desde distintas interpretaciones.

Por un parte, la información preventiva, en tanto que responsable de una misión protectora se ubicaría en el tiempo del antes de, previo a la materialización de un riesgo o de un peligro.

Ese momento temporal anterior a la ocurrencia de una emergencia o un desastre, ha sido definido de diversas formas a lo largo de las últimas décadas. En este sentido, Renedo, Gil y Valero (2007) hacen un repaso a las diferentes fases con las que la literatura científica delimita las fases de los desastres, de forma que la fases previas a la ocurrencia de un desastre se denominan advertencia y amenaza por Powell (1975) o preimpacto por Cohen y Ahearn (1980). Así lo describen Renedo, Gil y Valero (íbidem:73-75)

"la fase de advertencia nos indica cómo ciertas condiciones podrán dar lugar a un desastre, por ejemplo, la construcción de viviendas en las orillas de un riachuelo. En la fase de amenaza hay ciertos indicadores y señales que indican que se va a producir un desastre inminente, en esta fase se comunica a la población ese peligro inminente que se ha detectado.

La fase de preimpacto "es la que precede al impacto del desastre, en ella se incluyen las advertencias y amenazas para que la población se prepare y reaccione de manera segura minimizando las posibilidades de pérdidas"

Se trata de una visión centrada en el momento del impacto del desastre, en torno al cual se organiza el resto de las fases. El foco está puesto el el impacto, por lo que la prevención de éste necesariamente se ubica antes de él.

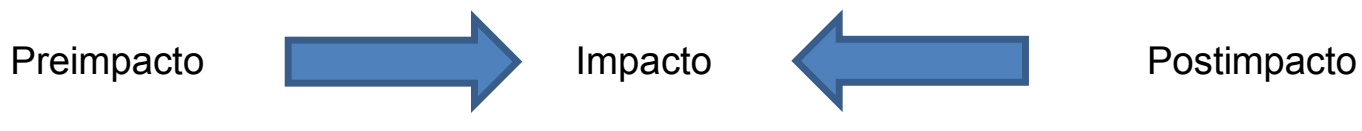

Información preventiva

Sin embargo, no es este el único modo de considerar el tiempo de la información 
preventiva.

La tercera Conferencia Mundial de Reducción de Riesgo de Desastres, en 2015, señala entre sus objetivos incorporar el conocimiento sobre riesgo de desastres en la educación formal y no formal, un conocimiento referido a la "prevención, mitigación, preparación, respuesta, recuperación y rehabilitación de desastres".

También en nuestra legislación (Ley 17/2015, del Sistema Nacional de Protección Civil) se hace referencia a estos procesos: "A los procesos ya consolidados del ciclo de la emergencia, previsión, prevención, planificación, intervención y recuperación se incorpora el de coordinación general de la acción política mediante la definición y seguimiento de estrategias integradoras de toda la actividad pública y privada en la materia".

Asimismo el Marco de Planificación Nacional de los Estados Unidos (National Planning Framework, 2014), señala las 5 áreas en las que se divide el Sistema de Planificación Nacional (según la directiva PPD8 de 11) y que incluye la prevención, protección, mitigación, respuesta y recuperación de desastres. En cada una de estas cinco áreas, tanto las previas como las posteriores a la ocurrencia del desastre, está contemplado diseminar public information and warning.

Según explica el departamento de Seguridad Nacional de los Estados Unidos, el Marco de Planificación Nacional de los Estados Unidos "describe la forma en que el conjunto de la comunidad-desde los miembros de ésta a los líderes del Gobiernodebería protegerse (safeguard) contra actos de terrorismo, desastres naturales así como otras amenazas" (pg.3 del documento marco).

Consideramos que esta visión, la enunciada por la EIRD y el departamento de Seguridad Nacional de los Estados Unidos, tiene un carácter proactivo que pone el foco no en el impacto del desastre, sino en la planificación en torno a él, bien sea antes, durante o después. En el marco de esta visión, la información y el conocimiento son necesarias en cada una de las fases y se convierten en un ingrediente clave para contribuir a esa planificación.

Tomando como base esta segunda visión, observaríamos que el carácter anticipatorio de la información preventiva pierde su carácter estanco y exclusivo de preludio al desastre, para desplegarse en un continuum de tiempo ininterrumpido, en el que la información y recomendaciones facilitadas en cada una de las fases contribuiría a la mejoría de los resultados de las fases posteriores.

En este caso, incluso el proceso de recuperación podría dejarnos lecciones 
aprendidas que se convertirían en informaciones preventivas de utilidad para un hipotético nuevo evento futuro, en previsión de que pudiese volver a repetirse. Hemos tratado de ilustrarlo mediante este gráfico en el que, a la última área prevista en el sistema de planificación nacional de los Estados Unidos, la recuperación, consideramos que debemos encadenarle otra nueva fase de prevención: lo que al final hayamos aprendido tendrá valor de información preventiva para otras amenazas y desastres en el futuro.

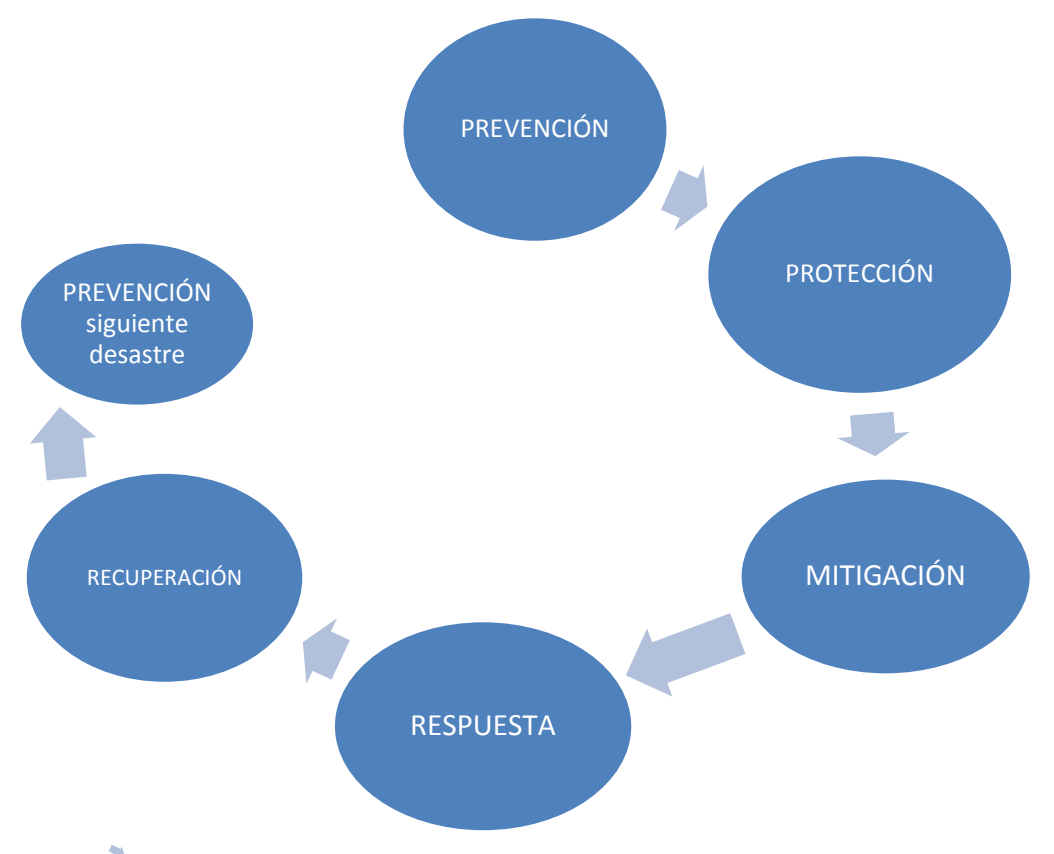

Consideramos que esta perspectiva de los desastres, donde el peso recae en la planificación alrededor de ellos y no tanto en el momento del impacto, contribuye a favorecer la proactividad en materia de preparación, diseño y diseminación de la información preventiva, convirtiéndola en una herramienta presente en todas las fases y asímismo favoreciendo el diálogo entre los diferentes actores.

Por otra parte, además de su carácter anticipatorio, bien sea como hemos visto desde 
un compartimento estanco o por el contrario conectada a las fases anteriores o posteriores de los desastres, en un tiempo contínuo, otra de las características del tiempo de la información preventiva es la repetición.

Según diversos estudios, la repetición de los mensajes es importante para que estos sean tomados en consideración y las personas decidan adoptar la medida o conducta recomendada por los gestores de emergencias, en el caso que nos ocupa, las instituciones de la protección civil (Renedo, Gil Valero, 2007), Fitzpatrick y Mileti (1994), Turner (1983), Baker (1979) o Rogers (1985). Entre otros resultados, la repetición contribuiría a disminuir los efectos de las informaciones erróneas o rumores, y ayudaría a reducir la ansiedad si no se ha comprendido bien el aviso.

Finalmente, el tiempo de la información preventiva es calendarizable. Puede incorporarse a la agenda comunicativa de las instituciones vinculadas a la protección civil de forma planificada y ajustada a determinados momentos del calendario, de forma que su preparación y diseminación se produzca al ritmo de determinados eventos del año.

Ejemplo de esta calendarización sería, por ejemplo, informar en invierno sobre como prevenir los incendios derivados de sistemas de calefacción, o en verano sobre como evitar los golpes de calor.

De esta forma, los mensajes preventivos pueden distribuirse en base a un calendario previamente definido, algo que le proporcionaría una doble ventaja: por una parte esta información puede ser percibida como más útil y próxima por parte de los ciudadanos, y por otra, tal como analizábamos en el apartado dedicado a la presencia de temas de prevención en los medios de comunicación, para los medios esta información y mensajes preventivos pueden ser más fácilmente insertables dentro de la lógica y narrativa mediáticas.

\subsubsection{LOS ACTORES PREVENTIVOS}

Alrededor de la información preventiva surgen distintos actores que participan del proceso de construcción de mensajes y significado. En la medida en que se opte por la unidireccionalidad o por el contrario, por la participación y el diálogo entre actores, ese proceso de construcción incorporará la visión de un mayor o menor número de ellos.

El actor que analizamos en la presente investigación, de forma especial, son las instituciones vinculadas a la gestión de protección civil y emergencias en España. 
Como hemos indicado en capítulos anteriores, la ley 17/2015 de 9 de julio, del Sistema Nacional de Protección Civil, define este sistema en los siguientes términos:

"La protección civil, como instrumento de la política de seguridad pública, es el servicio público que protege a las personas y bienes garantizando una respuesta adecuada ante los distintos tipos de emergencias y catástrofes originadas por causas naturales 0 derivadas de la acción humana, sea ésta accidental o intencionada".

Además de esta definición, el preámbulo añade los fines prioritarios de la protección civil, y por ende, de este actor "La prevención es uno de los fines prioritarios de la protección civil. Muchas de las políticas desarrolladas por las Administraciones Públicas, en tanto puedan afectar o condicionar la seguridad de las personas o los bienes, tienen objetivos preventivos. La ley propicia que todos estos esfuerzos se canalicen e integren a través de los órganos de coordinación que establece. La planificación, especialmente los planes de autoprotección, la formación del personal perteneciente al sistema de protección civil y singularmente la inclusión en los currículos escolares de contenidos sobre autoprotección y primeros auxilios, son instrumentos poderosísimos de prevención de carácter horizontal que esta ley procura"

Por otra parte, en España, el servicio público de la protección civil integra a diferentes actores de distintos niveles de la administración, desde la local a la nacional. La propia ley destaca la gran variedad de estos actores, indicando, entre otros, que "las Comunidades Autónomas y las Entidades Locales han desplegado sus competencias propias en la materia", y especifica que (art.17) "Tendrán la consideración de servicios públicos de intervención y asistencia en emergencias de protección civil:

-Los Servicios Técnicos de Protección Civil y Emergencias de todas las Administraciones Públicas

- Los Servicios de Prevención, Extinción de Incendios y Salvamento, y de Prevención y Extinción de Incendios Forestales

-Las Fuerzas y Cuerpos de Seguridad

- Los Servicios de Atención Sanitaria de Emergencia

- Las Fuerzas Armadas y, específicamente, la Unidad Militar de Emergencias

-Los órganos competentes de coordinación de emergencias de las Comunidades Autónomas

-Los Técnicos Forestales y los Agentes Medioambientales

-Los Servicios de Rescate

-Los equipos multidisciplinares de identificación de víctimas 
- Las personas de contacto con las víctimas y sus familiares

-Todos aquellos que dependiendo de las Administraciones Públicas tengan este fin.

¿Con qué otros actores interactúan los integrantes del Sistema Nacional de Protección Civil en materia de información y comunicación preventiva? El abanico aquí es igualmente variado:

-Centros escolares

-Medios de comunicación

-Ciudadanos

-Grupos específicos de ciudadanos como: asociaciones, centros de ancianos -Organizaciones del tercer sector

Se trata de un amplio espectro de potenciales participantes en el diálogo de la prevención, diálogo que podrá tener un carácter más unidireccional, si se basa exclusivamente en el rol de los expertos (en este caso los servicios de protección civil) o ser más multidireccional si cuenta con la voz y participación del resto de actores.

\subsubsection{EL CONTENIDO PREVENTIVO}

¿Qué tipos de contenidos podemos observar dentro de la información preventiva? Consideramos que podemos clasificarlos de la siguiente manera:

1. Contenidos referidos a las características de los distintos tipos de riesgos, amenazas, desastres o emergencias.

Según la clasificación de la Dirección General de Protección Civil y Emergencias, del Ministerio del Interior, los riesgos se dividen en:

-Riesgos naturales: meteorológicos, inundaciones, incendios forestales, aludes, maremotos o tsunamis, movimientos del terreno, sequía, terremotos, volcanes, otros (clima espacial).

-Tecnológicos: nucleares, radiológicos, químicos, asociados al transporte de mercancías peligrosas

Otra de las divisiones posibles es la de riesgos crónicos frente a riesgos agudos.

Respecto a los tipos de emergencias, también existe un largo listado: incendios industriales, incendios de vivienda, accidentes de tráfico, accidentes en la montaña 
etc.

2. Contenidos sobre Planes Especiales o regulaciones

3. Contenidos sobre avisos y alertas relacionados con un evento potencialmente dañino que podría producirse de forma inminente.

Por ejemplo, una alerta de lluvias intensas acompañada de consejos sobre evitar pasar por cauces de barrancos.

4. Contenidos sobre consejos de actuación en determinados eventos de alcance inmediato, aunque no exista ningún tipo de alerta sobre ellos.

Por ejemplo, recomendaciones sobre el uso de material pirotécnico durante las fiestas que se celebran esta semana en nuestro municipo.

5. Contenidos sobre las medidas de autoprotección a adoptar para evitar verse envuelto en alguna de las situaciones precedentes o bien para reaccionar y minimizar sus efectos si estas se producen.

6. Contenidos sobre cómo actuar en evacuaciones y confinamientos.

Por su importancia y dado que posteriormente durante el trabajo de campo hemos analizado el caso concreto de las evacuaciones, lo abordaremos en este punto con mayor detenimiento. Según la Dirección General de Protección Civil de España, la evacuación es una medida esencial de autoprotección ante emergencias en edificios, ya que supone un alejamiento del peligro. El objetivo es que los ocupantes se desplacen en condiciones de seguridad hacia una zona exterior segura.

En un sentido más amplio, Sorensen y Vogt (2006:183), señalan que "El término evacuación se utiliza para describir la acción de retirarse (withdrawal) de personas de un área específica debido a una amenaza o peligro".

Las evacuaciones han sido uno de los procesos comunicativos más analizados desde la investigación social de los desastres, de forma que décadas de estudios han logrado arrojar algunos consensos, tal como revelan las revisiones realizadas a esas investigaciones (Renedo, García y Valero 2007, Sorensen \& Vogt íbidem).

Las investigaciones de Lindell y Perry (1992, 2004), Mileti y Sorensen (1988, 1990) han analizado entre otras cosas cómo hay factores tanto de la emisión y la recepción de los avisos de evacuación que repercuten en el tipo de respuesta, y cómo se producen los procesos de toma de decisiones por parte de las personas que deben evacuar. A lo largo de estas décadas se han formulado distintos modelos y se han perfilado los distintos condicionantes que influyen en la toma decisión de evacuar. 
Sin pretensión de realizar un compendio exhaustivo sobre todos esos modelos, sí consideramos útil para la presente investigación resaltar aquellos aspectos sobre los que existe un consenso bastante generalizado.

$\underline{\text { Indicios }}$

La evacuación tendrá más probabilidades de producirse si la persona (receiver) que debe evacuar percibe indicios claros de que puede producir el evento negativo anunciado, y de que este puede originarle daños

\section{Las fuentes y la confirmación de los avisos}

El emisor (sender) del aviso de evacuación ha de resultar creíble. Existirá tendencia a que el receptor del mensaje trate de confirmar ese aviso por distintos canales, como fuentes oficiales, familia, medios de comunicación, etc.

\section{Familia unida}

La familia tratará de mantenerse unida durante el proceso de evacuación, o bien tratará de reunirse si no está junta en ese momento (incluso si para ello sus actos entran en contradicción con los avisos de evacuación).

\section{El mensaje}

El mensaje ha de ser claro y creíble, y debe contener información específica sobre qué, dónde y cuándo ha ocurrido u ocurrirá el evento que nos conduce a evacuar, y qué medidas y acciones protectivas podemos adoptar para evitar daños.

Es importante la repetición del mensaje.

\section{Condicionantes del receptor}

Existen factores relacionados con el receptor que influirán en su respuesta de evacuación: experiencia previa con este tipo de situaciones de emergencia o desastre, conocimiento y preparación sobre el plan de acción, evaluación de si tiene tiempo de evacuar, etc. 
Respecto al tipo de respuestas que finalmente se producen en una situación de evacuación, Renedo, García y Valero (2007:94) indican que pueden oscilar desde la negación, a la inacción, la indefensión, la hipervigilancia o la respuesta protectiva (esto es, la evacuación).

Sorensen \& Vogt (2006:184-185) distinguen hasta 8 tipos de evacuaciones:

-Según la clasificación de Drabek y Stephenson (1971), las evacuaciones pueden ser: *Por invitación: quien decide que los ocupantes del área afectada han de evacuar, se encuentra fuera del área afectada

*Por decisión o elección: las personas afectadas procesan el aviso de alerta y deciden evacuar

*Por defecto: por ejemplo, las personas que no pueden regresar a sus casas porque su barrio fue evacuado en su ausencia

*Por compromiso: los evacuados siguen órdenes aún no queriendo o no sintiéndolo necesario

-En base a la distinción realizada por Perry, Lindell y Greene (1981), existirían cuatro tipo de evacuaciones:

*Preventiva: se produce en el preimpacto y tiene corta duración

*Protectiva: se produce en el preimpacto y tiene larga duración

*Rescate: se produce en el postimpacto y tiene corta duración

${ }^{*}$ Reconstructiva: se produce en el postimpacto y tiene larga duración

Sorensen y Vogt señalan además (ídem) que la investigación sobre los numerosos condicionantes tanto del sender como del receiver en situaciones de evacuación revelan que es necesario superar la concepción de un sistema de aviso lineal y de arriba-abajo mediante el que un actor (gestores de emergencias) avisa a otros (ciudadanos) de que hay que evacuar.

La experiencia indica que las respuestas no van a producirse de esta forma lineal y, además, las características sociales y demográficas evolucionan con el tiempo y por tanto pueden repercutir en esos avisos. Señalan como ejemplos de estos cambios las nuevas tecnologías que se traducen en aspectos como el GPS, la existencia de proveedores privados de avisos, y la posibilidad de enviar y recibir masivamente imágenes e información. 


\section{CAPÍTULO 3. MARCO EMPÍRICO}

\subsection{ENTREVISTAS EN PROFUNDIDAD}

\subsubsection{OBJETIVOS, MÉTODO Y COMPOSICIÓN DE LA MUESTRA}

Tras concluir que las instituciones vinculadas a la protección civil sostienen un discurso en el que se destaca la importancia de trasladar contenidos de prevención de emergencias a la infancia y adolescencia, queríamos saber cómo se concretaba esa idea en la práctica. Para ello realizamos una serie de entrevistas en profundidad con el fin de conocer algunos de los principales actores institucionales en prevención e infancia en España, opiniones cualificadas que nos permitían seguir profundizando en la investigación.

A la hora de seleccionar la muestra, se ha tenido en cuenta que se tratase de actores que hubiesen desarrollado ya en la práctica durante los últimos años, en España, actividades de difusión o de formación para niños o adolescentes en materia de prevención de riesgos y emergencias. Todos los entrevistados han cumplido este requisito. El abanico de actividades que reflejan las experiencias aportadas por los participantes de las entrevistas en profundidad es variado y enriquecedor: desde apruebas piloto a simulacros en centros educativos, campañas sobre incendios, cuadernos educativos, guías didácticas o talleres, por citar solo algunos de los ejemplos. Por todo ello, se considera que la composición de la muestra permite dibujar cuál es el panorama actual de este tipo de actividades actualmente en España, entre otros puntos. El conjunto de las preguntas realizadas se describe en próximos apartados.

La composición de la muestra de entrevistados es la siguiente:

-Esther Gorjón. Enfermera de emergencias y portavoz del proyecto "Educación Civil en Emergencias", también llamado EdCivEmerg.

-Montserrat Rodríguez. Técnico de Protección Civil de la Generalitat Valenciana. Dirección General de prevención, Extinción de Incendios y Emergencias.

-Elena Puertas. Psicóloga. Dirección General de Protección Civil y Emergencias.

Subdirección General de Planificación, Operaciones y Emergencias. Grupo de Psicología de Catástrofes. 
-Luis Carmena. Director Fundación Fuego para la Seguridad contra Incendios y

Emergencias; y Director Técnico Fundación Fuego.

- Raquel Manjón Cembellín. Responsable de Prevención del Instituto de Prevención,

Salud, y Medio Ambiente de la Fundación MAPFRE

Se ha seguido el método de entrevista en profundidad mediante la confección de un cuestionario cerrado. Las entrevistas se han llevado a cabo mayoritariamente en el lugar de trabajo de los entrevistados, registrándose el audio de la entrevista, y en aquellos casos en que la presencia física no ha sido posible se han llevado a cabo conversaciones telefónicas y el entrevistado ha contestado a las preguntas por escrito. Tras explicarles a los entrevistados los objetivos de la investigación, se les ha formulado un cuestionario de 18 preguntas divididas en cinco bloques:

*La experiencia desarrollada por la institución

*Cómo comunicar prevención de emergencias a la infancia

*Actores en la comunicación de la prevención

*El niño en la sociedad

*Tendencias

\subsubsection{CUESTIONARIO}

Las preguntas realizadas a cada uno de los entrevistados son las siguientes:

Bloque 1. Experiencia de la institución/compañía/proyecto al que representa el entrevistado

1. ¿En qué consiste la actividad que llevan ustedes a cabo para el público infantil?

2. ¿Por qué han elegido esta modalidad pedagógica y no otra?

3. ¿Hay diálogo y feedback con el público infantil o es una comunicación más unidireccional?

4. ¿Ha participado algún otro actor social en el desarrollo o puesta en marcha de su actividad? (organismos públicos, comunidad educativa, fundaciones, etc.). ¿Cuál?

5. ¿Se han medido alguna vez los resultados de su actividad? ¿De qué manera y con qué resultados?

Bloque 2. Cómo comunicar prevención de emergencias en la infancia 
1. ¿Cuáles piensa que deberían ser los contenidos básicos que se habrían de trasladar a los niños en materia de prevención de emergencias? ¿Hay algún tipo de contenido a evitar? ¿Por qué?

2. Por favor indique si está más de acuerdo con a) o con b), y por qué motivo.

La educación sobre los riesgos y cómo evitarlos (por ejemplo: incendios de vivienda):

a ) Debe adaptarse a las características locales del entorno conocido por el niño, como las condiciones geográficas, culturales, etc.

b) No debe tener en cuenta las características locales, sino ser una explicación universal susceptible de ser comprensible en cualquier lugar de un país o del mundo.

3. ¿Qué fórmulas considera más idóneas para acercar el mundo de la prevención de emergencias a los niños?

4. ¿Dónde piensa que se han de abordar estos temas?: ¿casa, colegio, televisión, la red, instalaciones y dependencias de servicios de emergencias, fundaciones, empresa privada?, etc. ¿Por qué?

5. ¿Cuál ha de ser el rol del niño en este proceso? ¿De qué forma puede incrementarse su participación?

6. ¿Piensa que las nuevas tecnologías abren nuevas formas de comunicarse con la infancia en estos temas? ¿Por qué?

Bloque 3. Actores sociales en la comunicación de prevención

1. ¿Qué tipo de instituciones piensa que están más implicadas en la difusión de temas de prevención de emergencias entre los niños? (organismos de emergencias, instituciones educativas, compañías, etc.) ¿Por qué sucede así?

2. ¿Cree que hay diálogo entre los diferentes actores sociales o cada uno funciona de forma independiente a los demás?

3.¿Piensa que se implican más las instituciones de carácter local, autonómico, nacional o internacional? ¿Por qué?

Bloque 4. El niño en la sociedad

1. Diga si está de acuerdo o no con estas afirmaciones y por qué:

- El niño formado en prevención de emergencias es capaz de trasladar esa información a los adultos

- Un niño formado en prevención de emergencias será en el futuro un trabajador más seguro

2. ¿Considera que en nuestra sociedad estamos preocupados ante riesgos crónicos como aquellos relacionados con la alimentación o la contaminación? ¿Considera que en nuestra sociedad estamos preocupados ante riesgos agudos como una inundación en nuestro municipio o un incendio en un colegio? ¿Por qué? 
Bloque 5. Tendencias.

1. ¿Qué tendencia piensa que seguirá la comunicación en prevención de emergencias e infancia en los próximos diez años? ¿Por qué?

2. Puede añadir aquí las consideraciones adicionales que desee, si algún tema de interés para usted no se ha abordado en las preguntas anteriores.

\subsubsection{ANÁLISIS DE LAS ENTREVISTAS EN PROFUNDIDAD}

Tras la realización y transcripción de las entrevistas se ha procedido a analizar las respuestas de los participantes, para poder extraer los datos y conceptos más significativos. Se ofrecen a continuación los resultados, expuestos en el mismo orden en el que se han realizado las preguntas.

\section{BLOQUE 1. EXPERIENCIA DE LA INSTITUCIÓN/COMPAÑÍA/PROYECTO AL QUE REPRESENTA EL ENTREVISTADO}

\section{En qué consiste la actividad}

-Educación Civil en Emergencias se ha centrado en la difusión de la iniciativa de profesionales de las emergencias en España para que los primeros auxilios, las emergencias, la protección civil y la educación vial formen parte del currículo escolar de manera obligatoria. Para ello han hecho actividades de difusión y reuniones con representantes políticos.

Tambien se han difundido conceptos de prevención en redes sociales y de forma presencial, con actividades extraescolares y la formación de 1800 niños de 6ํㅡ de Educación Primaria (se trata de una prueba piloto en Alcorcón).

-Desde la Dirección General de prevención, Extinción de Incendios y Emergencias, de la Generalitat Valenciana, trabajan por implantar los Planes de Autoprotección en los centros escolares, haciendo partícipes a los ocupantes de los centros, entre los que se encuentra el público infantil.

- Dirección General de Protección Civil y Emergencias. Subdirección General de Planificación, Operaciones y Emergencias. Grupo de Psicología de Catástrofes.

Tienen distintos proyectos y actividades: 
*Guías didácticas para profesores de todos los riesgos en los que tiene competencia la protección civil. El objetivo es que los profesores implanten a lo largo del curso actividades y juegos para que los niños se conciencen y los niños aprendan pautas de autoprotección y de prevención en relación a los riesgos, tanto en el entorno escolar como en el entorno familiar. Se trata de aprender la cultura de la prevención de forma transversal. Esas guías didácticas llevan un CD interactivo de juegos y actividades con los niños.

${ }^{*}$ Certamen de unos premios para la seguridad y la protección en colegios de toda España, organizado por Ministerio de Educación y Ministerio del Interior. Se incentiva así que los colegios trabajen el tema de la seguridad y de la protección.

*La Prevención empieza en la Escuela, siguiendo el lema de la propia Estrategia Internacional para la Reducción de Desastres. La Escuela Nacional de Protección Civil, en Rivas (Madrid), se abre para los colegios de la zona, y se les entrena en distintas pautas de prevención y autoprotección. Hay distintos talleres (primeros auxilios, seguridad vial, cooperación, incendios).

*Video de "Autoprotección de centros escolares".

* Stand en la Feria de Aula, en el IFEMA, para divulgar todos estos materiales.

*Simulacro internacional de accidente nuclear en la central nuclear de Almaraz, en Cáceres. En todo el programa de información preventiva a la población se incluye a la población infantil. También se ha rodado un vídeo en uno de los colegios de la zona, sobre los comportamientos a seguir por parte de los niños en caso de que un accidente nuclear ocurriera en horario escolar.

*Web infantil, con actividades básicas, explicaciones y recomendaciones, en relación a los distintos riesgos, para que desde las distintas instituciones y la gente que visite la página, también comprenda la importancia de que los niños puedan ya tener desde las primeras etapas evolutivas este tipo de entrenamiento y este tipo de información.

\section{-Fundación Fuego para la Seguridad contra Incendios y Emergencias.}

Campamentos infantiles de emergencias para niños y niñas de entre 5 y 12 años. Realizan cinco actividades distintas, en torno a cinco emergencias que pueden darse en lo que es el día a día de las familias, del colegio y de su entorno en general. Participan también otros efectivos, como Bomberos de la Comunidad de Madrid. Se ve, actuación ante incendios, primeros auxilios, rescates acuáticos, incedios forestales y rescate de animales. 
- Área de Prevención del Instituto de Prevención, Salud, y Medio Ambiente de la Fundación MAPFRE.

*Campañas de Vivir en Salud (vida saludable y ejercicio físico), prevención de accidentes(CuidadoSOS)

* Semana de Prevención de Incendios. Es una campaña que normalmente se realiza en colaboración con los cuerpos de bomberos de las distintas Comunidades Autónomas o Ayuntamientos. Conjuntamente con ellos el área de prevención de MAPFRE elabora material, y durante una semana en concreto, entre septiembre y diciembre, se hacen eventos. Quien lo realiza son los cuerpos de bomberos. Estos cuerpos detectan en su zona cuáles son las necesidades que existen de formación y adecúa la Semana de la Prevención de Incendios en base a eso.

\section{2. ¿Por qué han elegido esta modalidad pedagógica y no otra?}

Atendiendo a las respuestas de los entrevistados, detectamos que en la gran mayoría de los casos existe una apuesta clara por la vertiente práctica de las actividades que llevan a cabo, ya que señalan que es la experiencia vivida la que puede llevarnos a una mejor comprensión de los conocimientos y habilidades relacionados con la prevención y la autoprotección. Así, señalan que "la práctica ayuda a fijar mejor los conocimientos que sólo la teoría", o que "los códigos de buenas prácticas se interiorizan prácticando: es el mejor método de concienciación”. También se insiste en la idea de que, sobre todo en las edades más tempranas, es necesario estimular la atención de los niños, algo que puede lograrse con sesiones cortas y prácticas, y con un cierto componente lúdico.

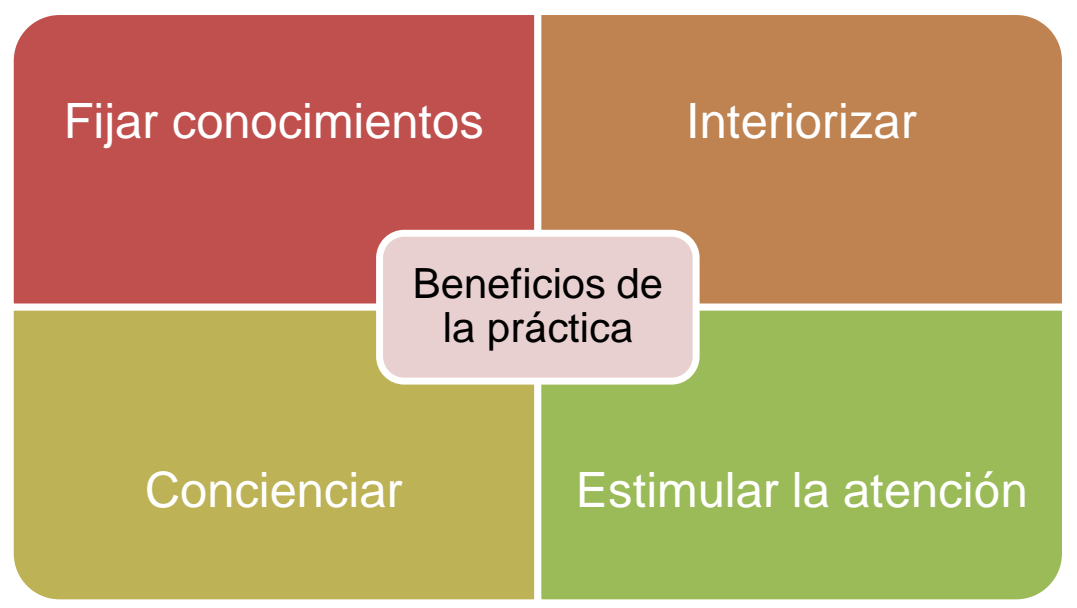


También se desprenden otras ideas respecto a la forma de integrar o relacionar las actividades con el currículo escolar de los centros educativos.

Así, hay quien aboga por modificar el currículo para que estos contenidos tengan cabida, mientras que otros apoyan la introducción mediante métodos de transversalidad. En este segundo grupo de opinión, algunos eligen esta opción porque aducen que se ha de desarrollar una visión global de la prevención, y otros porque valoran que el currículo ya está demasiado repleto de otras asignaturas y es mejor facilitar la tarea de que se incorpore a los centros educativos sin necesidad de ampliar el currículo.

\section{3. ¿Hay diálogo y feedback con el público infantil o es una comunicación más unidireccional?}

Siempre que la actividad sea atractiva, hay feedback y los niños cuentan sus propias experiencias, expresan sus propias ideas respecto al riesgo y las emergencias o muestran interés por las actividades.

Por otra parte, algunas instituciones llevan a cabo sus actividades a través de monitores que son profesionales de la gestión de protección civil y emergencias, con lo que en este caso la relación y el feedback no se produce de forma tan directa entre la institución-el niño, sino entre el niño y el monitor. La institución que está en el fondo de la organización de la actividad, en este caso, aparece como un concepto más abstracto en esas ocasiones.

\section{4. ¿Ha participado algún otro actor social en el desarrollo o puesta en marcha de su actividad (organismos públicos, comunidad educativa, fundaciones etc.)? ¿Cuál?}

En su gran mayoría sí que hay participación de otros actores sociales. Fundamentalmente se trata de los profesionales del campo de las emergencias, como los cuerpos de bomberos, policía o los servicios sanitarios, por citar algunos ejemplos. Tras ellos, les siguen los centros educativos y las administraciones autonómicas y locales.

En menor medida, ha habido contactos con la sociedad científica y las ONG. 


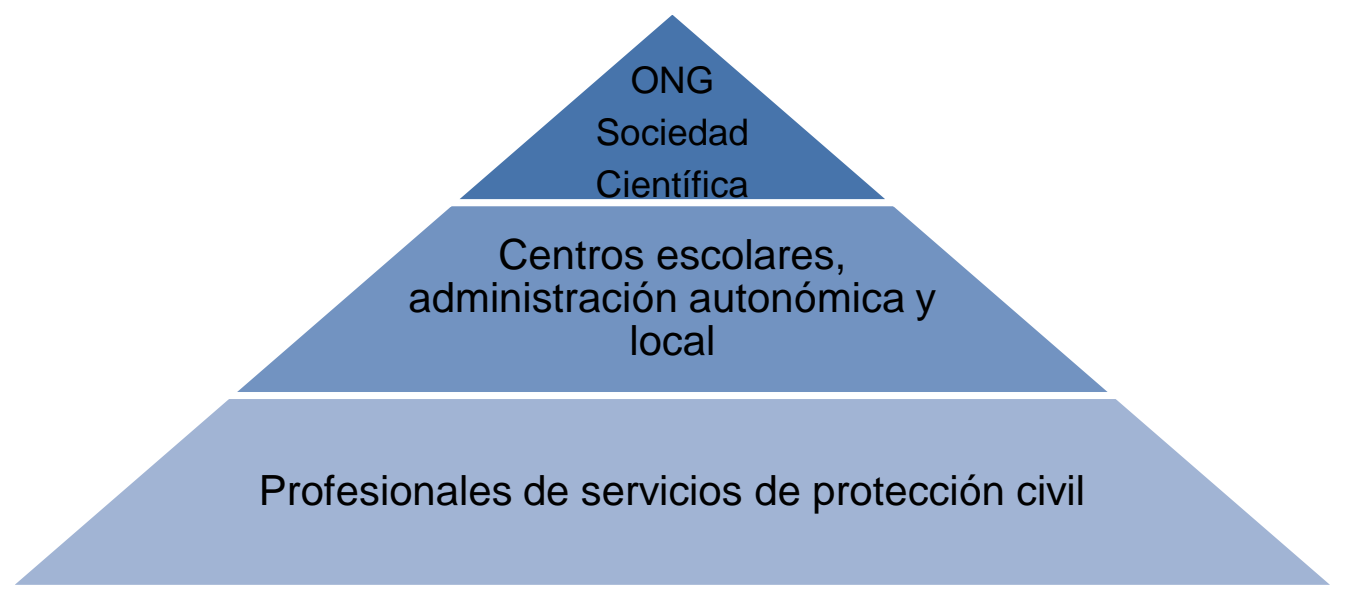

\section{5. ¿Se han medido alguna vez los resultados de su actividad? ¿De qué manera y con qué resultados?}

Encontramos todo tipo de respuestas. Para algunas instituciones, sí que existen mediciones consistentes en encuestas y ejercicios de pregunta-respuesta tras la realización de las actividades, que miden los conocimientos aprendidos, y de los que las instituciones indican que siempre han arrojado resultados positivos en cuanto al incremento de conocimiento.

Sin embargo, otras instituciones indican que no se ha llegado a formular una estructura sistemática de mediciones, y que esto se ha convertido en una asignatura pendiente en general en todos los estudios de prevención.

\section{BLOQUE 2. CÓMO COMUNICAR PREVENCIÓN DE EMERGENCIAS EN LA INFANCIA}

1. ¿Cuáles piensan que deberían ser los contenidos básicos que se habrían de trasladar a los niños en materia de prevención de emergencias? ¿Hay algún tipo de contenido a evitar? ¿Por qué?

Hay unanimidad en considerar que los contenidos que se habrían de trasladar a los niños han de ser completos y variados, y que abarquen todos aquellos aspectos relacionados con los riesgos y la actuación ante emergencias: conocer los distintos tipos de riesgos naturales, humanos o tecnológicos, los primeros auxilios, pautas de actuación ante emergencias, prevención de enfermedades o educación vial, entre otros. También hay consenso en considerar que todos estos contenidos han de ir incorporándose paulatinamente en todos los ciclos educativos, e ir adaptándose a la edad de cada curso o ciclo. 
Respecto a si hay algún contenido a evitar, se señala que no hay que dejar fuera ningún tipo de contenido, aunque sí que se ha de ser cuidadoso con aquellos aspectos que connoten negatividad o tengan un carácter traumático.

No hay que asustar ni tampoco sobreproteger. Hay que fomentar una cultura de la prevención y mostrar que las cosas peligrosas lo son, sin ocultarlo.

2. Por favor, indique si está más de acuerdo con a o con b y por qué motivo.

La educación sobre los riesgos y cómo evitarlos (por ejemplo: incendios de vivienda):

a ) Debe adaptarse a las características locales del entorno conocido por el niño, como las condiciones geográficas, culturales, etc.

b) No debe tener en cuenta las características locales, sino ser una explicación universal susceptible de ser comprensible en cualquier lugar de un país o del mundo.

Hay una tendencia mayoritaria a considerar que no deben tenerse en cuenta las características locales dado que hoy en día existe cada vez más una mayor movilidad que hace que los niños puedan tener que enfrentarse a distintos riesgos 0 emergencias en lugares diferentes a su región o país de origen.

Aún así, se considera también que paralelamente quizá se debería hacer más hincapié e insistir más en aquellos riesgos que sí que son más propios de su entorno.

3. ¿Qué fórmulas considera más idóneas para acercar el mundo de la prevención de emergencias a los niños?

Hay una clara unanimidad en designar cuáles son las vías de entrada ideales de los contenidos de prevención de emergencias en el universo de los niños.

Por una parte, ha de ser a través de los centros escolares, empezando desde el mismo momento de la escolarización y continuando con una adaptación a las distintas edades del alumnado.

Además, esa entrada ha de tener en consideración que la mejor manera de acercarse a los niños es mediante los juegos, la participación y la práctica. 
4. ¿Dónde piensa que se han de abordar estos temas?: ¿casa, colegio, televisión, la red, instalaciones y dependencias de servicios de emergencias, fundaciones, empresa privada?, etc. ¿Por qué?

En general, se considera que se ha de abordar de forma integral a través de los colegios, los padres y los servicios de emergencia. También los medios de comunicación pueden jugar un papel importante.

No se ha de basar en acciones puntuales, ya que no llegan a suficiente gente y si no se repiten, se olvidan. Ha de ser más bien un aprendizaje a lo largo de la vida.

Por otra parte, también se ha puesto de manifiesto por parte de algunos entrevistados que, aunque estos temas deban abordarse de una forma integral, el origen o la coordinación de estas acciones ha de partir inicialmente de los servicios y organismos de emergencias.

\section{5. ¿Cuál ha de ser el rol del niño en este proceso? ¿De qué forma puede incrementarse su participación?}

Hay amplia coincidencia en cuál ha de ser el rol del niño en este proceso, y de cómo puede favorecerse su participación.

Se le ha de otorgar un rol activo y participativo, de forma que se sienta implicado. Hay que hacerle sentir protagonista y mostrarle la responsabilidad que tiene como ciudadano y lo importante que puede ser su labor.

Por otra parte, otra vía para favorecer un rol activo es haciendo que el niño se encargue de trasladar lo aprendido a sus compañeros o a otros niños más pequeños. En esta cadena, el niño es incluso capaz de transmitir sus conocimientos a otros actores de su entorno próximo, como su familia.

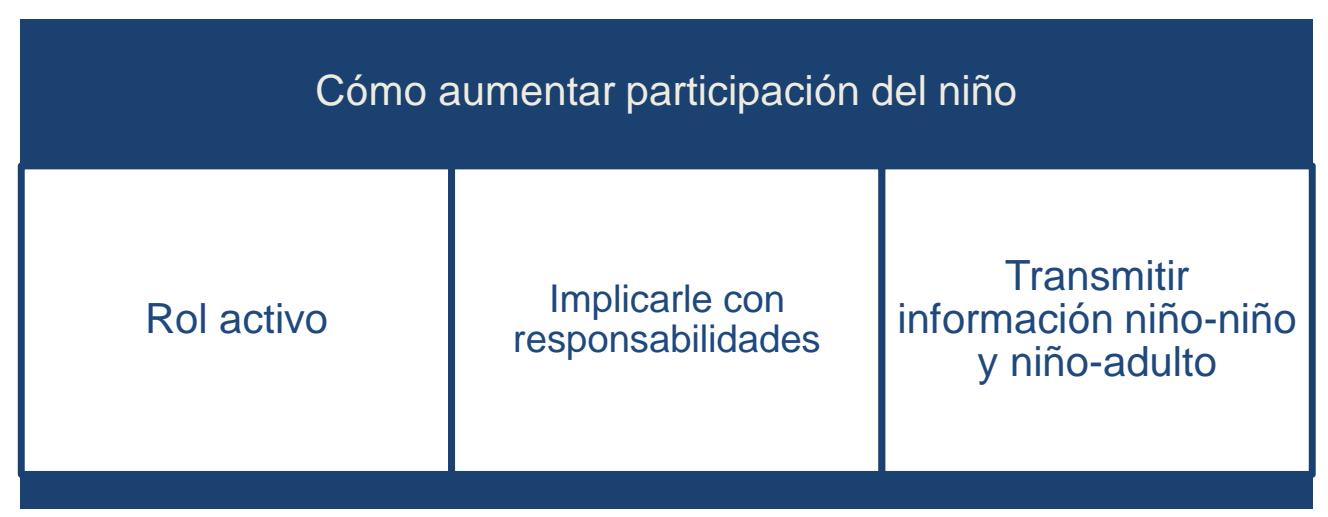


Otra de las ideas puestas de manifiesto en este apartado es que, respecto a la participación de los niños según su edad, entre los 6 y los 12 años son más receptivos que en el grupo de entre 13 a 18, a quienes es más difícil llegar e interesar.

\section{6. ¿Piensa que las nuevas tecnologías abren nuevas formas de comunicarse con la infancia en estos temas? ¿Por qué?}

Las nuevas tecnologías pueden abrir nuevas formas de comunicarse con la infancia en estos temas. Las nuevas generaciones son nativos digitales, y las nuevas tecnologías son muy importantes para ellos y tienen mucho peso en su vida diaria.

Son una herramienta muy interesante para difundir los conocimientos y habilidades de prevención a través de juegos interactivos y videjuegos, ya que son una forma divertida y rápida de facilitar información, y además pueden convertirse en un buen recordatorio de todo lo aprendido.

Algunos matizan que estas nuevas tecnologías han de ser complementarias y no sustitutivas de otros métodos.

También hay quien destaca que para algunos colectivos pueden convertirse en una herramienta fundamental e imprescindible: por ejemplo, para determinadas formas de discapacidad el uso de ciertas tecnologías va a ser la vía que les permita acceder a los conocimientos o datos relativos a prevención de riesgos o emergencias.

BLOQUE 3. ACTORES SOCIALES EN LA COMUNICACIÓN DE PREVENCIÓN DE EMERGENCIAS

1. ¿Qué tipo de instituciones piensa que están más implicadas en la difusión de temas de prevención de emergencias entre los niños? (organismos de emergencias, instituciones educativas, compañías, etc.) ¿Por qué sucede así?

La mayoría opina que son los organismos de emergencias aquellos que están más implicados en la difusión de estos temas entre los niños, debido a que están más concienciados al conocer las consecuencias de la falta de prevención y saber cómo ésta ayuda a disminuir dichas consecuencias o su frecuencia y gravedad.

También la mayoría consideran que las instituciones educativas son las menos implicadas, bien sea porque exista una falta de conocimiento que les lleve a no verse 
capacitadas para desarrollar estas enseñanzas, o bien porque no lo ven como algo prioritario en el conjunto de la gran cantidad de tareas y objetivos a alcanzar durante el curso escolar.

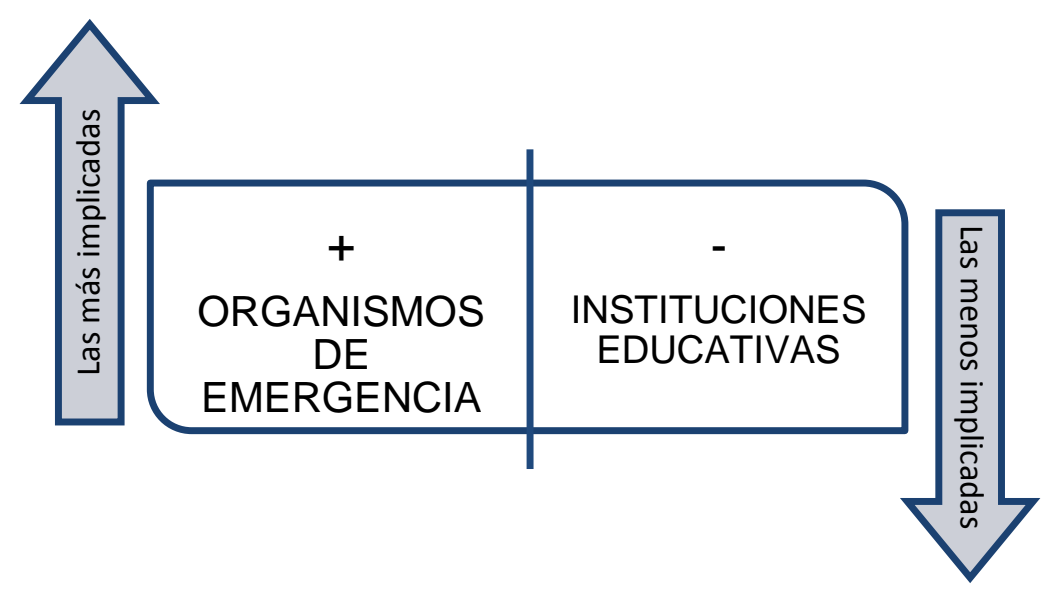

En menor medida, entre los entrevistados hay quien opina que no hay suficiente implicación por parte de ninguna de las instituciones, ni instituciones de emergencias ni educativas, y quien remarca que serán las personas concretas que ostenten responsabilidades, y no las siglas de la institución, quienes marcarán el mayor o menor nivel de implicación de esta.

\section{2. ¿Cree que hay diálogo entre los diferentes actores sociales o cada uno funciona de forma independiente a los demás?}

El nivel de diálogo, según los entrevistados, oscila entre insuficiente e inexistente. Para los que consideran que es insuficiente, señalan que sí hay cierto nivel de diálogo pero que no se da siempre, y que aún habiéndose alcanzado determinados consenso en algunos aspectos, sería necesario que hubiera todavía más, entre otras cosas para rentabilizar mejor el trabajo que se realiza desde los varios frentes.

Entre quienes indican que el diálogo no existe, señalan que se debe a que en demasiadas ocasiones las distintas iniciativas se impulsan individualmente, e incluso en algunos casos se busca un rédito de marca o repercusión que temen perder si se comparten actividades o iniciativas con otros actores. 
3. ¿Piensa que se implican más las instituciones de carácter local, autonómico, nacional o internacional? ¿Por qué?

Hay tendencia a considerar que son las instituciones locales, sobre todo los Ayuntamientos $u$ organismos vinculados a administraciones locales las que se implican más, entre otras cosas porque trabajan con la sociedad de una forma más directa.

En cuanto a otros niveles de instituciones, consideran que va a tener peso no la institución en sí, sino el grado de implicación que tenga la persona o personas que ostenten un cargo de responsabilidad en dicha institución.

\section{BLOQUE 4. EL NIÑO EN LA SOCIEDAD}

1. Diga si está de acuerdo o no con estas afirmaciones y por qué:

- El niño formado en prevención de emergencias es capaz de trasladar esa información a los adultos

- Un niño formado en prevención de emergencias será en el futuro un trabajador más seguro

Los entrevistados están de acuerdo con ambas afirmaciones.

Respecto a la primera, consideran al niño "un canal para trasladar información a adultos", ya que en cuanto llegan a casa suelen contar lo que han hecho en el colegio. Son "un vector de difusión de conocimientos excepcional y pueden enseñar a un adulto todos esos conocimientos o hacer que el adulto tome conciencia de su propio desconocimiento y se preocupe por aprender". También son capaces de decirle a un adulto lo que puede y lo que no puede hacer ante determinada situación.

Hasta ahora, señalan, los conocimientos en torno a la prevención de riesgos y emergencias solo se daban en foros profesionales y no en todos, por lo que la situación en la que nos encontramos es la de adultos poco concienciados que conviven con niños en vías de adquirir esos conocimientos y concienciación.

Respecto a si esa formación en prevención de emergencias repercutirá en su futuro como trabajador más seguro, consideran que sí dado que se trata de interiorizar hábitos de autoprotección y conductas preventivas que se extenderán a su futura vida trabajadora. 


\section{2. ¿Considera que en nuestra sociedad estamos preocupados ante riesgos}

crónicos como aquellos relacionados con la alimentación o la contaminación? ¿Considera que en nuestra sociedad estamos preocupados ante riesgos agudos como una inundación en nuestro municipio o un incendio en un colegio? ¿ Por qué?

En general se percibe que no hay preocupación por los riesgos, ni los crónicos ni los agudos, pero quizá menos por los agudos. Respecto a los crónicos, algunos de los factores alegados para la falta de interés detectada es que la gente no suele preocuparse por este tipo de temas "hasta que realmente le ve las orejas al lobo", y que si bien hubo una época con un nivel imporante de concienciación sobre riesgos medioambientales y de salud, la crisis económica ha hecho que estas preocupaciones queden relegadas a otro lugar.

En cuanto a los riesgos agudos, se señalan factores como determinadas percepciones sociales, de tal forma que la gente tiene la sensación de que "eso no nos va a pasar" y que en cualquier caso "ya están los servicios de emergencia" para ocuparse de estos asuntos.

También se hace referencia al desconocimiento de estos temas, que hace que, por ejemplo, por regla general los padres no se paren a pensar en si el lugar en el que estudian sus hijos cumple con las normas de seguridad.

Por otra parte, consideran que ese desconocimiento puede conducir hacia actitudes de rechazo hacia determinadas situaciones preventivas, de tal forma los simulacros pueden llegar a molestar y a parecer una pérdida de tiempo

En resumen, los entrevistados hacen alusión a determinados factores sociales que ya en capítulos anteriores hemos expuesto como freno al fomento de una actitud preventiva, tales como desconocimiento de los riesgos y de la autoprotección, sensación de invulnerabilidad, y confianza en los sistemas expertos para gestionar las situaciones de emergencia. 


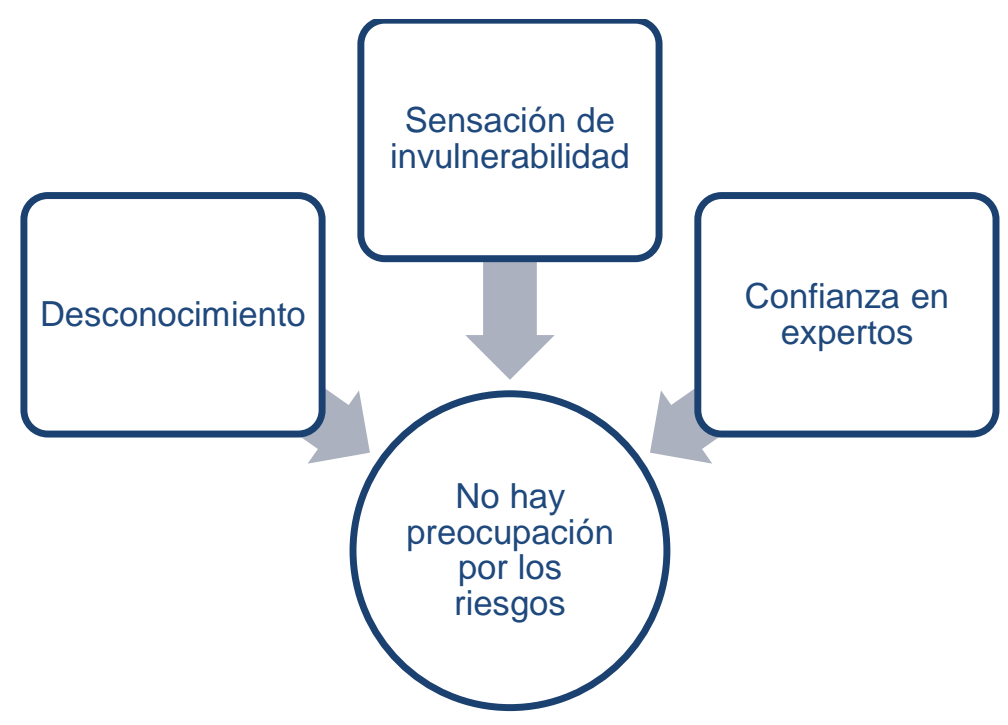

\section{BLOQUE 5. TENDENCIAS}

1. ¿Qué tendencia piensa que seguirá la comunicación en prevención de emergencias e infancia en los próximos diez años? ¿Por qué?

En general hay una visión positiva sobre cuál será la evolución de la comunicación de la prevención de emergencias en la próxima década, aventurando que habrá más formación en los colegios, en las empresas y también a través de difusión en redes sociales. También las nuevas tecnologías ofrecerán nuevas posibilidades de llegar a los distintos públicos.

Por otra parte, también se detecta que la crisis económica puede afectar a esta evolución, bien frenando los cambios, bien provocando un desfase entre los conocimientos adquiridos por la ciudadanía y las condiciones de seguridad de las instalaciones o lugares públicos. 


\subsubsection{CONCLUSIONES DE LAS ENTREVISTAS EN PROFUNDIDAD}

Tras llevar a cabo este análisis de las entrevistas en profundidad, extraeremos las principales líneas de opinión observadas:

\section{EXPERIENCIA DE LA INSTITUCIÓN/COMPAÑÍA/PROYECTO AL QUE REPRESENTA EL ENTREVISTADO}

\section{Tipos de actividades}

Hay una amplia variedad de tipos de actividades, y la gran mayoría se desarrolla en el marco de los centros escolares. A través de las respuestas de los entrevistados se puede confeccionar el siguiente listado de actividades:

-Prueba piloto para que los temas de primeros auxilios, emergencias, protección civil y educación vial formen parte del currículo escolar obligatorio.

-Implantación de planes de autoprotección en los centros escolares

-Guías didácticas para profesores sobre distintos riesgos

Concursos escolares sobre temas de seguridad y prevención

Puesta en práctica en colegios de la "Semana de la Prevención empieza en la escuela", de la Estrategia Internacional para la Reducción de Desastres

Vídeos sobre autoprotección en centros escolares

Web infantil con recomendaciones y actividades

-Campamentos infantiles de emergencias

-Campañas de difusión de riesgos y medidas de prevención sobre vida saludable, prevención de accidentes y de incendios: Vivir en Salud, CuidadoSOS, Semana de la Prevención de Incendios

\section{Motivos para seleccionar estas metodologías}

\section{El poder de la práctica}

-La práctica ayuda a comprender e interiorizar conocimientos y habilidades relacionadas con las prevención y la autoprotección

-Practicar es el mejor método de concienciación

-La educación en los niños pequeños ha de contener aspectos lúdicos y dinámicos 


\section{Las actividades se han de conectar con el currículo escolar}

-Las distintas actividades encuentran la forma de abordar los temas de prevención y autoprotección desde el currículo escolar.

Hay dos tendencias opuestas en cuanto al tipo de relación propuesto con el curículo:

*Hay que modificar el currículo para que se incorporen espacios específicamente dedicados a estos temas

*No hay que modificar el currículo sino aprovechar las posibilidades que ofrece la transversalidad para introducir estos conceptos en el contexto de otras materias, de una forma global

\section{La comunicación con el público infantil durante las actividades, ¿es unidireccional o hay feedback?}

Sí hay feedback. Los participantes cuentan sus propias experiencias y los conocimientos que ya tienen sobre la materia. Es una oportunidad para contrarestar ideas preconcebidas erróneas.

Por otra parte, el feedback se da más con los monitores de las actividades (habitualmente profesionales de las emergencias) que directamente con personal de la institución. La imagen de la institución puede quedar desdibujada para el participante, que es el público infantil.

\section{Actores que participan en la puesta en marcha de la actividad}

Sobre todo participan actores del campo de las emergencias, tanto si la actividad la organiza un organismo público como una fundación

En segundo lugar, los centros educativos y las administraciones autonómicas y locales.

\section{Mediciones y resultados de las actividades}

Algunas instituciones elaboran mediciones y otras no.

Las que sí que lo hacen, señalan que se trata de cuestionarios sobre conocimientos aprendidos, tras la actividad, y que siempre se registra un incremento de conocimientos entre los participantes 
Por el contrario, otras instituciones indican que no se han realizado hasta la fecha mediciones sistemáticas, y que esto es una asignatura pendiente de todo el campo de prevención de emergencias

\section{CÓMO COMUNICAR PREVENCIÓN DE EMERGENCIAS EN LA INFANCIA}

\section{Contenidos para la infancia sobre prevención de emergencias}

Los tipos de contenidos a facilitar han de ser:

-Completos y variados, incluyendo: los tipos de riesgo, primeros auxilios, actuaciones en emergencias, prevención de enfermedades, educación vial

- Adaptados a la edad

- Presentes en todos los ciclos educativos

Se recomiendan las siguientes pautas para difundir estos contenidos:

-No hay que esconder los peligros sino mostrarlos. No hay que sobreproteger

-No se debe incidir en eventos negativos o traumáticos. No hay que asustar

La educación sobre riesgos y cómo evitarlos, ¿debe adaptarse a las características locales?

No debe adaptarse a las características locales, dado que la gran movilidad geográfica de los niños y futuros adultos les hace susceptibles de encontrarse frente a todo tipo de situaciones de emergencia. Aunque se puede hacer un mayor hincapié en los riesgos más propios de su entorno.

Fórmulas más idóneas para acercar los temas de prevención de emergencias a los niños

- Ha de ser a través de los centros escolares

-Adaptadas a las distintas edades

-Fórmulas participativas, prácticas y lúdicas

\section{En qué entorno se han de abordar estos temas}

-Las acciones han de partir inicialmente de los profesionales y servicios de emergencia 
-A partir de ahí, ha de haber un abordaje integral: servicios de emergencia, colegios, padres, medios de comunicación

-Aprendizaje a lo largo de la vida

\section{Rol del niño y vías de participación}

-Rol activo y participativo

-Hacerle sentir protagonista

-Implicarle y mostrarle su responsabilidad

-El niño puede ser el encargado de transmitir esas enseñanzas a otros compañeros

-Por extensión, acaba transmitiendo esas enseñanzas a su familia

-Es más complicado lograr la participación de los adolescentes que de los niños

\section{El papel de las nuevas tecnologías}

-Hay que contar con ellas, pues son fundamentales para la vida diaria de los nativos digitales

-Útiles para la difusión de conceptos de prevención mediante juegos interactivos y videojuegos. También para el recordatorio de dichos conceptos.

-Ofrecen diversión y rapidez

-Como herramienta, han de ser complementaria pero no sustitutiva

-Para algunos colectivos, como los discapacitados, su uso puede ser vital

\section{ACTORES SOCIALES EN LA COMUNICACIÓN DE PREVENCIÓN DE EMERGENCIAS}

\section{Grado de implicación de las distintas instituciones en el ámbito de la prevención de emergencias en la infancia}

-Las más implicadas son las instituciones y organismos de emergencias, porque conocen las consecuencias de la falta de prevención

-Las menos implicadas son las instituciones educativas, por desconocimiento, o por falta de interés debido a la sobrecarga de otras tareas y prioridades

Grado de implicación de las instituciones locales, autonómicas, nacionales o locales

-Las instituciones locales se implican más porque se comunican y actúan con el ciudadano de una forma más directa 
-En el resto de instituciones, el nivel de implicación dependerá del grado de implicación de la persona que ostenta el cargo de responsabilidad

\section{EL NIÑO EN LA SOCIEDAD}

\section{El niño en la cadena de la prevención}

-El niño es canal de transmisión de conocimientos e información para su entorno adulto, sobre todo la familia

-Los adultos toman así conciencia de su propio desconocimiento

-La formación en prevención de emergencias infantil repercute en los futuros hábitos laborales del niño

\section{Percepción social de los riesgos crónicos y agudos}

-No hay preocupación por los riesgos crónicos dado que la sociedad no se preocupa en general "hasta que no le ve las orejas al lobo". Además la crisis económica ha desplazado estas prioridades.

- No hay preocupación por los riesgos agudos debido a:

*Sensación de invulnerabilidad

${ }^{*}$ Desconocimiento de los riesgos

*Confianza en los servicios de emergencia para atender la situación

\section{TENDENCIAS}

\section{Tendencias para la próxima década}

-Más formación en los colegios, en las empresas

-Más difusión en las redes sociales

-Mayor uso de las nuevas tecnologías para nuevas formas de comunicarse con el público

-La crisis económica frenará en parte esos avances 


\subsection{ESTUdiO DE CASO. LA PREVENCIÓN EN LAS WEBS DE PROTECCIÓN CIVIL ESPAÑOLAS}

\subsubsection{CARACTERÍSTICAS DE LA INVESTIGACIÓN}

Las instituciones vinculadas a la protección civil y las emergencias tienen en la web una de sus vías de comunicación con sus públicos. En este espacio, la institución se define, expone sus objetivos y funciones, mantiene al día sus últimas noticias o facilita información útil sobre normativas y regulaciones. $Y$ lo que es más importante para la investigación que nos ocupa, ofrece información y recomendaciones sobre cómo evitar, minimizar o afrontar riesgos o situaciones de emergencia.

El presente capítulo tiene como objetivo analizar cómo los organismos públicos protección civil y emergencias en España comunican esa información y recomendaciones a través de sus webs. Más concretamente, trataremos de ver cómo están incorporando al público infantil en el discurso de la prevención y cómo están adaptando los contenidos y los formatos accesibles a través de sus webs a un destinatario infantil y adolescente.

Para poder llevar a cabo dicho análisis se ha llevado a cabo el siguiente proceso metodológico.

El universo a analizar lo componen las webs de aquellos organismos públicos de protecció civil y emergencias del estado Español, del que extraeremos una muestra representativa. Dado que las competencias de gestión de determinados ámbitos están delegadas a las respectivas Comunidades Autónomas, la muestra serán 17 webs vinculadas a la gestión de la protección civil de cada una de las 17 Comunidades Autónomas.

La detección de dichas webs se ha realizado mediante la introducción en la barra de buscador del concepto "1-1-2 más el nombre de la Comunidad Autónoma". De esta forma localizamos la dirección web deseada y nos ponemos en la misma posición de un internauta que quiera buscar información o recomendaciones de este tipo de webs, probablemente de la web propia de la autonomía en la que reside. 
Trataremos de responder a las preguntas:

-¿Qué webs encontramos al realizar la búsqueda 1-1-2 + el nombre de la Autonomía?

- ¿Hay contenidos sobre temas de prevención o autoprotección? ¿Hay alguna sección dedicada a este tipo de contenidos pero dirigidos a niños o adolescentes?

-¿Qué diferencias de contenido y formatos existen entre los contenidos específicamente dedicados a la infancia y adolescencia y aquellos otros destinados al público en general?

Con todos los datos obtenidos, trataremos de describir el panorama de las páginas web institucionales vinculadas a un organismo autonómico, recopilando las características y los contenidos de dichas páginas.

Se analizará tanto la información textual, como icónica. Asimismo, intentaremos plasmar qué representación se ofrece de los niños en relación con las situaciones de riesgo y emergencia: si son potenciales víctimas, causantes de una situación de emergencia, si viven ajenos al peligro o pueden ser consciente de él, si son ellos los que pueden cuidar de su autoprotección o bien han de confiar en los adultos, etc.

Finalmente, se expondrán con más detalle aquellos casos que consideramos "mejores prácticas".

Tras las conclusiones, estas se compararán con las obtenidas del análisis de la web de la FEMA de Estados Unidos. El motivo es que la Agencia Federal para el Control de las Emergencias lleva varios años incorporando innovación a la hora de comunicar los riesgos y emergencias a los niños estadounidenses, por lo que es una buena fuente de información y recursos para esta temática. Nuestro objetivo será detectar semejanzas y diferencias en la comparativa entre esta web y el caso español.

En resumen, se trata de una investigación descriptiva, ya que trataremos de mostrar el panorama actual de las webs, pero tambien explicativa, porque intentaremos indagar en las causas, los temas, los personajes o la selección de recursos educativos que se hallan en estas páginas.

\section{Proceso de recogida de la muestra}

El proceso de recogida de la información ha consistido en acceder a cada una de las webs para a partir de ahí:

-Localizar aquellas secciones que se engloben bajo alguno de estos conceptos: "consejos" "recomendaciones" "prevención" "autoprotección" "información preventiva", dado que esta son las vías detectadas a lo largo de la web para localizar este tipo de 
contenidos objeto de nuestro análisis. Como se ha destacado en anteriores apartados, durante el transcurso de este estudio se ha detectado que los conceptos más frecuentemente usados en las webs son "información preventiva" y "recomendaciones".

Una vez se han localizado estas secciones, se trataba de distinguir si estaba dirigida a un público general o/y si hay además una sección destinada a la infancia y adolescencia. Se han extraído muestras de contenidos para ambos tipos de públicos, para poder trazar un mapa general y a la vez poder realizar una comparativa.

De cada web se han obtenido materiales originalmente preparadaos para descargar desde la web, o bien se han descargado transformándolos a PDF y JPG. Con todas las unidades recogidas trataremos de trazar un panorama que analice cuantitativamente y cualitativamente la situación actual, atendiendo a variables como el formato, el tipo de contenidos, el tipo de recursos pedagógicos utilizados etc, así como la representación que se haga del niño respecto al papel que juega en su propio proceso de autoprotección.

\section{Composición de la muestra}

Hemos estudiado el material obtenido de las siguientes webs. Se indica en este listado el organismo público al que pertenecen y el nombre de la correspondiente web. Tras el listado, se adjuntan algunas páginas de muestra de cada web.

\section{Andalucía}

Sistema Emergencias 112 Andalucía (Consejería de Justicia e Interior de la Junta de Andalucía)

\section{juntadeandalucia.es}

\section{Aragón}

112 SOS Aragón/ Alertas 112 (Protección Civil de la Consejería de Interior del Gobierno de Aragón)

aragon.es

\section{Asturias}

Entidad Pública 112 Asturias- Servicio de Emergencias del Principado de Asturias 
112asturias.es

4. Cantabria

112 Cantabria (Dirección General Protección Civil-Consejería Presidencia y JusticiaGobierno de Cantabria)

112.cantabria.es

5. Castilla y León

Junta de Castilla y León-Emergencias 112 Castilla y León

112.jcyl.es

\section{Castilla La Mancha}

Dirección General de Protección Ciudadana-Emergencias 1-1-2-Castilla la Mancha http://pagina.jccm.es/justicia/112/presentacion

\section{Cataluña}

Generalitat de Catalunya- Emergències 112 Catalunya

112.gencat.cat

\section{Comunidad de Madrid}

112 Emergencias Comunidad de Madrid

madrid112.es

\section{Comunidad Valenciana}

Generalitat Valenciana-Conselleria de Governació i Justícia-Servei 1-1-2 Comunitat Valenciana

$112 \mathrm{cv} . \mathrm{com}$ 
10. Extremadura

Junta de Extremadura-Centro de atención de urgencias y emergencias 112 Extremadura

gobex.es

\section{Galicia}

Axencia galega de emerxencias-112 Emerxencias Galicia

112galicia.org

\section{Illes Balears}

Consejería de Hacienda y Administraciones Públicas-Dirección General de Emergencias e Interior- Centro de Emergencias (112)

caib.es

13. Islas Canarias

Gobierno de Canarias-1-1-2 Canarias

112canarias.com

\section{La Rioja}

1-1-2- Emergencias SOSRioja

larioja.org

\section{Murcia}

Dirección general de seguridad ciudadana y emergencias de Región de Murcia-112 Región de Murcia

112 rm.com 
16. Navarra

Agencia Navarra de Emergencias

navarra.es

17. País Vasco

Eusko Jaurlaritza. Gobierno Vasco. Departamento de Seguridad. Dirección de Atención de Emergencias y Meteorología

interior.ejgv.euskadi.eus 

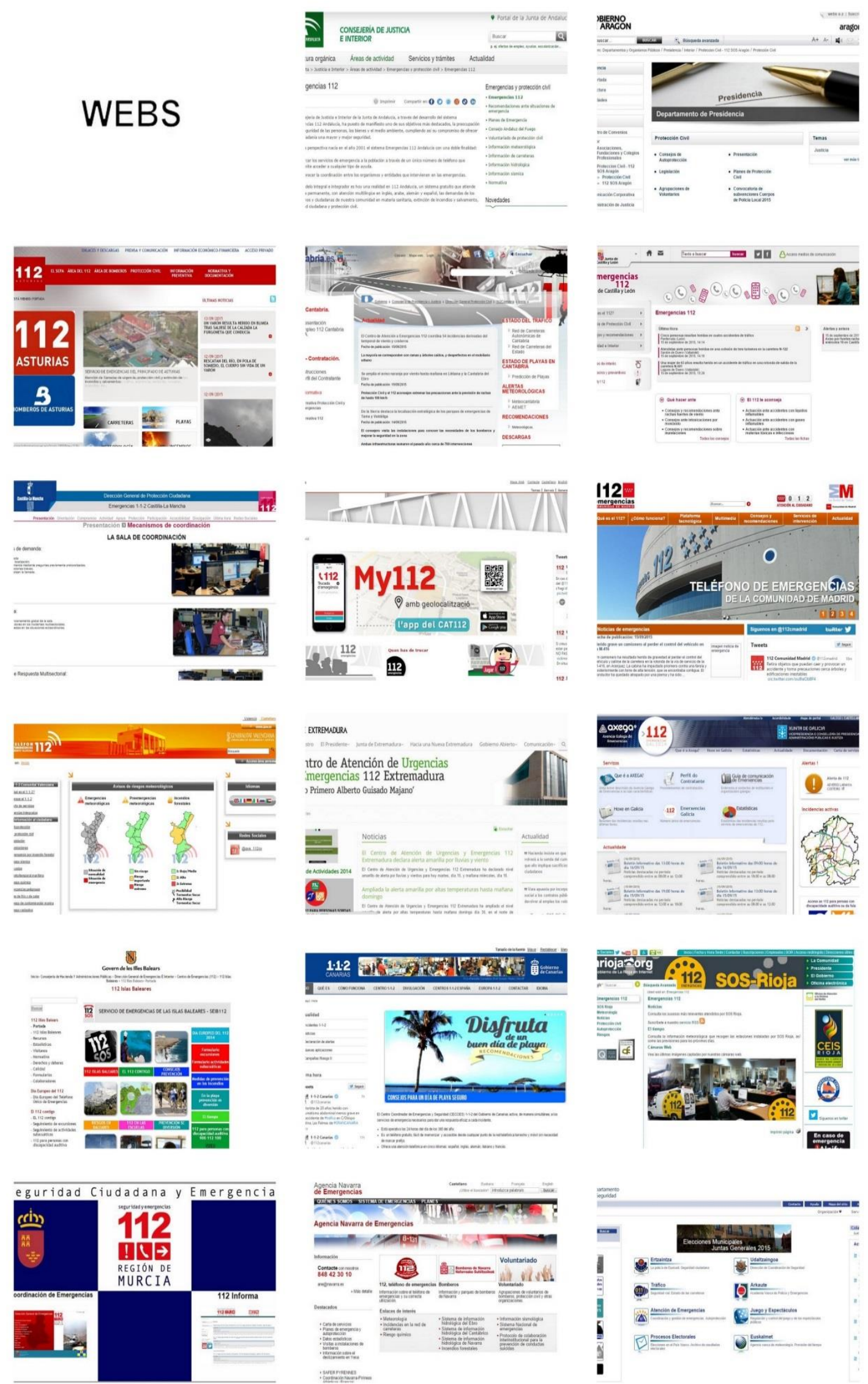


\subsubsection{RESULTADOS}

En el presente apartado pondremos de manifiesto los principales resultados a nivel cuantitativo, y trataremos de acompañarlo de algunas conclusiones de carácter cualitativo.

En algunas de las conclusiones, aportaremos ejemplos visuales extraídos de las webs que ayudarán a visualizar y clarificar de una manera más directa el aspecto al que hacen referencia. Estos ejemplos son una representación del total de archivos documentales, capturas de pantalla de webs, y mp4 descargados y almacenados para su análisis, y que arrojan una cifra global de 225 archivos almacenados. La captura y el almacenamiento de datos se ha realizado durante los meses de junio a agosto de 2015, por lo que se trata de una información y contenidos totalmente actualizados a la hora de finalizar esta investigación.

CONCLUSION 1. Presencia en la web de contenidos para la infancia o adolescencia

- Un 58,82 \% de webs de Comunidades Autónomas tienen contenidos de información preventiva y/o recomendaciones específicamente diseñados para el público infantil y juvenil, adaptados en aspectos como léxico, formato o recursos pedagógicos utilizados.

- Por tanto el $41,18 \%$ no tienen contenidos específicamente diseñados para el público infantil y juvenil.

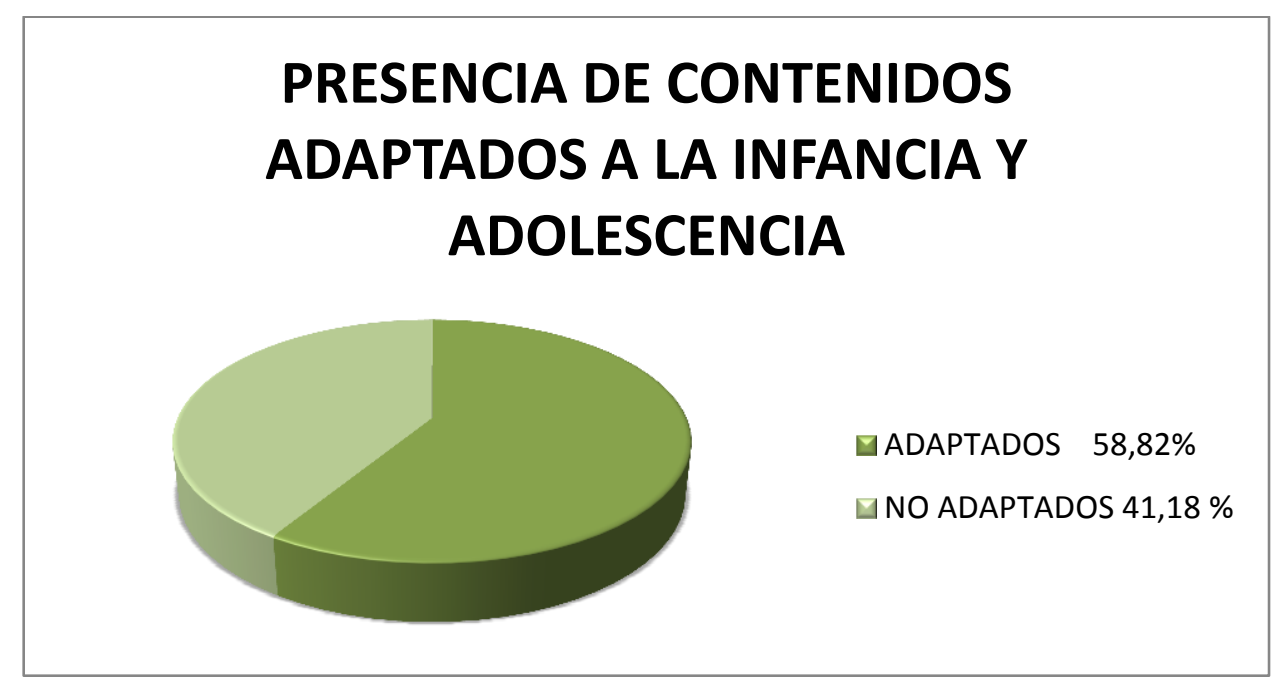


- Observemos ahora un tercer grupo de contenidos. Se trata de aquellos que sin ser específicamente adaptados y dirigidos a un público infantil o juvenil, sí versan sobre temáticas relacionadas con ellos, como consejos dirigidos a adultos para proteger a los niños de determinados peligros. El destinatario de estos contenidos es un público adulto, a quien se le informa o recomienda en referencia a aspectos relacionados con niños o adolescentes.

Este tipo de contenidos aparecen tanto en aquel grupo de webs que sí contaban con contenidos diseñados para niños (concretamente en un $80 \%$ de esas webs), como en el otro grupo en el que no había contenidos diseñados para niños (en este caso en un $20 \%$ ). Es un dato que consideramos remarcable dado que este tipo de recomendaciones también pueden llegar a trasladarse a los niños vía la comunicación padres-hijos, o profesor-alumnos, por lo que posteriormente también nos detendremos en su análisis.

- Del grupo de 41, $18 \%$ de webs que no tenía contenidos adaptados para niños, hay que remarcar que en un 5,88 \% tampoco ofrece contenido de prevención para adultos.

\section{CONCLUSIÓN 2. Tipos de contenidos para el público infantil}

Recordemos que el 58,82 \% de webs de Comunidades Autónomas tienen contenidos específicamente diseñados para un público infantil y adolescente. Respecto al tipo de contenidos que aparecen en esas webs, se clasificarían de este modo.

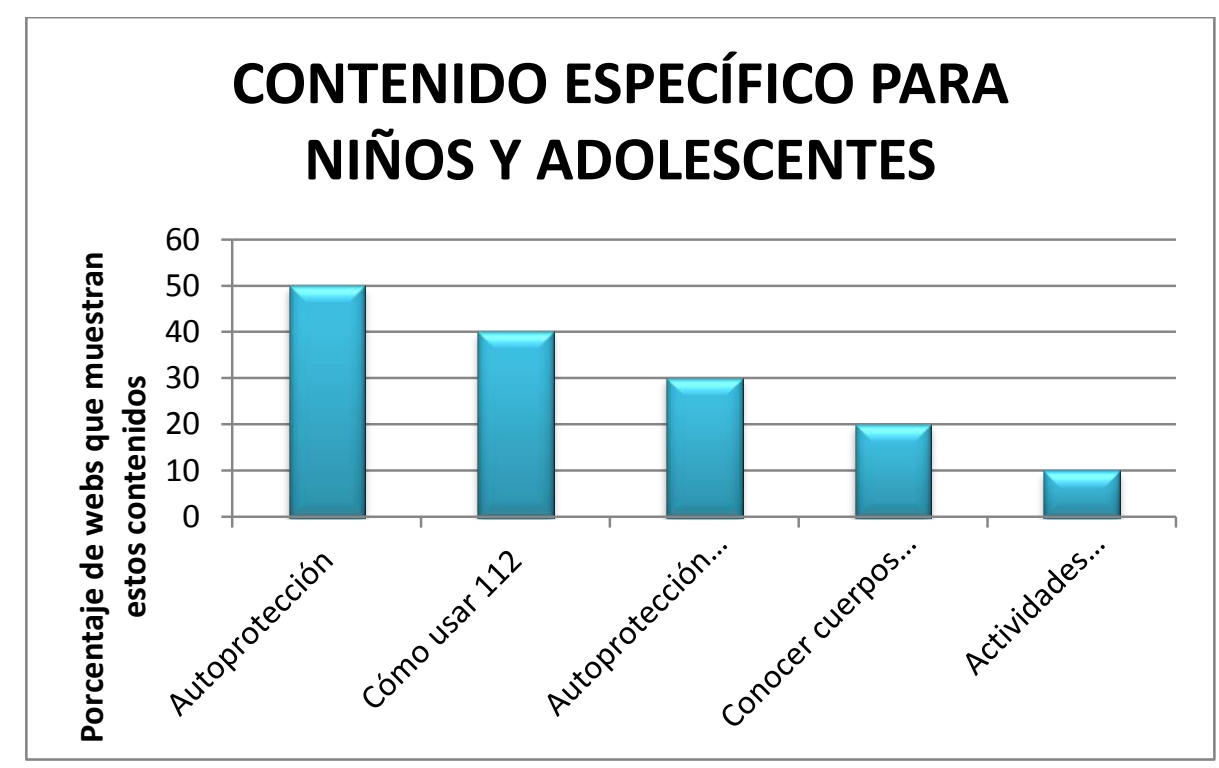

-En el $50 \%$ de las páginas web aparecen consejos y recomendaciones de autoprotección, sobre como actuar frente a distintos tipos de riesgos y emergencias. 
-En el 40\% aparecen indicaciones sobre como usar el 1-1-2.

-En el 30\% aparecen conceptos vinculados a autoprotección escolar, evacuaciones, unidades didácticas para un entorno escolar.

-En el 20\% aparecen conceptos vinculados a conocer los distintos tipos de cuerpos de emergencia y sus funciones. Con este porcentaje nos referimos únicamente a las webs en las que aparece específicamente una sección dedicada a dichos contenidos, ya que en otras webs la referencia a los cuerpos de emergencia y sus funciones aparece diseminada y se hace referencia a ella por relación con otros aspectos. Por tanto, sería una cifra a revisar y que previsiblemente aumentaría si se tuviesen en cuenta estas otras formas de aparecer ese contenido en la web.

-En el $10 \%$ de las páginas aparece información sobre actividades organizadas por los distintos servicios de 1-1-2 (charlas en los colegios, visitas escolares etc.).

\section{CONCLUSIÓN 3. Formatos para el público infantil}

Respecto a los formatos utilizados en las webs que tienen contenidos específicos para niños, hallamos los siguientes resultados:

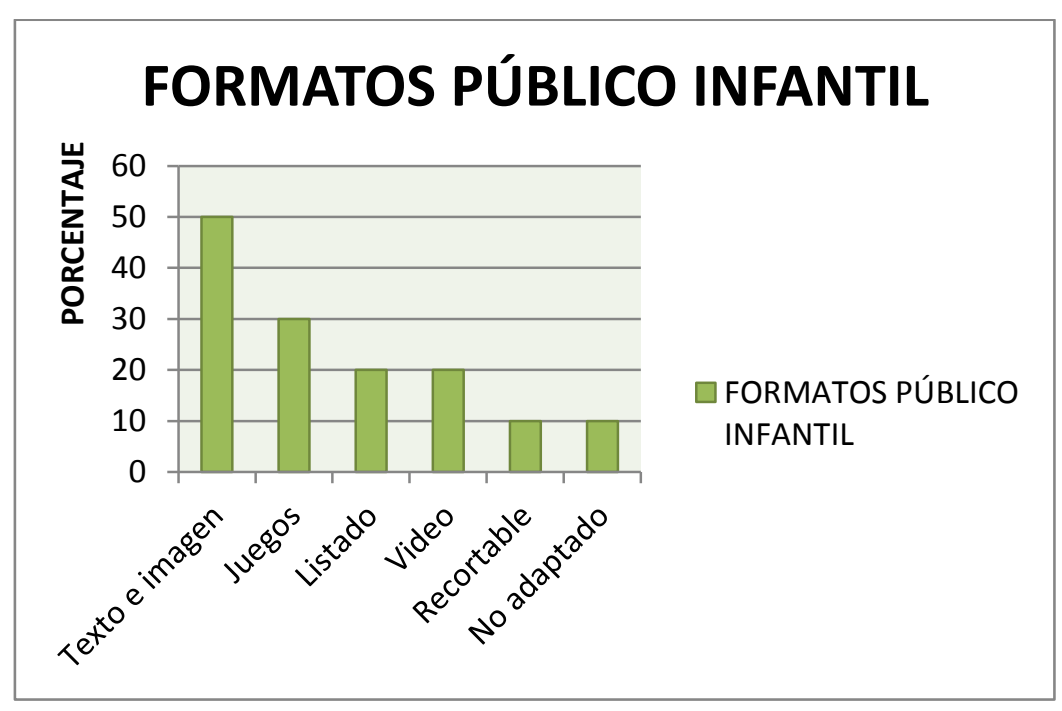

-En un $50 \%$ de webs se utiliza un formato que combina la utilización de un texto breve con el uso de imágenes fotográficas o ilustraciones, desglosándose ese porcentaje de la siguiente forma: 
${ }^{*}$ En un $20 \%$ cuadernos con dibujos y/o o fotografías y actividades

${ }^{*}$ En un $10 \%$ cuento con estructura narrativa

*En un $10 \%$ cómic

*En un $10 \%$ pósters, folletos y trípticos

-Por otra parte, en un $30 \%$ de las webs se utilizan juegos de distinta tipología tales como rompecabezas, juegos de memoria, asociación, puzzle etc.

-En un $20 \%$ listados de recomendaciones, instrucciones o prohibiciones.

-En un 20\% vídeos

-En un 10\% recortable

-En un $10 \%$ se usa el mismo formato y contenido que en la respectiva sección de adultos, pero mostrada a través de otro link. Realmente en este caso no se produce una adaptación de formatos y contenidos.

\section{CONCLUSIÓN 4. Contenidos para público general, centrados sobre aspectos relativos a la infancia o la adolescencia.}

Respecto al tipo de contenidos destinados a un público general, pero que gira en torno a aspectos relacionados con la protección y formación de la infancia en materia de riesgos y emergencias, podemos realizar el siguiente desglose:

-Las recomendaciones sobre cómo proteger o velar por la seguridad de los niños frente a determinados riesgos aparecen en el $60 \%$ de las webs

-Material sobre la protección de alumnos, destinado a profesores y centros escolares: se muestra en el $30 \%$ de las páginas.

-Charlas y actividades organizadas por el 1-1-2, aparecen en el 30\% de las webs

-Cómo usar el servicio telefónico del 1-1-2: en un 20\% 
-Recomendaciones para evitar que los niños provoquen situaciones de riesgo o emergencias (tales como utilizar cerillas): $20 \%$

-Seguridad vial: $10 \%$

Podemos apreciarlo en el siguiente gráfico:

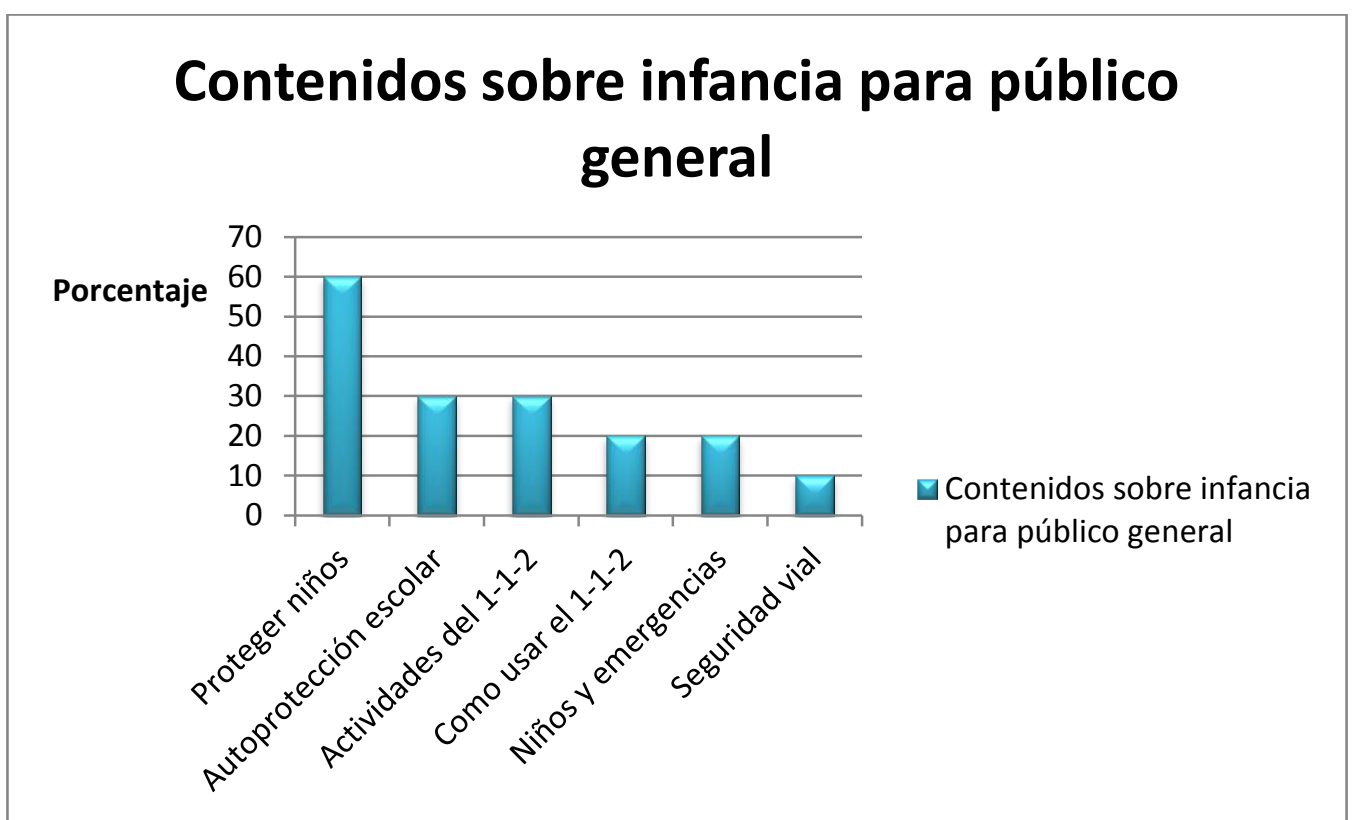

CONCLUSIÓN 5. Formatos para público general, centrados sobre aspectos relativos a la infancia o la adolescencia

-El listado se usa en el $50 \%$ de las webs, convirtiéndose en el recurso que más veces se utiliza. De hecho en el $30 \%$ de esas páginas es el único formato que se utiliza.

-Posters, folletos y trípticos: en el 30\%

-Noticias en formato informativo sobre charlas y actividades organizadas por el 1-1-2: $30 \%$

-Manuales: $20 \%$

-Los videos se usan en el $20 \%$ de las webs

-Cómics: 10\% 
-Otros: $10 \%$

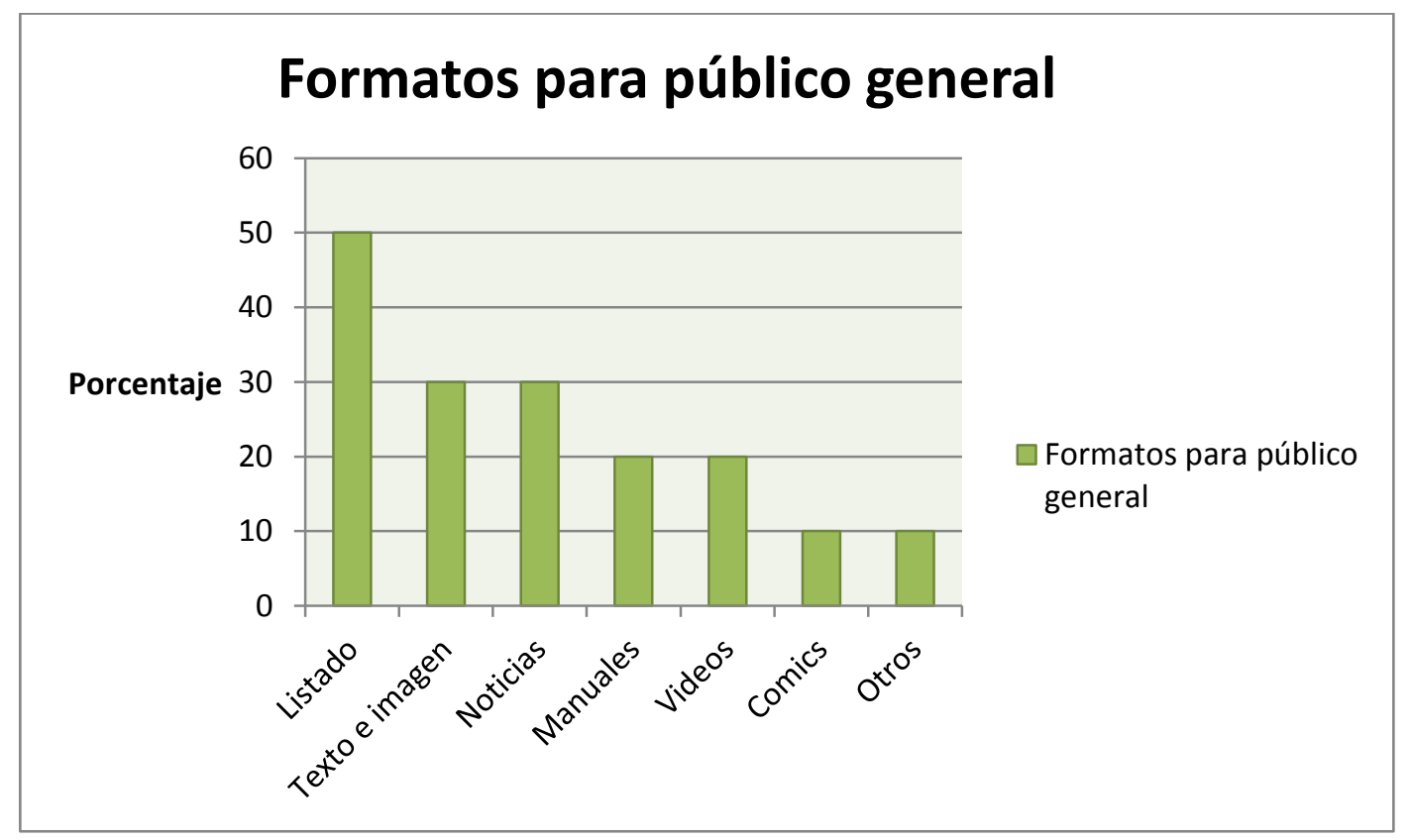

CONCLUSIÓN 6. Contenidos y formatos destinados a un público general que no versan sobre niños y adolescentes.

A diferencia de aquellos contenidos vinculados de una forma u otra a la infancia, en los contenidos dedicados a un público general, de las 17 webs analizadas:

Un 88,22 \% ofrece consejos y recomendaciones de autoprotección

Un $47 \%$ explica los distintos tipos de riesgos

Un 29,4 \% informa sobre alertas y avisos relacionadas con aspectos tales como preemergencias o situaciones meteorológicas.

Un 17,64\% explica cómo realizar simulacros.

Un 17,64 \% ofrece datos con un enfoque bastante experto, sobre informes estadísticos, planes de emergencia y planes de protección civil.

En un $11,76 \%$ hay links a otros organismos.

En un 5,88\%: legislación. 
En un $5,88 \%$ hay incidencias en curso

En un 5,88\% se informa sobre autorizaciones

Podemos observar las diferencias de presencia de unos y otros contenidos en el siguiente gráfico:

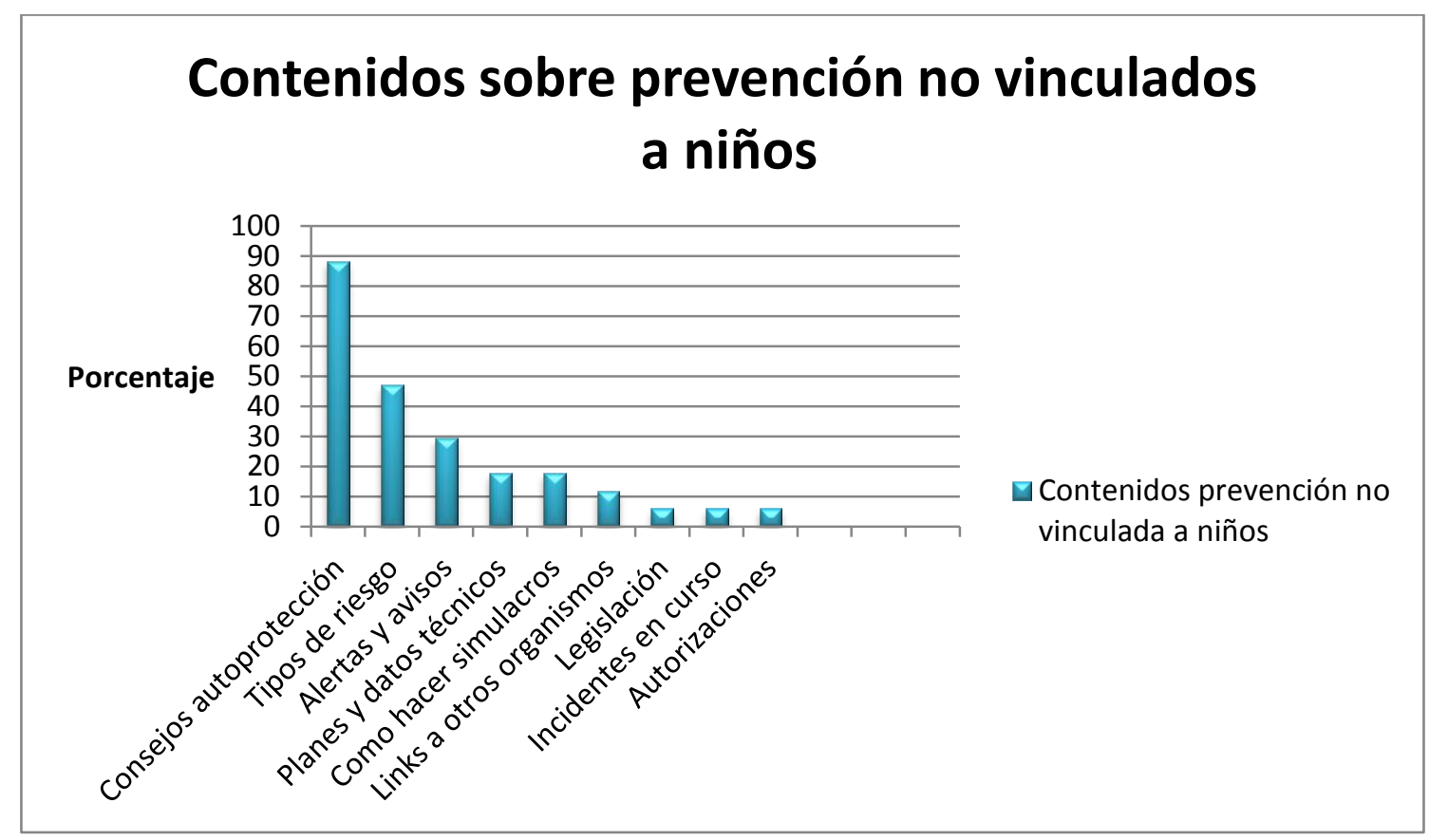

Y a diferencia de aquellos formatos relacionados con la infancia, en los formatos dedicados a un público general, sobre aspectos generales de autoprotección, de las 17 webs analizadas:

- Un $88,22 \%$ ofrece listados

-Un $41,17 \%$ ofrece folletos, trípticos, y pósters

-Un 17,64\% ofrece vídeos

-Un 11,76\% explicaciones un poco más extensas largas que los listados

-En un 5,88\% aparecen respectivamente:

*Manuales sin ilustraciones

${ }^{*}$ Cómic 
*Juego (quiz sobre qué recursos movilizar para una emergencia)

*Links a otras webs

*Noticias

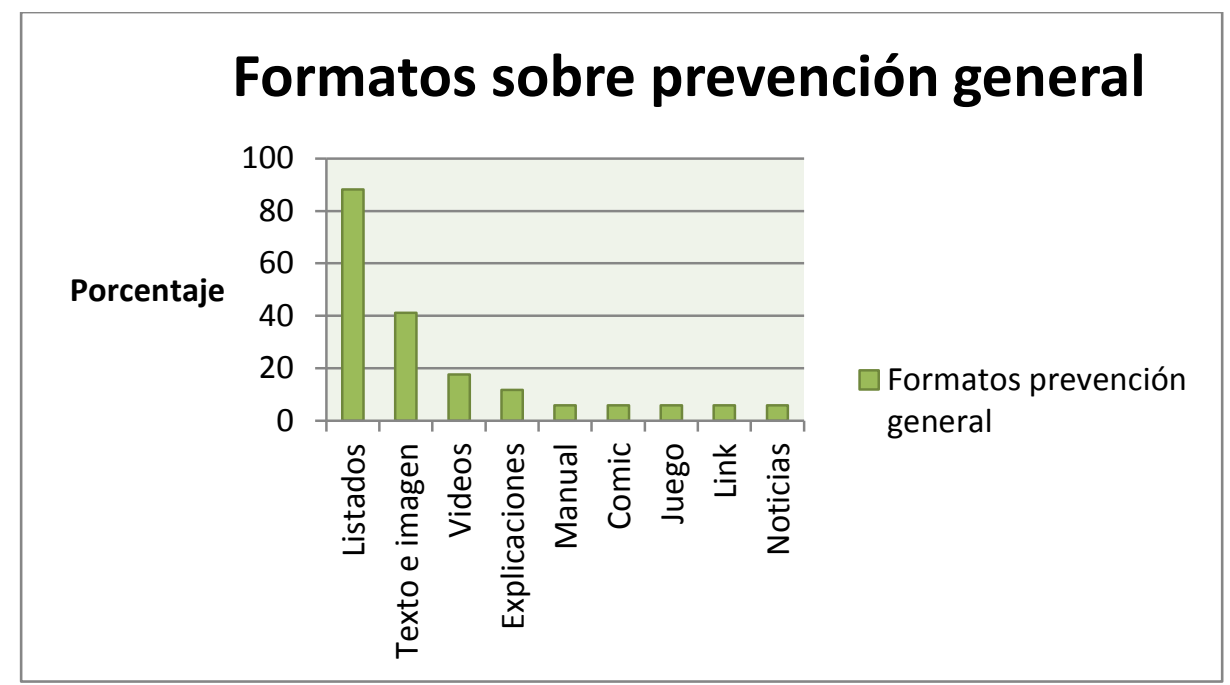

\subsubsection{ANÁLISIS DE LOS RESULTADOS OBTENIDOS}

\subsubsection{Comparativa de contenidos dirigidos a niños y a adultos}

Si comparamos los contenidos más difundidos en las secciones dedidas a un público infantil y adolescente frente a los contenidos para un público adulto (conclusiones 2 y 6), se observa que en ambos tipos de público el contenido más difundido tiene que ver con pautas de autoprotección, aunque varía el nivel de presencia en uno y otro tipo de webs.

Así, en el $88,22 \%$ de las secciones de adultos figuran contenidos de autoprotección, mientras que estos contenidos están presentes en el $50 \%$ de las secciones infantiles. Pese a la diferencia de presencia, unas y otras webs si coinciden en que se trate del contenido en el que más se incida.

A partir de ahí, aumentan las diferencias, ya que los segundos y terceros puestos de tipos de contenidos más utilizados para cada tipo de público son muy distintos. Así, en las secciones infantiles el segundo y tercer tipo de contenidos más utilizados son respectivamente cómo utilizar el teléfono 1-1-2, y recomendacioes sobre 
autoprotección en el entorno concreto de la escuela. Por su parte, en las webs de adultos el segundo y tercer tipo de contenidos con mayor presencia en las páginas son respectivamente explicaciones sobre los distintos tipos de riesgos, y sobre alertas y avisos (por ejemplo por situaciones relacionadas con la meteorologia).

Por otra parte, a partir de los datos obtenidos, se pueden comparar cuáles son aquellos formatos más utilizados, entre los de las secciones destinadas a la infancia y las secciones destinadas exclusivamente a un público general, para ver si son semejantes, distintos o mantienen algunas coincidencias.

Respecto a los dos formatos más utilizados para los niños observamos que:

-En un $50 \%$ de las webs se usaba la fórmula de la combinación de un texto breve con fotografías o ilustraciones. Recordemos que aquí se incluían cuadernos, cuentos, cómics, folletos, pósters y trípticos.

El segundo formato más utilizado, con un $30 \%$ de uso, son los juegos.

Por su parte en las webs de adultos:

-El formato más repetido es el listado, que aparece por amplia mayoría en un 88,22\% de las webs. Cabe recordar que, en oposición a esta cifra, en las páginas infantiles sólo se usaba en un $20 \%$ de los casos, lo cual marca una de las mayores diferencias entre uno y otro tipo de webs.

-El segundo formato más usado en las secciones de público general es, con un $41,17 \%$, aquel formado por texto breve combinado con fotografías o ilustraciones, en este caso a través de folletos, trípticos y pósters.

En este caso habría bastante similitud con la presencia de este tipo de formatos en las webs destinadas a niños, que se situaba en un 50\%. En posteriores apartados observaremos cómo, si bien el formato es el mismo, hay una serie de diferencias en el producto final destinado a cada uno de los dos públicos, por lo que analizaramos estos sus aspectos distintivos. 


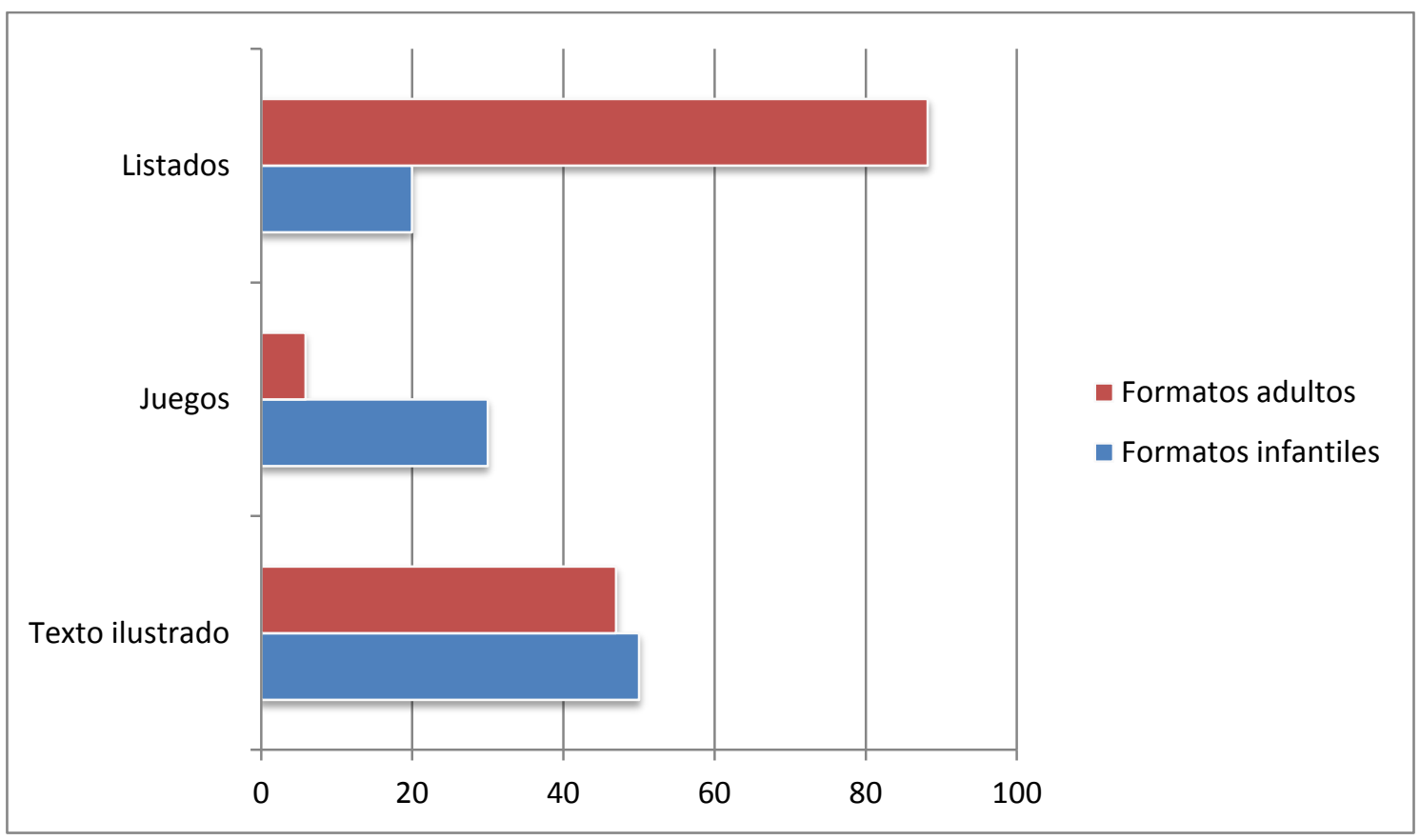

\subsubsection{Análisis de los formatos más utilizados para infancia y adolescencia}

\section{A) CUADERNO, CUENTO, CÓMIC, PÓSTERS, TRÍPTICOS}

Para ahondar en el formato más utilizado en el caso de los niños y adolescentes, hemos recopilado algunos ejemplos extraídos de las webs que nos ayuden a ver mejor sus características, realizando para ello un análisis de carácter cualitativo. Se trata de ejemplos que nos ayudarán a ilustrar estas conclusiones.

\section{Cómic}

"En Pau, l'Arnau i l'Anna en... Terra de foc!" Se trata de un cómic enmarcado dentro de la campaña "Revetlles en precaució" (la traducción aproximada para el término sería "Verbenas con precaución"), de la Dirección de Protección Civil del Gobierno de Cataluña. Está destinado a la prevención de situaciones de riesgo relacionadas con el uso de material pirotécnico en las fiestas populares. Tiene 28 páginas, y sus protagonistas son una pequeña pandilla de niños y adolescentes y sus familias. 


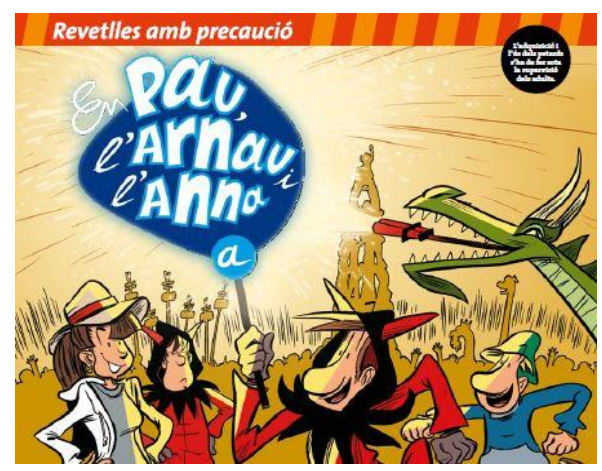

Al tratarse de un cómic con finalidad educativa, contiene una presentación donde la institución pública, en este caso la Dirección de Protección Civil, expone los objetivos del cómic que vamos a leer:

"Este cómic nos acerca a los consejos de prevención y nos informa sobre la manipulación correcta de los petardos". También se aprovecha esta introducción para reiterar un mensaje muy difundido a lo largo de todas las webs analizadas, la recomendación de llamar siempre al 1-1-2. Además la institución declara su deseo de que "Esperemos que ayude a pasar una fiesta más segura y divertida, pero con prudencia y respeto".

Aquí se recogen algunos de los elementos que consideramos fundamentales en la comunicación preventiva dirigida a edades tempranas:

-La manifestación expresa de que se tratan de consejos de prevención, la verbalización de que el contenido que vamos a conocer tiene carácter de recomendación.

-El recuerdo constante de la conveniencia de llamar al 1-1-2

-La combinación de seguridad y diversión, que pasa no por la prohibición sino por el uso de la prudencia para desarrollar nuestras actividades

Al tratarse de un cómic, la historia se narra mediante una sucesión de ilustraciones acompañadas por textos y que están enmarcadas en viñetas. El lenguaje del cómic es coloquial, y en el ejemplo que nos ocupa, al estar destinado a adolescentes se utiliza un lenguaje y situaciones propias de de su edad, como el uso de los chats de móvil. También menciona temas de su entorno social propio: el uso de las nuevas tecnologías, los noviazgos, la amistad, la hora de la merienda... El objetivo es transmitir al destinatario cercanía e identificación. 


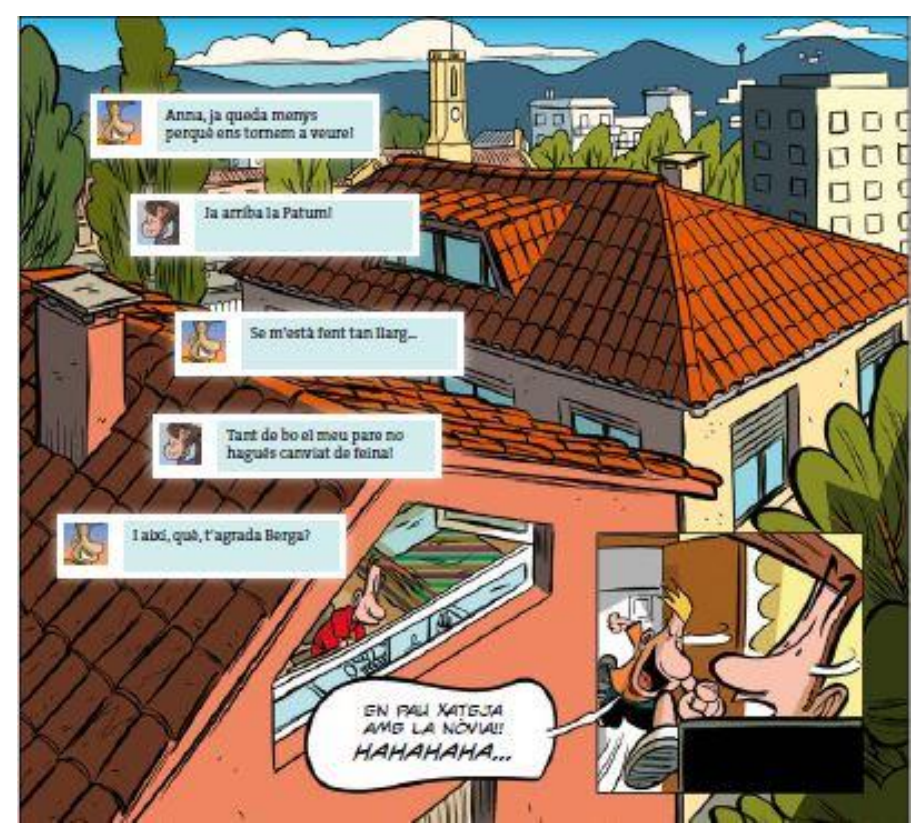

Por otra parte, en los cómics tradicionalmente predomina la acción. Sin embargo, en "Revetlles amb precaució", aunque resulta dinámico, la acción no predomina tanto sino que se intercala con muchas escenas dedicadas a que los personajes dialoguen sobre aquellos conceptos que intuimos que la institución quiere transmitir, algo que le diferenciaría del cómic tradicional. Pensamos que esto viene motivado por el hecho de que se trata de un cómic con finalidad educativa. También le diferencia del cómic tradicional que las mayores peripecias o el conflicto vivido por el protagonista aparecen hacia el final de la historia, y son bastante accesorias, teniendo menos peso que todo lo visto hasta ese momento.

Respecto a la forma en la que los personajes charlan sobre temas de prevención en el texto, en algunos casos son los propios personajes adolescentes los que se los ofrecen a otros adolescentes, o a niños más pequeños. Se trata de un ejemplo de la educación entre iguales, en la que son los propios miembros del grupo, más formados, los que ofrecen esa formación a los demás. No hay apelación a la autoridad de un adulto. Por ejemplo, en una de las páginas un personaje adolescente le enseña a otro más pequeño como tirar petardos, indicándole lo que no puede hacer, con un claro "No...", y reforzando positivamente lo que sí puede hacer y hace bien con un claro "Muy bien!". En otra página, los adolescentes leen un folleto sobre "Consejos de seguridad". No es una figura de autoridad adulta la que se lo enseña, sino que en un entorno natural y habitual, una charla en un parque, abordan el tema. 

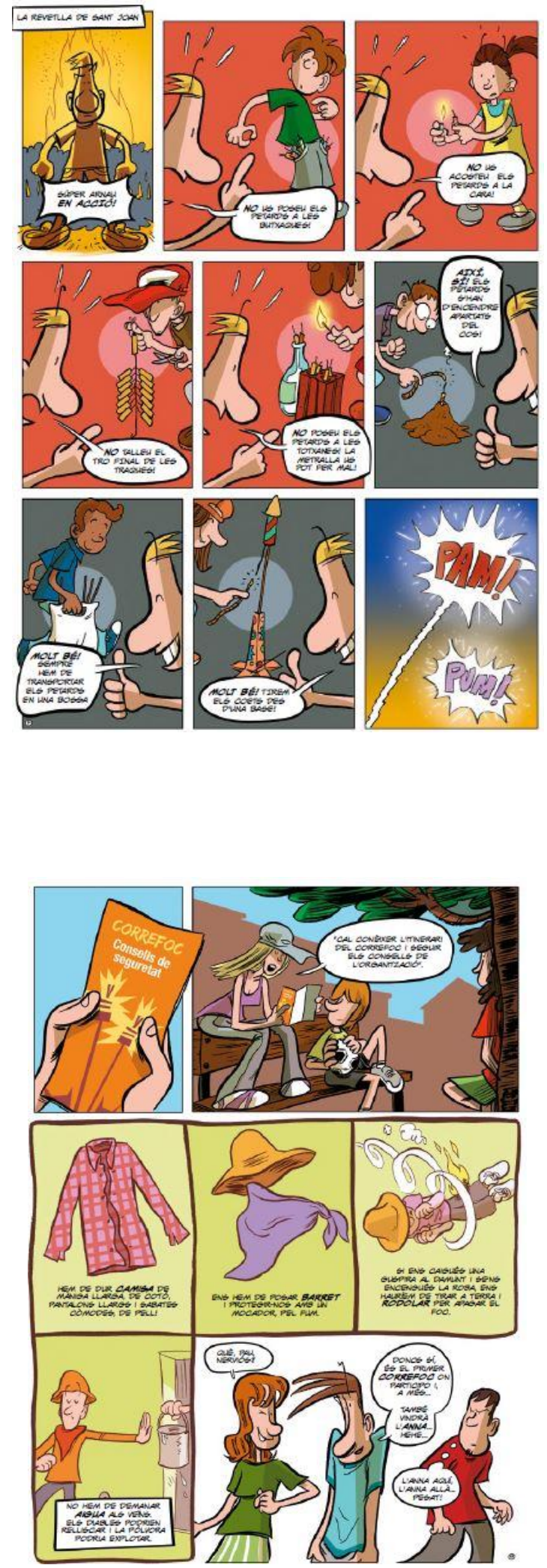

¿Qué representación se hace del riesgo? No es algo a lo que temer, sino al que manejarlo previamente y evitar su materialización, gracias a nuestras decisiones y comportamientos. 


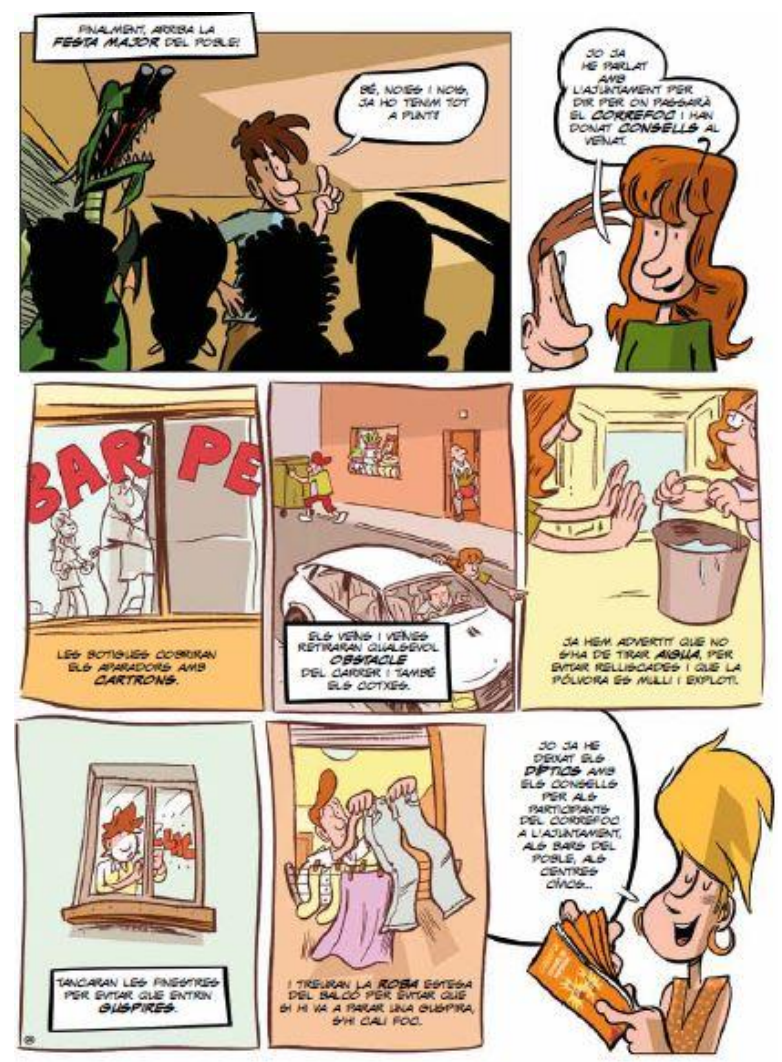

\section{CUADERNO}

El uso de cuadernos en las webs de gestión de emergencias y protección civil tiene la finalidad de ofrecer consejos de prevención e información a través de textos breves e ilustraciones agrupados en un único documento, cuya parte final puede incluir actividades a rellenar por el lector y relacionadas con los conceptos y consejos expuestos.

Está en cierto modo emparentado con el póster, ya que no hay una estructura narrativa que narre una historia de principio a final a lo largo del cuaderno, sino que cada página contiene en sí misma toda la información y elementos gráficos y textuales necesarios como para ser comprendida de principio a fin sin necesidad de conocer las páginas anteriores y posteriores.

Sería ejemplo de cuaderno la obra "Pequeños consejos de autoprotección para los más pequeños", editado por el Gobierno de Aragón. Cada página está planteada como un póster o folleto: en cada página una ilustración muestra un personaje diferente adoptando una pauta segura de actuación frente a un hipotético riesgo. 
El dibujo es caricaturesco y representa a distintos niños y niñas. Por otra parte, un texto breve acompaña el dibujo, con las ideas clave que se quieren reflejar.

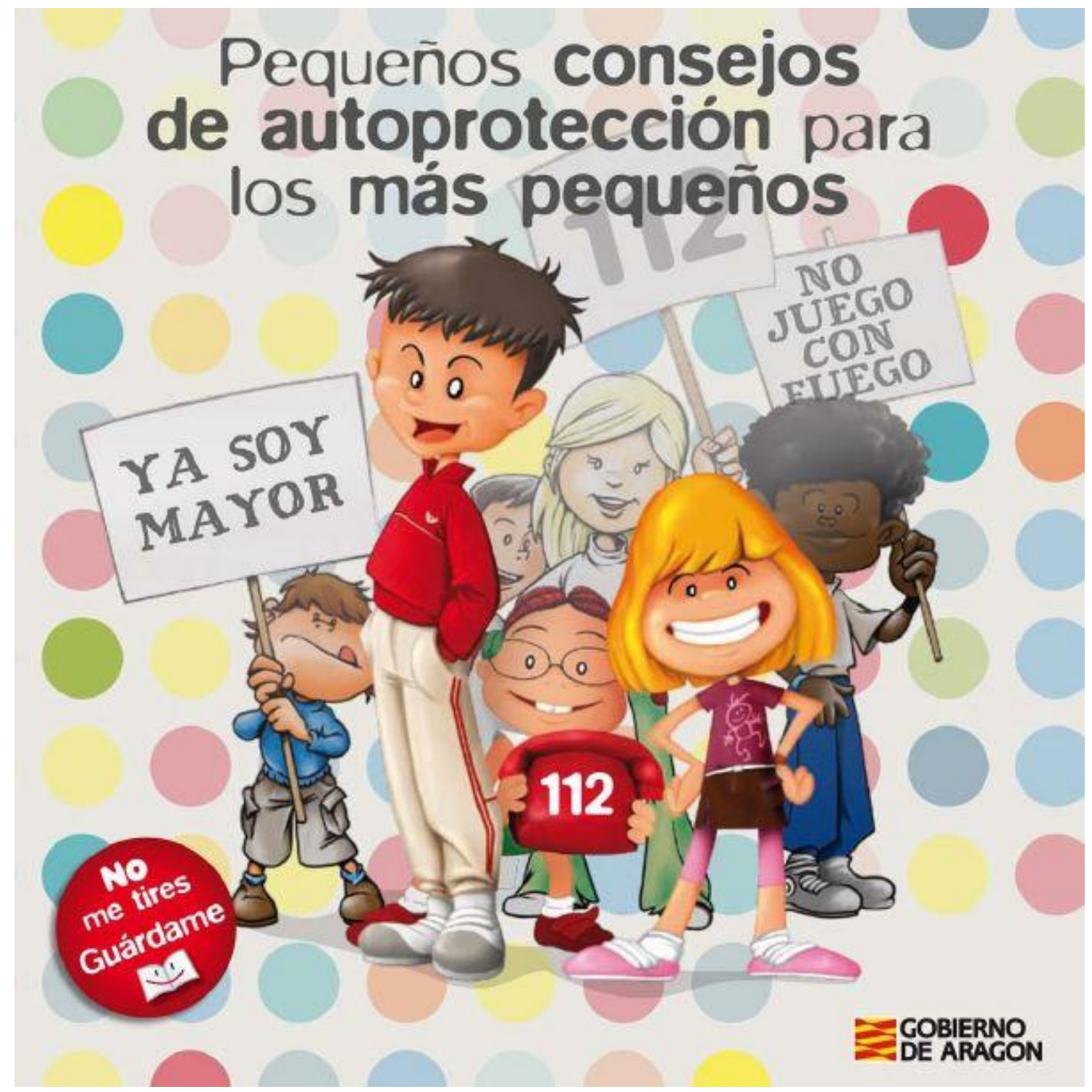

A continuación mostramos algunos ejemplos que ponen de manifiesto las principales características de estos materiales, y en las que se observan algunas de las cuestiones que hemos estado abordando en apartados anteriores respecto a los tipos de contenidos.

Así, se representa la imagen del niño como una persona con capacidad para cumplir él mismo con unas pautas de autoprotección. 


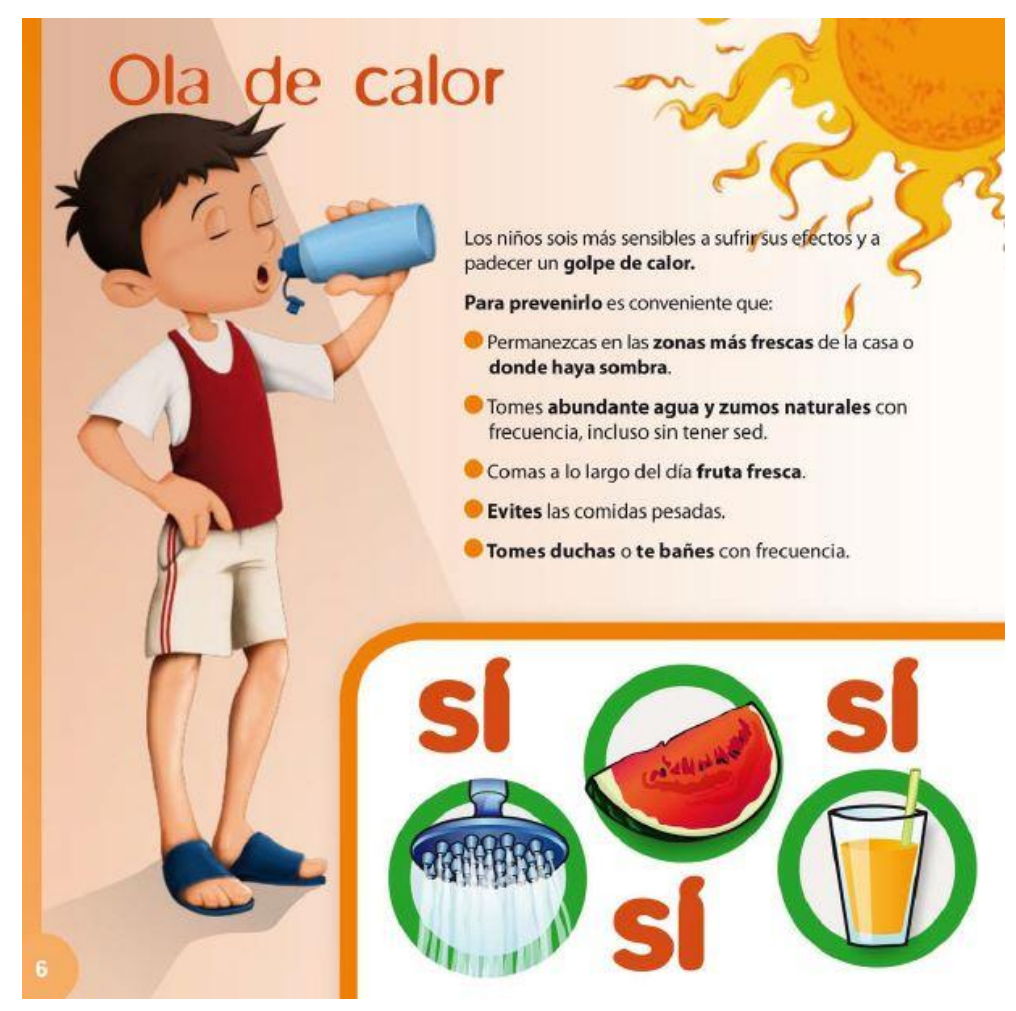

Por otra parte, se recuerda la necesidad de llamar al 1-1-2. Incluso hay una página específica donde figuran todas las pautas para solicitar esta ayuda telefónica, y como viene siendo habitual en todas las webs, se recalca que no se puede llamar para jugar.

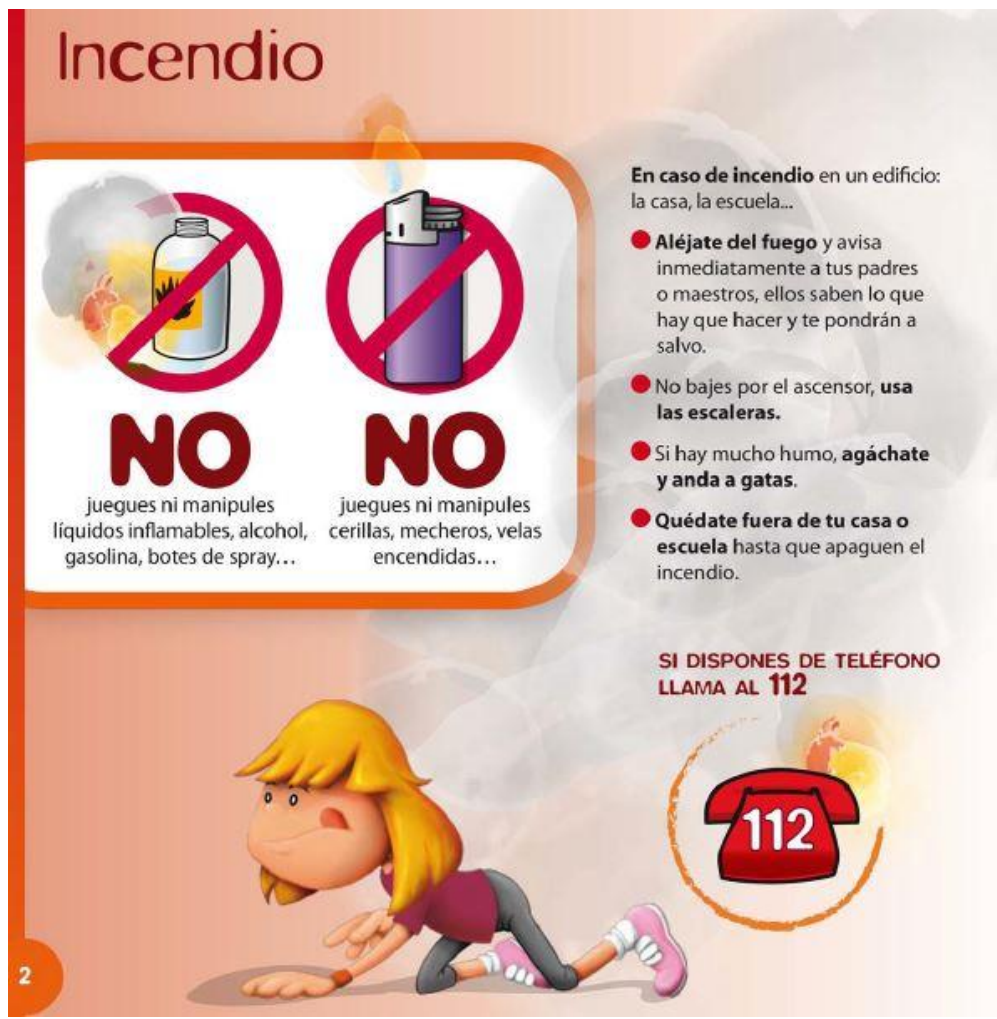


Respecto a representación de la relación entre el niño y los adultos, estos se muestran como alguien en quien el niño puede confiar en una situación de emergencia. Al mismo tiempo, observamos que el niño también aparece como transmisor de información para los adultos, forma parte de la cadena de la autoprotección y prevención convirtiéndose en un eslabón muy importante.

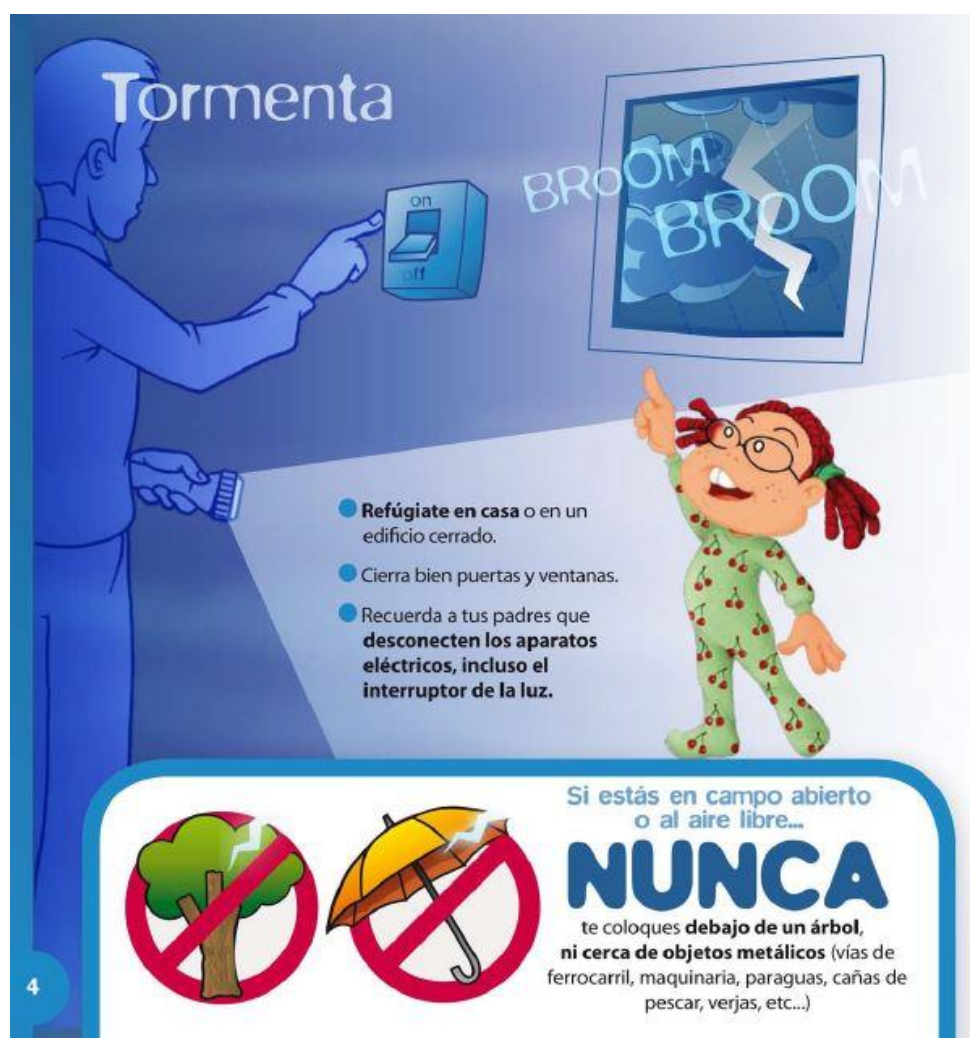

\section{EL CUENTO}

El ejemplo a analizar procede de la web de Castilla y León, y está dirigido a niños de entre 6 y 8 años.

Mantienen elementos de los cuentos pero otros han desaparecido. Por ejemplo, respecto a esta segunda observación, el material no lleva un título que haga referencia al personaje o sus peripecias, sino que se titula "Prevención de incendios", que vendría a ser más bien el consejo preventivo que se quiere ofrecer. 
Por otra parte, la historia no concluye con el final, sino que tras éste se ofrecen una serie de páginas con actividades para realizar por parte del lector, un recurso que se utiliza como refuerzo a todo lo aprendido (sopa de letras, colorear, etc.).

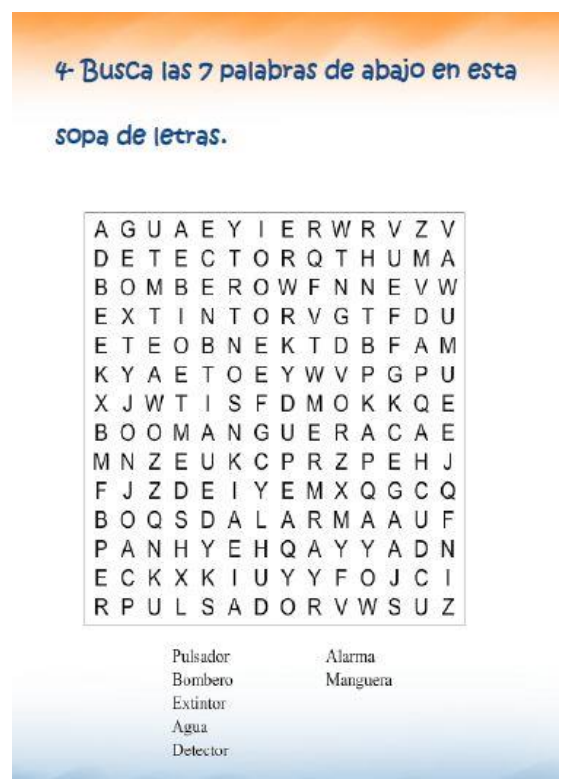

Sin embargo, sí se mantienen otros elementos heredados de los cuentos. Muestra de ello es que hay un narrador, en este caso un extintor llamado "Maxi", que indica que va a contarnos una historia que le sucedió. Se trata además de una referencia a la magia o lo fantástico propios de los cuentos, ya que se trata de la la introducción de un personaje, un extintor, que en la vida real sería inanimado pero que se presenta comoanimado en la narración.

iHola! Soy Maxi el extintor, os voy a

contar una historia que me pasó.

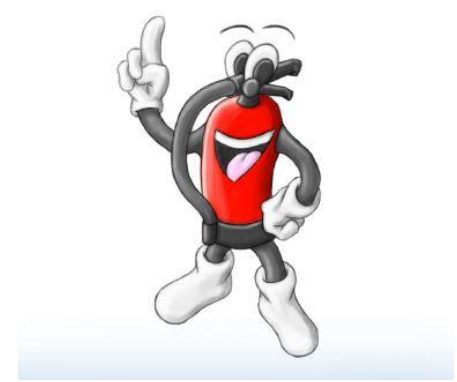


Hay una estructura narrativa y una secuencia de acontecimientos que mantienen coherencia entre sí. En un primer momento hay una situación de orden y equilibrio (una fiesta de cumpleaños) que se rompe cuando los niños se olvidan una vela encendida cerca de una piñata, iniciándose un incendio (representacion del conflicto). Se establecen relaciones de causalidad.

Laura, una de sus amigas, cogió la vela para jugar cerca de la piñata.

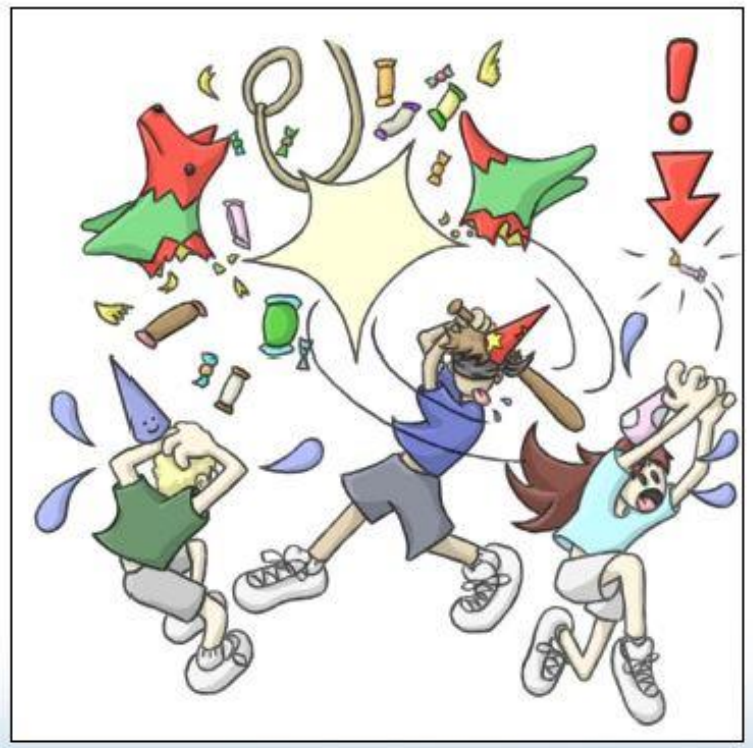

Los mandó salir de la casa a gatas y pegados a la pared, para no respirar el numo.

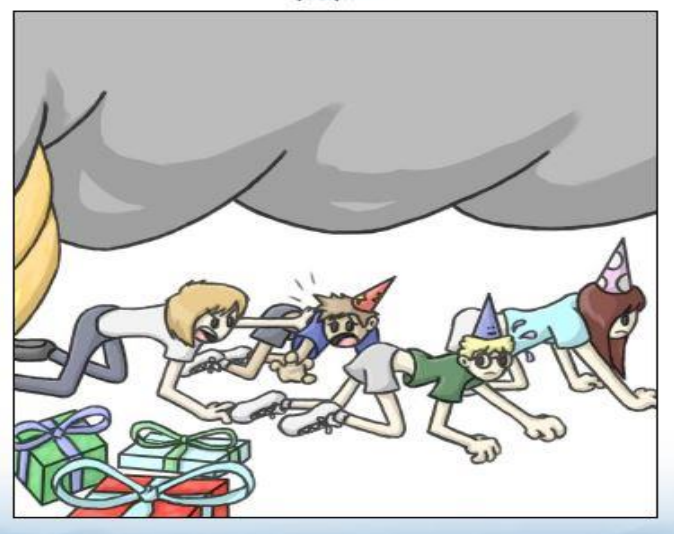


Son los adultos los que restablecen de nuevo el equilibrio: la madre con las primeras reacciones de autoprotección (de nuevo se incide en la idea de que se puede confiar en los adultos) y los bomberos con su actuación a a su llegada.

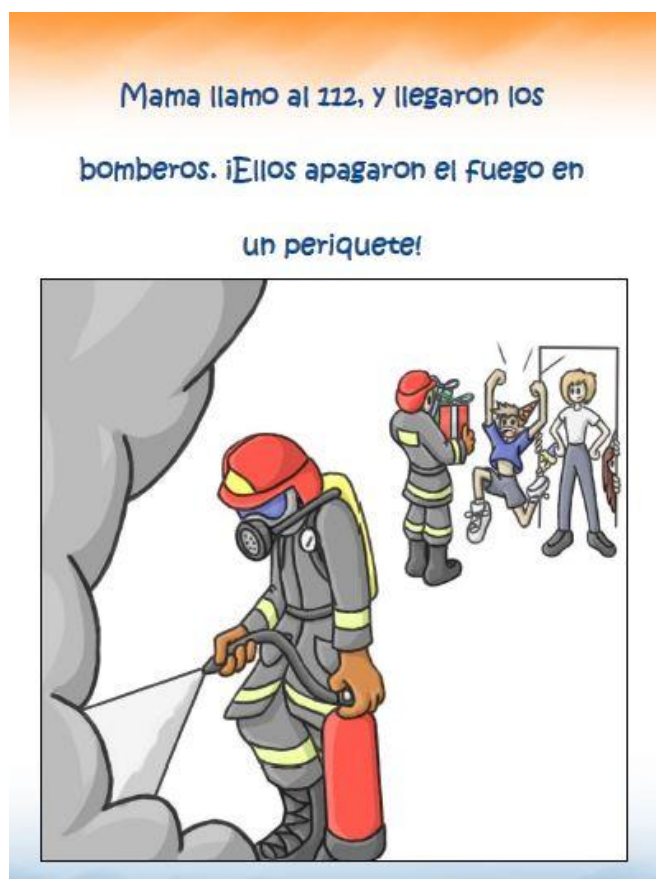

En general, consideramos que los cuentos pueden ser unos buenos transmisores de mensajes y enseñanzas sobre la vida cotidiana.

\section{PÓSTERS Y TRÍPTICOS}

A lo largo de las webs analizadas hemos hallado distintos ejemplos de pósters, folletos y trípticos, digitalizados y puestos a disposición de los internautas para descargar. Una de las ventajas de esta digitalización es que más allá del propósito inicial con el que fueron creados algunos de estos materiales por las instituciones correspondientes (colgar en paredes, repartir en lugares de pública concurrencia, etc.), ofrecen al destinatario la posibilidad de imprimirlo en el tamaño que le resulte más útil, sea para pegarlo en una ventana o pared de casa o el colegio, repartirlo en un aula como un folio A-4, o proyectarlo en clase para verlo en pantalla. Por ello, resulta un recurso educativo muy útil para este tipo de enseñanzas.

Respecto a los contenidos, se trata de pósters que podríamos denominar educacionales, que alertan al ciudadano, en este caso al público infantil y juvenil, 
sobre los riesgos o peligros a los que se puede enfrentar y sobre cómo adoptar conductas seguras para prevenirlos.

Contienen las características de los pósters, en este caso de los pósters educacionales. Según el Canada's National Art Centre, este tipo de pósters:

-Tratan de reclamar rápidamente nuestra atención

-La información está presentada de forma clara y completa

- Tratan de convencer al receptor de tomar precauciones. En este caso se apela a los niños y jóvenes a participar en su propio proceso de autoprotección. En este sentido, tanto el texto como el material gráfico nos lanzan un mensaje que está diseñado para para que actuemos en forma concordante a lo se nos sugiere.

Por ello, este recurso nos parece un medio adecuado para propiciar el establecimiento de determinados hábitos de seguridad y también determinadas actitudes preventivas.

Respecto a la imagen, tiene preponderancia sobre el texto. El mensaje se expresa gráficamente de forma clara y se apoya en un breve texto que complementa o da énfasis a la idea que se nos sugería.

A continuación analizaremos las ideas reflejadas en estos pósters, así como elementos físicos, tales como imagen, texto, color, composición, tamaño y formato.

\section{La mascota Panchito}

El primer ejemplo procede de la web de Extremadura y concretamente de una campaña protagonizada por una mascota, un perro, llamado Panchito (del mismo personaje existen también vídeos, como se expondrá en el apartado dedicado a este tipo de recursos audiovisuales). El emisor de las recomendaciones no es directamente el organismo de protección civil, en este caso el Centro de atención de urgencias y emergencias 112 Extremadura, sino su, vamos a llamarlo así, trasunto: un perro llamado Panchito.

Para poder identificar su adscripción a la Protección Civil, Panchito va ataviado con indumentaria propia este cuerpo: una gorra naranja y un distintivo, que en este caso pasa a estar presente en un colgante al cuello que así lo identifica. Hay una identificación directa y clara entre la mascota y el organismo al que representa. 


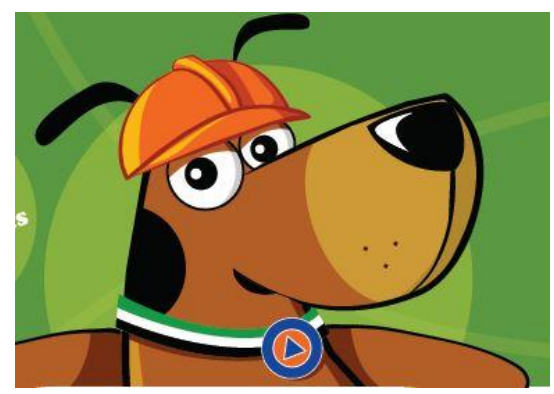

Se utilizan en los pósters y folletos de Panchito imágenes naturales, esto es, se representan personas, animales y cosas. El tipo de imagen es ilustración aunque en menor ocasión se utiliza también alguna fotografía. Panchito es siempre el protagonista de las distintas escenas.

El tipo de dibujo es bastante estilizado, y los colores usados, planos y con pocos matices. Son colores muy llamativos, que ayudarán a la memoria visual a recordar posteriormente. Los textos son cortos, directos y claros.




Además de un vistoso color y la claridad en los mensajes, se utilizan también otros recursos que contribuyen a captar la atención e interés de los destinatarios.

Así, se usan recursos propios de los cuentos: un personaje animal adquiere características humanas, tales como la indumentaria o la capacidad de hablar o reflexionar. Es un elemento mágico de la tradición de los cuentos que en este caso se ha incorporado a un póster.

Además, se ha elegido como protagonista a un perro. En la cultura popular y literaria el perro tradicionalmente se ha identificado con valores tales como fidelidad, amistad o inteligencia, valores que en este caso son adecuados para mostrarle como un aliado en el caso de las emergencias.

Otro de los recursos utilizados es el humor. El ambiente y las situaciones en las que se ve envuelto Panchito tienen un cierto carácter caricaturesco y paródico, algo que podríamos interpretar en este análisis como un elemento para llamar la atención del destinatario, así como para no fomentar actitudes negativas o temerosas con respecto a las situaciones de riesgo.
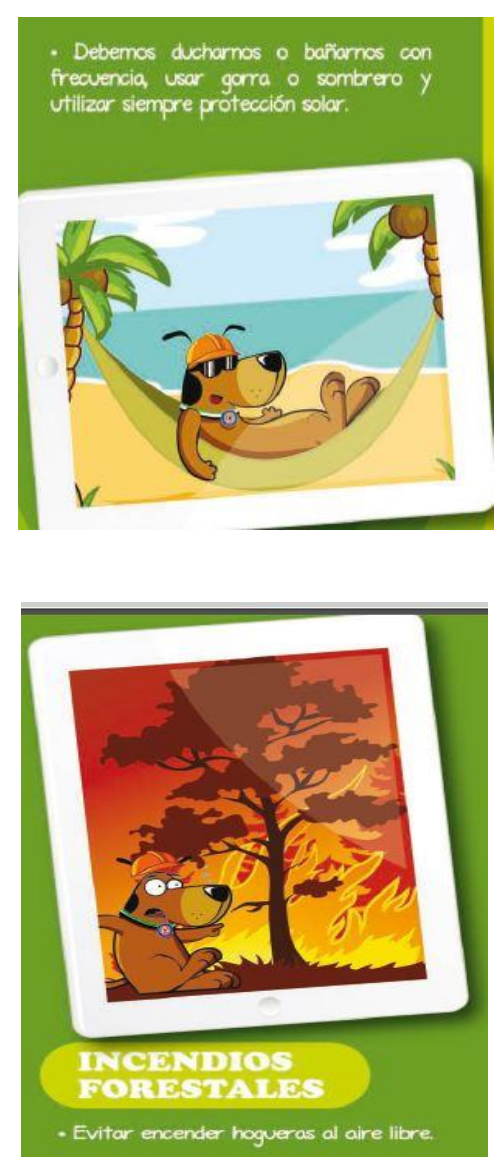
Otro de los elementos que contribuyen a conseguir la atención del destinatario es el color. Panchito siempre aparece con los mismos colores: el marrón para la piel y el naranja asociado a la protección civil para sus accesorios. De esta forma, el color se convierte en un elemento de reconocimiento para los distintos pósters protagonizados por un mismo personaje. Son colores llamativos y cada escena está enmarcada con rebordes para destacar más. El marco utilizado remite a algún tipo de soporte digital, como una tablet, esto es, un elemento que lo hace contemporáneo, reconocible y atractivo para el niño.

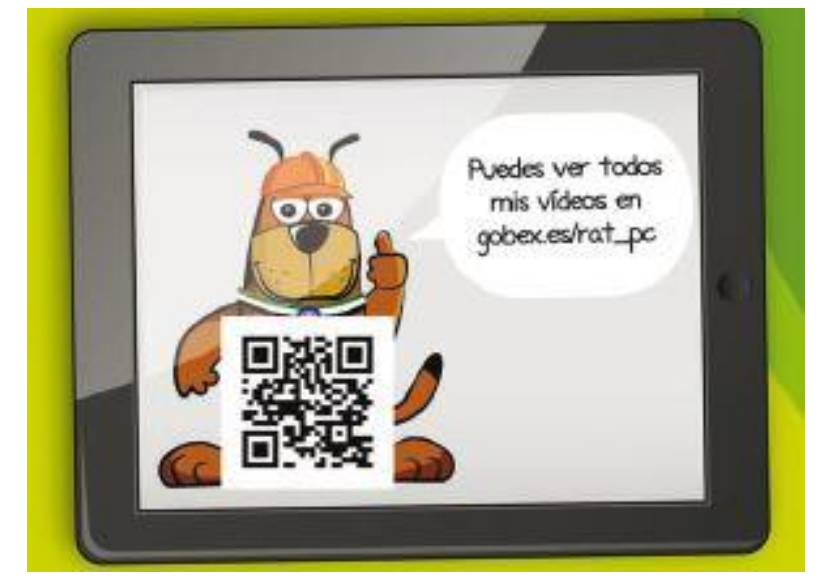

Respecto al lenguaje, se observa que los textos son relativamente cortos y con un lenguaje comprensible para niños de diferentes edades, por ejemplo:

"Para evitar que nos de un golpe de calor debemos estar siempre en las zonas frescas de la casa o en zonas de sombra"

¿Qué representación se hace de las situaciones de riesgo y de cómo solucionarlas? Los contenidos coinciden con los del cuaderno de autoprotección analizado anteriormente. En esta representación del niño, en este caso como destinatario de la información, se muestra un niño con distintas capacidades: es capaz de vigilar por su autprotección, de llamar al 1-1-2 e incluso de recordar a los adultos determinadas pautas de actuación. También se muestra, de nuevo, una figura de adulto en quien se puede confiar.

Se remarca que hay cosas que puede llevar a cabo un niño, vigilando por su propia autoprotección: "Entra despacio en el agua, para que no te duela la tripa". 
Además, los niños pueden llamar al 112: "Si ves un fuego avisa a los mayores y al $112 "$.

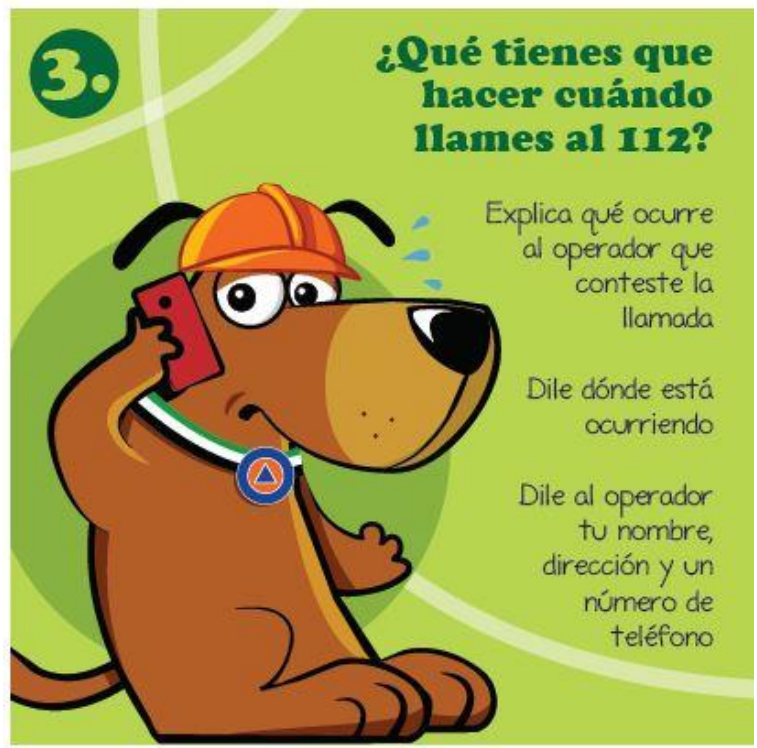

Por su parte, los adultos son personas en quienes se puede confiar, y con quien se puede contar en situaciones de emergencia: "Si notamos que nos estamos mareando,eso puede significar que tenemos un golpe de calor. Lo primero que debemos hacer es avisar a nuestros padres. Ellos sabrán qué hacer".

Otra de las facetas de los niños remarcadas a través de estos materiales es que los niños pueden "supervisar" su propia seguridad y la de los demás y recordarles a los adultos lo que deben hacer: "Báñate siempre con chaleco o manguitos y recuerda a tus papás o a un adulto que te los ponga antes de entrar en el agua"

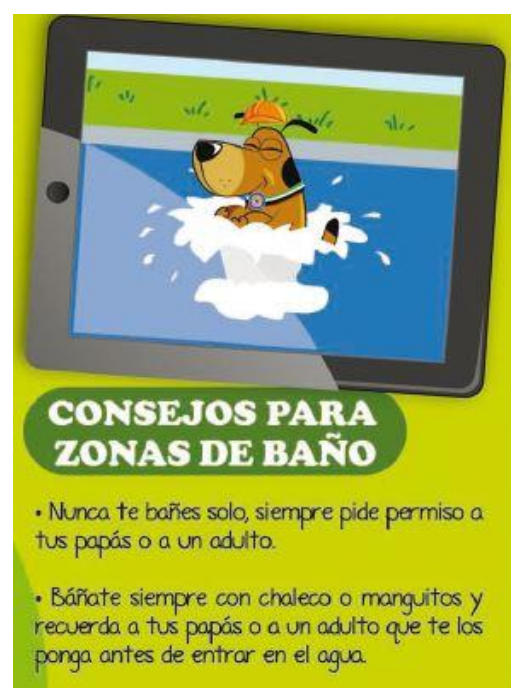


"Recuerda a papá y a mamá: Que ante cualquier urgencia hay que llamar al 112; (...) que si vamos a hacer un viaje para ver a los abuelos o a los tíos, hay que revisar el coche, llenar el depósito de gasolina y llevar agua que nos ayude a evitar la deshidratación".

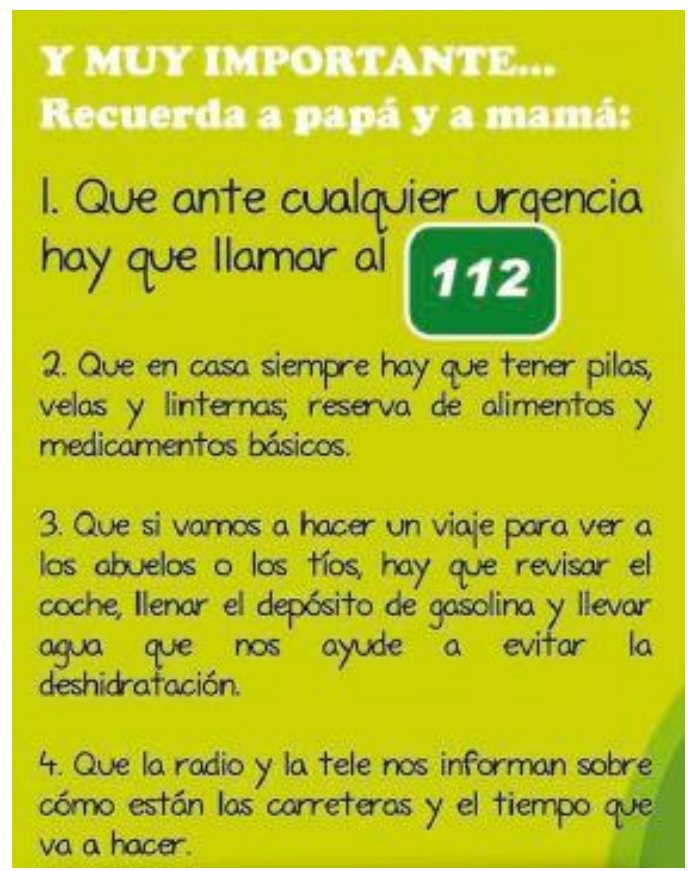

A través de esta colección de pósters se representa un niño que puede controlar ciertos aspectos de su propia autoprotección, con capacidad para cuidar de sí mismo, y al mismo tiempo que puede y debe contar con los adultos, tanto a la hora de seguir sus indicaciones como para indicarles a su vez cuáles son las cosas que deben hacer. En este caso es un niño que podríamos denominar "transmisor" de información y conocimiento a sus generaciones anteriores.

Con características similares a los pósters hallamos los trípticos. En este caso la información se ofrece en un formato manejable manualmente, y en el que cada parte es un consejo importante en sí mismo. En ocasiones, el mismo material aparece o bien en varios pósters diferentes, o bien todo reunido en un único tríptico. 


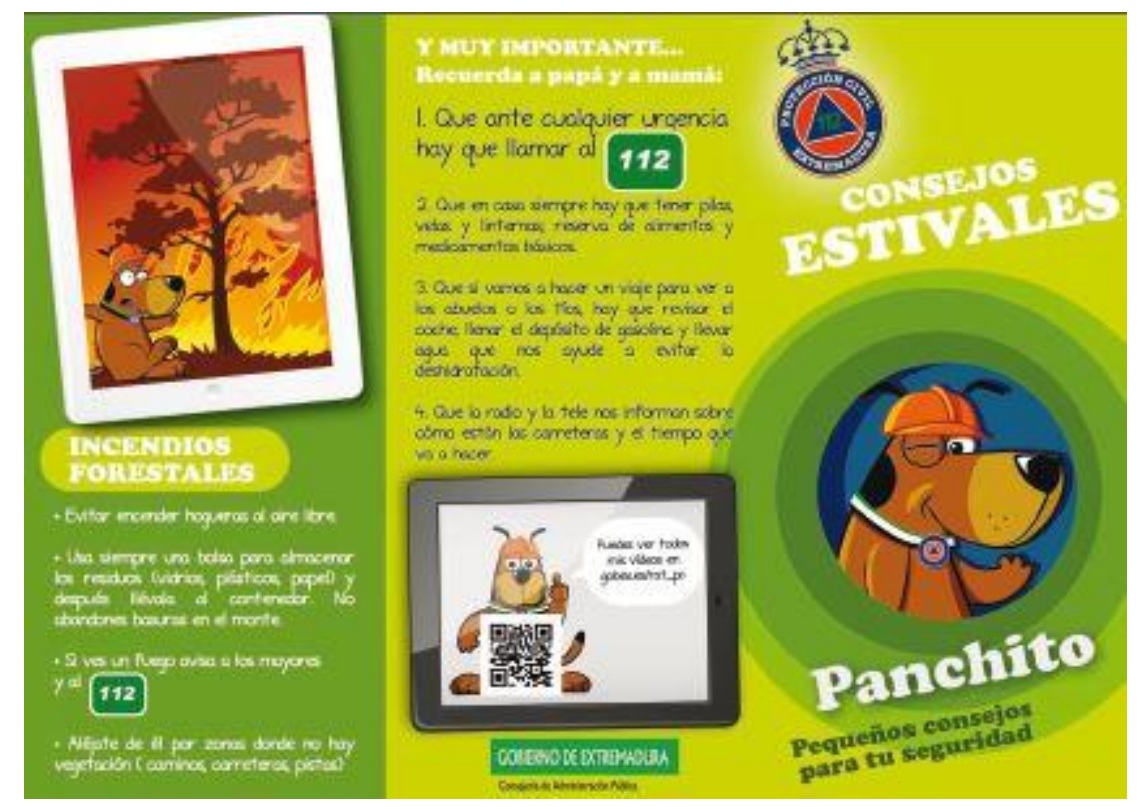

\section{B) LOS JUEGOS}

Recordemos que en un $30 \%$ de las páginas se utilizaba lo que se estas webs se denomina juego, incluyendo: rompecabezas, juegos de memoria y asociación, juegos interactivos o puzzle.

Más que un juego en tanto en cuanto que "ejercicio recreativo sometido a reglas, y en el cual se gana o se pierde" (RAE), a través de un análisis más pormenorizado se observa que de lo que se trata es de sistemas para reforzar los conceptos aprendidos y tratados anteriormente a lo largo de la web, como una suerte de sistema para grabar mejor dichos contenidos en la memoria.

No hay contrincantes o grupos de jugadores, sino que se trata de ejercicicos individuales en los que el participante debe poner a prueba su capacidad de recordar lo aprendido. Aunque la presentación suele plantearse como un reto, como un desafío hacia nosotros mismos y nuestras capacidades, no va a salir de dicho juego un "ganador" y un "perdedor". Toda competición es contra sí mismo. En este sentido, consideramos que la vertiente realmente participativa del juego todavía está por explorar en el ámbito de los contenidos web, limitados por los escasos sistemas de feedback e interactividad entre varios usuarios en este tipo de páginas. 
A continuación podemos observar algunos ejemplos de juegos, extraídos en este caso de la web de Cataluña:

$\underline{\text { Juegos para practicar la memoria }}$

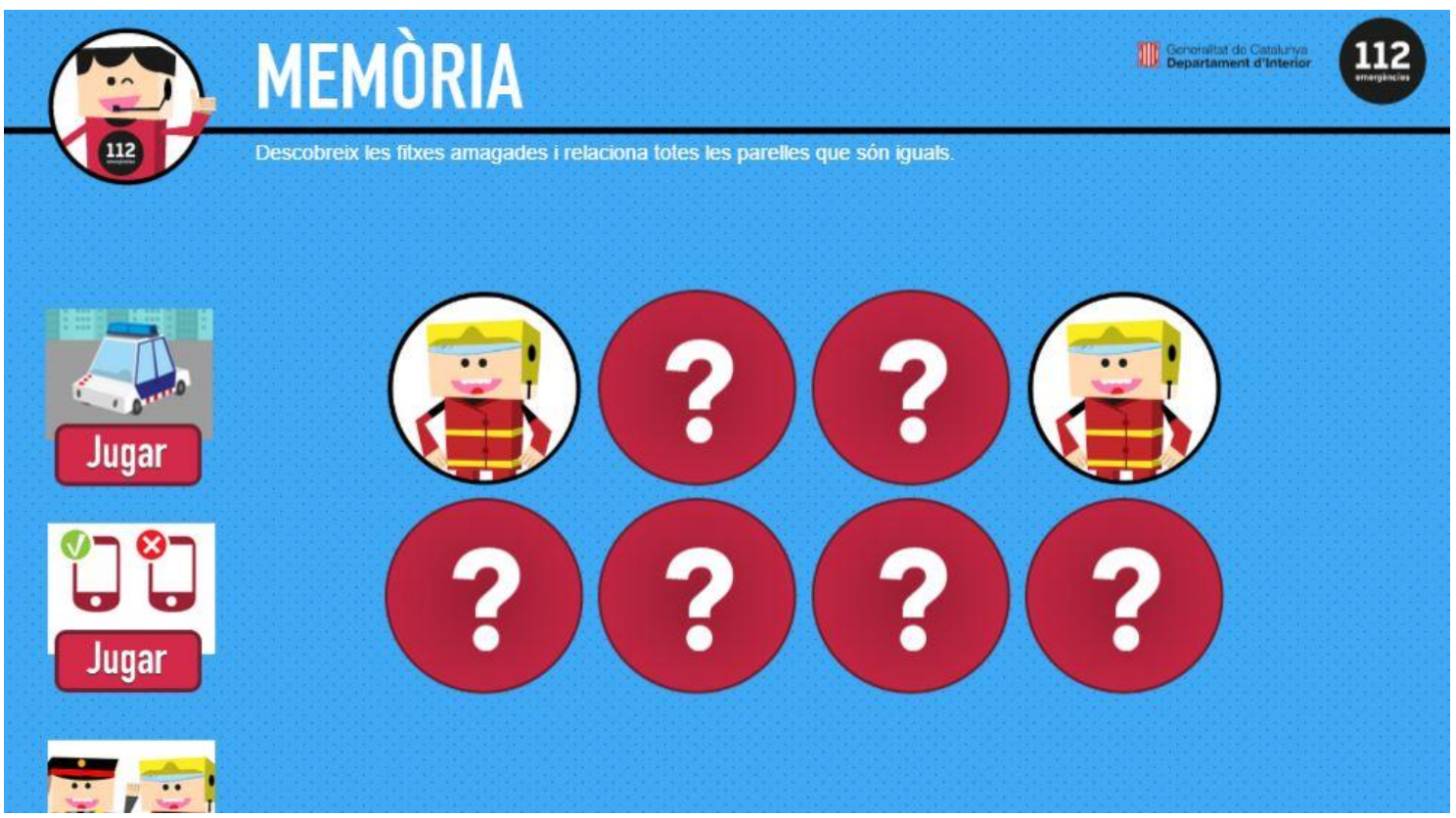

$\underline{\text { Rompecabezas }}$

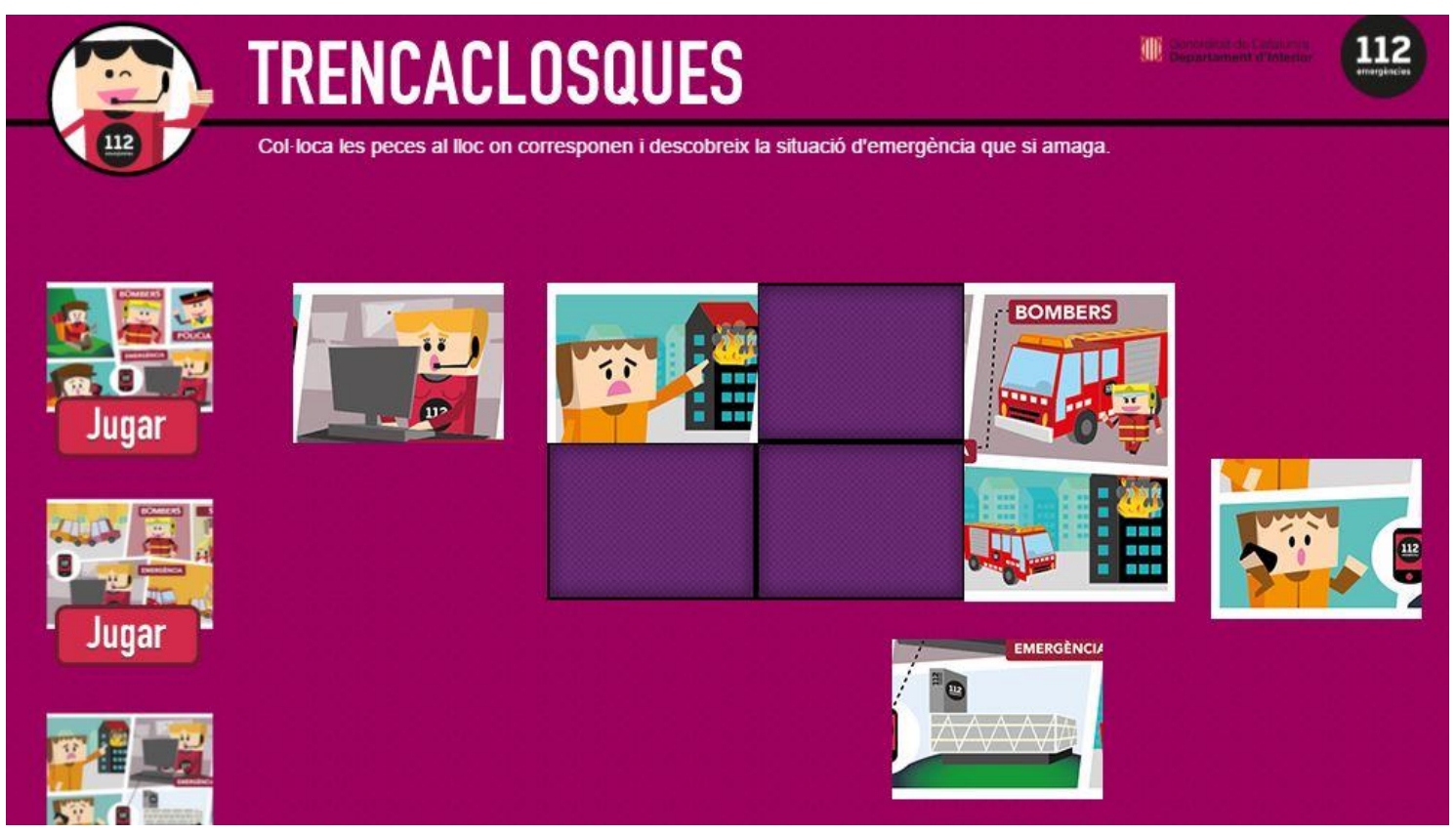




\section{$\underline{\text { Pasatiempos para colorear }}$}

\section{Prepareu-vos per a les emergències !}

Les situacions d'emergència a vegades es poden donar de forma sobtada. Cal tenir preparats equips especifics d'emergència amb els articles bàsics necessaris, tant per als casos d'evacuació com per als casos d'aillament temporal.

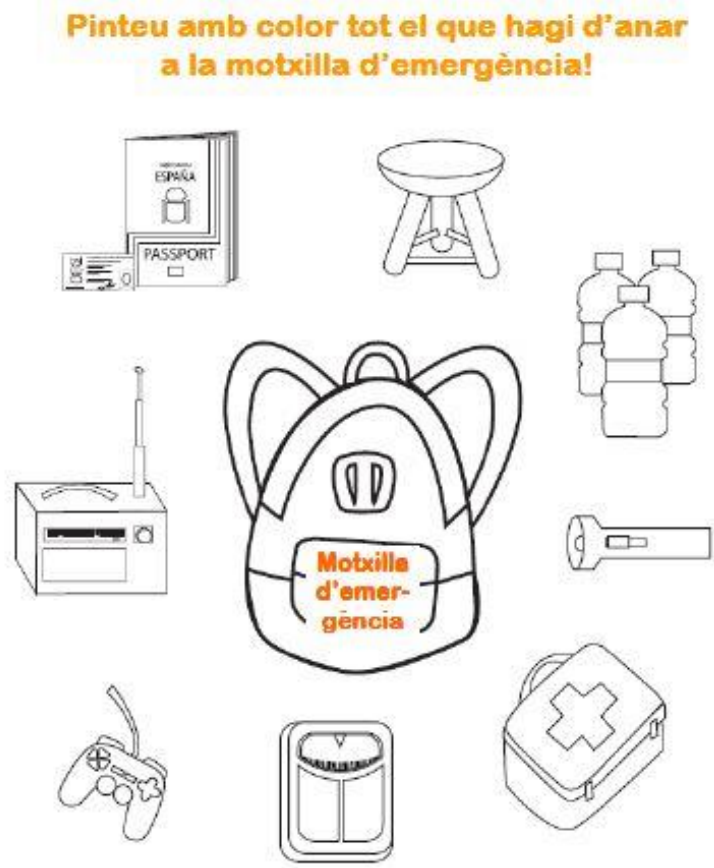

De la web de la Comunidad Madrid recuperamos este otro ejemplo, en el que el participante debe seleccionar qué servicios de emergencia activará para atender a los distintos tipos de situaciones.

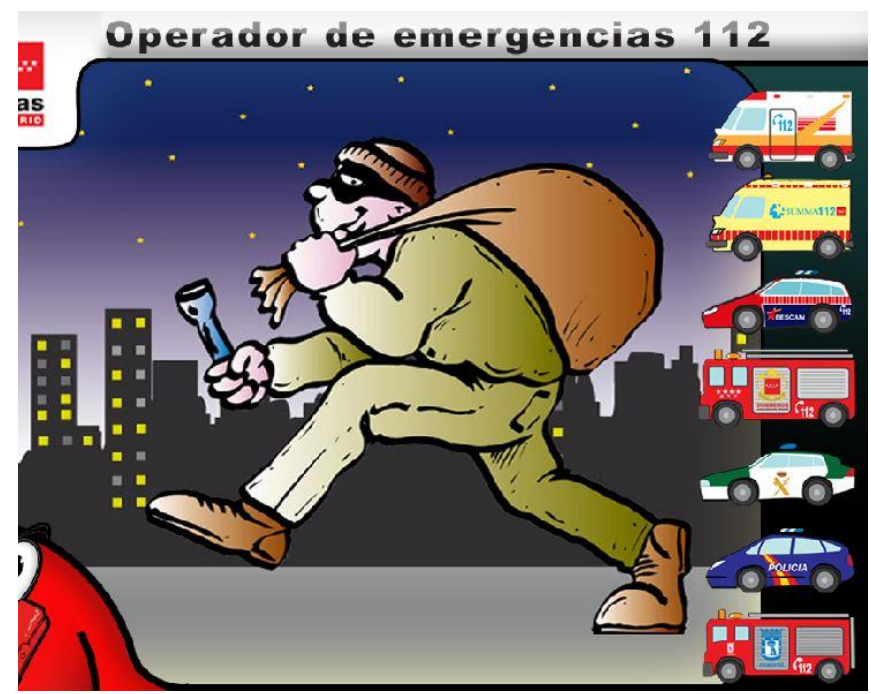




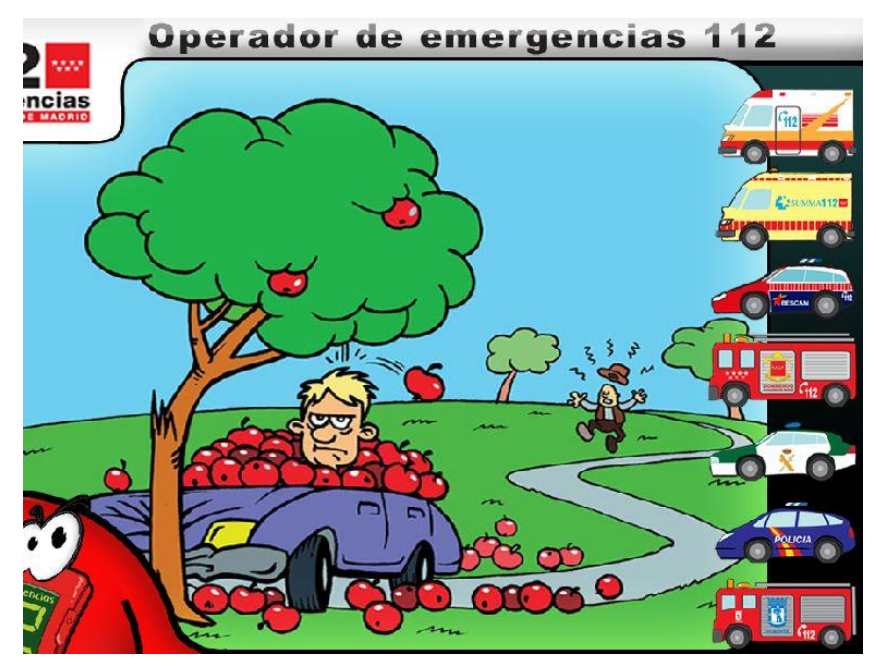

Por otra parte, otros de los juegos analizados se comparten en las webs españolas pero proceden de la página europea del 1-1-2, que tiene su propio "Kids' corner". Encontramos por ejemplo referencia a estos juegos en la web de la institución canaria. Hallamos en esa sección infantil europea puzzles, páginas para colorear, o juegos de preguntas y respuestas (quiz).

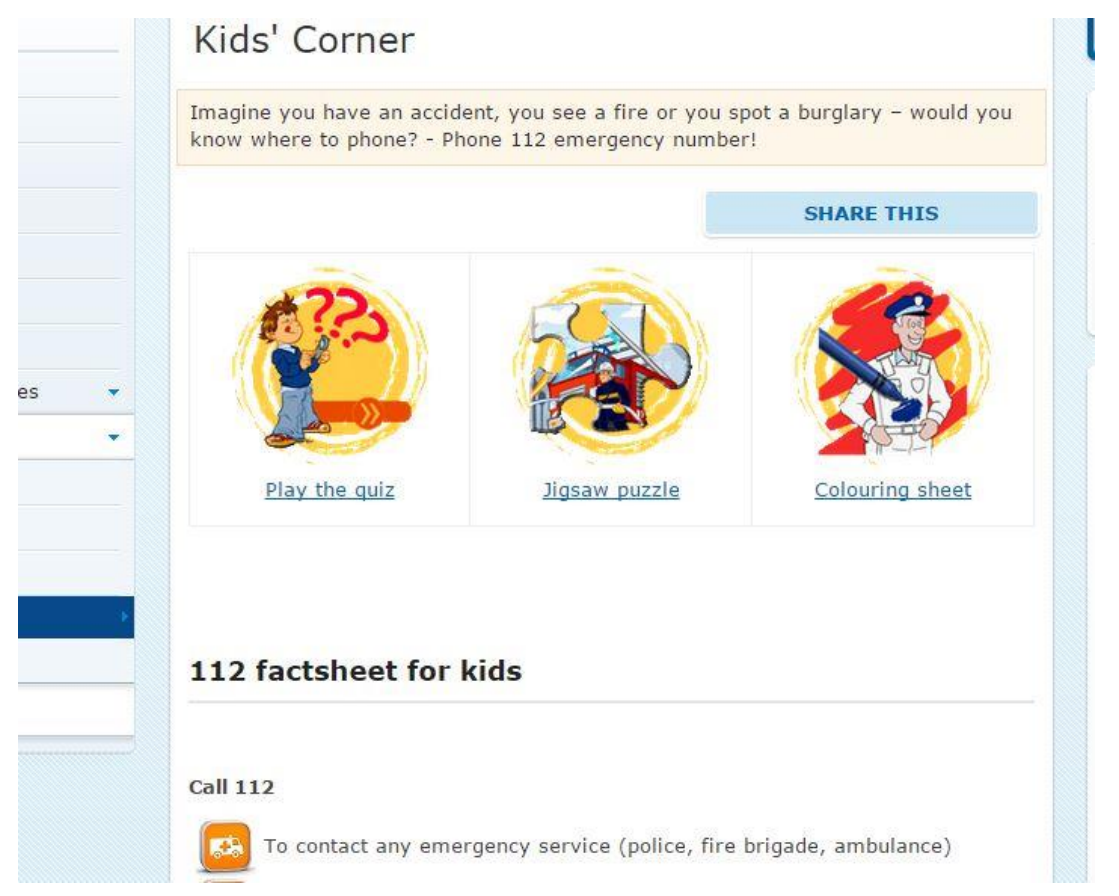




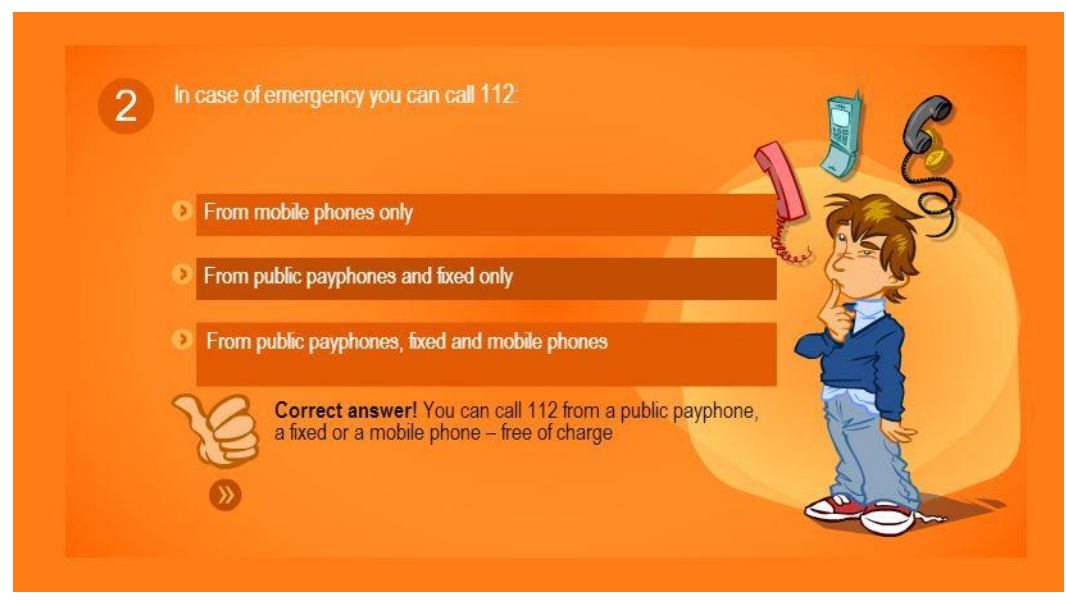

\subsubsection{Diferencias con los formatos dedicados a un público general}

Si bien en las webs dedicadas a un público infantil el recurso del listado aparece en un $20 \%$ de las ocasiones, siendo minoritario, en las del público general se usa en un $88,22 \%$ de las webs, pasando a ser el recurso más frecuentemente utilizado. Esto marcaría una diferencia fundamental respecto al tipo de recursos que más se ha popularizado en las secciones infantiles.

El listado puede cumplir una función útil cuando se trata de tener a golpe de vista una serie de conceptos. En este sentido actúa como una guía, es fácil de repasar, y a la hora de memorizar nos permite chequear rápidamente si efectivamente nos acordamos de todo. Sin embargo, a lo largo de la presente investigación se ha detectado como en algunas ocasiones el listado puede convertirse en un recurso que no sólo no ayude a las funciones que tenía encomendadas, sino que cosideramos que incluso podría llegar a actuar como un elemento disuasorio si se vuelve monótono o reiterativo y no se apoya en otro tipo de recursos. $Y$ es que en numerosas ocasiones los listados de las secciones de adultos examinados a lo largo de esta investigación ofrecían el aspecto que se muestra en los ejemplos siguientes. 
- No acerque focos de calor (bombillas, cigarros, estufas, etc.) a materiales combustibles (pantallas, cortinas, alfombras, muebles, adomos navideños, etc.), ni al contrario, materiales combustibles a fuentes de calor

- No cubra las lámparas y estufas con papeles o prendas puestas a secar.

- No permita a los niños jugar con cerillas o mecheros, ni los deje solos junto

a velas o fuego encendido.

No desatienda en ningún caso:

- Alimentos en el fuego.

- Planchas, chimeneas o estufas encendidas.

- Evite la presencia de cualquier combustible en la zona donde se está

cocinando. Procure guisar con mangas cortas o ajustadas.

- Limpie periódicamente las campanas extractoras de humos y los

aspiradores.

- Evite acumular objetos y materiales combustibles (papeles, pinturas, ropas, muebles viejos, bombonas de gas...) que no sean necesarios.

- No utilice sprays en espacios poco ventilados o cerca de focos de calor

- Si es fumador o hay fumadores en el edificio, debe adoptar una serie de medidas al respecto:

- Utilice ceniceros grandes y vacielos con frecuencia. Apague bien las colillas, mojándolas con agua antes de tirarlas

a la basura.

- No fume en la cama.

- Recuerde que en los edificios públicos no está permitido fumar.

- Utilice correctamente los aparatos e instalaciones eléctricas:

- No sobrecargue los enchufes con demasiados aparatos.

- Evite empalmes provisionales.

- Al desenchufar un aparato no tire del cable, sino de la clavija

- Mantenga en buen estado los aparatos eléctricos y la instalación eléctrica en general.

- Disponga un interruptor diferencial en el cuadro eléctrico y un conductor de puesta a tierra en todas las bases de

los enchufes.

- Desconecte los aparatos que no se estén utilizando.

- Cuando se ausente del domicilio no deje ningún aparato eléctrico funcionando.

Las noticias sobre incendios son frecuentes, a menudo por la falta de medidas básicas de prevención que harían que el número de incidentes fuese menor. Por ello cabe seguir las siguientes recomendaciones:

En el bosque

- No hagas fuego.

- No utilices materiales pirotécnicos cerca de zonas de riesgo de incendio.

- No ensucies el bosque con basuras de ningún tipo.

- Apaga las colillas y cerillas, y no las dejes en el bosque.

- Limpia los límites y alrededores de tu casa.

- Si ves humo en zona forestal telefonea al 112 y aléjate.

- Huye siempre en dirección contraria al humo y al viento, y siempre por las zonas con falta de vegetación.

- No te alejes nunca hacia arriba ni por barrancos o vaguadas.

- No cruces caminos ni carreteras sin visibilidad por el humo.

\section{En casa}

- Ten en cuenta que las chimeneas tengan matachispas.

- Recuerda la obligación de tener limpios de vegetación seca y suciedad 50 metros alrededor de las urbanizaciones.

- Si el fuego llega, encerraos en vuestra casa y cerrad las puertas, ventanas y toda entrada de aire.

- No salgas de la vivienda si no te lo ordenan las fuerzas y cuerpos de seguridad. 


\section{Plan de Autoprotección escolar}

- Es preceptivo realizar un Plan de Autoprotección del Centro.

- Dicho Plan se complementará con ejercicios periódicos de simulacros de evacuación.

- Procuren que los simulacros de evacuación no conlleven peligro de caídas ni riesgos de otro tipo.

- Programen actuaciones informativas al objeto de transmitir a todos los ocupantes las instrucciones de comportamiento frente a una situación de emergencia.

- Las personas responsables de los equipos técnicos contra incendios deben tener la formación y capacitación adecuada para su utilización.

\section{Incendios, cómo evitarlos}

- Identifiquen los elementos combustibles presentes en el Centro Educativo (madera, papel, textiles,...

- Eliminen los elementos combustibles carentes de uso actual y futuro

- No coloquen mobiliario ni otros objetos combustibles en elementos y vías de evacuación.

- Sitúen los elementos que pueden arder, pero que tienen un uso muy esporádico (mobiliario circunstancial, archivos de años anteriores...) en recintos específicos adecuados.

- Almacenen los productos de limpieza y de botiquín en locales apropiados.

- No utilicen o almacenen gas en zonas de sótanos y semisótanos.

- Empleen elementos decorativos ignífugos.

- No utilicen sistemas de calefacción no autorizados (aparatos de infrarrojos, estufas de gas,...)

- No usen las salas de calderas como almacén.

- Las reparaciones o modificaciones de las distintas instalaciones deben ser realizadas por personal autorizado.

- Verifiquen las condiciones de seguridad de la instalación para extracción de humos (campanas, conductos, filtros, etc.)

- Introduzcan las sustancias combustibles que se emplean en actividades docentes (laboratorios, plástica, etc.) en recipientes herméticos y guárdalos en armarios metálicos apropiados provistos de cerraduras.

- Los recintos y armarios donde se almacenan o utilizan productos que desprenden gases o vapores inflamables deben tener las condiciones de ventilación adecuadas.

- Ciertos recintos, como cuartos de basura, almacenes, cuartos de calderas, etc. pueden ser considerados como locales de riesgo especial, por tanto, deben tener una condiciones de protección contra incendios más exigentes.

- Los laboratorios y talleres de Centros de Formación Profesional, atendiendo a la cantidad y peligrosidad de los productos utilizados así como al riesgo de los procesos en los que se utilicen dichos productos, estarán clasificados como locales de riesgo especial, por lo que cumplirán reglamentaciones específicas aplicables a las actividades a las que estén destinados.

- Las maquinarias utilizadas en los centros donde se imparta Formación Profesional deben estar diseñadas para evitar cualquier peligro de incendio o de sobrecalentamiento o de explosión provocado por la propia máquina o por los gases, líquidos, polvos, vapores y demás sustancias producidas o utilizadas por la máquina.

- No depositen libros en lugares próximos a los radiadores.

Tal y como se observa en estos tres ejemplos de diferentes Comunidades Autónomas, uno de los inconvenientes es que no hay jerarquización visual, por lo que es difícil para una persona no experta distinguir entre ideas principales y secundarias. Con esta fórmula, además, resulta más complicado relacionar unas ideas con otras o comprender factores de causalidad.

Por otra parte, no se utilizan otros elementos visuales que nos ayuden a reforzar la memoria y el recuerdo de determinados conceptos. Cada una de las líneas es igual visualmente a la anterior y a la posterior. Esto no contribuye a ayudar al lector a retener la información necesaria para actuar en un tiempo futuro, donde habremos de rememorar lo aprendido.

Otro de los problemas observados es que si todos los conceptos de uno o diversos apartados adoptan este mismo formato, la lectura para el público internauta se convierte en un proceso monótono que puede llegar a distraer su atención o cansarle. 


\section{PÓSTERS, FOLLETOS Y TRÍPTICOS PARA ADULTOS}

Un $41,17 \%$ de la secciones dedicadas a un público general contienen folletos, trípticos, y pósters con ilustraciones y/o con fotos. Materiales que combinan imagen y texto breve, mostrando la fuente de riesgo o el comportamiento seguro a seguir. Para el público general, este es el segundo recurso más utilizado tras el listado, lo cual demuestra que, sin alcanzar el nivel de utilización que se hacía en las secciones infantiles, sigue siendo también un recurso fundamental.

Veamos algunos casos signficativos. En Asturias, hallamos materiales que combinan el aspecto de un póster con el de un listado. De nuevo, el que era el recurso más usado para el público general, el listado, reaparece aquí aunque en esta ocasión combinado con otros recursos, haciendo valer su clara preponderancia. Sin embargo ahora, al combinarse con esos otros recursos, gana en claridad, favorece su adecuada interpretación y puede resultar más atractivo para el público.

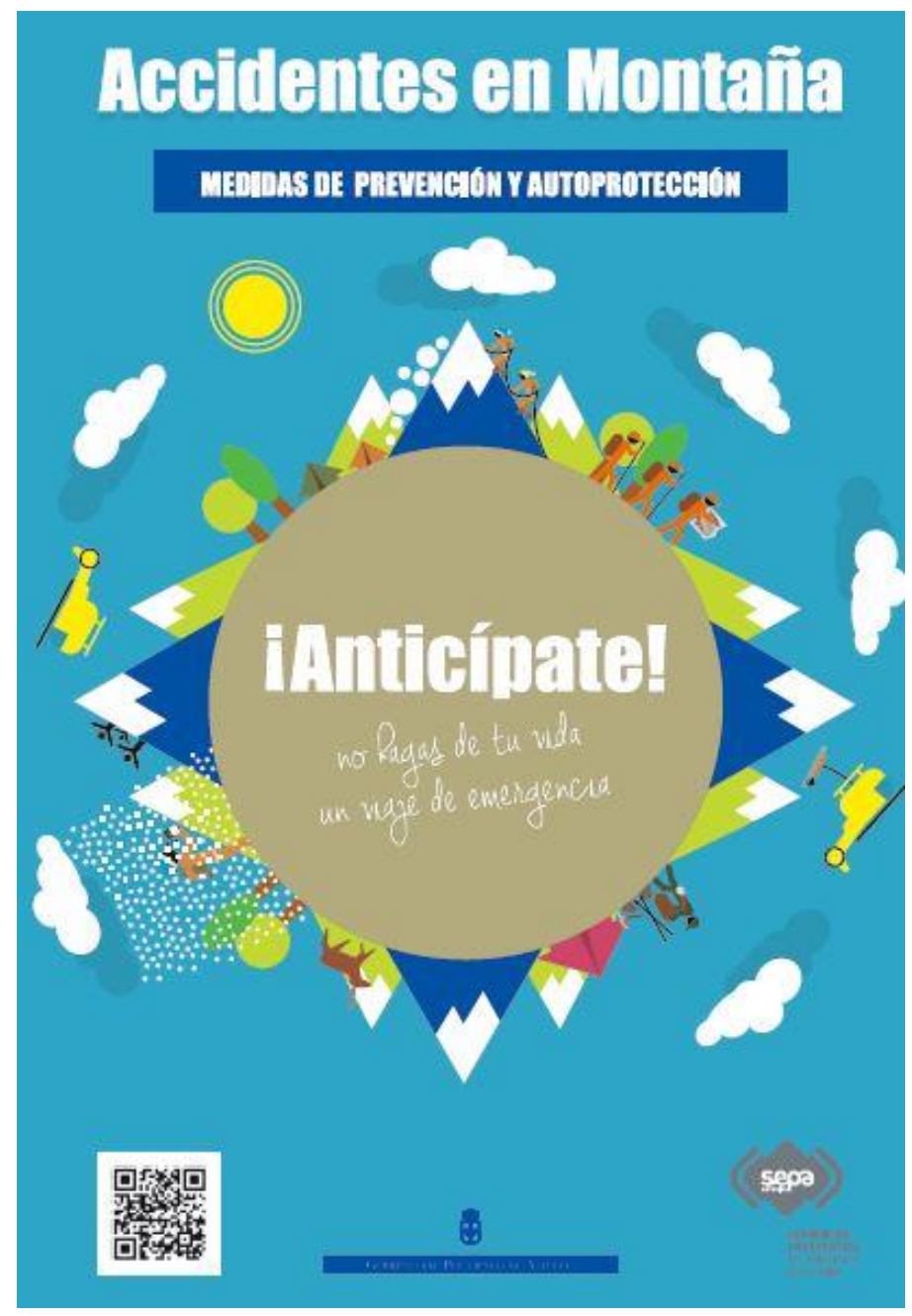


La montaka es el medio donde se realizan muchas actividacies deo ocio y deportivas (senderlismo, escalada, ascensiones, esqui, barranquismo, etc.s), pero se debe tener en cuenta que debido al aun aplicando las medidas de prevención adectuadas pueden generar un accidente.

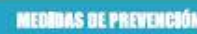

- Slempre que salgas a la montana deja dicho donde vas y cuando vuelves a tu famla o

- Prepare con antelación la ruta que vaya a realiza.

- Nunca vayas solo

- Infórmate antes de salir de la predicción meteorológica y del riesgo de aludes.

- Informate de la localizacion de los ratugios o cabahas donde resguardarse en caso de - El materal y equipo a ual zar deberan estar siempre en perfectas condiciones de uso. Lleve

- Preste atención y respete las indicaciones de los carteles y otras seralzaciones sobre revons

- Guarda fuerzas para el regreso. sl es preciso hay que saber renunciar,

- Utiliza mapas y libras. Si careces de experiencia acude a los guias de montaña.

- Real za cursos de primeros auxilios en montafia. Te ensefiar án a prevenir y actuar en caso

- Cuia tu preparación fisica. El montafismo exige estar en buena forma. - En caso de que disminuya la visilid dad par niabla, no sigas caminando, permanece queto

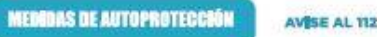

- Si no tienes telefono piensa en el retugio o pueblo mas cercano y la forma de llegar a el

- Si estas con un terido y es posible no lo dejes solo.

- Al informar sobre el accidente es importante espec ficar con claridact

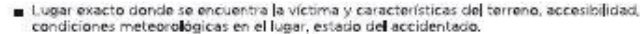

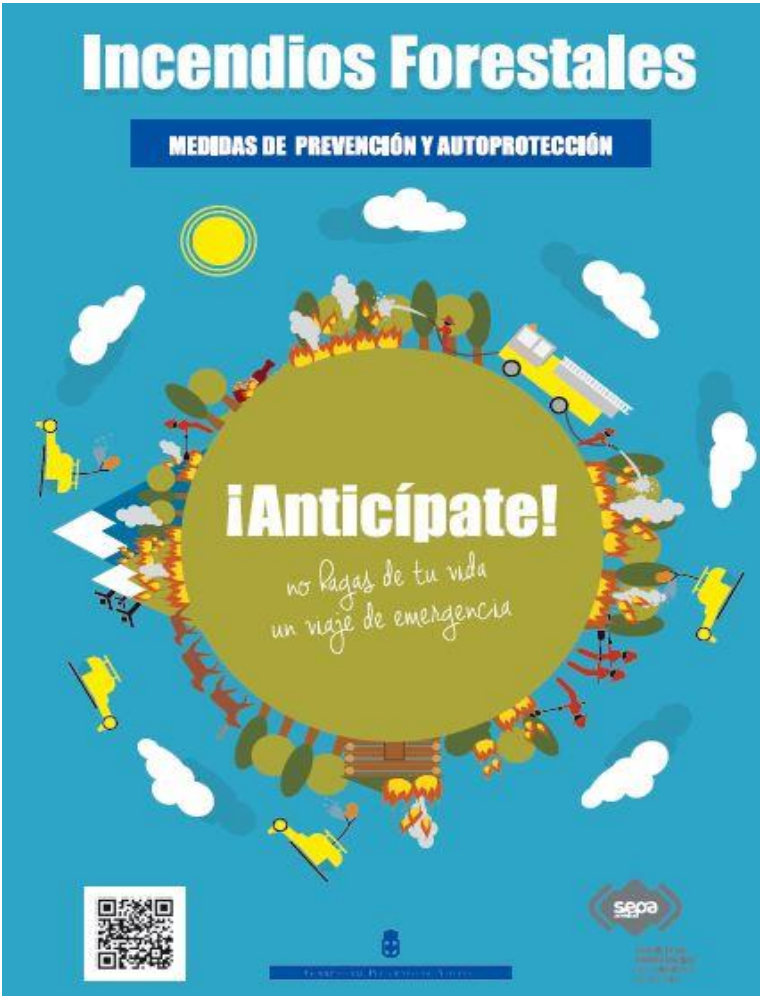




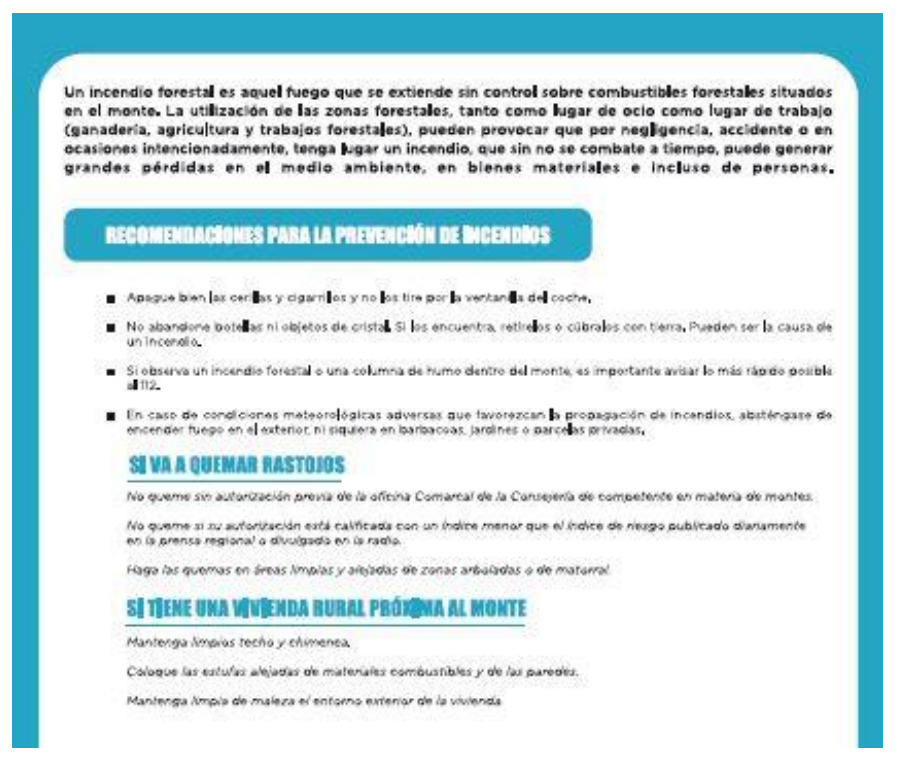

Por su parte, en Navarra también hallamos ejemplos de folletos en los que aparecen ilustraciones y consejos o informaciones muy resumidos, en frases cortas. En el ejemplo que mostramos a continuación, observamos una de las princiaples diferencias de estos materiales con respecto a sus equivalentes infantiles: en los del público general los consejos e informaciones ofrecidas tienen una mayor relación con normas que en el caso de los niños, donde se hace más referencia a actitudes seguras y pautas de actuación.

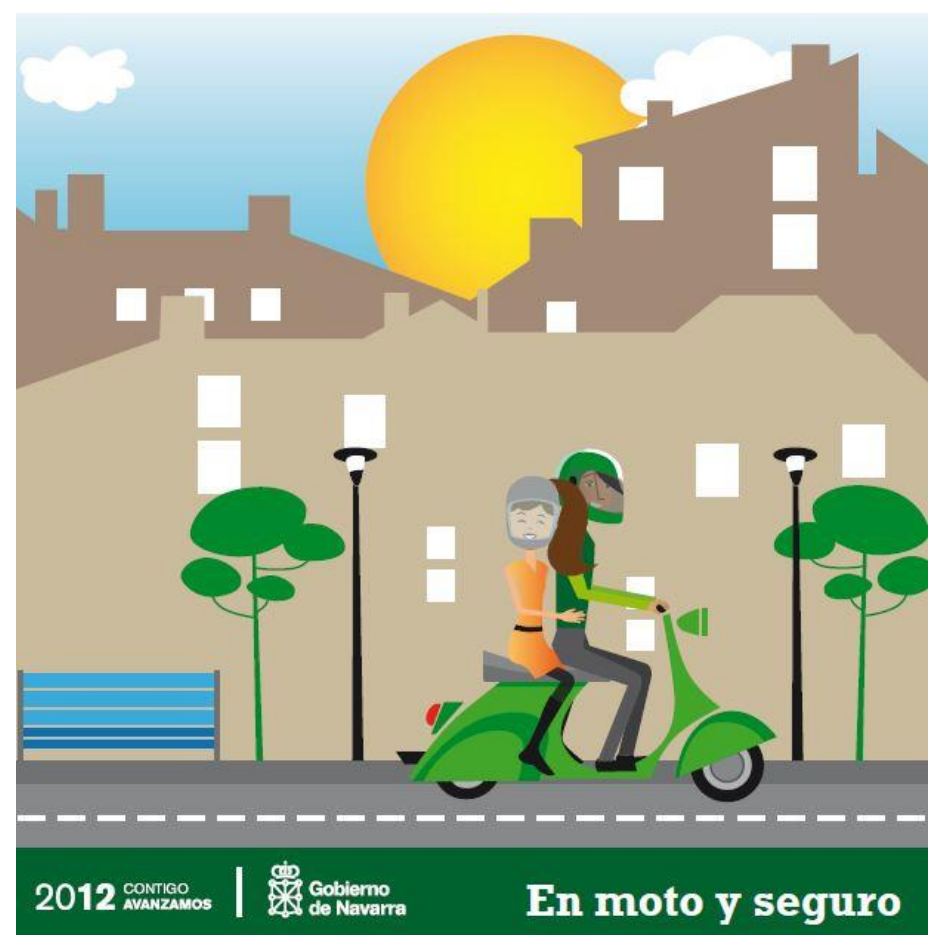




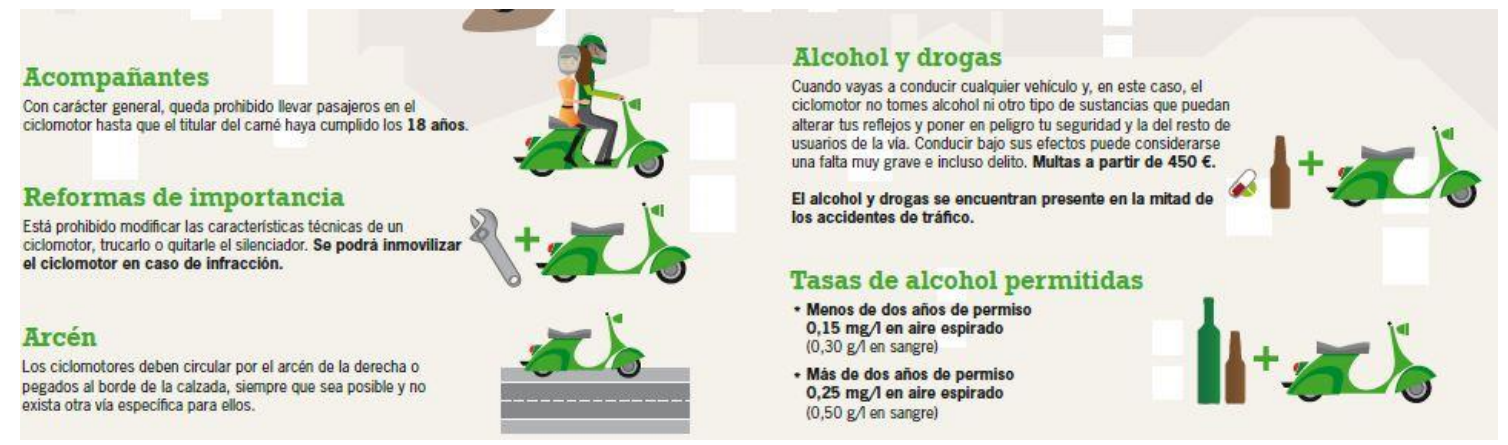

En resumen, los folletos dedicados a un público general mantienen algunas semejanzas con los del público infantil, pero en ellos se aprecian también sus propios elementos diferenciadores. Por una parte, en la de los folletos para el público general hay mayor presencia textual y ésta además suele presentarse en el formato de listado. Por otra, se hace mención a conceptos y contenidos relacionados con normas y regulaciones, un aspecto que no figura en los materiales propios del público infantil.

\subsubsection{Formatos de interfaz pedagógica}

Algunos de estos materiales para público general tienen un estilo completamente distinto al de los pósters o folletos hallados en los apartados infantiles, pero otros, aún estando destinados a un público adulto, contienen características que los hacen ser simultáneamente aptos para niños o adolescentes.

Comparten características de uno y otro territorio, el del universo infantil y el del público en general. Por este motivo, hemos elegido para denominarles el concepto de "interfaz pedagógica", estableciendo un paralelismo con el concepto de incendios de interfaz urbano-forestal, siendo esta la zona en la que el terreno forestal entra en contacto con zonas edificadas. Como en ese tipo de territorios, muy frecuentes en el territorio Mediterráneo, hallamos en estos recursos pedagógicos características de ambos mundos. Son recursos híbridos, en los que se tocan ambos terrenos, el infantil y el de adultos, y donde el resultado es un material utilizable por ambos tipos de público. Analicemos algunos ejemplos.

Los siguientes folletos, extraídos de la web de Extremadura, figuran en las secciones de adultos y están destinados a un público adulto, pero hallamos en ellos algunos rasgos propios de los recursos infantiles. 
Así, se utilizan frases cortas, huyendo del uso del listado tan frecuentemente difundido en las secciones de adultos. Se utilizan algunos recursos que sirven para captar la atención del público, de la forma llamativa en la que también se haría en los materiales infantiles: se utiliza una combinación de colores vivos, se juega con las asimetrías, los resaltes, los cambios de tamaño de letra... el objetivo de todos estos elementos es captar la atención de aquel que observa este material.
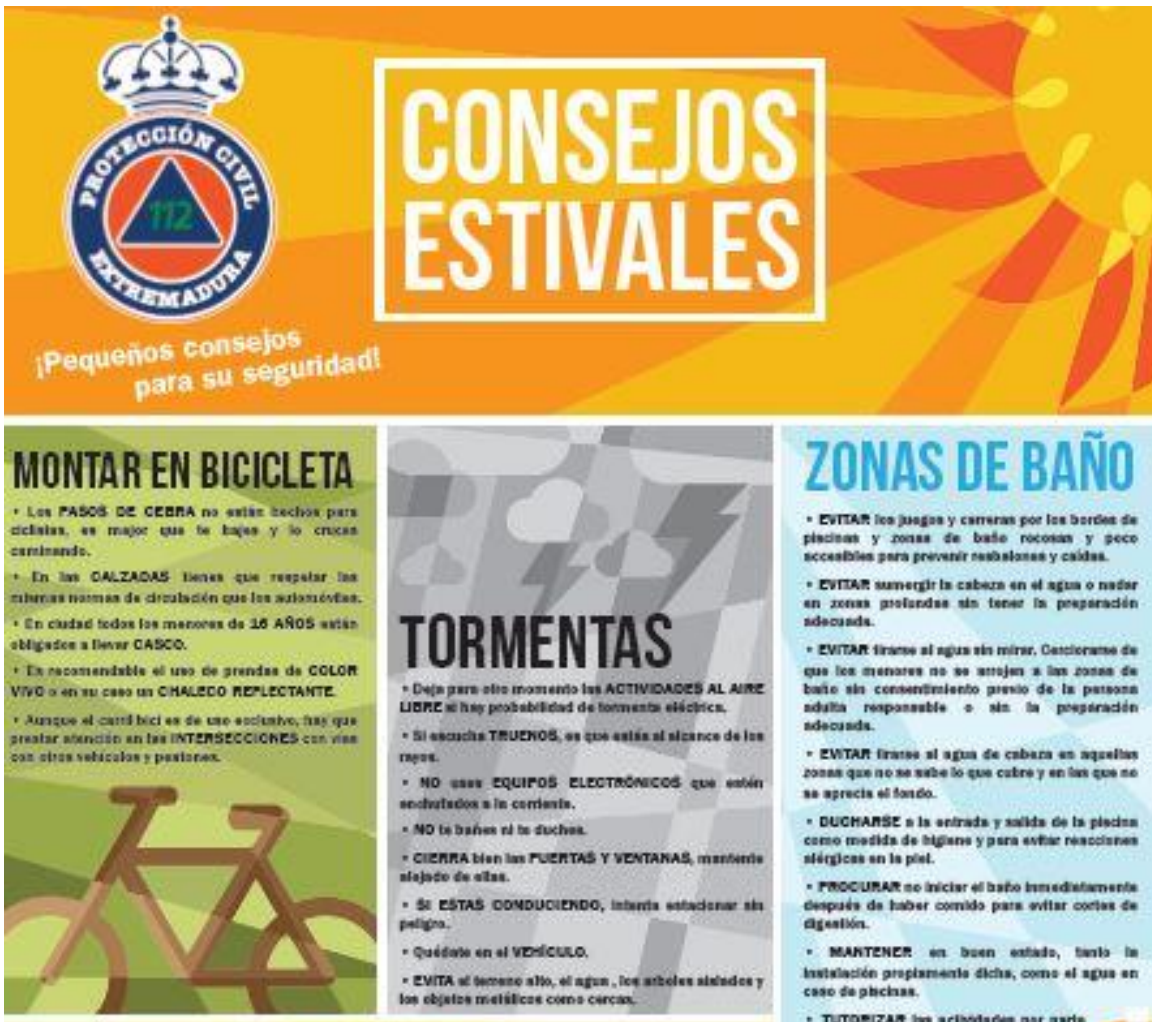

\section{INCENDIOS FORESTALES}

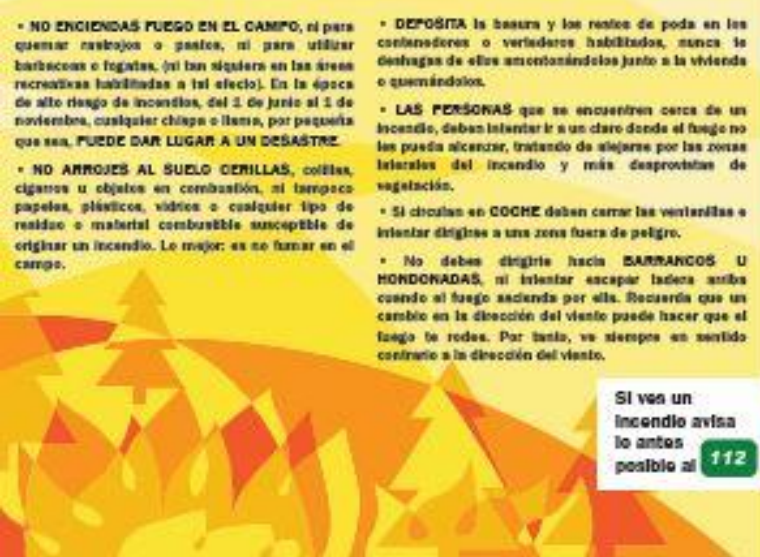

\section{ZONAS DE BAÑO}

- Evrtas leo jugan y cameras poe las berent de

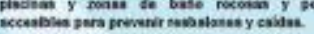

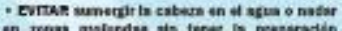

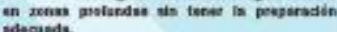

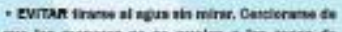

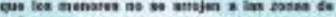

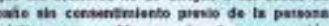

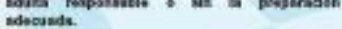
- EVTin trates al apa de cabara en ayselis

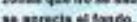

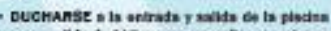

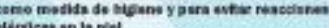

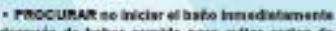

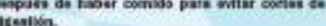

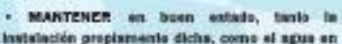
caso do phechas.

- nutomizer ine scimoducien par garts

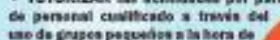

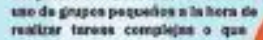

amoten un als niturge

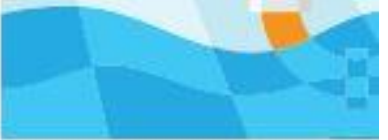

Y RECUERDE:

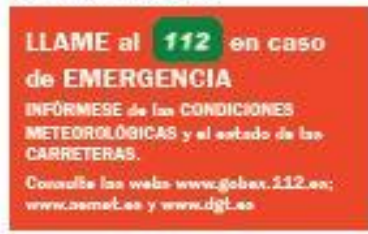

COUERNO OE EXTREMADURA 


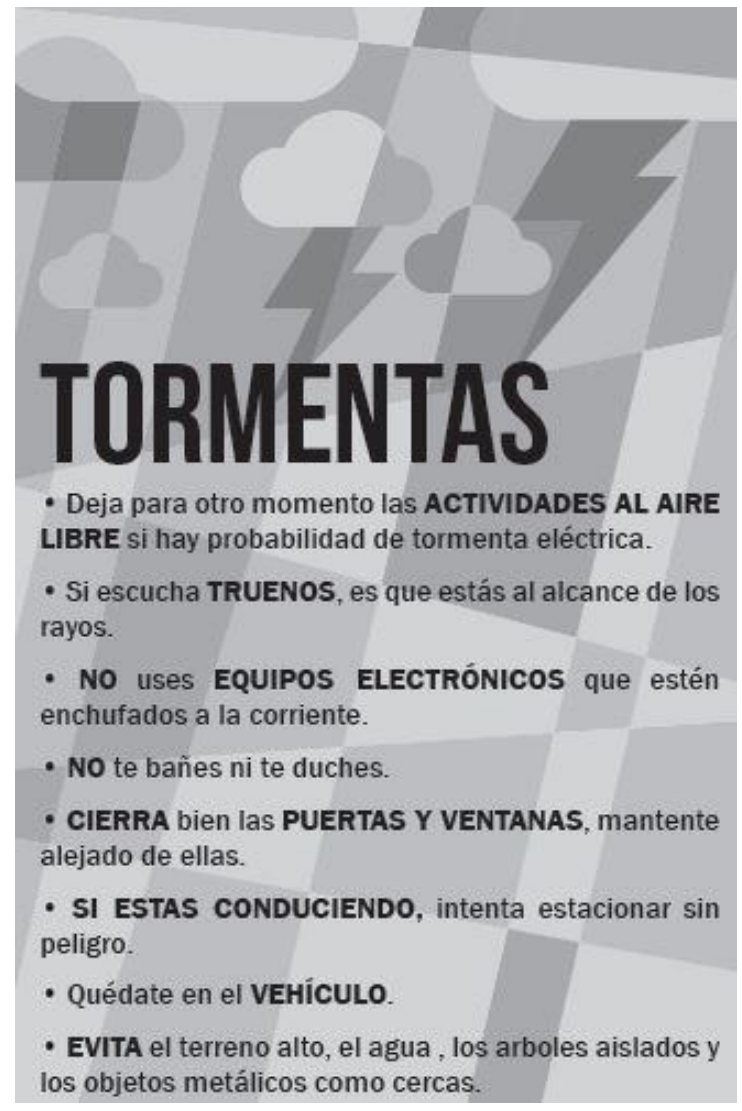

\section{INCENDIOS FORESTALES}

- NO ENCIENDAS FUego EN El CAMPO, ni para quemar rastrojos 0 pastos, ni para utilizar barbacoas o fogatas, (ni tan siquiera en las áreas recreativas habilitadas a tal efecto). En la época de alto riesgo de incendios, del 1 de junio al 1 de noviembre, cualquier chispa o llama, por pequeña que sea, PUEDE DAR LUGAR A UN DESASTRE.

- No ARROJes al sUelo cerilLas, colillas, cigarros u objetos en combustión, ni tampoco papeles, plásticos, vidrios o cualquier tipo de residuo o material combustible susceptible de originar un incendio. Lo mejor: es no fumar en el campo.

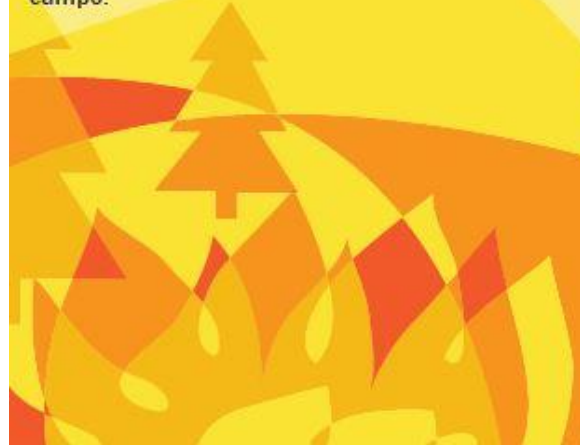

- DEPosita la basura y los restos de poda en los contenedores 0 vertederos habilitados, nunca te deshagas de ellos amontonándolos junto a la vivienda o quemándolos.

- LAS PERSonas que se encuentren cerca de un incendio, deben intentar ir a un claro donde el fuego no les pueda alcanzar, tratando de alejarse por las zonas laterales del incendio y más desprovistas de vegetación.

- Si circulan en COCHE deben cerrar las ventanillas e intentar dirigirse a una zona fuera de peligro.

- No debes dirigirte hacia BARRANCOS HONDONADAS, ni intentar escapar ladera arriba cuando el fuego ascienda por ella. Recuerda que un cambio en la dirección del viento puede hacer que el fuego te rodee. Por tanto, ve siempre en sentido contrario a la dirección del viento.
Si ves un

incendio avisa

lo antes

posible al 112 
Junto a estos rasgos examinados, más propios del mundo infantil, este folleto guarda también algunas de las características del de los adultos, sobre todo por lo que respecta a la presencia o no de determinados personajes. A diferencia de numerosos materiales infantiles, aquí no hay mascotas o animales que adquieran protagonismo en la ilustración. Tampoco seres inanimados que estén dotados de características humanas. Se aleja por tanto totalmente del terreno de la fantasía o de la narrativa infantil.

Otros ejemplos nos muestran que la interfaz pedagógica puede intensificar su ambivalencia todavía más. $Y$ es que llegamos a encontrar otros materiales que parecen tener una proximidad todavía mayor respecto a los estilos y lenguajes infantiles, y que, aún figurando en la sección general o de adultos, podrían llegar a ser utilizados por los niños a través de una guía adulta.

Es el caso de la web de Baleares. En los apartados dedicados al público general, aparece un folleto denominado "Guía rápida para prevenir accidentes", y está centrada en los accidentes del ámbito doméstico. Cada página funciona de forma independiente, de forma que cada una está destinada a un tema o actitud segura: el uso del 1-1-2, caídas y traumatismos en casa, intoxicaciones alimentarias, quemaduras, riesgo eléctrico, asfixias, incendios y explosiones. Sin estar específicamente ubicado dentro de un apartado infantil o juvenil, sus recursos, contenidos y estilo lo hacen apto para también ser utilizado por un público infantil, bien de forma individual o abordando el material conjuntamente con sus familiares. Veamos por qué.

El folleto está protagonizado por una familia: padre, madre, niños, abuelo y un perro, con lo cual el abanico del público que pueda sentirse identificado se amplía.

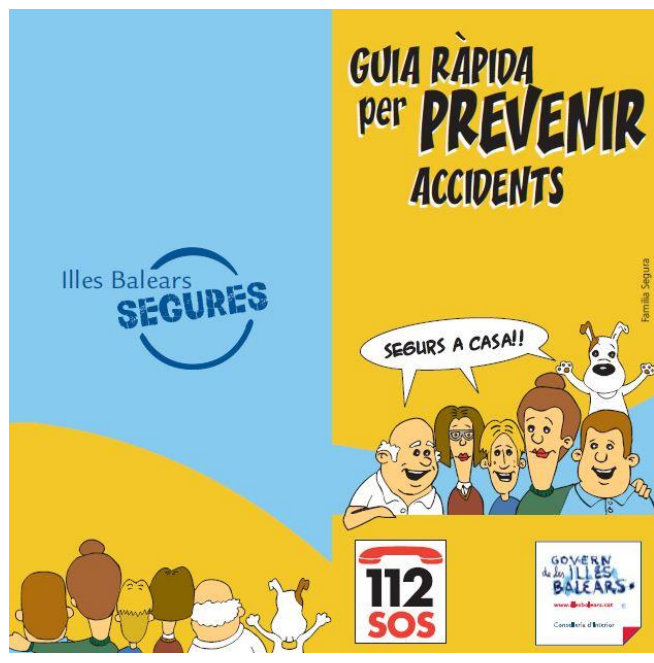


Como hemos visto en casos anteriores, de nuevo la figura del perro aparece asociada a valores de sentido común, prudencia, vigilia e inteligencia. En cada página, es el can el que trata de llamar la atención sobre un peligro que solo él está detectando, con lo que, como en las narraciones infantiles o la fábula clásica, un animal adquiere capacidades humanas.
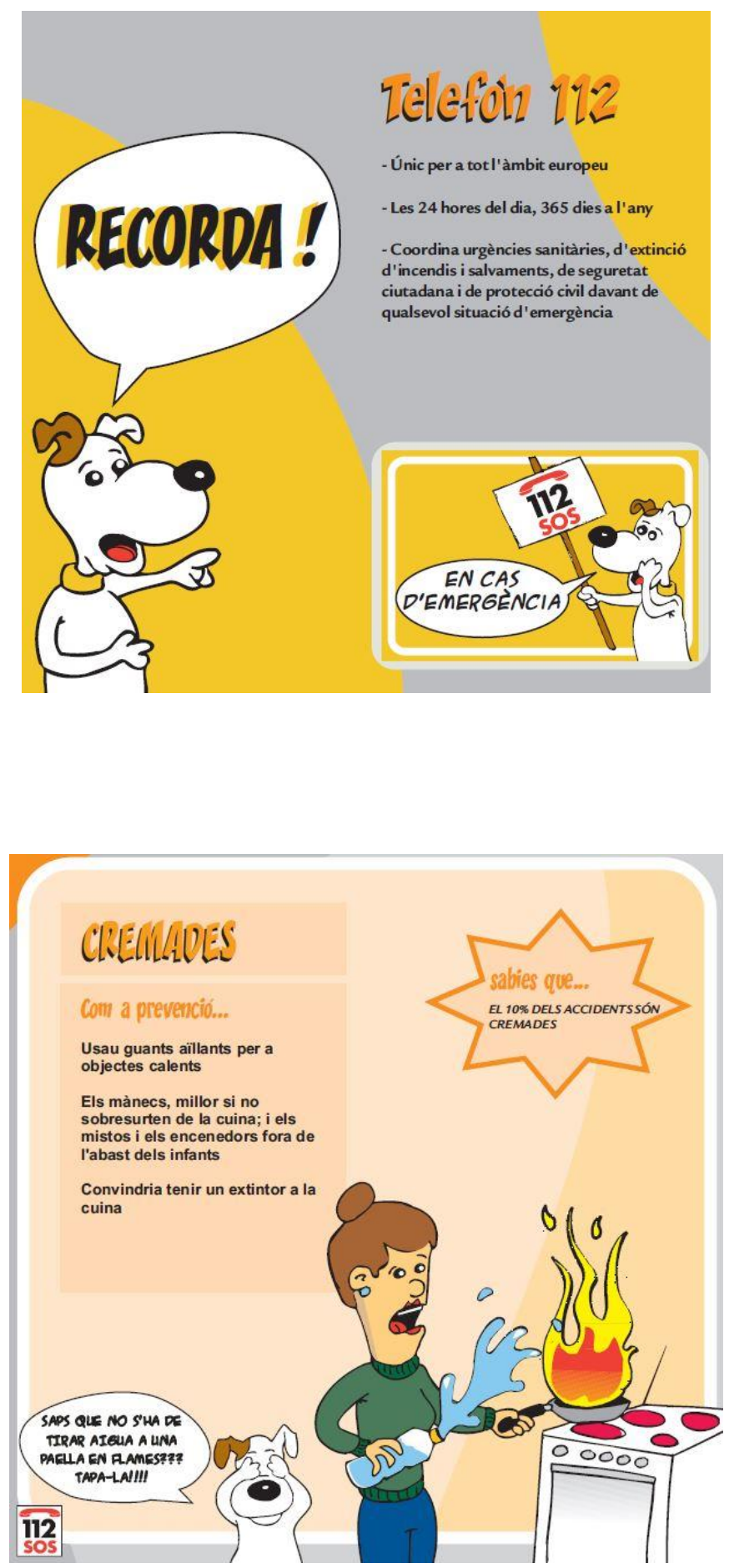
Un nuevo ejemplo de interfaz pedagógica lo hallamos en la web de Cataluña, donde también hallamos materiales que se ofrecen en los apartados de adultos pero que contienen todas las peculiaridades para un uso infantil: se utilizan imágenes llamativas y estilizadas, contienen mucho color, y los conceptos aparecen plasmados en oraciones cortas.
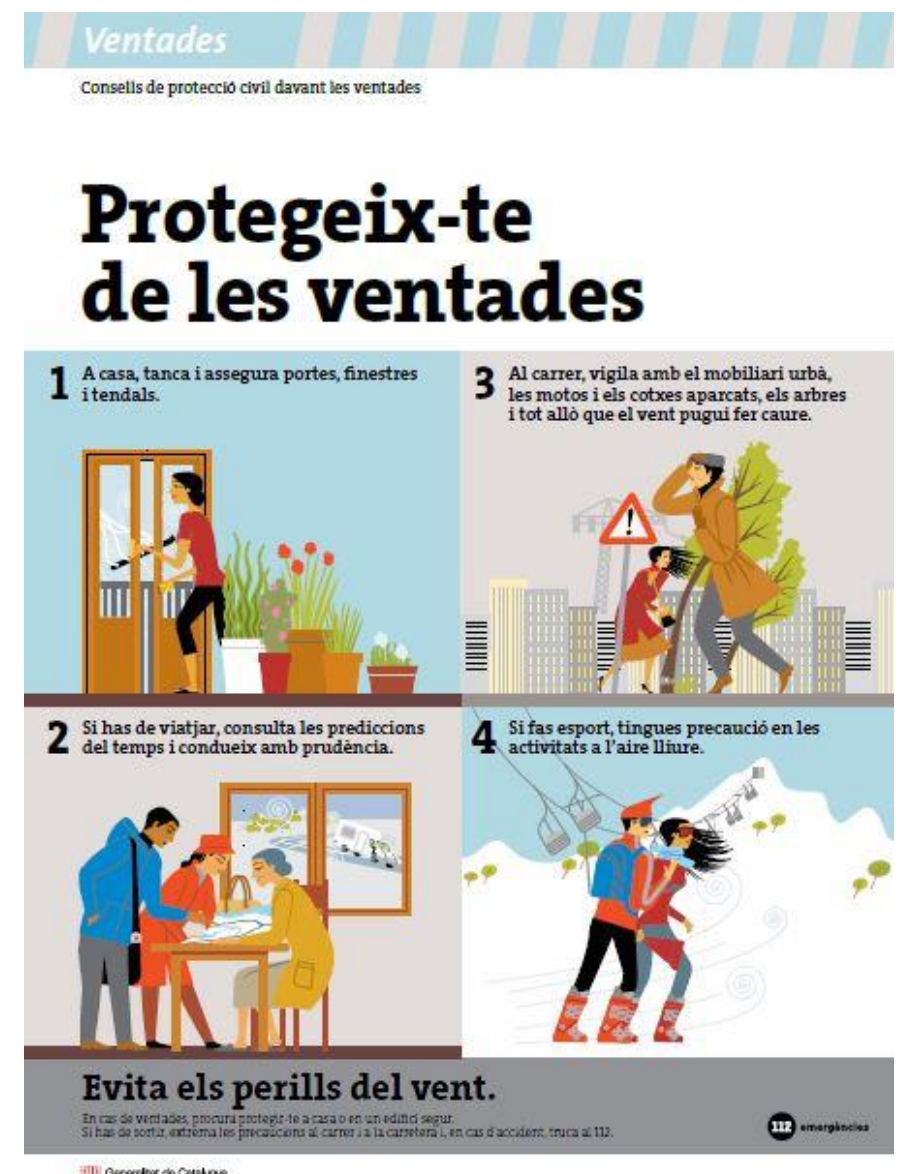

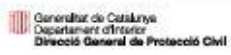

Además, sobre esos mismos materiales, que ya de por sí podrían ser manejados por niños guiados por un adulto, se realiza en ocasiones una readaptación para favorecer un mejor manejo del recurso por parte del público infantil, introduciendo deliberadamente ligeros matices que entre otras cosas favorecen la interactividad.

El tipo tipo de ilustraciones y de mensajes es el mismo pero se introduce una invitación a la actividad para que el niño o adolescente que pudiera utilizar ese material lleve a 
cabo acciones lúdicas que le ayuden a recordar lo aprendido, como en el siguiente ejemplo. Aquí, se han de colocar pegatinas en el espacio que corresponda.

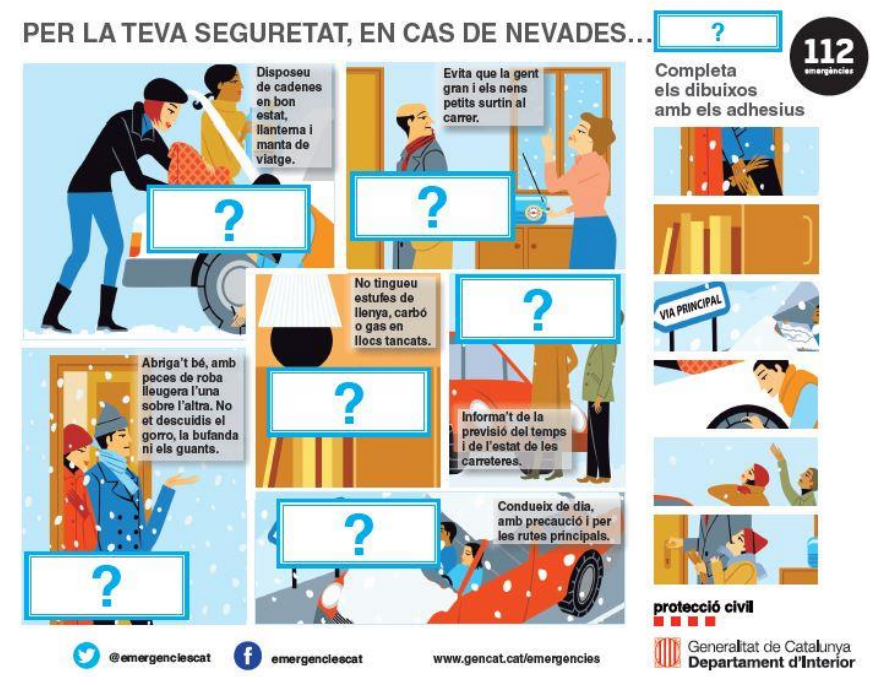

Otra de las pruebas de ese ajuste infantil de un material inicialmente incorporado a la sección de adultos es el siguiente ejemplo. Se trata de una cinta métrica para pegar en alguna pared de la casa. Aunque este material se ofrezca en la sección de adultos, sabemos que los niños de la casa también lo utilizarán: son los únicos que todavía están en edad de crecer.

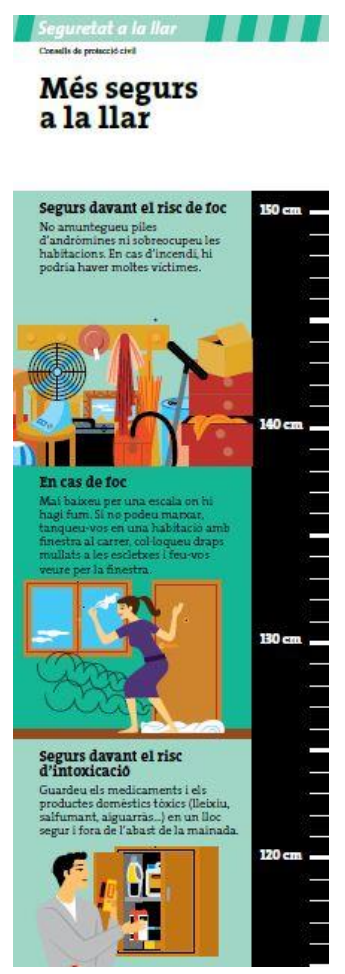




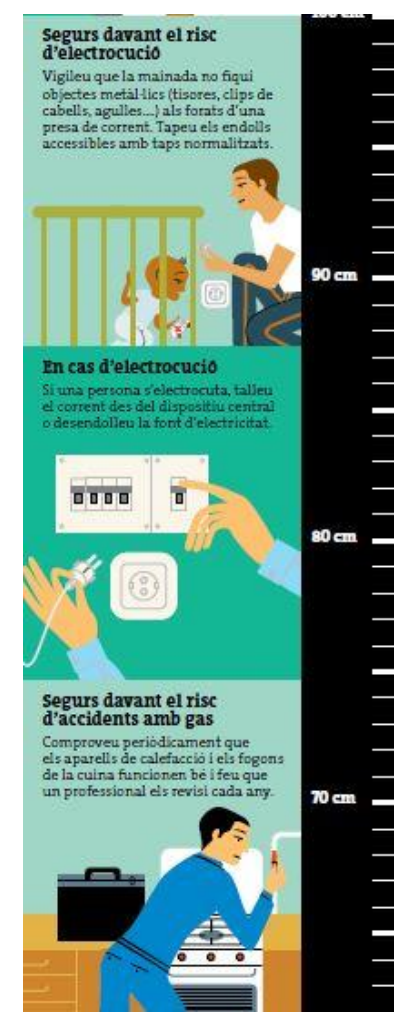

\subsubsection{El vídeo como recurso}

El examen a estas webs revela que el material audiovisual no es hoy por hoy un recurso muy utilizado, ni en las webs de adultos ni en la de niños, utilizándose tanto en un caso como en el otro sólo en un $20 \%$ de las páginas web.

En los casos de vídeos para un público general, se trata generalmente de un experto que ofrece información sobre diferentes temas. Estos suelen versar sobre los riesgos propios y más frecuentes de cada Comunidad Autonoma, así como correspondientes a la época del año en la que va a ofrecerse el consejo. Por tanto se tiene en cuenta la calendarización de los riesgos (por ejemplo el mayor riesgo de nevadas en invierno) para seleccionar el momento en el que se ofrecen los vídeos. Es el caso del País Vasco o de las Baleares. 
Captura de pantalla de la web del País Vasco

Consejos 2014

Diciembre 2014 - Días festivos

Diciembre es un mes marcado por los dias festivos. Viajamos y hacemos mucha vida en el exterior. Por ello, es necesario que seamos
prudentes y planifiquemos nuestras actividades tras consultar la predicción meteorológica de Euskalmet, bien en su página web o en Twitter.
Por supuesto, en caso de emergencia utilizaremos el teléfono único para emergencias, el 112 , que es además el teléfono de emergencias en
Europa. La seguridad en los desfiles de Olentzero y Cabalgata de Reyes

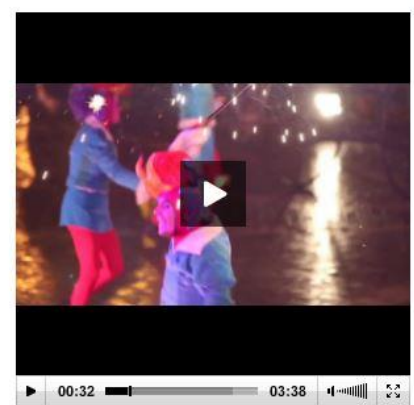

Cotillones y fiestas masivas
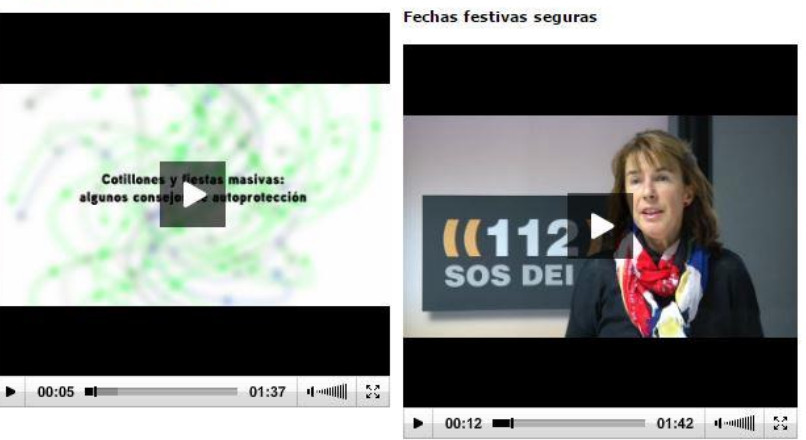

Noviemhre 2014 - Calefarrinnes

Captura de pantalla de la web de Baleares

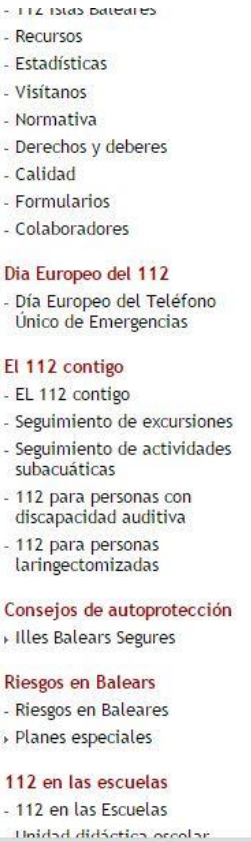

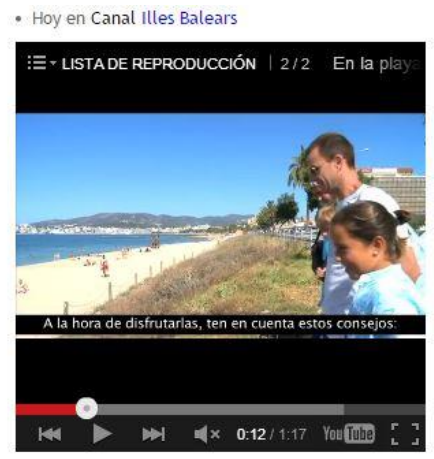

En este caso, consejos de autoprotección a tener en cuenta para ir a la playa

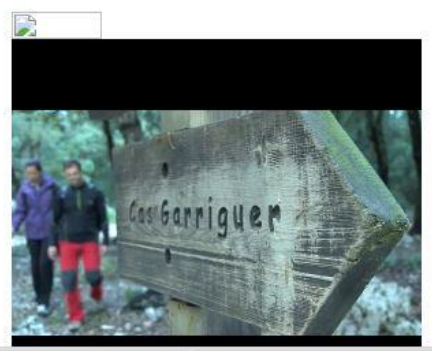


Por su parte respecto a los vídeos para niños vemos que son escasos pero los ejemplos existentes son interesantes. En estos casos el narrador o los protagonistas son niños o bien pertenecen a un universo infantil. Una muestra especialmente significativa corresponde a los dibujos animados de la campaña de Panchito, anteriormente mencionada y que pertenece a la web de Extremadura.

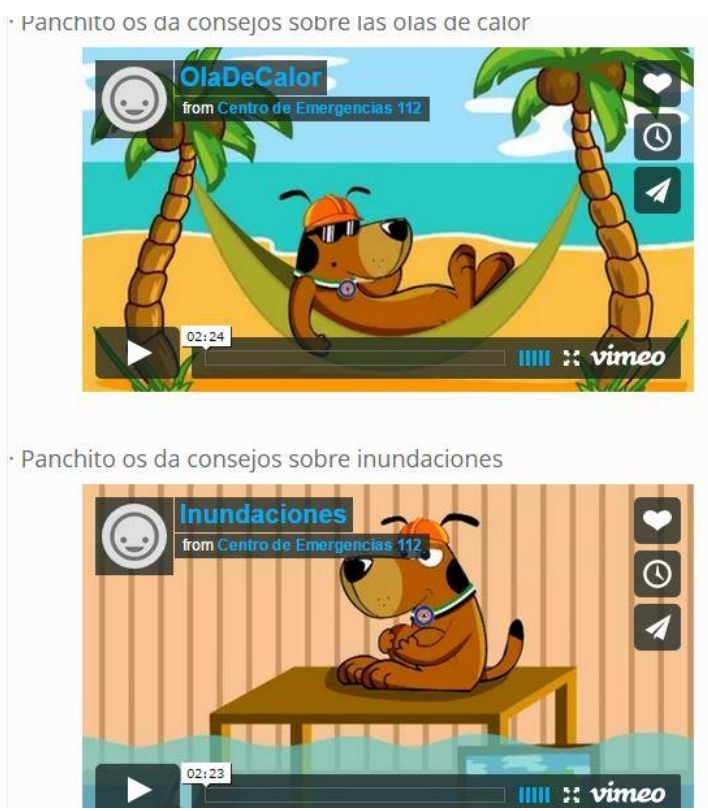

Esta serie de dibujos animados tiene características que se repiten en cada uno de los episodios.

Se inicia con una cabecera de 10 segundos. Cada episodio se centra en un riesgo: olas de calor, inundaciones, las evacuaciones de colegios, o como llamar al 1-1-2, entre otros. Cada capítulo se dedica a uno de estos temas, y su duración oscila entre los dos y tres minutos.

Pese a hacer referencia implícita a los riesgos y sus consecuencias, estos conceptos no son mencionados expresamente. Lo que hay es alusión al concepto de peligro, que se repite en distintas ocasiones en expresiones tales como "puede ser peligroso", "el agua puede ser peligrosa", etc. Tampoco se alude a conceptos como autoprotección o prevención sino a ideas como "debemos tener cuidado". Pensamos que son fórmulas para que un público de corta edad pueda comprender mejor lo que está viendo.

Otra de las características es que cada episodio se inicia con una situación de partida que remite a la tranquilidad y el orden, mostrando a Panchito ubicado en un lugar 
agradable donde se pueden realizar actividades también placenteras, cotidianas o divertidas, como una playa o un colegio. Son espacios fácilmente reconocibles entre sus públicos y que a estos les pueden resultar familiares. Tras este momento inicial, se nos advierte de que ese mismo espacio puede tornarse un lugar peligroso, mostrando que los riesgos se esconden en cualquiera de los lugares que frecuentamos habitualmente.

De nuevo se refleja aquí la idea de orden y ruptura de orden tradicional del relato clásico.
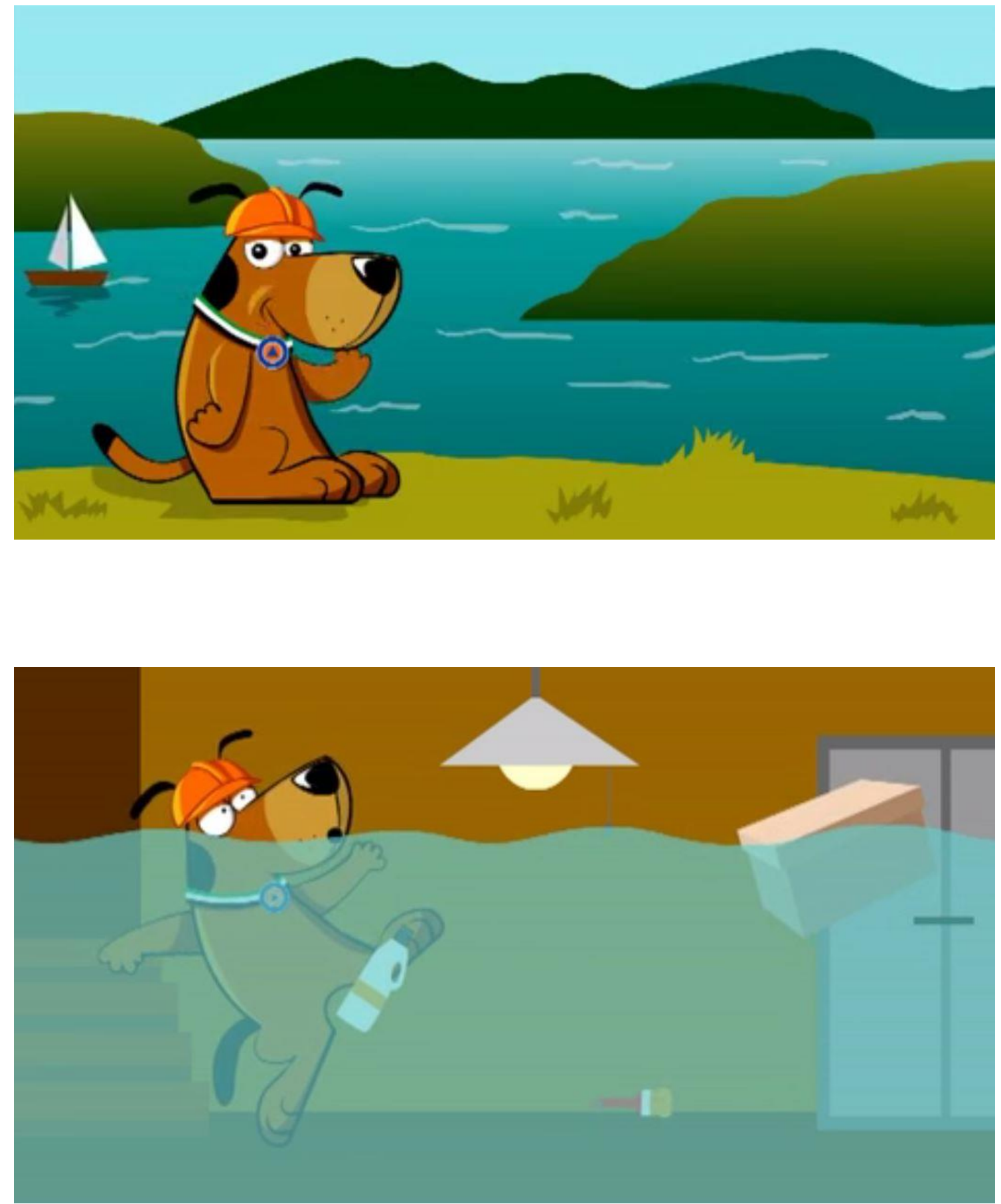
Respecto a su caracterización, Panchito lleva gorro de protección civil naranja y un collar al cuello con el escudo de protección civil, identificándose con la institución que emite estos mensajes de protección. Además en cada episodio a su atuendo se le añaden complementos ligados al tipo de situación: gafas de sol, gorro de nieve... Con ello, podemos visualizar mejor la situación en la que va a verse envuelto el protagonista, y al mismo tiempo pensamos que puede funcionar como un recurso humorístico para captar la atención de los más pequeños.

Durante todo el episodio se mantiene una música pausada y alegre, de fondo. Esto, junto a los colores vistosos, pasteles y planos de cada imagen, remiten a un universo infantil donde hasta las amenazas son tratadas desde un punto de vista positivo.

Para algunas explicaciones, se recurre a utilizar un fondo de color verde pizarra oscuro sobre el que aparecen dibujos en blanco con un trazado que recuerda a la tiza. Pensamos que el objetivo es llamar la atención del niño de forma que este reconozca que se le va a explicar algo, tal como en su vida cotidiana haría su maestro al utilizar la pizarra para explicarle la lección en clase.

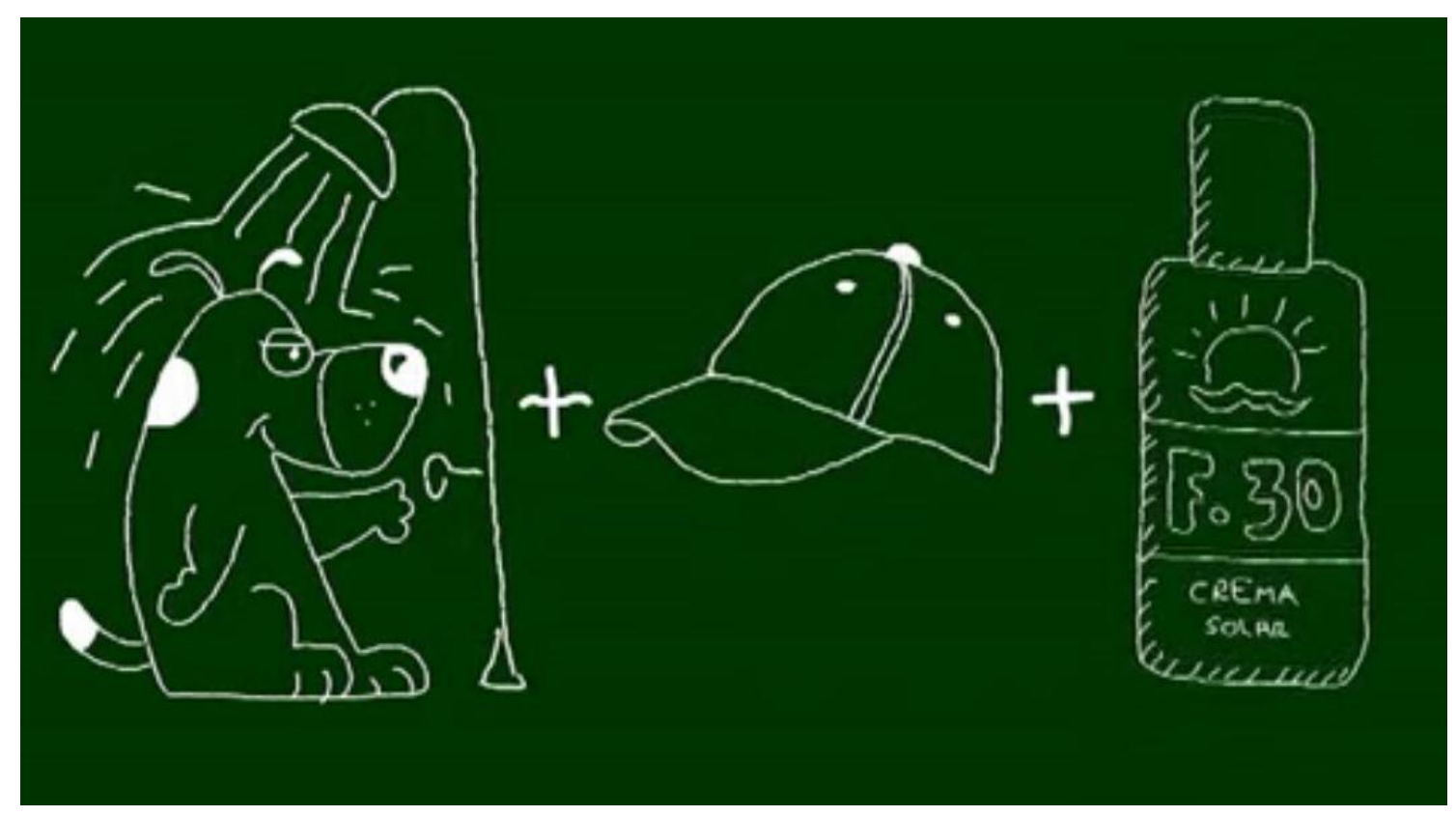

También para mantener vivo el interés del espectador, se recurre a la formulación de preguntas como ¿sabías que...? ¿y que podemos hacer si...? 
Una de las principales ideas que se plasma en cada capítulo es en la de apelar a una autoridad adulta, ya sea profesores, padres o personal de emergencias. Los adultos se representan como alguien en quien se puede confiar y a quien se ha de recurrir en las situaciones de emergencia.

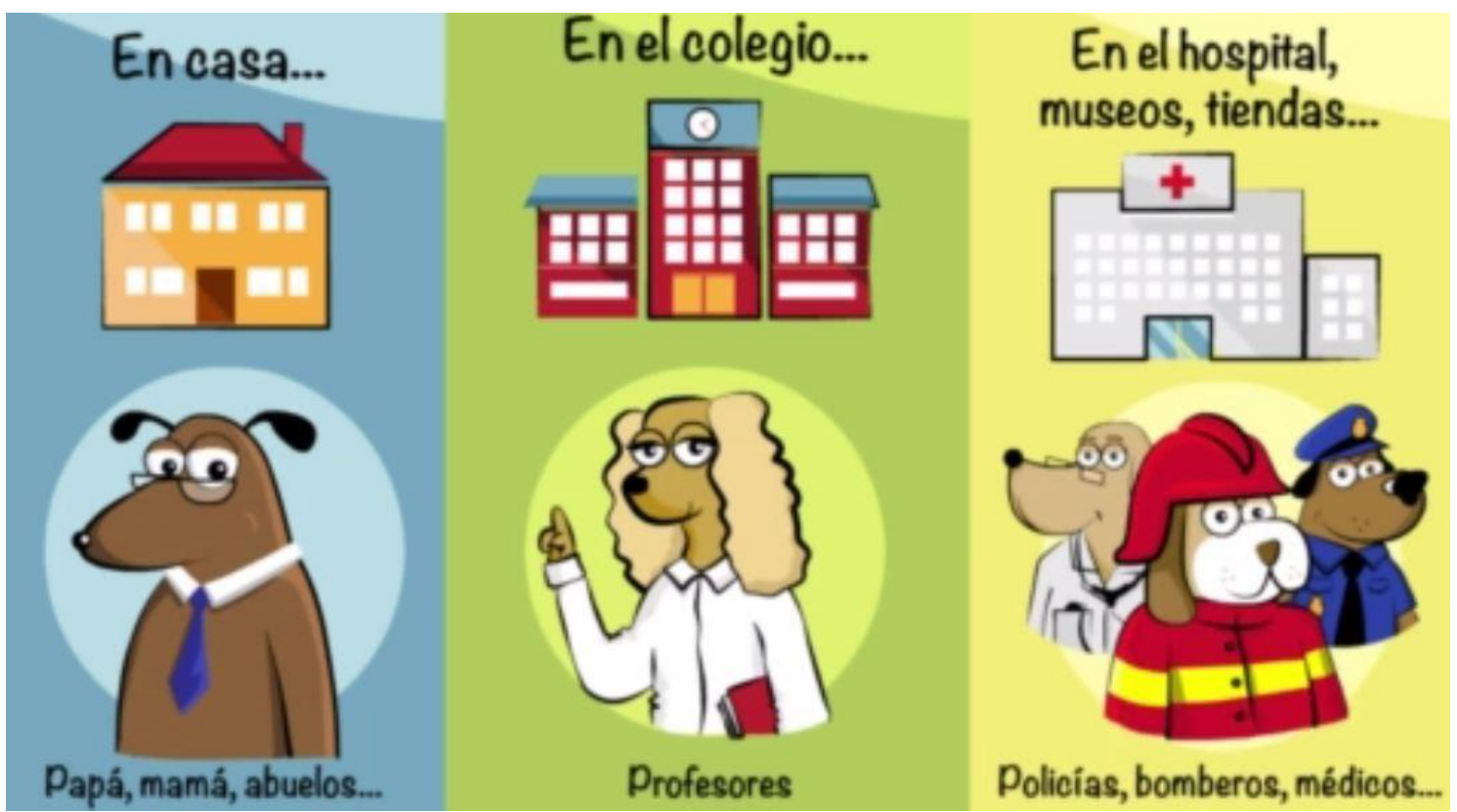

Al final de cada episodio, se recuerda la utilidad de llamar al número de emergencias $1-1-2$

En el capítulo dedicado específicamente a las pautas sobre como usar el 1-1-2 también se recuerda que este servicio telefónico no debe utilizarse innecesariamente, siendo esta una idea en la que también se insistía mucho en las webs para público general. Pero si bien allí se remarcaba que a los niños debía enseñársele que "el 1-12 no es un juego", en lo que parecía ser una reprimenda, en este episodio de la serie de Panchito se elude esa visión regañadora y se ofrecen razones sobre por qué no se puede llamar al 1-1-2. No se alude a la posibilidad de llamar al 1-1-2 para jugar, sino que se evita mencionar el posible aspecto lúdico y lo que se hace es referirse al concepto de llamadas innecesarias:

"Si ocupamos las líneas por nada, puede que alguien que está en un aprieto no pueda ser atendido". 

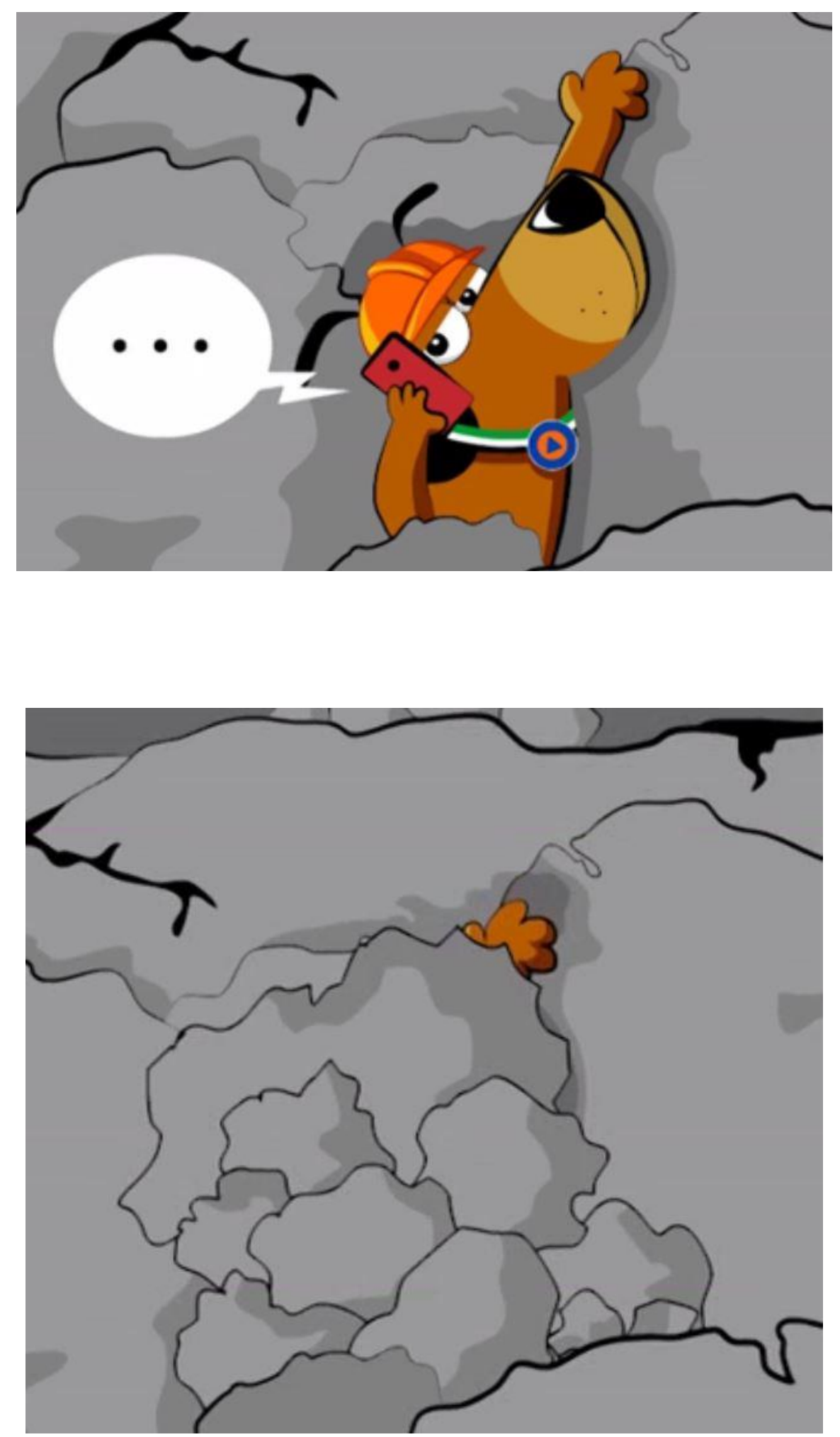
También se indica una solución si, por alguna circunstancia, estamos llamando innecesariamente al 1-1-2:

"Es una buena idea no colgar hasta que alguien conteste y decirle al operador del 1-12 que llamaste por error, porque si no la policía, los bomberos o una ambulancia pueden ser enviados donde estés para asegurarse de que todo está bien, mientras que otra persona que puede necesitar en ese momento una ambulancia, se queda sin la ayuda".

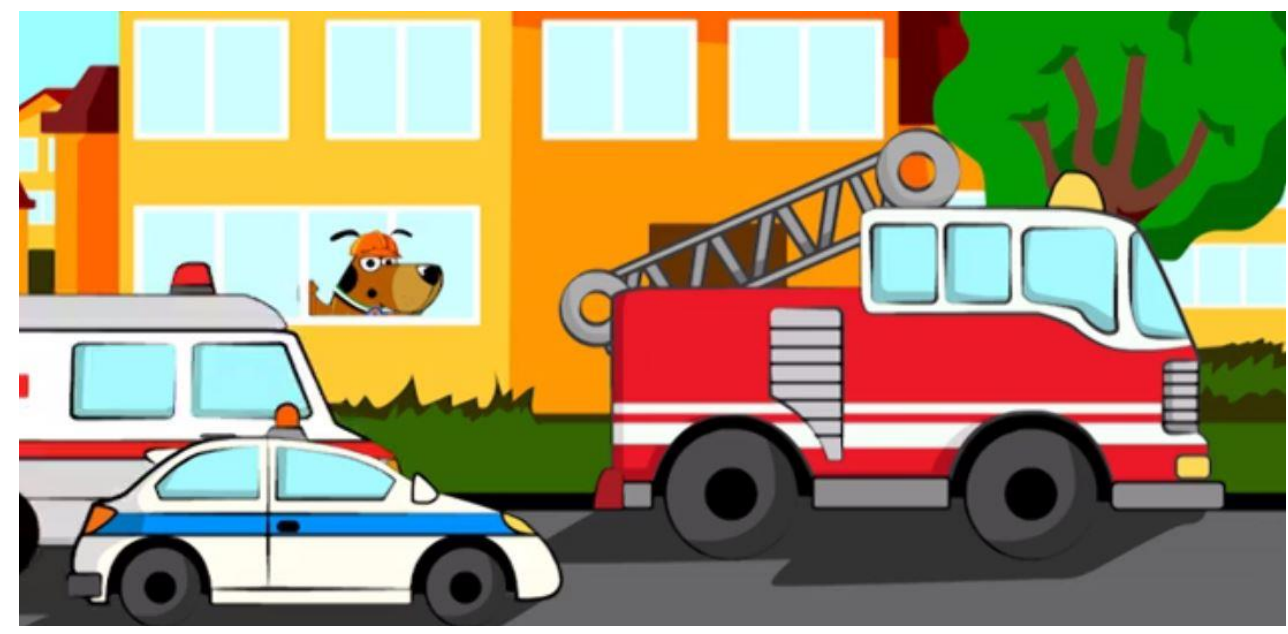

Ese enfoque va más allá de prejuzgar a los niños como personas inconscientes y traviesas que tratarán de jugar con el teléfono 1-1-2. En vez de presuponer una futura conducta inadecuada, y regañar al niño anticipatoriamente por ello, lo que se hace es explicarle las consecuencias de sus actos y cómo puede remediar la situación antes de provocar un mayor problema.

En general, respecto al uso del formato audiovisual en el conjunto de las webs, consideramos que está infrautilizado, alcanzando sólo a un $20 \%$ de ellas, y siendo, por contra, un recurso con un gran potencial.

Por una parte, el vídeo o los dibujos animados como recursos formativos son muy versátiles y adaptables a cualquier tipo de edad. Sobre el soporte escrito, consideramos que tiene la ventaja de poder alcanzar a personas que todavía no leen o no lo hacen con fluidez, como las edades preescolares o los primeros cursos del colegio, y en el otro extremo, en el de las personas adultos, ser útil para personas 
ancianas que por distintas razones puedan tener dificultades para poder efectuar una lectura (en casos de patologías de la vista o problemas de alfabetización).

Por otra parte, debido a la gran multitud actual de soportes capaces de reproducir videos (televisión, cine, teléfonos móvil, ordenadores, tablet...) y de sistemas para compartirlos (redes sociales, mensajería electrónica etc.), tiene un gran potencial de distribución y alcance.

Asimismo, los distintos lenguajes cinematográficos, televisivos o publicitarios, contienen tal variedad de riqueza de recursos narrativos, que una adecuada selección de estos con la finalidad de incorporarlos a productos audiovisuales destinados a la prevención de riesgos y emergencias, ofrecería un abanico de posibilidades muy amplio para diseñar contenidos adaptados a audiencias y públicos concretos. Consideramos que en el caso español actualmente se trata todavía de un terreno relativamente inexplorado, que podría ofrecer resultados muy interesantes.

\subsubsection{RESUMEN DE CONCLUSIONES}

-Hay diferencias marcadas en las webs niños-adultos, tanto en los contenidos como en los formatos.

- Tipo de representación que se hace de los niños:

*Capaz: puede aplicar pautas autoprotección, dar avisos mediante llamadas al 1-1-2...

${ }^{*}$ Confia en los adultos

*Transmisor en la cadena del conocimiento

*Por otra parte, sobre todo en las webs para adultos, también aparecen otras representaciones de los niños: por una parte como potenciales víctimas y, por otra, como causantes de situaciones de emergencia.

-Los formatos como juegos y cómics y pósters son de los más habituales y donde más se percibe una mayor adaptación a las características del público infantil y juvenil. 


\subsubsection{OTROS EJEMPLOS: WEB DE LA AGENCIA FEDERAL PARA EL CONTROL DE LAS EMERGENCIAS DE ESTADOS UNIDOS (FEMA)}

Durante los últimos años, la Agencia Federal para el Control de las Emergencias, de los Estados Unidos (FEMA), ha ofrecido también a través de su página web diversos materiales dedicados a la formación de sus ciudadanos más jóvenes. Una revisión a dichos materiales permite encontrar similitudes con algunos de los contenidos y formatos que hemos analizado en el caso español, aunque también detectar diferencias de las que vale la pena extraer sus aspectos más interesantes.

Hay que mencionar que los distintos materiales son accesibles y pueden descargarse tanto en inglés como en español. Es por ello que en la recopilación de los distintos ejemplos aparecerán casos de ambas lenguas.

Ofrecemos algunas de las muestras de estos materiales que la FEMA ha ofrecido durante los últimos años.

Descripción de los materiales:

-Be a Hero: Colección de recursos en los que los protagonistas son una pandilla de adolescentes que a través de cómics y juegos nos explican cómo actuar ante determinadas emergencias.

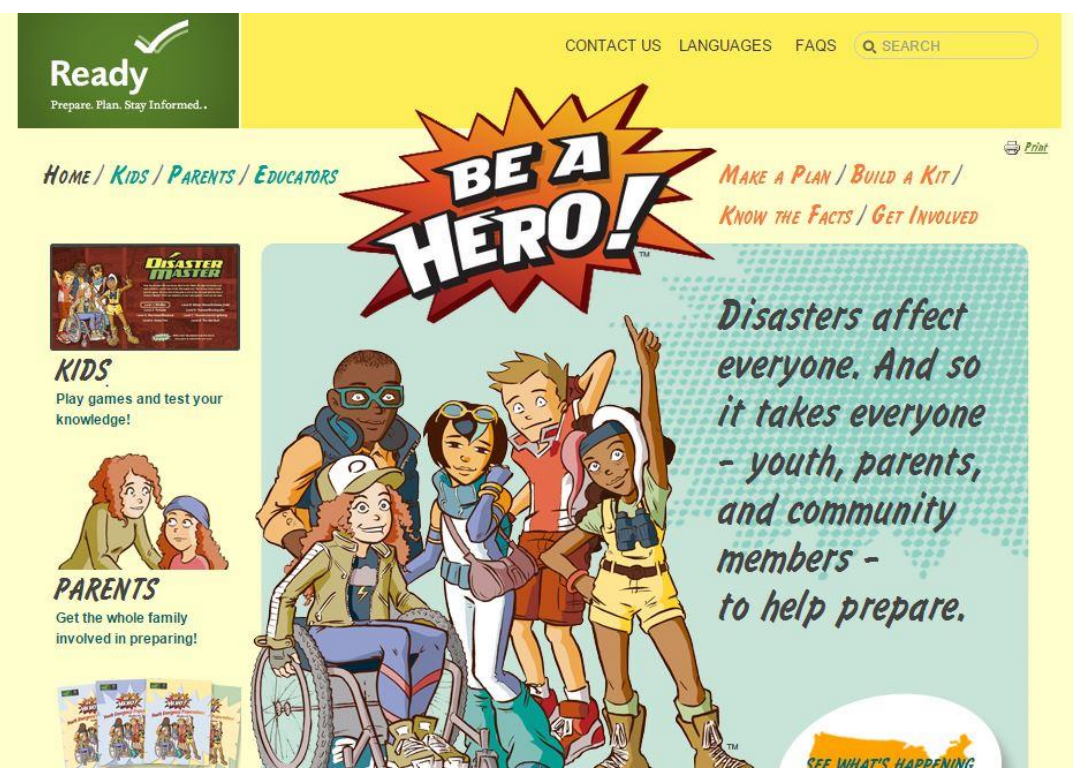


-Familia Puma: Colección de materiales formados por cómics, pósters, juegos y cuadernos de actividades protagonizados por una familia de pumas.

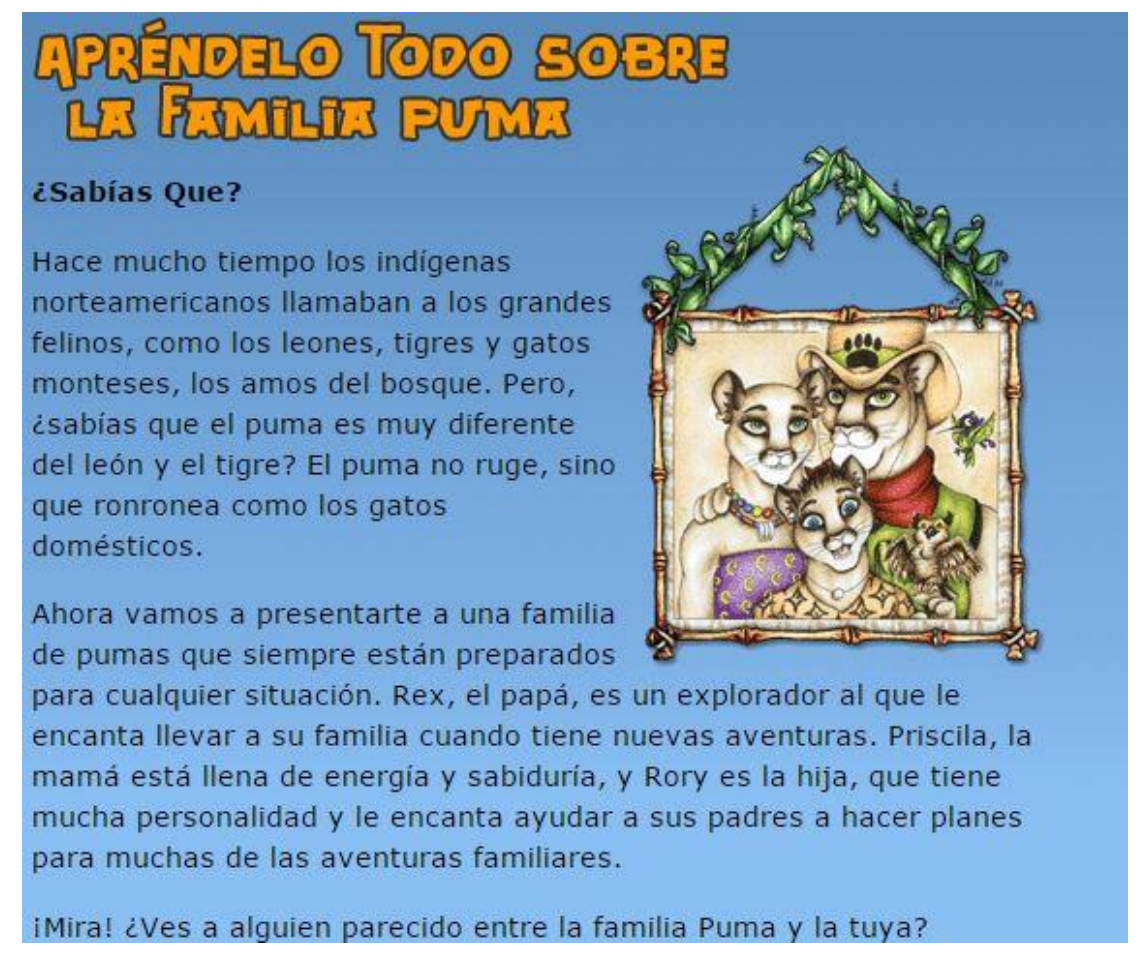

-Let's get ready-Sesame Street.

Colección de videos para niños de edad preescolar en la que los famosos personajes de Barrio Sésamo enseñan a los más pequeños la importancia de conocer aspectos como su nombre o su dirección, o qué productos debe incluir una mochila-kit de emergencia. Lo hacen a través de vídeos donde aparecen niños y también los famosos muppets, para mostrar temas sencillos que los más pequeños de la casa pueden llegar a comprender, como memorizar bien su nombre y su dirección, ayudar a preparar junto a sus padres un kit de emergencia, o descubrir que los bomberos o los médicos son un aliado en quien confiar.

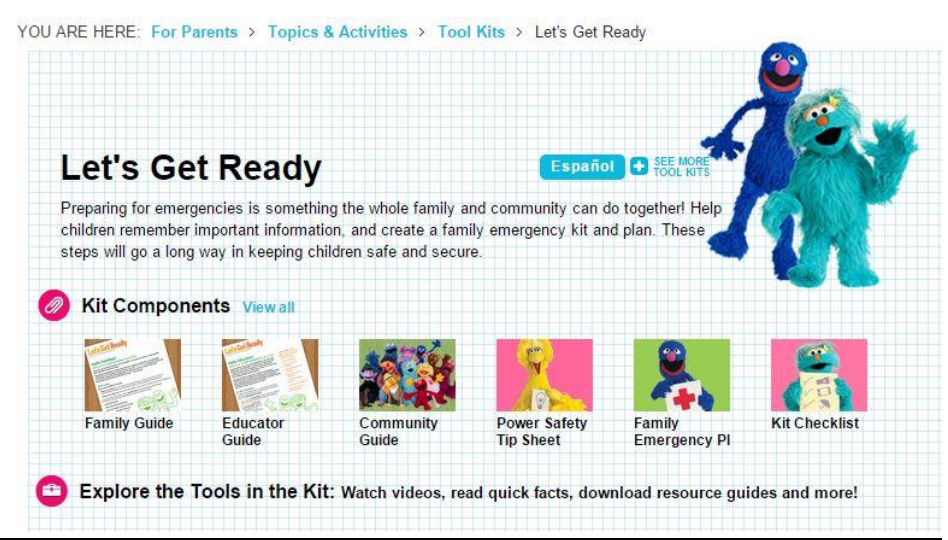




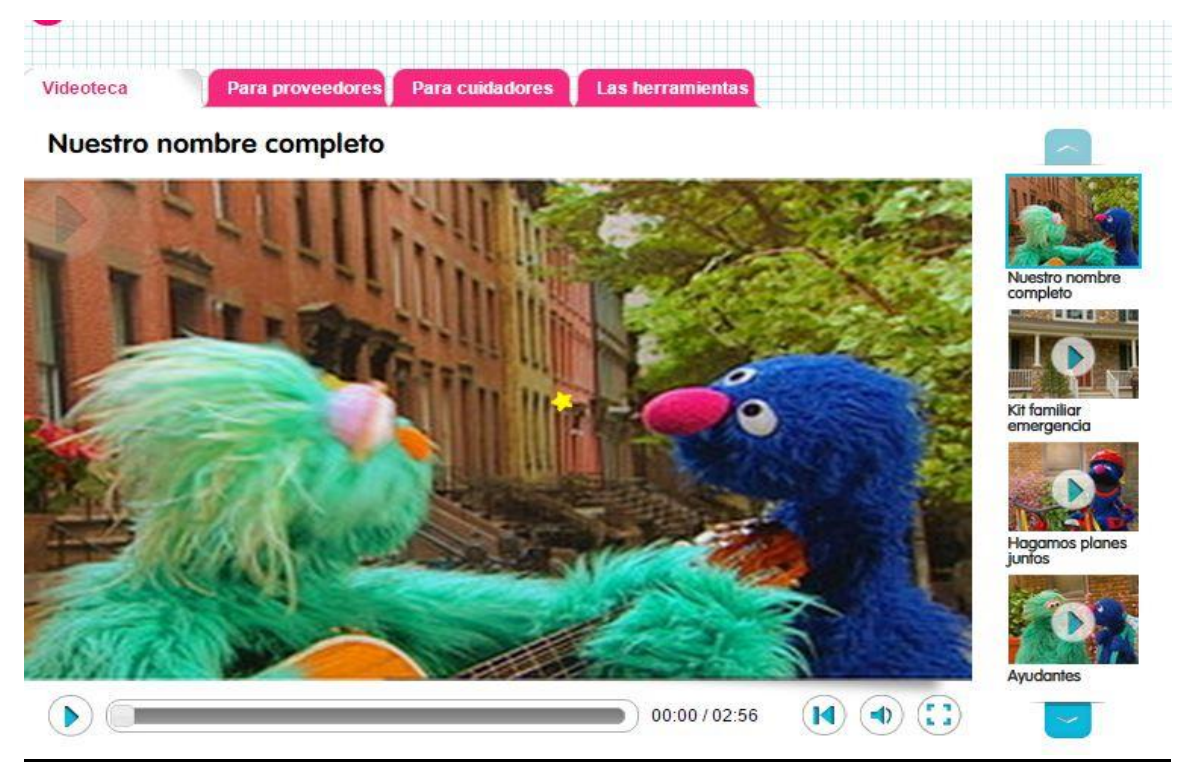

$\underline{\text { Similitudes con los materiales españoles }}$

En aquellos materiales en los que existe una narración, también se parte de una situación inicial en la que se produce un cambio que va del orden al desorden. Una situación ideal inicial se ve interrumpida por la aparición de un peligro.

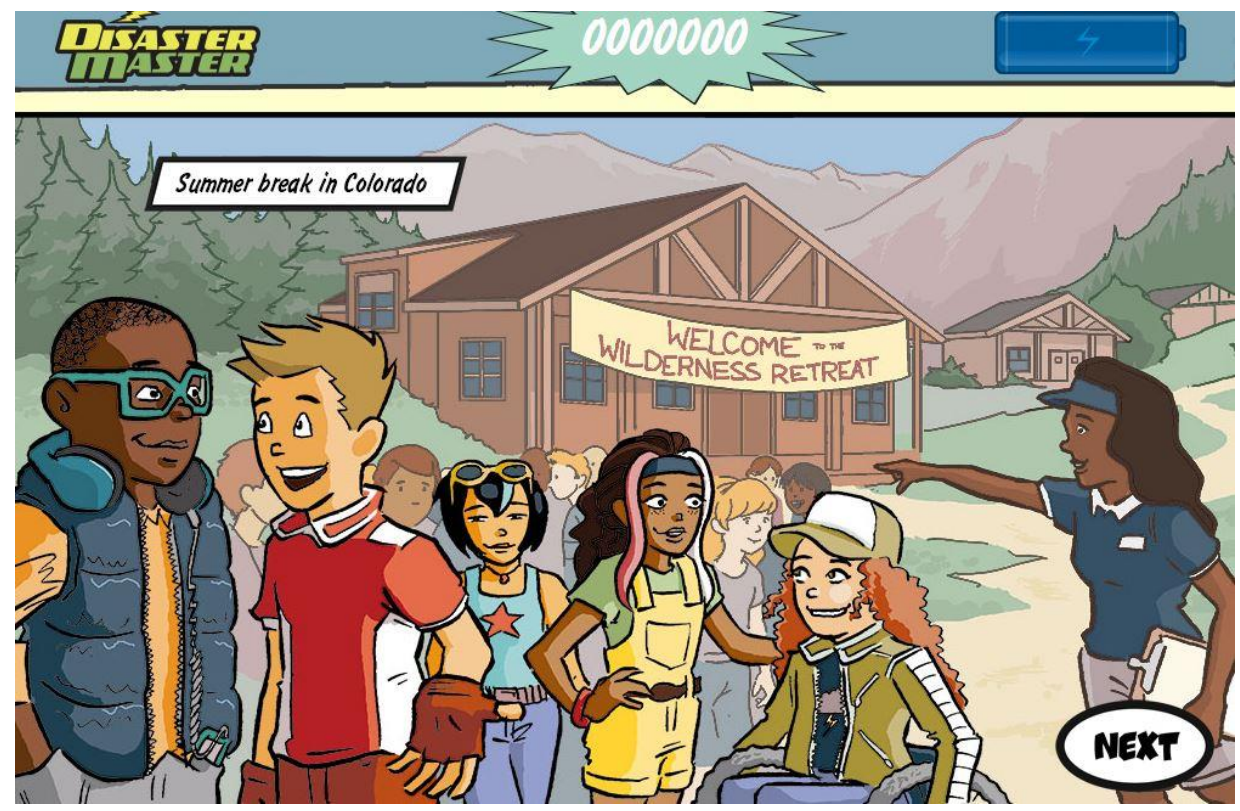




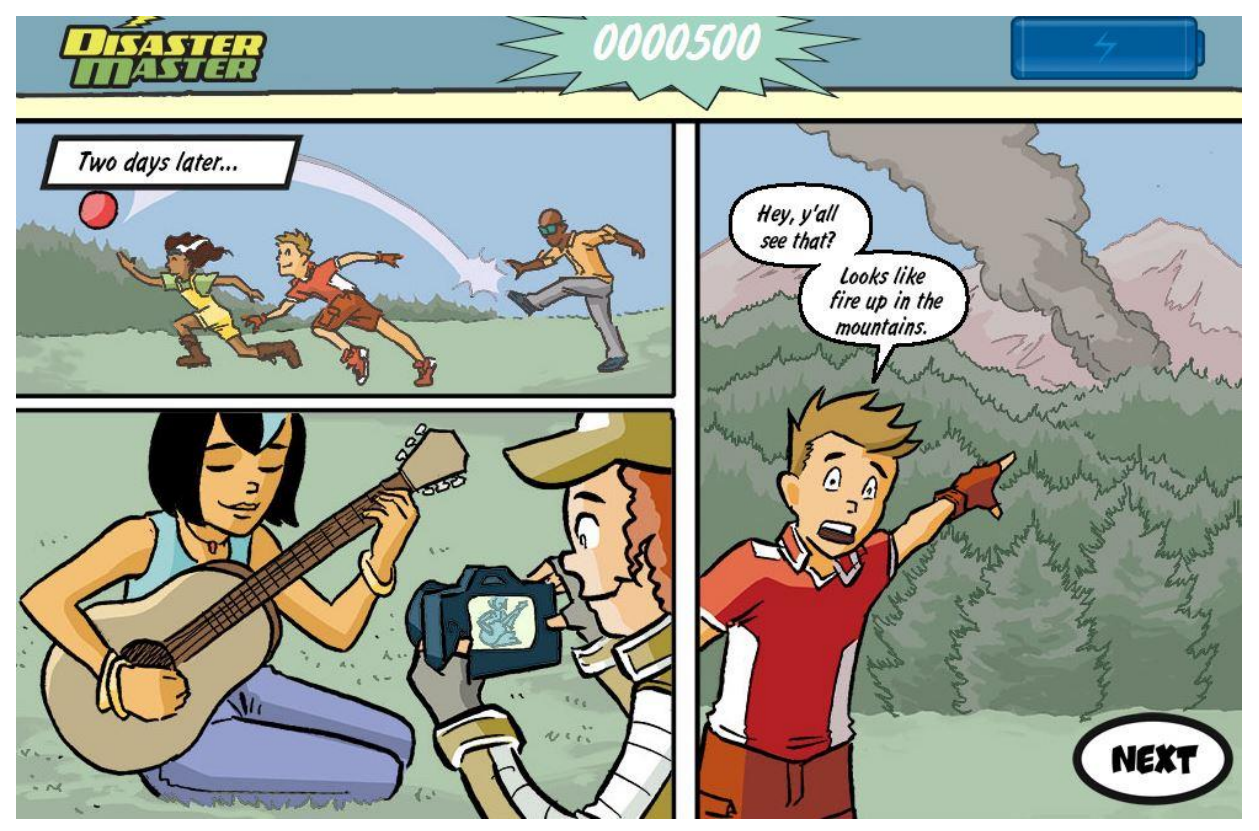

Respecto a la tipología de formatos utilizados, también hay algunas semejanzas. Coinciden en hacer uso de los juegos, de los cómics y de los folletos. Enumeramos a continuación algunos ejemplos de juegos de la FEMA:

-Juego de niveles en "Be a Hero". Se trata de ir respondiendo un cuestionario y, como curiosidad, es una mezcla de muchos recursos: compruebas tus conocimientos, es interactivo, y a medida que vas superando fases y contestando preguntas vas leyendo un cómic.

Tanto el cómic de "Be a Hero" como el de la "Familia Puma" son una muestra de cómo a través de los cómics se pueden transmitir conocimientos sobre los riesgos y emergencias y sobre cómo preparse ante ellos.

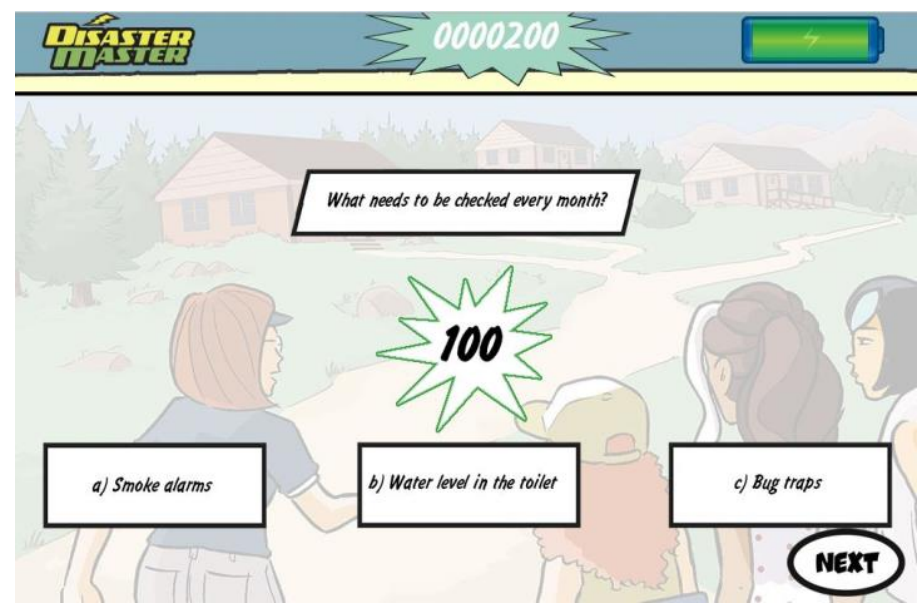


-Juego de niveles en "Be a Hero" para preparar un kit de emergencia. Vas superando niveles a medida que superas adecuadamente las pantallas. Está protagonizado por una chica discapacitada.
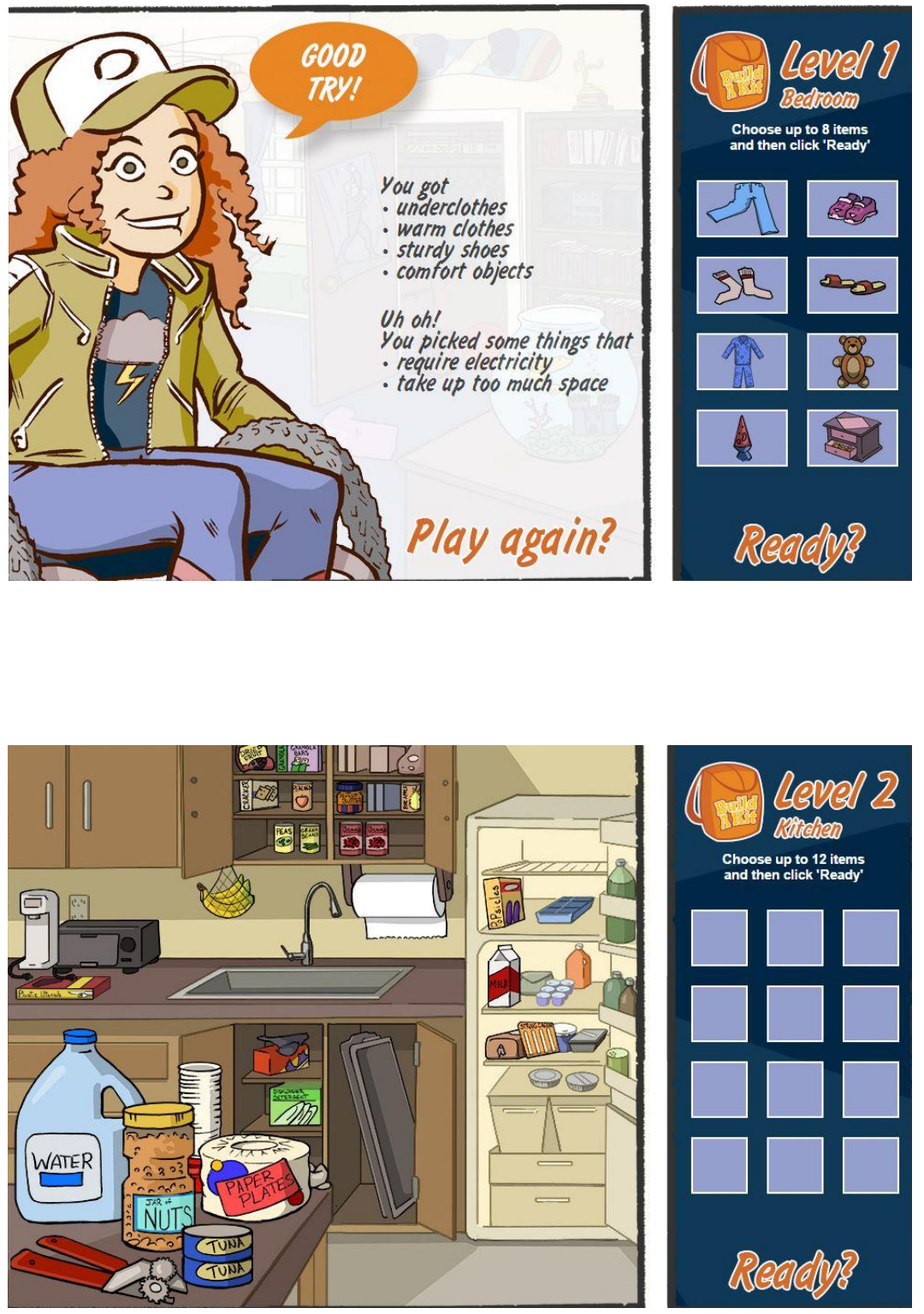

-En la "Familia Puma", por su parte, hallamos juegos en los que hay que buscar tesoros que nos sirvan para preparar nuestro kit de emergencia, o realizar sopas de letras o crucigramas. 


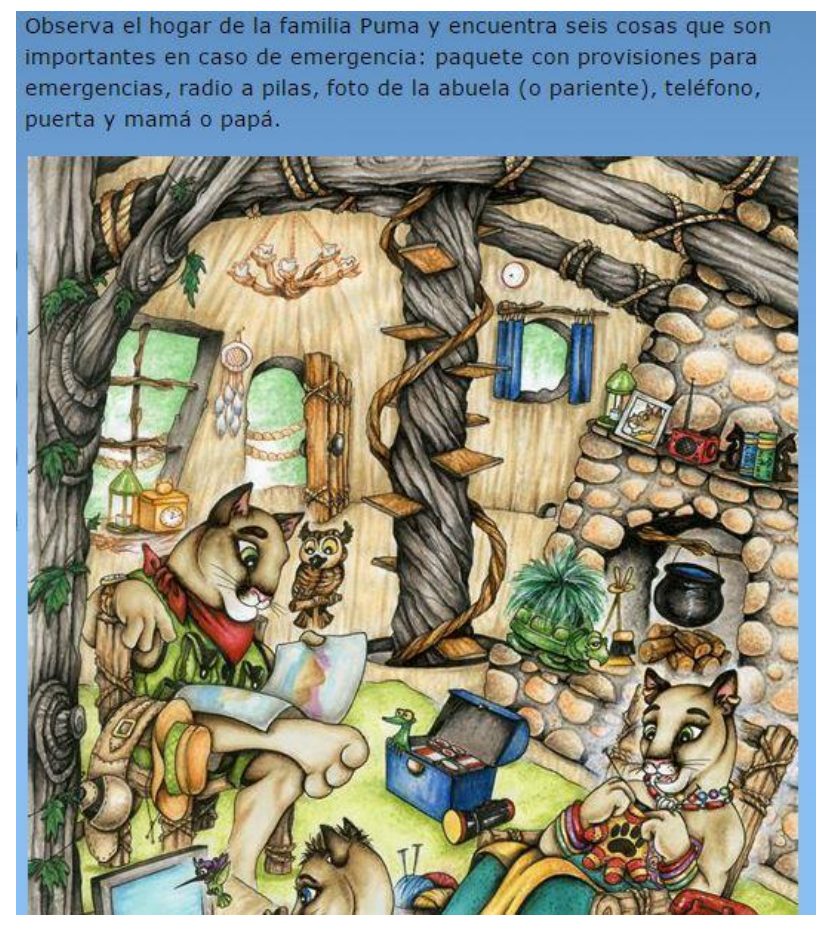

Diferencias respecto a los materiales españoles

En el caso estadounidense, se realiza una introducción de la figura de la discapacidad en el ámbito de la preparación ante emergencias, ya que una de las principales protagonistas de $\mathrm{Be}$ a Hero va en silla de ruedas. La figura de la discapacidad no sólo aparece en estos materiales destinados a un público adolescente, sino que también podemos hallar otras referencias en otras secciones destinadas al público general en la web de la FEMA.

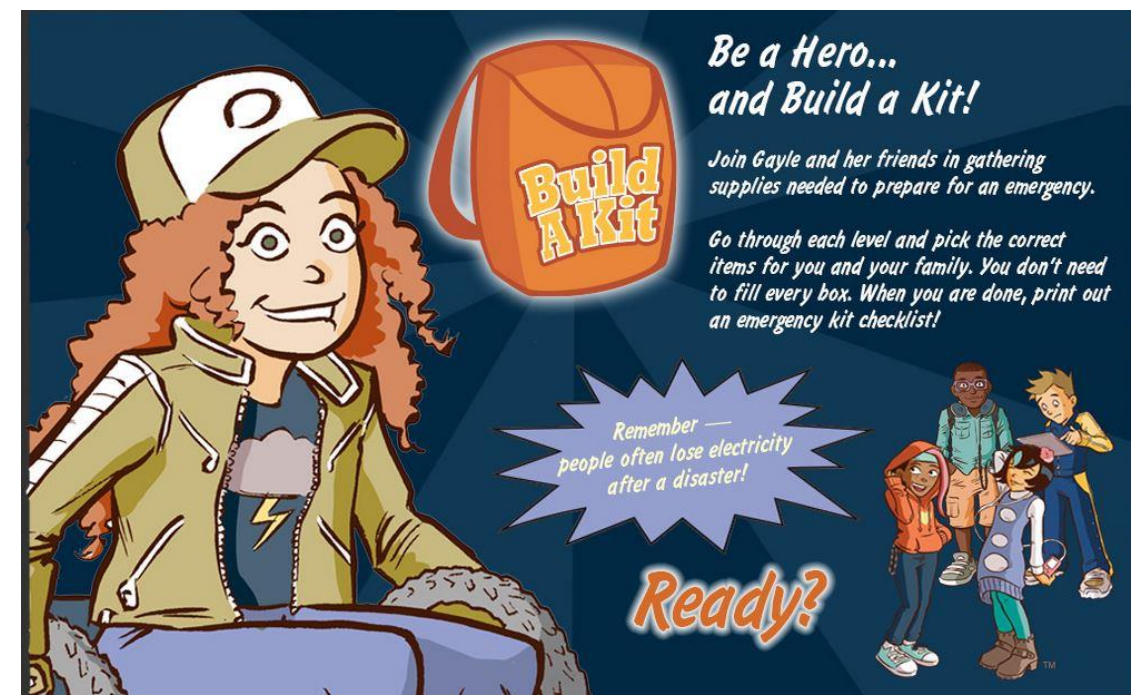


Otra de las diferencias es la edad del público, ya que se han llegado a crear materiales expresamente para preescolares, como la colección de Sesame Street.

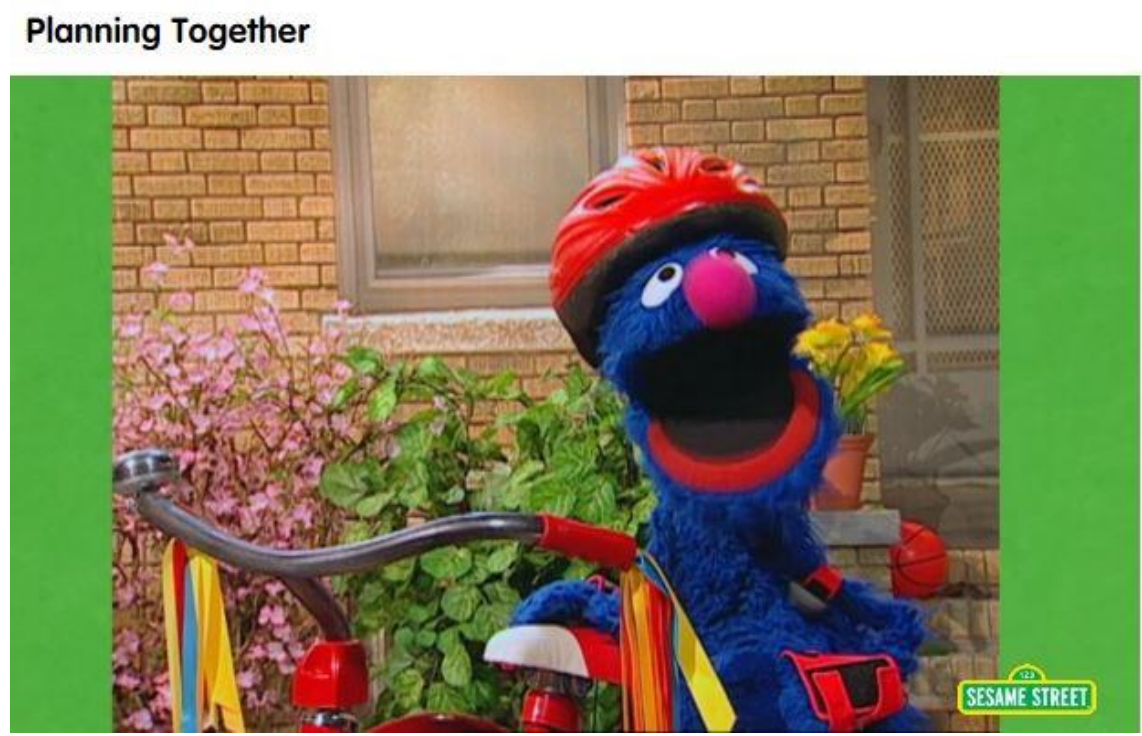

También es un rasgo distintivo el hecho de que en lugar de utilizar listados o explicaciones largas sobre un fenómeno o recomendación, el contenido puede aprenderse a través de juegos que se traducen en un sistema de aprendizaje basado en la prueba-error. En los juegos no se trata de "ganar" o "perder", sino de intentarlo de forma que aunque se falle ni se penaliza, ni se juzga negativamente el error. Por ejemplo, en $\mathrm{Be}$ a Hero se ha de aprender a preparar mediante un juego un kit de emergencia. Si fallas se te indica "Buen intento. ¿Lo intentas otra vez?”, indicándole al participante por qué estaba bien lo que había hecho bien, y cuáles eran los problemas que ofrecían sus actuaciones erróneas. 


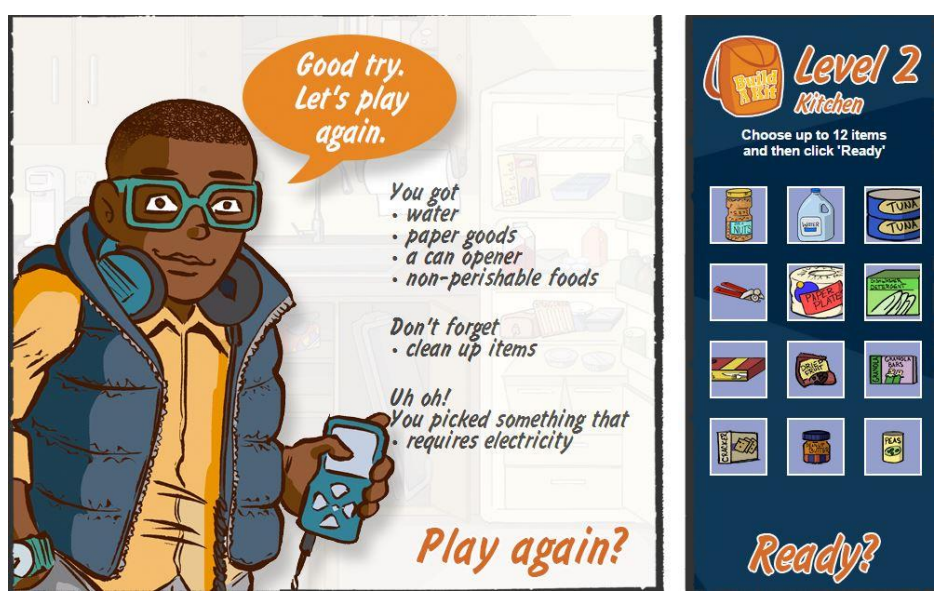

Respecto al tipo de contenidos difundidos, se insiste mucho en la preparación de un kit de emergencia. Pensamos que esto está relacionado con una mayor existencia en territorio estadounidense de desastres de grandes dimensiones, donde las inundaciones o los huracanes, por citar dos fenómenos, pueden dejar a los ciudadanos sin vivienda durante días o meses.

En esta imagen de los vídeos de Sesame Street, una pequeña niña coge una linterna de emergencia de una estantería del supermercado para colocarla en el carrito de la compra

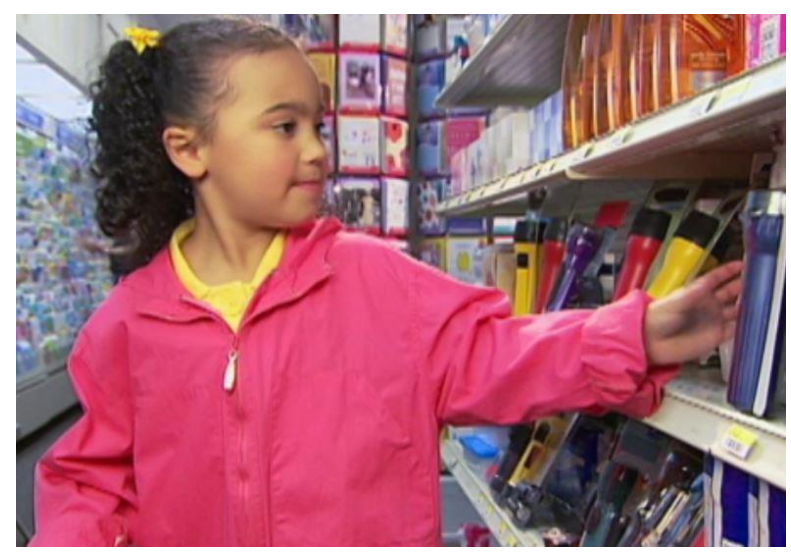

Se detecta también que los materiales incluidos en las secciones infantiles no están dirigidos sólo a niños. Así, hallamos contenidos en la sección infantil que están indicados para padres y profesores y para que estos los trabajen en clase con sus alumnos. 

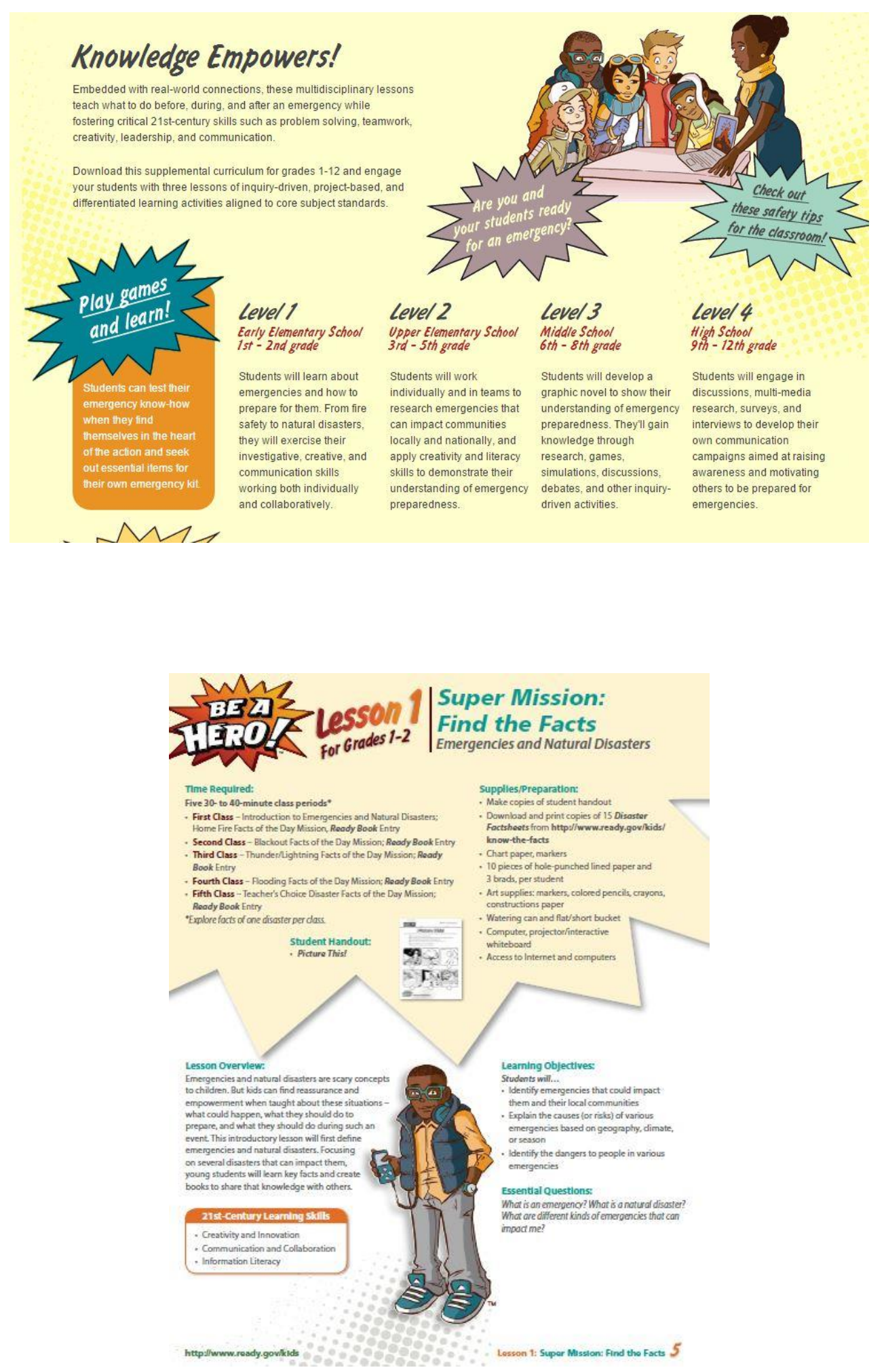

También existen materiales para que sean los padres los que aborden estos temas en casa con sus hijos. Es el caso de esta guía para padres de Sesame Street. 


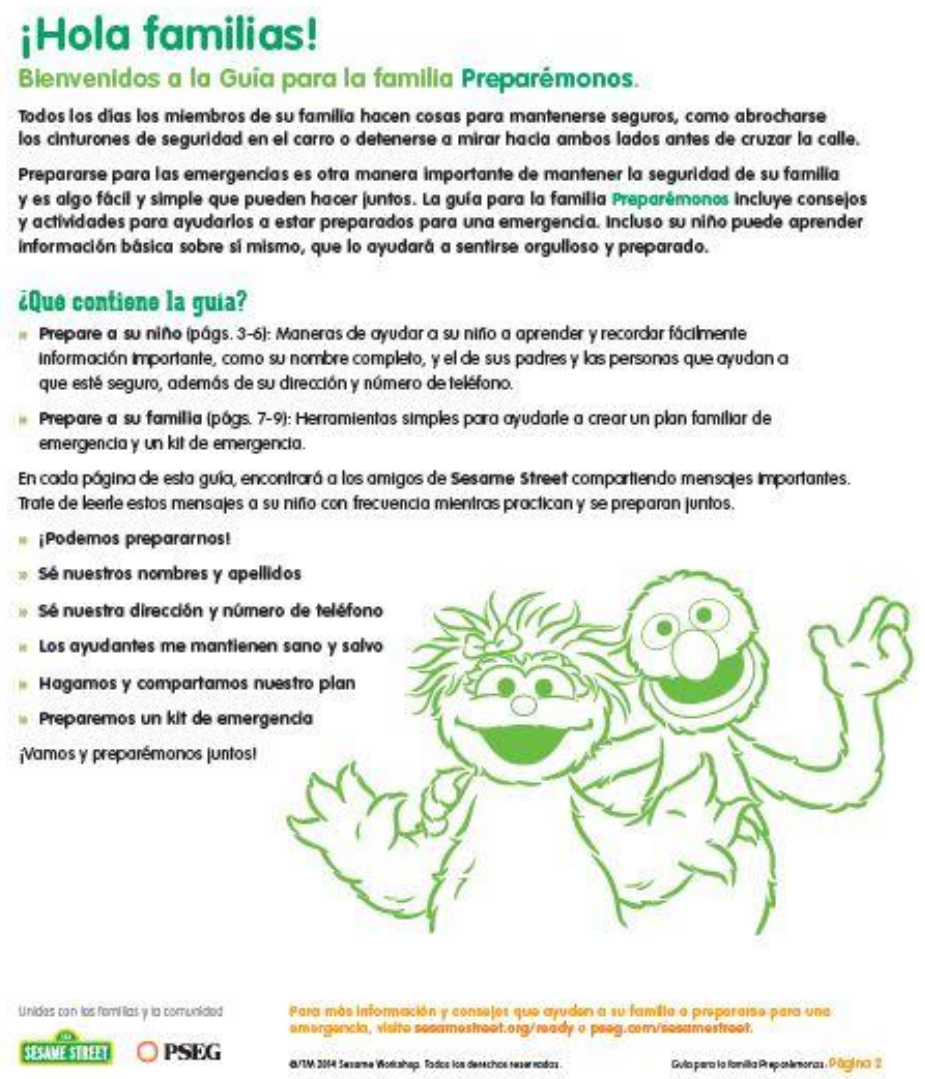

Por otra parte, en algunos de los materiales de la web infantil, ya sea un material para niños o bien esté destinado a los padres y profesores, se abunda en la idea de que estar preparado es cosa de todos, y que es recomendable compartir con toda la familia el material ofrecido en estas webs. Incluso se invita a llevar a cabo en el hogar juegos y actividades que pongan en práctica algunos de los conceptos allí aprendidos. Actividades como la preparación de un kit de emergencia, o la realización de juegos de role-play sobre como actuar durante un desastre.Tareas en las que puedan participar todos los miembros de la unidad familia.

Se insiste en el concepto de un trabajo conjunto, de tareas a compartir, y de la idea de que durante una emergencia o desastre, uno de los aspectos clave va a ser el reencuentro con los miembros de la familia. 


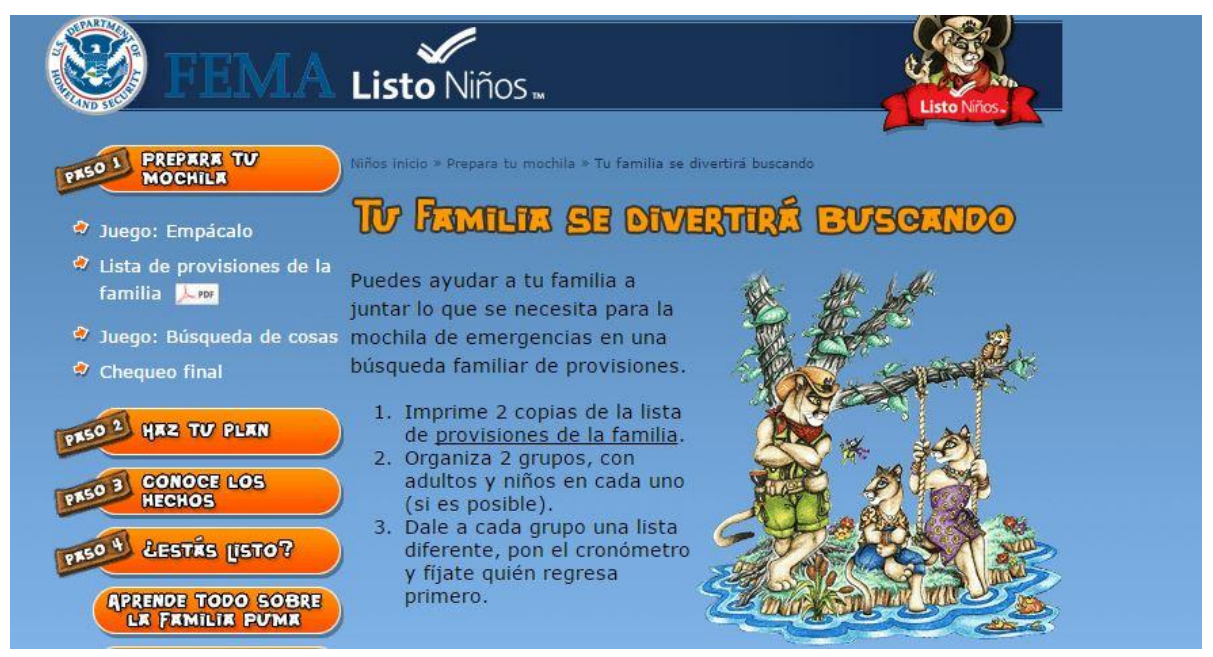

Esta idea está respaldada por diferentes estudios sobre los procesos y las reacciones de las familias durante una situación de emergencia. Como hemos visto en capítulos previos, diversos estudios en investigación social de desastres han destacado que la familia tratará de estar unida o bien de reencontrarse, y de que la principal fuente de información en quienes la gran mayoría de nosotros va a confiar va a ser en su propia familia.

Por eso uno de los contenidos en los que más se insiste a lo largo de estos materiales ofrecidos en la web de la FEMA es en cómo preparar un plan de comunicación en situaciones de emergencia, para poner estar en contacto durante esas situaciones. Un plan que siempre proponen que se plasme por escrito y que se dé a conocer a todos los miembros de la familia.

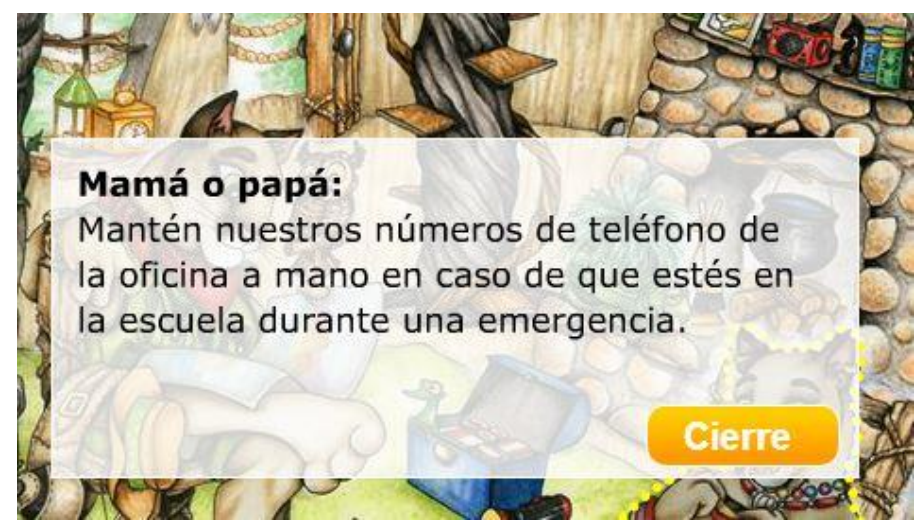




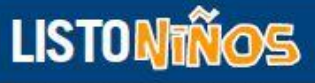

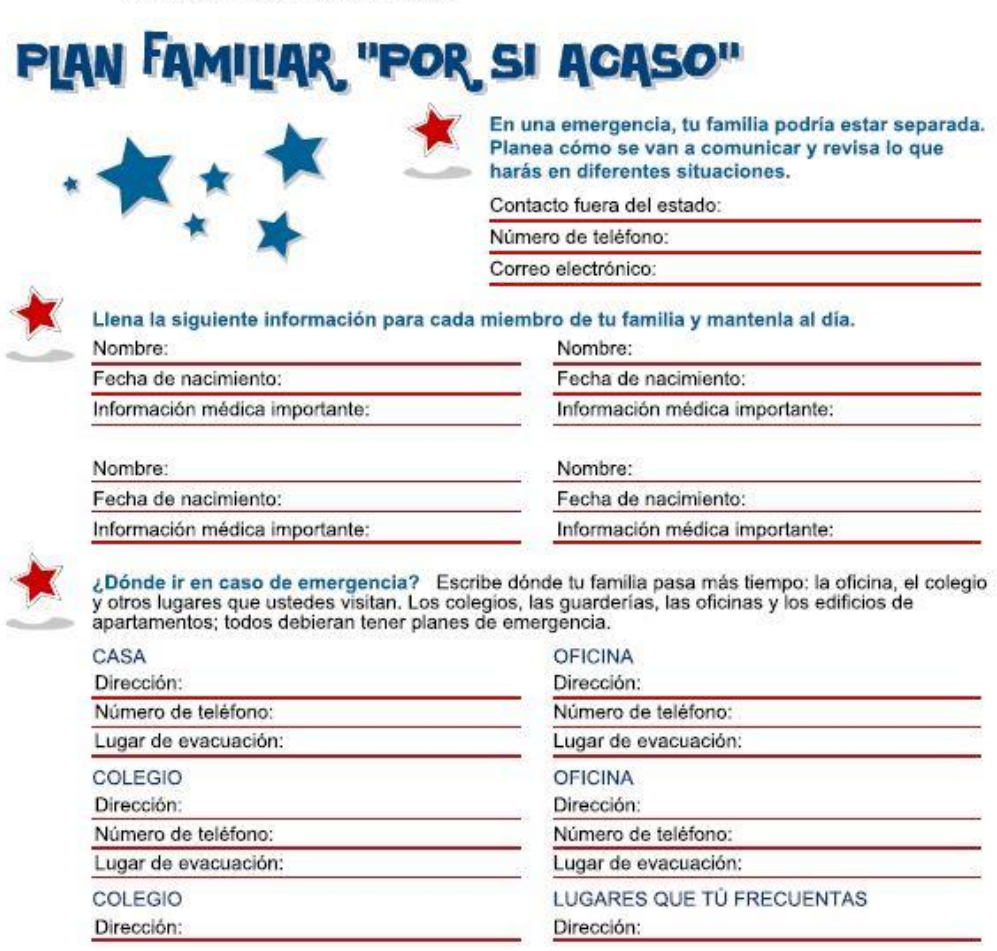

Al igual que en las webs infantiles españolas, no hay tendencia a utilizar listados y de hecho, en el caso estadounidense son inexistentes. Los contenidos que han de desarrollarse de una forma más extensa se presentan de una forma amena utilizando varias fórmulas.

Por ejemplo, la sección Know the facts está compuesta por unas pocas ideas, visualmente bien ordenadas y atractivas, y que finalizan con un breve test de tres preguntas para tomar conciencia de lo que hemos aprendido. Así lo vemos en esta ficha destinada a conocer mejor las situaciones y consecuencias derivadas de un gran apagón. 


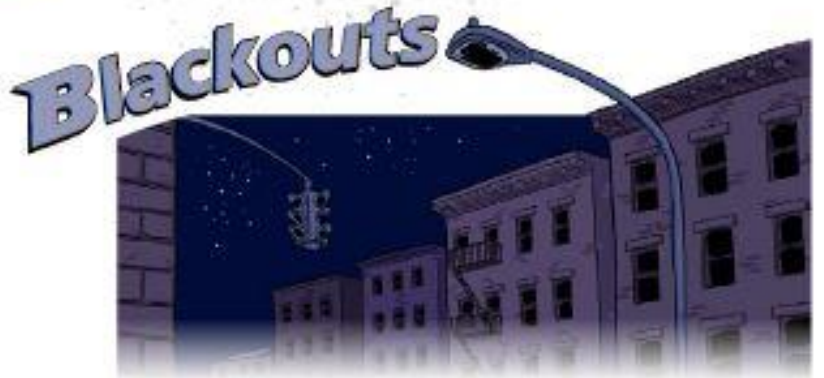

Blsckouts are a loss of power to an ares. They could be due to problems at power stations. damage to equiprrent, or the averuse of energy in a particular ares - like during a heat wave if everyone runs an air conditioner on high al day and night. We don't realine how dependent we are on power until we ore without it. Power affects the electricity we get in our homes, as wel as the water supply and transportation systems - from traffic lights to sirplanes.

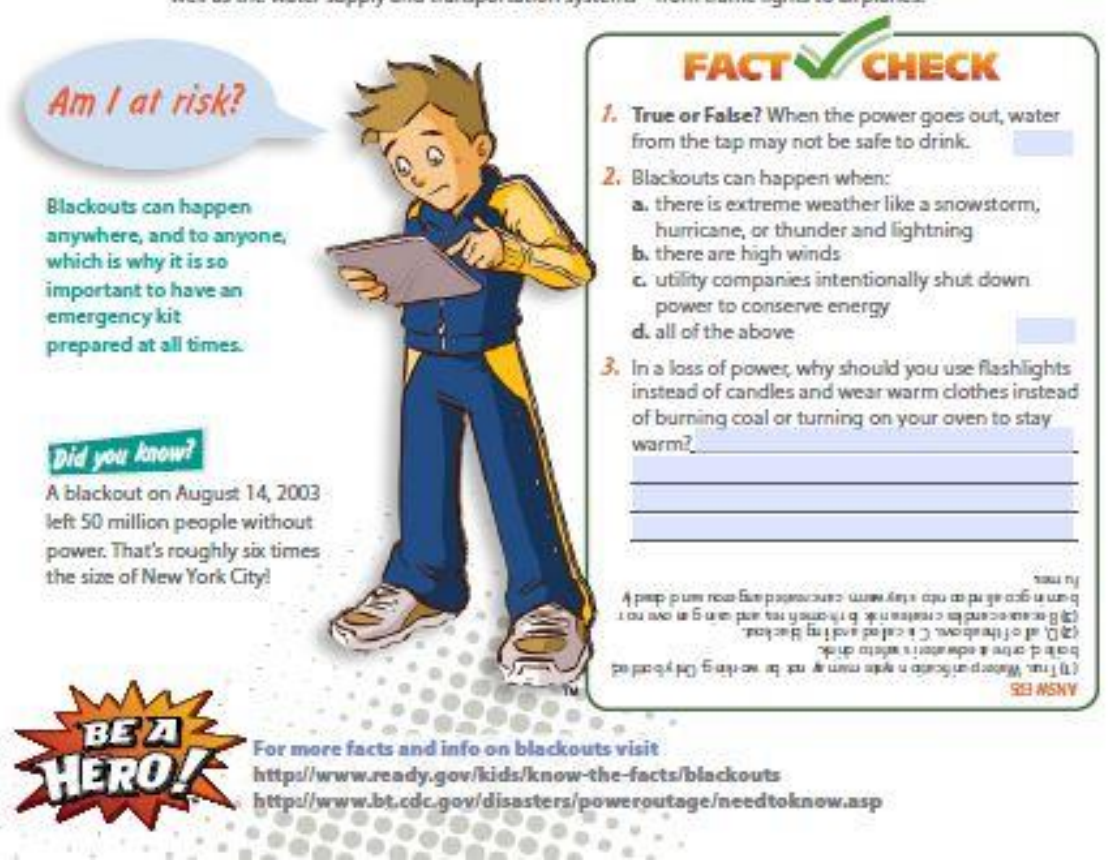

Otro de los ejemplos lo encontramos en la forma en que se aconseja a los padres sobre cómo comunicarse con sus hijos en una situación de emergencia. Este ejemplo es doblemente interesante. Por una parte, proporciona información útil basada en estudios psicológicos sobre como tranquilizar e informar a los niños antes, durante y después de una situación de emergencia.

Por otra, en vez de ofrecer estos datos a través de un largo listado de informaciones y consejos, se plantea como un buzón de consultas de padres a un grupo de expertos psicólogos. Esto hace que la acción de leer esta información sea mucho más amena. Es una fórmula bastante visual, y que transmite mayor viveza y proximidad, ya que no estamos leyendo una información general sino trata de mostrarse como personalizada 
en personas concretas y sus casos concretos. Pensamos que esta personalización contribuye a favorecer la memorización de la información.

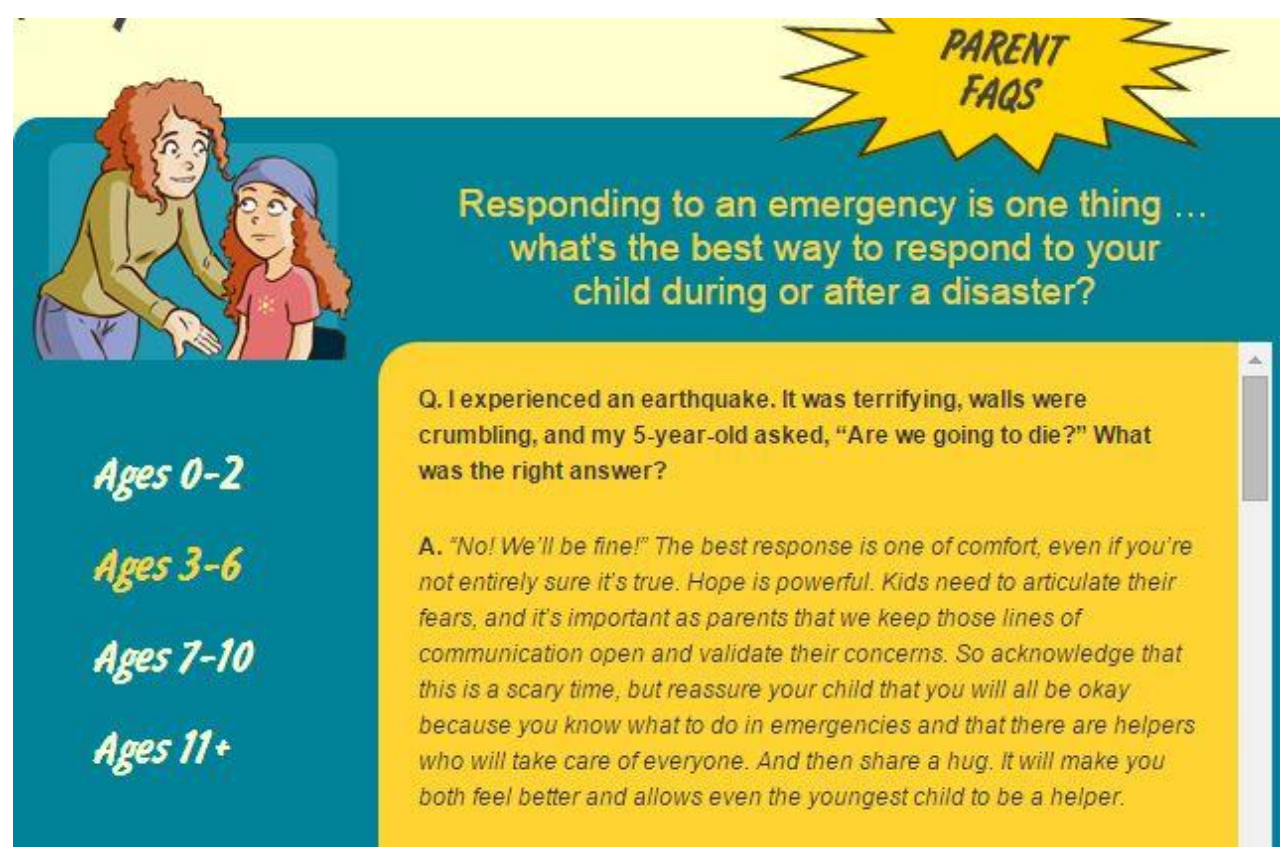

\section{in Cope}

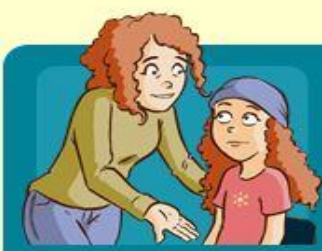

Responding to an emergency is one thing what's the best way to respond to your child during or after a disaster?

Ages 0-2

Ages 3-6

Ages $7-10$

Ages 11+
Q. There's a winter storm warning in effect and all we hear about on TV and the radio is "The Blizzard of the Century." My kids are getting scared. Any advice?

A. Turn off the TV. This advice holds true for children of all ages. Unless you need to see coverage of a storm for safety reasons (in which case, try not to do it in view of children) turn off the TV and radio. This is especially true after a disaster when scary images may be shown repeatedly. Young children may think the event is happening over and over and this can be terrifying. Instead, empower kids by enlisting their help to prepare for the storm. Have them gather warm blankets, or check on the pet's food. Giving them a job helps them feel in control, which reduces their anxiety. 
Otra de las principales características es que a lo largo de estos años se ha involucrado al mundo del espectáculo en la tarea de formar a la ciudadanía, en este caso a los niños, en aspectos como la prevención de emergencias. Siempre se ha tratado de tipos de espectáculo vinculados a unos determinados valores educativos, como es el caso de Sesame Street. Los valores añadidos de Sesame Street (alegría, educación, igualdad, aprendizaje, amistad) se trasladan en este caso al ámbito de la preparación ante las emergencias.

La familia Puma es otro de los ejemplos relacionados con el mundo del espectáculo, ya que sus ilustraciones están creadas por una dibujante de Disney, a quien también se le asocian valores positivos como inocencia, lucha contra el mal, o transmisión de moralejas, entre otros aspectos.

En resumen, hemos visto que en la web estadounidense se incide en algunos aspectos que no son tan abordados en las webs españolas, hablando en términos generales. Son aspectos como la importancia de prepararse en familia ante las emergencias, la necesidad de tener un plan para poder comunicarte con tus familiares, la introducción de la figura de la discapacidad, el recurso al mundo del espectáculo... Creemos que estas diferencias están en parte relacionadas con factores sociales y culturales de la cultura estadounidense, con lo que sería un reflejo de que la comunicación de la prevención de emergencias puede adaptarse al contexto cultural. 


\subsection{ESTUDIO DE CASO: SIMULACROS Y FORMACIÓN PREVENTIVA EN EL COLEGIO GRANGEL MASCARÓS DE L'ALCORA.}

\subsubsection{JUSTIFICACIÓN DE LA INVESTIGACIÓN}

Las leyes españolas sobre evacuación de centros docentes, autoprotección, o protección civil coinciden en remarcar la importancia de una formación de carácter práctico en el ámbito escolar, que redunde en el conocimiento de una adecuada evacuación y en una concienciación sobre la importancia de la prevención.

Por su parte, las distintas Conferencias Mundiales en Reducción de Desastres, así como los estudios auspiciados por la Estrategia Internacional en Reducción de Desastres insisten en la necesidad de incorporar el conocimiento en reducción de desastres a la educación formal en edades escolares. Finalmente, desde la investigación social en desastres, las evacuaciones se han convertido en uno de los principales objetos de estudio de forma que puedan conocerse mejor los mecanismos del comportamiento humano durante estas situaciones o los factores que influyen en la adopción de una conducta de evacuación recomendada.

Por todos estos motivos, se consideró oportuno analizar los procesos de comunicación que tienen lugar en los simulacros de evacuación de los centros escolares, desarrollando este estudio en dos fases.

En una primera fase, se llevó a cabo la observación de un simulacro de evacuación programado dentro de las fases de implantación del propio plan de autoprotección de un centro escolar (CP Santa Águeda de Benicàssim).

A partir de este primer simulacro se obtuvieron una serie de conclusiones que nos iban a servir para la segunda fase de la investigación.

Para la segunda fase se diseñó una investigación basada en el método de la observación participante, mediante un trabajo de investigación-acción participativa (Greenwood, 2000: 33) en la que se invitó a colaborar al Consorcio de Bomberos de Castellón y al CP Grangel Mascarós de l'Alcora. Ambos actores aceptaron desde el primer momento a involucrarse en esta investigación, implicándose en cada una de las partes de ésta.

Concretamente por parte del centro educativo actuaron como coordinadores la directora del centro, Noel Manzanares, y la responsable del proyecto de prevención de 
riesgos, Eder Gorriz. Por parte del Consorcio Provincial de Bomberos de Castellón partiparon el Jefe de Operaciones, Andrés Balfagó, el Jefe de Bomberos Voluntarios, Mikel Martínez, el Jefe del Parque de Bomberos Voluntarios de l'Alcalatén, David Monferrer, así como distintos bomberos del citado parque.

La observación mediante investigación-acción trata de fomentar iniciativas a favor del cambio social, en la que tanto el investigador como el resto de participantes puedan ofrecer aportaciones para la resolución del problema. En esta investigación "los conocimientos expertos se consideran importantes pero los conocimientos locales se consideran esenciales" (ídem). Los resultados de la investigación, además, son tenidos en cuenta por los grupos interesados para actuar a partir de entonces de acuerdo a ellos (íbidem:34).

En el caso concreto que nos ocupa, esta fase de la investigación tenía varios objetivos. Por una parte se trataba de ver cómo implementar la comunicación desarrollada durante un simulacro y estudiar si había puntos susceptibles de mejora, abordando el simulacro como un fenómeno comunicativo más allá de un mero entrenamiento de respuesta ante un incendio.

El segundo de los objetivos trataba de introducir nuevas actividades educativas y lúdicas que permitiesen abordar la formación en prevención de riesgo de incendios de una forma adaptada a la edad escolar.

Mediante el desarrollo de este proceso investigador, se logró incorporar al centro documentación y participación en actividades que introdujeron cambios y novedades en su cultura preventiva.

\subsubsection{OBSERVACIÓN DE UN SIMULACRO DE EVACUACIÓN}

Para esta primera fase se decidió realizar la observación de un simulacro de evacuación, que nos permitiera recoger datos acerca de su estructura, objetivos y fases de desarrollo, y, especialmente, que nos mostrara aquellos momentos más relevantes respecto a los procesos comunicativos.

En esta primera parte de la investigación no se trataba de introducir cambios en el proceso sino de obtener los datos que nos permitieran acercarnos a él y describir su naturaleza.

El simulacro se realizó en el centro de primaria CP Santa Águeda de Benicàssim (Castellón), donde se había activar el Plan de Autoproteccón tras detectarse humo en 
el laboratorio de química de la segunda planta. Además de los propios ocupantes del centro escolar, participaron el Parque de Bomberos Profesionales de la Plana Alta, dependiente del Consorcio Provincial de Bomberos de Castellón, Policía Local de Benicassim, Guardia Civil de Benicassim, SAMU de Benicassim, Servicio 1-1-2 y las centrales correspondientes de cada uno de los Servicios de Emergencias. Participaron como observadores del simulacro el Jefe del Parque Comarcal de Bomberos Plana Alta del Consorcio de Bomberos, representante del Ayuntamiento de Benicàssim, la técnico de la Dirección General de Prevención, Extinción de Incendios y Emergencias de la Generalitat Valenciana en Castellón, y la presente investigadora. Cabe resaltar que la técnico de la Dirección General, Montse Rodríguez, participó también en la fase de entrevistas en profundidad.

De este primer simulacro se obtuvo información importante sobre algunos aspectos generales y se detectaron otros que sería necesario tener en cuenta para potenciarlos o mejorarlos en el seno de una planificación comunicativa en el centro escolar. Cabe avanzar que estas conclusiones se sometieron a contraste durante la siguiente fase, la de investigación-acción participativa realizada en l'Alcora, donde antes de realizar ninguna propuesta de cambio se llevó a cabo la observación de un simulacro en dicho centro como punto de partida.

Por tanto, las reflexiones que en este apartado se expone se obtuvieron de la observación del simulacro de Benicàssim y se confirmaron una vez se realizó ese primer simulacro de l'Alcora.

Se exponen aquí las principales ideas extraídas de estas observaciones.

Los planes de autoprotección de los centros escolares contemplan distintas fases de implantación, que pasan por la difusión del plan, la formación, los ejercicios de adiestramiento y la realización de simulacros en los que participen ayudas externas. En todas las fases, la comunicación va a jugar un papel fundamental que no puede dejarse al azar sino que debe estar perfectamente planificada.

Tan importante es la realización de un simulacro como su posterior análisis por parte de los organismos y observadores participantes. La agencia encargada de supervisar el plan de autoprotección del centro, informará sobre la secuencia de actuación e incidencias, y realizará una valoración y recomendaciones a seguir de cara a futuros simulacros. El informe incluye valoraciones sobre aspectos como la organización funcional (si todos los participantes han cumplido con las funciones que tenían 
encomendadas), los equipos de emergencia (si han actuado adecuadamente), los medios técnicos de alarma, las vías de evacuación, etc etc.

Una de las conclusiones que se obtuvieron durante esta primera fase de observación es que podría incorporarse a este tipo de informes un apartado dedicado específicamente al análisis y valoración de los aspectos comunicativos del simulacro.

En los informes examinados, sí se derivaba alguna valoración al respecto de la comunicación a partir del análisis de otros objetivos, pero no de una forma específica. Consideramos que sería útil que los aspectos comunicativos pudiesen agruparse y analizarse expresamente, de forma que pueda supervisarse que todos los aspectos comunicativos se han desarrollado durante el ejercicio de evacuación en base a determinados parámetros.

Consideramos que, en general, esos parámetros deberán tener en cuenta una de las principales ideas de base de la cultura preventiva: que cada una de las medidas adoptadas, en este caso en el ámbito comunicativo, no agrave la situación inicial y además contribuya al proceso de resolución de la emergencia.

Otra de las conclusiones es que la realización de simulacros permite detectar incidencias comunicativas que de otro modo restan ocultas a los ocupantes del centro, de forma que no se manifiestan hasta que el simulacro o la emergencia tiene lugar en la práctica. Consideramos útil que, tras la realización de cada simulacro se haga recuento de estos aspectos comunicativos de forma que puedan subsanarse para próximas ocasiones.

Tanto a lo largo del simulacro de Benicàssim como del simulacro de l'Alcora, se pudieron detectar algunos ejemplos de estas incidencias comunicativas, que no consideramos exclusivas de los centros escolares analizados sino que por sus características, podrían producirse también en otras evacuaciones escolares.

Por ejemplo, la alarma de incendios puede no ser audible en todas las zonas del centro escolar y haber ocupantes del centro que no sepan que se les está avisando de evacuar. Les ocurrió a un grupo de alumnos y su profesor de educación física, que no escucharon la alarma desde el patio del colegio y siguieron dando clase ajenos a la supuesta situación de emergencia.

Por otra parte, se observó también que si no conocemos toda la estructura de información a facilitar al 1-1-2, podemos olvidar algún dato importante. Por ejemplo, en uno de los simulacros no se le comunicó al 1-1-2 que el ejercicio de evacuación ya 
había finalizado, con lo que para el servicio del 1-1-2 la hipotética emergencia continuaba activa pese a haberse ya resuelto y dado por finalizada.

Y, por su parte, si no facilitamos pautas en el punto de concentración de evacuados, pueden producirse algunos problemas: desinformación, desorden, comportamientos peligrosos... Fue precisamente el punto de concentración de evacuados el aspecto en el que se detectó un mayor reto comunicativo, ya que parecía que una vez haber logrado evacuar allí a todos los ocupantes, la comunicación pudiera darse por finalizada. Pero por el contrario, la práctica reveló que en realidad son muchos los aspectos comunicativos a tener en cuenta en el punto de concentración de evacuados, como posteriormente analizaremos.

La comunicación puede contribuir al éxito en la resolución de una emergencia, o puede conducir a agravarla y tener consecuencias muy negativas para quienes la sufren. Por ello y por todas las razones expuestas anteriormente, consideramos que los aspectos comunicativos de un simulacro tienen un peso específico suficiente como para ser preparados por parte de la comunidad escolar previamente a la realización de un simulacro, y como para ser analizados y supervisados posteriomente tanto por parte del centro escolar como por los organimos de emergencia participantes en los simulacros en los que se cuenta con ayudas externas.

A partir de la observación de los simulacros y de las conclusiones obtenidas, se ha elaborado desde esta investigación un listado con los principales aspectos comunicativos que deberán tenerse en cuenta a la hora de valorar por parte de los participantes en los simulacros escolares si la comunicación se ha desarrollado adecuadamente, o si se han producido incidencias que hayan agravado el desarrollo de la práctica. Con esos aspectos, se ha trazado una propuesta de modelo de informe comunicativo de simulacro escolar, que exponemos en el apartado siguiente.

\subsubsection{PROPUESTA DE MODELO DE INFORME COMUNICATIVO DE SIMULACRO ESCOLAR}

Para poder analizar el desarrollo comunicativo de un simulacro escolar, nuestra propuesta es la elaboración de un informe que esté basado en la revisión de seis áreas. Las hemos reunido en el siguiente cuadro: 


\begin{tabular}{|c|c|}
\hline OBJETIVO DE ANÁLISIS COMUNICATIVO & ELEMENTOS A ANALIZAR \\
\hline MEGAFONIAA Y ACÚSTICA & $\begin{array}{l}\text { Inventario de recursos acústicos, } \\
\text { funcionamiento, mensajes grabados }\end{array}$ \\
\hline INFORMACIÓN AL 1-1-2 & $\begin{array}{l}\text { Estructura de la llamada, información } \\
\text { importante facilitada }\end{array}$ \\
\hline INFORMACIÓN A AYUDAS EXTERNAS & $\begin{array}{l}\text { Información facilitada a bomberos, } \\
\text { sanitarios etc que ayude a resolver la } \\
\text { emergencia y no la agrave }\end{array}$ \\
\hline PAUTAS DE EVACUACIÓN & $\begin{array}{l}\text { Instrucciones para evacuar } \\
\text { adecuadamente }\end{array}$ \\
\hline COMUNICACIÓN EN PUNTO DE REUNIÓN & $\begin{array}{l}\text { Información y actitud para una espera } \\
\text { responsable, paciente e informada }\end{array}$ \\
\hline $\begin{array}{l}\text { COMUNICACIÓN } \\
\text { ESPECÍFICOS }\end{array}$ & $\begin{array}{l}\text { Recomendaciones para llevar a cabo } \\
\text { la evacuación de personas con } \\
\text { problemas de movilidad, así como } \\
\text { otras situaciones que doten de mayor } \\
\text { complejidad a su evacuación }\end{array}$ \\
\hline
\end{tabular}

Exponemos a continuación los parámetros que deberían considerarse para preparar y evaluar la comunicación desarrollada durante un simulacro. Hemos incorporado en algunos casos fotografías de los simulacros desarrollados en Benicàssim y l' Alcora con el objetivo de ilustrar mejor algunos aspectos.

\section{MEGAFONÍA Y ACÚSTICA}

-La alarma de incendios y la megafonía funcionan adecuadamente y se escuchan en todo el recinto de las instalaciones a evacuar.

-Mensajes a través de megafonía. En caso de utilizarse mensajes por megafonía, son cortos, y ayudan al recuerdo de pautas ("hay que dirigirse al punto de concentración de evacuados") y de una actitud adecuada ("no corran") 


\section{INFORMACIÓN AL 1-1-2}

-El Jefe de la Emergencia ha de llamar al 1-1-2 y facilitar la información necesaria en torno al simulacro. Es mejor utilizar teléfonos móviles o inalámbricos, en lugar de fijos, ya que facilita a quien llama el acceso a la línea, y al 1-1-2 que pueda comunicarse con el Jefe de la Emergencia.

Como recomendación, la información estará estructurada de la siguiente manera:

En la primera llamada deberá:

1. Indicar que se trata de un simulacro, para no crear falsas alarmas.

2. Identificarse y concretar de qué centro educativo está llamando.

3. Decir que hay una emergencia, y a partir de aquí, ir respondiendo a las preguntas que le hará el operador que recibe el aviso, concretando toda la información que le sea posible.

Algunos ejemplos de los datos a facilitar en esta fase son: la dirección del centro, número de plantas del edificio, si hay alguna persona herida, el número de ocupantes del edificio, etc.

Debe facilitarse toda la información útil de que se disponga, por ejemplo si se sabe donde se ha originado el fuego o qué tipo de materiales hay en esa zona. Estos datos pueden facilitarse en este momento si se conocen, o volver a llamar posteriormente para facilitarlos después.

Respecto a la información a facilitar a través de las siguientes llamadas:

1. Se puede volver a llamar durante la emergencia si se considera que hay información importante que no se ha mencionado antes o que supone una novedad en la evolución de la hipotética situación de emergencia (por ejemplo que todavía no han llegado los servicios de emergencia; si hay alguien herido...etc.).

2. Cuando todo el personal ha sido completamente evacuado, es conveniente volver a llamar al 1-1-2 para indicar que ya están todos los ocupantes evacuados o, por el contrario, que se ha detectado que falta alguna persona o aula por evacuar.

En cada nueva llamada, siempre hay que recordar que se trata de un simulacro.

3. Una vez que el responsable del cuerpo de bomberos determina que el simulacro se puede dar por finalizado, el Jefe de Emergencia del centro ha de llamar al 1-1-2 para indicar dicha finalización. 


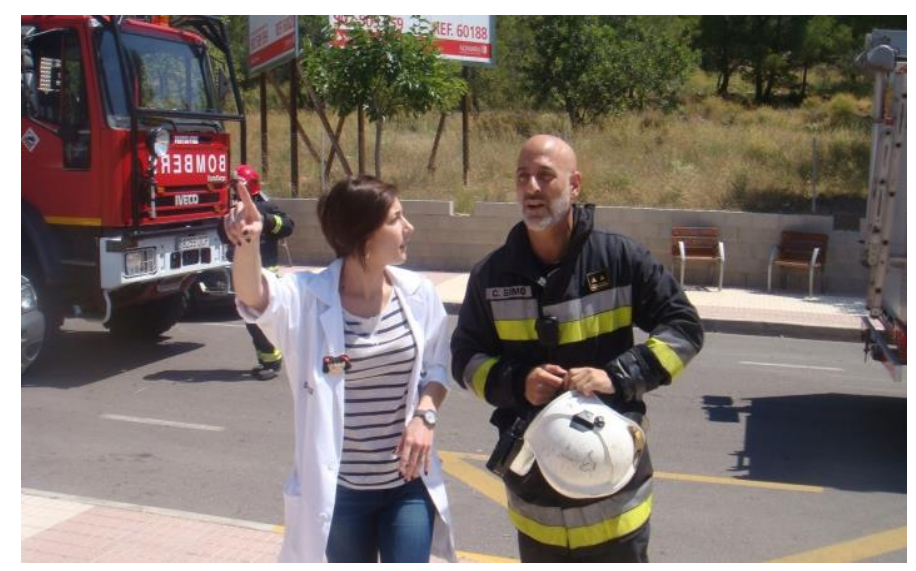

CP Santa Águeda

A su llegada al lugar del simulacro, los bomberos van a necesitar información importante que les pueda ayudar a resolver la hipotética emergencia de la forma más eficaz y segura posible.

El Jefe de la Emergencia del centro escolar deberá facilitarles esa información, respondiendo a las preguntas de los bomberos y aportando todos aquellos datos que considere relevantes para que éstos puedan desarrollar adecuadamente su labor de extinción y salvamento.

A continuación enumeramos el tipo de datos que pueden necesitarse en el diálogo entre el centro y el cuerpo de bomberos.

- ¿Qué ha ocurrido?

- ¿Se sabe dónde se ha iniciado la emergencia? ¿En qué planta o aula? ¿Qué material se almacena en esa zona?

- ¿Hay heridos?

- ¿Todos los ocupantes han desalojado el centro? ¿Quedan personas atrapadas dentro?

Por otra parte, es conveniente que una copia del Plan de Autoprotección esté ubicada en un lugar de fácil acceso en el centro, para que puedan consultarlo los bomberos o se les pueda facilitar. Este documento les proprcionará otros datos útiles, tales como la distribución de las aulas. 


\section{PAUTAS DE EVACUACIÓN}

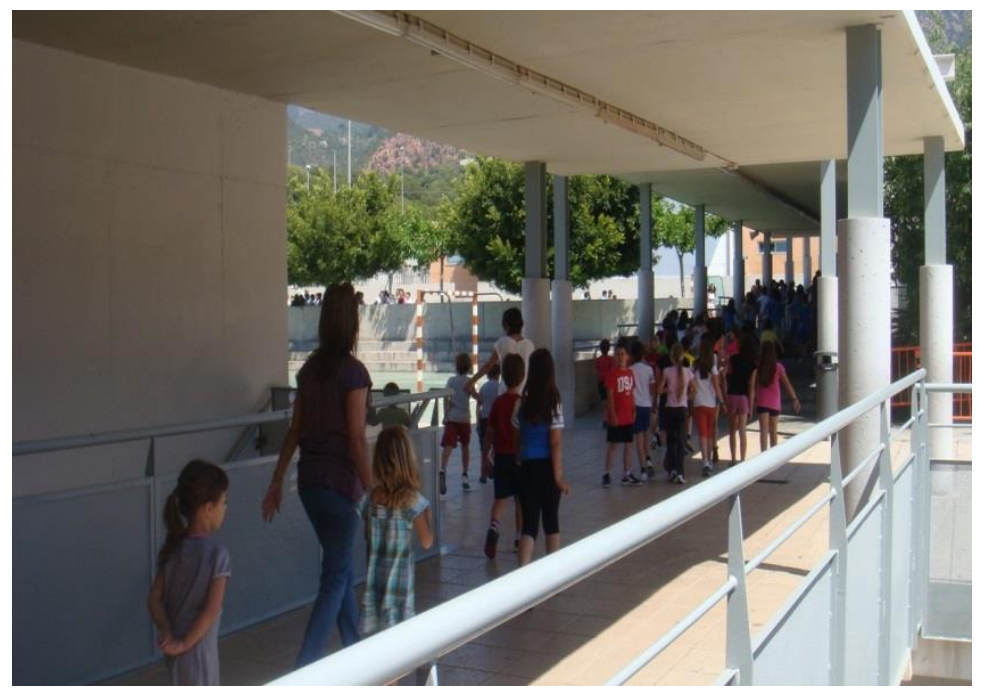

CP Santa Águeda

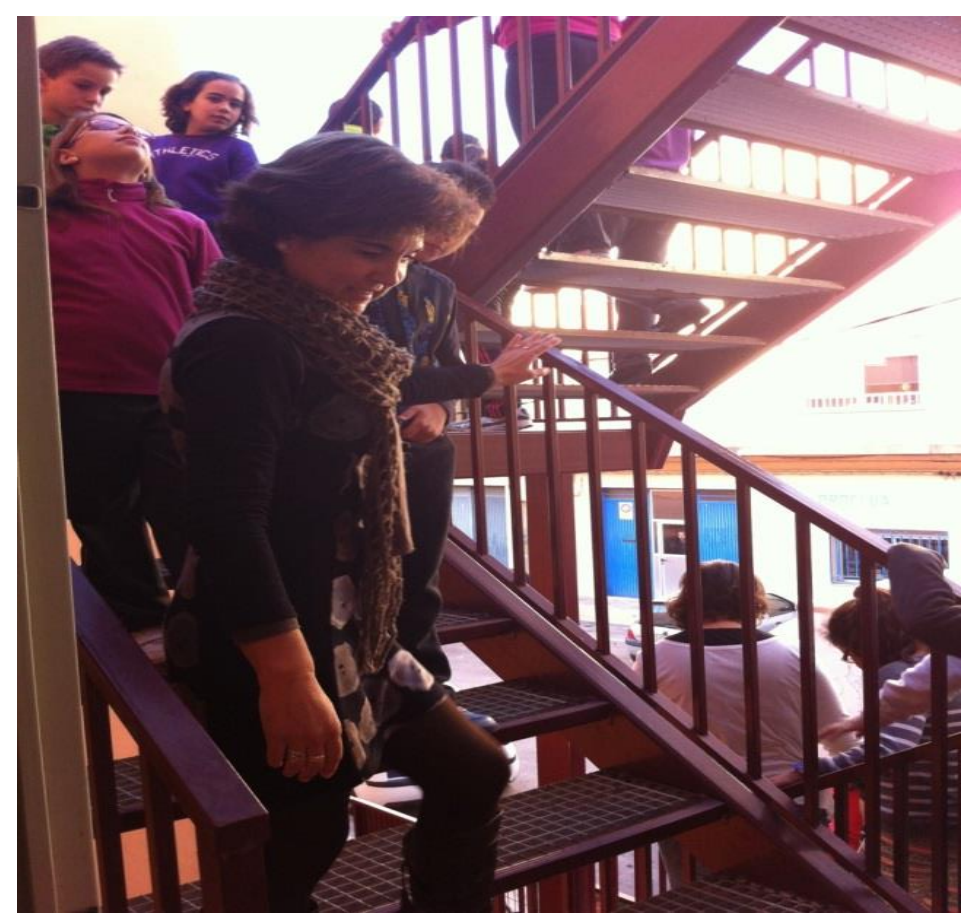

CP Grangel Mascarós 


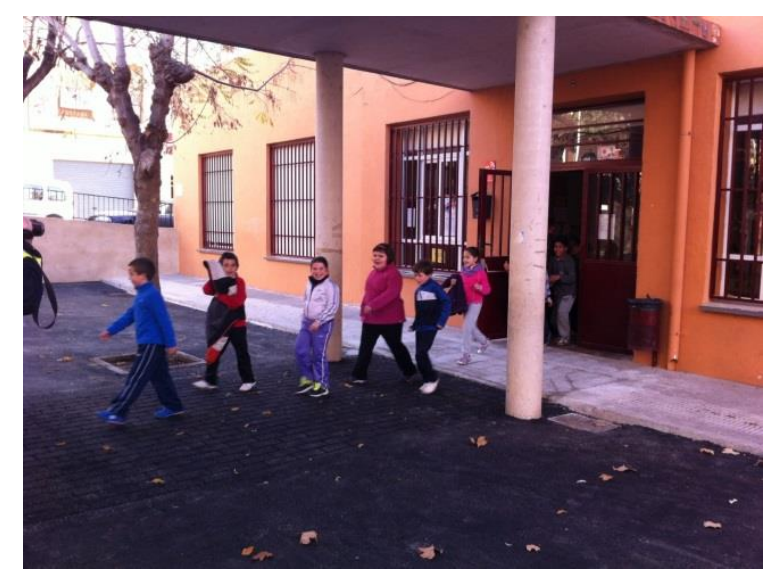

Respecto a cómo se ha de evacuar durante el simulacro, entendemos que todos los participantes conocen el plan de autoprotección y saben cómo han de actuar, habiendo practicado dicho comportamiento previamente durante la realización de ejercicios.

Por ello, las pautas que se comuniquen durante el simulacro tendrán una función de recordatorio, no de información inédita . De esta forma, se trataría de la comunicación breve de instrucciones claras, en las que incidir especialmente si la persona encargada de facilitarlas, el coordinador de planta en este caso, detecta que el comportamiento de las personas evacuadas está incumpliendo alguno de los pasos previstos.

La comunicación de estas pautas, siempre de forma breve, contundente y clara, se referirá a alguno de estos aspectos:

-Dar inicio a la evacuación. Ejemplo: "Saldremos en fila ordenadamente y vamos a dirigirnos hacia el punto de reunión"

-Apelación a la calma y a la tranquilidad para realizar el desplazamiento por la vía de evacuación sin atropellos, empujones etc.

-Estar atento al desarrollo de la evacuación para incidir, en caso de que el comportamiento de alguna de las personas evacuadas lo hiciese necesario, en los aspectos siguientes: no hay que recoger nuestras cosas (libros, chaquetas, etc.), no hay que volver a clase bajo ningún concepto, no nos hemos de detener en una vía de evacuación etc, etc. 


\section{LA COMUNICACIÓN EN EL PUNTO DE REUNIÓN}

Nos encontramos aquí con uno de los principales retos comunicativos detectados durante los simulacros.

En una primera revisión, parecía que el hecho de haber conseguido concentrar a todos los evacuados en la zona previamente preestablecida suponía la culminación del simulacro y por ende de su proceso comunicativo, un proceso que se iniciaba con el primer aviso de incendio, pasaba por la información facilitada al 1-1-2 y a los servicios de emergencia, y aparentemente hallaba su punto final con la llegada al punto de reunión.

Pero los puntos conflictivos comunicativamente hablando allí detectados eran muchos y variados y ponían de manifesto que, por seguros que nos sintamos una vez ubicados en el punto de reunión, lejos del humo y del fuego, un simulacro no acaba hasta que así lo decretan los bomberos y lo informa la Dirección de la Emergencia.

Las conclusiones respecto a la comunicación en el punto de reunión fueron las siguientes:

a) Sorprendentemente, uno de los factores que más problemas añadidos causaba tenía que ver con el lenguaje no verbal y con la forma en que los evacuados se agrupaban. $Y$ es que algunas aulas no recibieron ninguna instrucción verbal por parte de sus profesores respecto a cómo debían permanecer en el punto de reunión.

Se detectó entonces que los grupos formados, a los que su profesor sí que les indicó donde y como colocarse mientras esperaban el desenlace del simulacro, se mantenían en orden durante todo el proceso, especialmente si la disposición espacial consistía en estar sentados, o colocados en fila junto a una pared. Los alumnos permanecían en estas posiciones hasta que se daba por finalizado el simulacro, hablaban menos que los que no habían sido formados, y los que conversaban lo hacían en un tono de voz sin gritos.

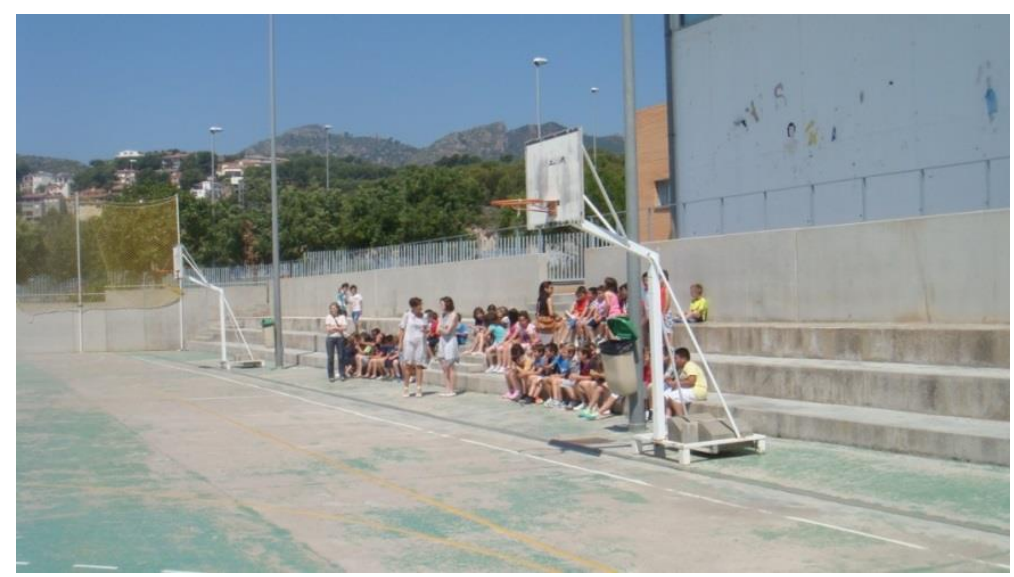




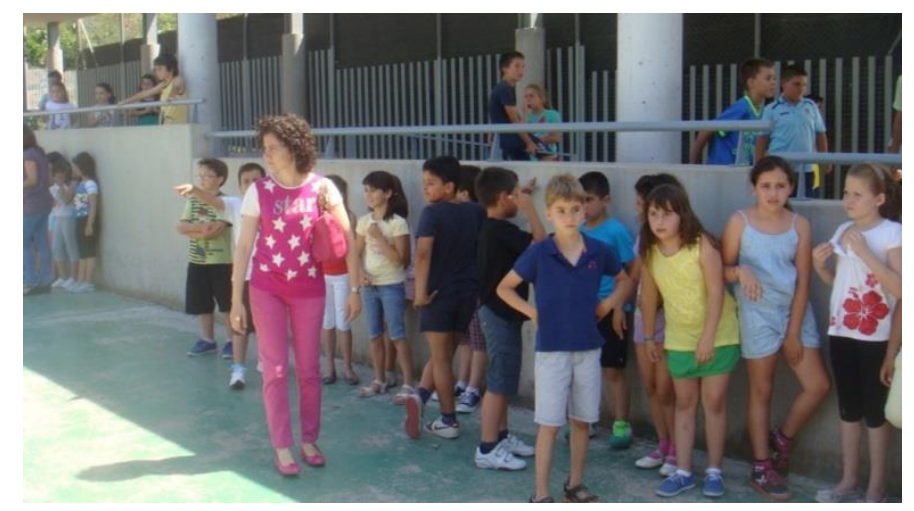

CP Santa Águeda

Por su parte, los grupos no formados, que no habían recibido ninguna instrucción respecto a estar sentados o colocados en fila junto a una pared, hablaban más entre sí y mostraban más alboroto, tanto verbal (volumen de voz) como físico (movimientos, saltos, juegos).
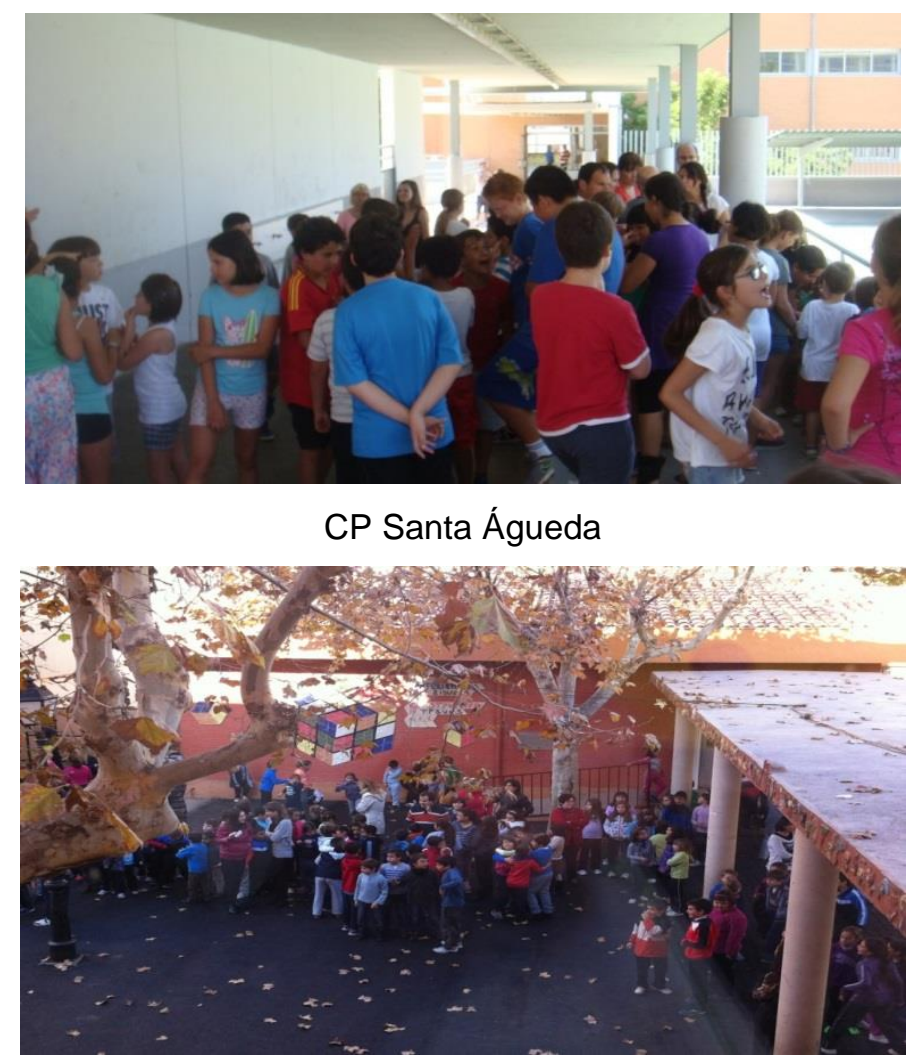

CP Grangel Mascarós

La disposición física de las personas evacuadas, y sus repercusiones tanto en lenguaje verbal como no verbal, tenía las siguientes consecuencias en los procesos comunicativos del simulacro: 
*Dificultad para facilitar y recibir datos o instrucciones, debido al ruido generado.

*Dificultad para el profesorado para recabar datos importantes, como realizar un recuento de alumnos o que este recuento esté bien realizado. En algunos casos faltaban alumnos (habían quedado confinados en el interior del edificio) y debido a la ausencia de orden, se tardaba mucho en detectar esta falta.

*La falta de instrucciones claras sobre cómo colocarse o qué hacer durante el tiempo de espera podía provocar un incremento de la tensión emocional.

Los nervios, la impaciencia o la curiosidad podían elevarse. Así, uno de los alumnos, ya concentrado en el punto de reunión, echó a correr hacia la escalera de incendios para tratar de poder volver a entrar al edificio y ver cómo trabajaban los bomberos. En otro caso, a la llegada de los bomberos, otro alumno se acercó hasta la puerta de entrada para observarles mejor, hasta que otro niño se le acercó para decirle que volviese a su grupo.

Por su parte, los alumnos ordenados en filas pegadas a la pared o en escaleras, se mantuvieron tranquilos durante todo el tiempo.

Por tanto, nuestra recomendación tras la observación de estos simulacros es que durante las situaciones en las que los evacuados estén ya ubicados en el punto de concentración, su disposición física sea sentados o en fila pegados a la pared, de forma que el lenguaje no verbal de todos los evacuados transmita orden y tranquilidad.

En el colegio de l'Alcora, una de las decisiones adoptadas por parte del personal del centro tras la puesta en marcha de la investigacion-acción fue que, para futuras ocasiones, en cuanto los ocupantes del centro estuviesen evacuados se solicitaría a los servicios de emergencia el balizamiento de la zona mediante cinta, para acotar físicamente el área en la que debían permanecer los alumnos.

La idea no es baladí: a la llegada de los servicios de bomberos los alumnos les recibían como auténticos héroes con palmas y gritos de júbilo. El balizamiento era una forma de recordar que pese a eso, no debía invadirse el espacio de trabajo de los bomberos, por su seguridad y por la de los demás. 


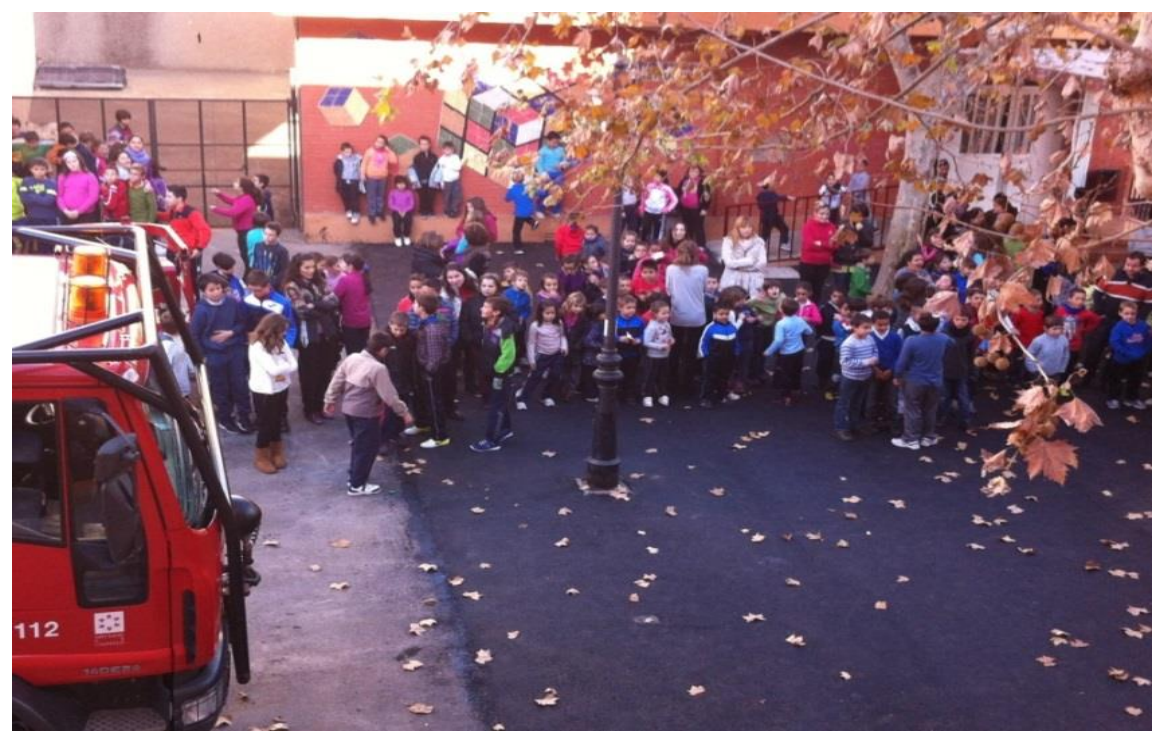

Grangel Mascarós. Segundo simulacro: con baliza. En esta imagen los bomberos acompañan a dos ocupantes del centro tras rescatarles del interior del edificio.

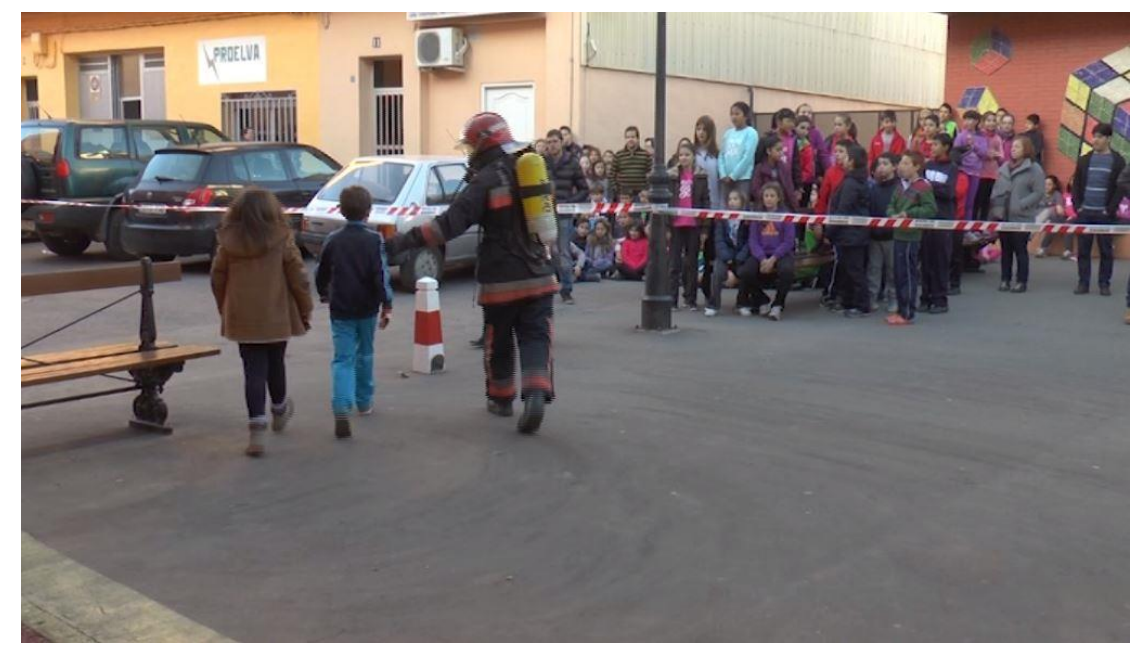

b) La actitud también comunica.

El simulacro es la preparación ante una hipotética situación de emergencia para que, llegado el caso, estemos preparados para actuar y sepamos en todo momento lo que debemos hacer. La actitud de los participantes durante su desarrollo es fundamental. 
En uno de los simulacros, cuando los alumnos se habían reunido en el punto de reunión y aunque todavía faltaba por evacuar a alguno de los ocupantes del centro, uno de los grupos participantes y su profesor se pusieron a jugar a la pelota.

Observamos que este tipo de información puede resultar contradictoria. Si el centro educativo trata de hacerle ver al participante en el simulacro que la realización de este es importante, y que se espera de él que cumpla con una serie de pasos y espere a que se le indique en el punto de concentración hasta que la situación vuelve a la normalidad, consideramos que una invitación al juego en esta situación puede transmitir una idea confusa.

Jugar puede tener una finalidad educativa, si a partir de esa acción comprendemos mejor el tema objeto de ese juego. Incluso en una situación de larga espera, el desgaste psicológico podría aconsejar llevar a cabo actividades, como un juego, que ayudasen a paliar ese cansancio, siempre y cuando esa actividad no comportase algún tipo de peligro para la seguridad del individuo o grupo evacuado.

Pero los simulacros y las evacuaciones de un centro escolar son rápidas.

La realización de un simulacro no necesita de técnicas de distracción o de divertimento durante alguna de sus fases, y menos de actividades que comporten el movimiento y desplazamiento del grupo. Más bien al contrario, se requiere que todo el mundo esté atento, consciente, y sepa que ha de mantenerse tranquilo porque los bomberos y el resto de servicios de emergencia participantes están trabajando para restablecer la normalidad.

Por tanto, consideramos que realizar actividades como la realización de juegos, introducen un elemento de distracción innecesario que, de forma peligrosa, puedan transmitirle a los niños y niñas la idea de que estar concentrados en el punto de reunión no es algo en lo que ellos tengan un importante papel que desarrollar.

En resumen, respecto a los procesos de comunicación en el punto de reunión:

-Lenguaje no verbal: profesores y alumnos han de mantener un lenguaje no verbal que connote calma, orden y tranquilidad. El ordenamiento del grupo en filas junto a la pared o en la posición sentados puede facilitar este orden. 
El orden contribuirá a: facilitar el recuento de evacuados, ofrecer y recibir informaciones y pautas de actuación relevantes, no elevar la tensión emocional, evitar que los evacuados traten de volver a entrar en el edificio o se acerquen a la zona de trabajo de los servicios de emergencia.

- Lenguaje verbal:

*Las instrucciones han de ser relativas a la situación de espera en el punto de concentración. Por ejemplo, que nadie puede volver a entrar en el edificio.

*Se pueden lanzar mensajes que contribuyan a la calma, recordando que se está trabajando por solucionar la emergencia y que debemos permanecer tranquilos.

* Se ha de verbalizar claramente el recuento de evacuados y si están todos o falta alguien

* Se ha de estar atento para detectar rumores y datos inciertos que puedan crear inquietud en el grupo, por ejemplo sobre el estado de personas confinadas o con quien no se haya podido contactar. En todo momento, se ha de transmitir un mensaje de calma y no alimentar rumores por confirmar.

\section{COMUNICACIÓN PARA CASOS ESPECÍFICOS}

Hay otros aspectos que también se han de tener en cuenta a la hora de comunicar la adecuada realización del simulacro en un entorno escolar, y que supondrían una adaptación de la comunicación del simulacro a casos o incluso a colectivos específicos.

No es el objetivo de esta investigación facilitar conclusiones sobre los distintos colectivos que pueden necesitar una adaptación concreta a distintas necesidades comunicativas. Consideramos que sería necesaria una investigación mucho más profunda para poder ahondar en todos los aspectos relevantes de esas adaptaciones, una profundización que excede los límites de esta investigación.

Futuros estudios planificados con este objetivo podrían permitirnos indagar en dichos aspectos y colaborar a trazar un mapa de aquellos colectivos a los que les beneficiaría una adaptación a sus necesidades comunicativas concretas. Por ejemplo, ¿de qué manera podemos entrenar en la realización correcta del simulacro a un niño inmigrante que acabe de ser escolarizado por primera vez y no conozca bien el idioma del centro? ¿Y si otro alumno tiene alguna discapacidad relacionada con la visión o la escucha? Los distintos colectivos tienen distintas necesidades y la adaptación formativa y comunicativa que se realice para ellos respecto a los temas de evacuaciones deberá tener en cuenta muchos matices, y sin duda, deberá apoyarse 
en el diálogo y la preparación conjunta entre expertos, servicios de emergencia y los colectivos objeto de dicha adaptación. Un reto comunicativo de interés para futuras investigaciones.

Respecto al apartado dedicado en el presente estudio a la comunicación para casos específicos, nos ceñiremos al caso de los alumnos con problemas de movilidad, debido a que este punto ha tenido que ser abordado desde los simulacros concretos realizados en esta investigación, ya que varios de los alumnos participantes tenían este problema. En alguno de los casos, se deía a problemas de carácter crónico, en otros era de carácter temporal debido a algún tipo de accidente o lesión. La observación de estos casos y el análisis que de ellos se realizó junto al equipo de bomberos y a la dirección de la emergencia, nos permitió obtener unas primeras conclusiones que puedan contribuir al propósito del presente estudio.

Así, se determinó previamente a la realización del simulacro de l'Alcora, que los alumnos con problemas de movilidad serían acompañados personalmente por su tutor en la evacuación. Debido a que el tiempo necesario para que estos alumnos evacuaran se presumía mayor, dado que la velocidad a la que podían moverse era menor, los bomberos recomendaron que debían ser las últimas personas en evacuar para evitar el riesgo de crear tapones en la vía de evacuación que pudieran enlentecer el flujo de evacuación del resto de participantes.

A partir de ahí, se decidió que el tutor debía encargarse de que, una vez el resto de alumnos estuviesen fuera del aula, acompañar en la evacuación a las personas con problemas de movilidad reducida. Se aconsejó también que se tratara de transmitir un mensaje de tranquilidad y confianza en estos casos para la persona evacuada, en previsión de que el hecho de evacuar en el último lugar pudiese generarle inquietud. La idea a transmitir era que, pese a salir en último lugar, continuaba estando dentro del tiempo establecido y adecuado para la evacuación.

Esta decisión se adoptó tras debatirlo el personal de bomberos, la comunidad educativa y la investigadora, aunque desde la presente investigación consideramos que para poder hacer extensible esta medida a todos los colectivos con problemas de movilidad reducida debería también abordarse este punto junto a representantes de estos colectivos. 


\subsubsection{INTERVENCIÓN EN LOS PROCESOS COMUNICATIVOS DEL CENTRO ESCOLAR EN MATERIA DE PREVENCIÓN DE EMERGENCIAS. PROPUESTAS DE INVESTIGACIÓN- ACCIÓN}

\subsubsection{Introducción}

Tras la primera fase de observación de simulacros escolares, en las que no se llevó a cabo una intervención directa por parte de la investigadora sobre los procesos comunicativos que se desarrollaban en ellos, se procedió a una segunda fase en la que se planificaron varias áreas en las que sí se propondrían acciones a realizar, ya que como se ha señalado, además de observar la realidad se pretendía intervenir en ella con el fin de introducir mejoras.

Como se ha señalado antes, participó el CP Grangel Mascarós de l'Alcora en su totalidad y de manera más específica como coordinadores del centro la directora Noel Manzanares y la responsable del proyecto de prevención de riesgos, Eder Gorriz.

Por parte de la investigación, se formularon distintas propuestas al centro educativo y al Consorcio de Bomberos, que incluían un total de cuatro áreas:

1.Revisión e incorporación al centro de todos aquellos documentos útiles para los aspectos comunicativos de los simulacros.

2.Sesiones de trabajo con el profesorado

3.Diseño de actividades específicas para niños

4.Realización de un vídeo en la que la comunidad educativa mostrase su participación en un simulacro.

Adjuntamos aquí el documento presentado desde la investigación al centro educativo y al Consorcio de Bomberos, como guía de trabajo para las siguientes fases. Posteriormente se exponen los resultados de cada una de las fases. 


\section{DOCUMENTO № 1.}

\section{PROPUESTAS DE ACTUACIÓN COMUNICACIÓN SIMULACROS Y EMERGENCIAS COLEGIO GRANGEL MASCARÓS, ALCORA (CASTELLÓN). \\ Propuestas incluidas en el estudio de campo de la tesis doctoral "Comunicación en prevención de emergencias. Hacia un nuevo modelo de gestión"}

Tras el informe y las conclusiones, se propone el siguiente plan de trabajo a desarrollar conjuntamente entre Centro educativo- Consorcio de Bomberos-Amanda, que se realizaría cronológicamente en los siguientes 4 pasos, a desarrollar por este orden:

1. Revisión de la situación actual de los aspectos comunicativos que figuran en el documento "Conclusiones". Introducir documentalmente los aspectos que sean necesarios.

2. Sesión de trabajo con el personal del centro con funciones en una situación de emergencia, y cuyos nombres y funciones aparecen reflejados en el documento de Conselleria "Responsables d'una emergencia. Consignes d'actuació". Se sumaría también a Eder Górriz.

Objetivos: repasar aquellos aspectos más importantes de los simulacros de incendio, incluidos sus aspectos comunicativos.

3. Sesión de trabajo con los niños. Actividad educativa a consensuar con el centro.

\subsection{Conceptos a remarcar:}

- Un simulacro de incendio NO es un incendio. Nos sirve para prepararnos, tenemos que practicar bien para estar bien preparados ante un incendio que se pudiera producir.

- Pasos de la evacuación segura.

- Punto de reunión:

${ }^{*}$ Calma y orden

* Qué tenemos que hacer mientras estamos en el punto de reunión

3.2. Aspectos a consensuar con el centro educativo: edades de los niños, ¿todos los del centro o sólo unos grupos?, metodología, tipo de actividad.

4. Filmación de un video que combine: imágenes del simulacro con entrevistas de profesores, alumnos, Consorcio, y donde sobre todo se remarquen los conceptos del 
punto 3.1. Duración aprox: no más de 4-5 minutos. Puede quedarse como material para próximos cursos.

El vídeo reflejaría los diferentes puntos de vista de los participantes en un simulacro, para entre todos construir un relato claro, expresivo, y útil sobre la experiencia de prepararse ante una emergencia.

Se evitaría la unidireccionalidad que representa la comunicación tradicional basada exclusivamente en: mensaje de figura experta (bombero, personal de emergencias) a inexperto (comunidad educativa), y por el contrario se potenciaría la multilateralidad en la comunicación, fomentando la participación de la comunidad educativa y poniendo de relieve la utilidad de su punto de vista a la hora de relatar audiovisualmente qué es un simulacro y para qué sirve.

Cabe señalar que el desarrollo del proceso reflejado en el documento nำ 1 supuso un juego de equilibrios en la participación de los actores implicados.

Por una parte, desde la investigación queríamos evitar la unidireccionalidad de la comunicación de los expertos hacia el centro escolar, y por otra, tal como remarcan diversos estudios de la EIRD y la ONU también resultaba necesario como punto de partida formar al formador para poder poner en marcha la formación en materia de riesgos, emergencias y desastres. Esto se hacía especialmente necesario en materia comunicativa, dado que este aspecto como hemos señalado al principio de este capítulo no suele ser analizado ni preparado en el ámbito de los simulacros de evacuación de los centros escolares.

Por tanto, hubo un esfuerzo por combinar en el desarrollo de la investigación una vertiente más directiva, para guiar los pasos del estudio en pos de los objetivos establecidos, y al mismo tiempo, otra vertiente de carácter flexible para que fuesen los propios participantes, esto es, el centro escolar y el servicio de bomberos, los que adoptasen sus propias medidas y decisiones que les condujesen a una mejora de sus procesos.

Exponemos a continuación el desarrollo de las 4 áreas de actuación propuestas en el documento $\mathrm{n}$ ํ1 (creación de un documento sobre los aspectos comunicativos, sesión de trabajo con el personal del centro, sesión de trabajo con los niños, filmación de un vídeo). 


\subsubsection{Incorporación de documentación y creación de un Manual de Comunicación en Situaciones de Emergencia}

Tras la realización del primer simulacro se le facilitó al colegio Grangel Mascarós un documento con las conclusiones y recomendaciones obtenidas, para que a partir de él pudiesen implantar los cambios comunicativos necesarios para llevar a cabo mejoras.

Un de las recomendaciones que se les hicieron fueron que diseñaran y redactaran su propio Manual de comunicación para situaciones de emergencia que les sirviese para mejorar algunos aspectos de la comunicación de los simulacros así como para estar más preparados comunicativamente hablando de cara a una hipotética situación de emergencia real. Para que pudiesen tener más información al respecto, les fue facilitado un documento de recomendaciones sobre cómo elaborar el manual y se les propuso que el manual resultante formase parte de su Plan de Autoprotección del Centro.

Habitualmente los centros escolares no cuentan con este tipo de manuales, ni siquiera dentro del Plan de Autoprotección, cuyo documento además suele responder a modelos predeterminados por las correspondientes administraciones, en modelos documentales fijos sobre los que se van incorporando los datos y peculiaridades propios de cada centro. Estos modelos sirven de guía y por tanto ayudan también a simplificar y clarificar el trabajo, y dejan poco margen a aspectos o apartados que no estén incialmente previstos.

Pero desde la presente investigación se consideraba que si el centro creaba su propio Manual de Comunicación y lo incorporaba a su Plan de Autoprotección, esto implicaría una serie de beneficios, como tomar conciencia de la importancia de planificar y gestionar los aspectos comunicativos, así como garantizar a las generaciones futuras del colegio un punto documental de partida para seguir trabando en esos aspectos.

Así que se acordó con el centro que elaborarían dicho Manual y que para prepararlo contarían con documentación adicional informativa que se les facilitaría desde el personal investigador, y que en parte procedería de las conclusiones y recomendaciones derivadas de la observación de los simulacros, y sería complementada con todos aquellos datos que se considerasen útiles para su caso.

El manual elaborado por el centro se adjuntaría al Plan de Autoprotección en una sección anexa, indicando en todo caso en el apartado que correspondiese, que se 
trataba de un documento fruto de una experiencia piloto de carácter académico, con el fin de no encontrar ninguna traba respecto a la homologación oficial del Plan.

Adjuntamos a continuación la documentación que desde la investigación le fue facilitada al centro para elaborar su manual, y a continuación el documento que el propio centro elaboró. Obsérvese que en la versión del centro que aquí figura, la sección del manual destinada a los medios de comunicación refleja únicamente el nombre de la presente investigadora, dado que ella tenía encomendada la preparación de la documentación relativa a esa sección. Fue incorporada con posterioridad, y la adjuntamos también aquí con el resto de materiales archivados. 
DOCUMENTO 2: Documentación facilitada al Colegio Grangel Mascarós para la implementación de la comunicaciónn durante los simulacros.

CONCLUSIONES Simulacro colegio grangel mascarós, alcora (CASTELLÓN).

Simulacro perteneciente al estudio de campo de la tesis doctoral "Comunicación en prevención de emergencias. Hacia un nuevo modelo de gestión"

Tras el simulacro y la realización del posterior informe, se considera que para la preparación de los próximos simulacros y la ejecución de los mismos, sería importante tener en cuenta los siguientes aspectos comunicativos:

1. Plano colegio: Indicar mediante señalética los espacios donde se ha de prestar una especial atención a la comunicación. Se trata de fijar una serie de símbolos visuales que recuerden aquellos aspectos a comunicativos a tener en cuenta en los puntos más complicados de la evacuación. Este nuevo plano de "riesgos comunicativos" no sustituiría al actual y oficial, sino que sería un anexo a realizar como parte de la prueba piloto. Por ejemplo, se incluirían señales en los siguientes puntos del plano:

- Patio: por dificultades de audición de la sirena

- Ruta evacuación: riesgo de desorden, necesidad de recordar "de uno en uno", etc.

- Punto de encuentro: espacio de riesgo de sobreexcitación. Recordar que se debe usar la comunicación para: calmar / dar alguna información sobre la situación

2. Activación de la alarma. Si un pulsador está en la zona afectada por la emergencia, usar el otro pulsador.

3. Establecer un sistema de aviso a los grupos que estén en el patio. ¿Serviría el megáfono? ¿Qué otros sistemas se pueden establecer?

4. Aviso al 1-1-2.

Añadir al final una llamada indicando que ya se ha dado por finalizado el simulacro.

5. Ruta de evacuación: transmitir a los alumnos instrucciones para bajar de uno en uno / para bajar tranquilos. Este mensaje lo puede dar combinadamente el profesor de cada aula cuando empiezan a salir los alumnos de su clase, y el coordinador de planta que está pendiente de que ésta se desarrolle adecuadamente. 
6. Evacuación de los niños con movilidad reducida: indicarles que saldrán al final (siempre en compañía de su profesor). Que la comunicación tenga en cuenta la posible preocupación del niño/niña, para tranquilizarle.

7. Punto de reunión: trabajar más el orden y la calma. Evitar gritos, juegos, sobreexcitación. Se ha de guardar filas con la mayor calma posible, hasta que se declare el fin de la emergencia. Mientras tanto, se puede hacer hincapié en aspectos como: reforzar la importancia del papel colaborativo de los niños para el buen desarrollo de la evacuación / explicar los trabajos que están desarrollando los bomberos para solucionar la situación / anticiparse a las posibles expectativas del alumnado: indicar que hay que esperar a que los bomberos terminen sus trabajos, que después se podrá regresar a las clases, etc.

8. Confeccionar, si el colegio no lo tiene, un manual de comunicación en situaciones de emergencia, que de forma sintetizada tenga en cuenta los siguientes puntos. Si sí que dispone de dicho manual, revisar la siguiente check-list para comprobar si se dispone de toda esta información. Esta misma chel-list serviría tanto para las emergencias como para los simulacros de evacuación/confinamiento:

* Listado de personas que han de tener alguna función comunicativa: nombre de la persona y función.

* Establecer si es necesario una figura colaboradora: un alumno por cada clase o el conserje (gente que en un momento dado refuerce ideas como: calma, orden, etc.)

* Elaborar un listado de informaciones a facilitar al 1-1-2

* Cómo comunicar al conserje la orden de desconexión de los sistemas

* Alarmas y megafonía: inventario de los recursos acústicos de los que disponemos; redacción de los mensajes que se emitirán por megafonía; decidir si se usan mensajes pre-grabados y si es así, redactarlos y grabarlos.

* Definir los mensajes e instrucciones que ha de dar el coordinador de planta para avisar de que hay que evacuar.

* Definir los mensajes e instrucciones que ha de dar el profesor a sus alumnos cuando reciban la orden de evacuar el aula

* Cómo gestionar comunicativamente la evacuación del personal con movilidad reducida. Cómo informar de que saldrán los últimos, sin generar más ansiedad.

* Qué mensajes se transmitirán a los alumnos durante la ruta de evacuación.

* Cómo comunicarse con los grupos que estén en el patio

* Listado de informaciones a facilitar a la llegada de los bomberos 
* Qué informaciones y mensajes hay que dar en el punto de reunión a los alumnos: calma y orden; manejo de expectativas, qué información se les puede ofrecer.

*Qué datos recoger en el punto de reunión: número de alumnos, recuento clases.

* Cómo comunicar el fin de la emergencia (o simulacro) a todos los afectados (o participantes)

El manual también ha de contemplar las pautas comunicativas de aplicación en caso de situaciones graves (se ha de valorar y prefijar en el manual cuáles serán las situaciones graves, por ejemplo: personas heridas / desperfectos en el edificio que impidan la continuidad de la actividad, etc.). Habría que destinársele un apartado en el manual a los siguientes puntos:

* Cómo comunicar la situación de emergencia a los familiares (por ejemplo familiares que quieran acercarse al centro durante una situación en que los alumnos estén confinados).

* Cómo comunicarse con los medios de comunicación que cubrieran una hipotética noticia de emergencia

* Cómo comunicar una mala noticia a los compañeros de alumnos o profesores afectados. 

emergencia.

-Quién ha de comunicar: el portavoz del centro. Ha de ser único, para facilitar la coordinación informativa y la coherencia de los mensajes. No pueden haber más de un portavoz. Preferiblemente será el director/directora del centro, u otra persona con responsabilidad y que previamente haya sido designada desde el centro.

-Cómo comunica:

*Por escrito: enviando un comunicado por mail y/o:

*Oralmente: leyendo un comunicado ante los medios de comunicación, o bien ofreciendo declaraciones donde se responda a las preguntas de los medios.

Donde comunica: en un lugarr del centro que no haya sido afectado por la emergencia y que quede fuera de los ojos de los curiosos y viandantes.

Recomendaciones generales:

-Se ha de mostrar solidaridad hacia las personas afectadas por la emergencia.

-No se han de facilitar datos personales de los afectados (edad, nombre, etc.), ni informes médicos. Se han de utilizar frases más generales que no invadan la intimidad, como "un menor" (en vez de "un niño de 9 años llamado Javier"), "un trabajador del centro", "ha resultado herido y ha sido atendido por los servicios sanitarios", sin entrar en más detalles concretos o personales.

*Se ha de explicar: qué ha pasado, a quién le ha pasado, cuándo ha pasado, donde ha pasado *Se ha de explicar qué tareas lleva a cabo el centro para gestionar la emergencia y para devolver la situación a la normalidad, tanto para el presente como para el futuro.

"No se ha de conjeturar sobre "por qué ha pasado", ni "cómo ha pasado", ya que seguramente eso estará en proceso de investigación. Se pueden utilizar fórmulas como "se está estudiando si puede haber sido originado a causa de (...) pero se trata de una hipótesis que se está investigando y que tendrá que confirmarse o no durante los próximos días".

*Si muchos medios de comunicación acuden a los alrededores del centro, con muchos vehículos, muchas cámaras etc etc, se puede solicitar a los organismos de las fuerzas de seguridad que nos ayuden a delimitar una zona a partir de la cual los medios de comunicación 
no puedan sobrepasar esa zona. El objetivo es no entorpecer la emergencia y preservar la intimidad de las personas que estudian o trabajan en el centro.

*Hay que agradecer públicamente la colaboración de aquellas entidades que hayan participado en la emergencia: Bomberos, Policia, Guardia Civil, personal sanitario, etc. etc. 


\section{MANUAL DE COMUNICACIÓ EN SITUACIONS D'EMERGENCIA}

CEIP FCO. GRANGEL MASCARÓS 
CURS $2013-2014$

\section{PERSONAL AMB FUNCIÓ COMUNICATIVA}

Tots els mestres tenen una funció comunicativa amb els alumnes amb els qui estiguen en el moment de l'emergència, però hi ha alguns que tenen funcions comunicatives més específiques.

\begin{tabular}{|c|c|}
\hline $\begin{array}{l}\text { Coordinadora General } \\
\text { Noel Manzanares Juan } \\
\text { Marta Palanques Prades }\end{array}$ & $\begin{array}{l}\text { - Declararà l'inici i el fi de l'emergència } \\
\text { - Activarà la alarma i telefonarà a I'112 } \\
\text { - Gestionarà la comunicació amb les famílies } \\
\text { - Interlocutor amb ajudes externes } \\
\text { - Rebrà i donarà informació a la resta de } \\
\text { responsables }\end{array}$ \\
\hline $\begin{array}{l}\text { Coordinadors de planta } \\
\text { Planta baixa: } \\
\text { Sara Sales } \\
\text { Sarai Rodriguez Castilla } \\
\text { Primera planta: } \\
\quad \text { Fernando González Romero } \\
\text { Ederlinda Górriz Ferrer } \\
\text { Segona planta: } \\
\text { Eva Contreras Ramos } \\
\text { Rosa Andreu Saborit } \\
\text { Aulari infantil: } \\
\text { Luís Escuriola } \\
\text { Marta Palanques Prades }\end{array}$ & $\begin{array}{l}\text { - Rebrà i donarà informació al Coordinador } \\
\text { General } \\
\text { - Transmetrà les ordres oportunes a tot el } \\
\text { personal de la planta assignada. }\end{array}$ \\
\hline $\begin{array}{l}\text { Resp. de desconnectar } \\
\frac{\text { instal'lacions }}{\text { Luís Escuriola }} \\
\text { Neiser Cardona Gómez }\end{array}$ & $\begin{array}{l}\text { - Informarà al Coordinador General de la } \\
\text { desconnexió de les diferents instal·lacions del } \\
\text { centre. }\end{array}$ \\
\hline $\begin{array}{l}\text { Responsable de primers auxilis } \\
\text { Elisa Andreu Gil } \\
\text { Maite Devis Esteve }\end{array}$ & $\begin{array}{l}\text { - Rebrà i donarà informació al Coordinador } \\
\text { General } \\
\text { - Interlocutor amb els serveis d'auxili exterior } \\
\text { (informarà de l'avaluació inicial de les lesions } \\
\text { d'alumnes i personal) }\end{array}$ \\
\hline
\end{tabular}




\begin{tabular}{|l|l|}
\hline Professorat del centre & - Mantindrà als alumnes en ordre \\
& - Donarà les instruccions per realitzar una \\
& evacuació ordenada \\
& - Rebrà i donarà informació al Coordinador de \\
& planta \\
\hline
\end{tabular}

\section{FIGURA COL-LABORADORA DE CADA CLASSE}

Degut a l'edat dels nens i a la situació de les vies d'emergència, en l'etapa d'Infantil no hi haurà figura col'laboradora de classe. De tota manera es pot designar a un adult extern.

Llistat dels alumnes escollits.

\begin{tabular}{|l|l|}
\hline 1r primària & \\
\hline 2n primària $\mathrm{A}$ & \\
\hline 2n primària $\mathrm{B}$ & Jorge Iserte / Hecham Lahlahi \\
\hline 3r primària & \\
\hline 4t primària $\mathrm{A}$ & \\
\hline 4t primària $B$ & \\
\hline 5é primària & \\
\hline 6é primària & \\
\hline
\end{tabular}




\begin{tabular}{|l|l|}
\hline $\begin{array}{l}\text { MESURES D'EMERGÈNCIA: } \\
\text { MODEL D'AVÍS PER A AJUDES EXTERNES } \\
\text { MESALITAT VALENCIANA }\end{array}$ & FITXA Núm. \\
\hline
\end{tabular}

3. LLISTAT D'INFORMACIONS PER A L'112

\section{FITXA MODEL D'AVÍS PER A AJUDES EXTERNES}

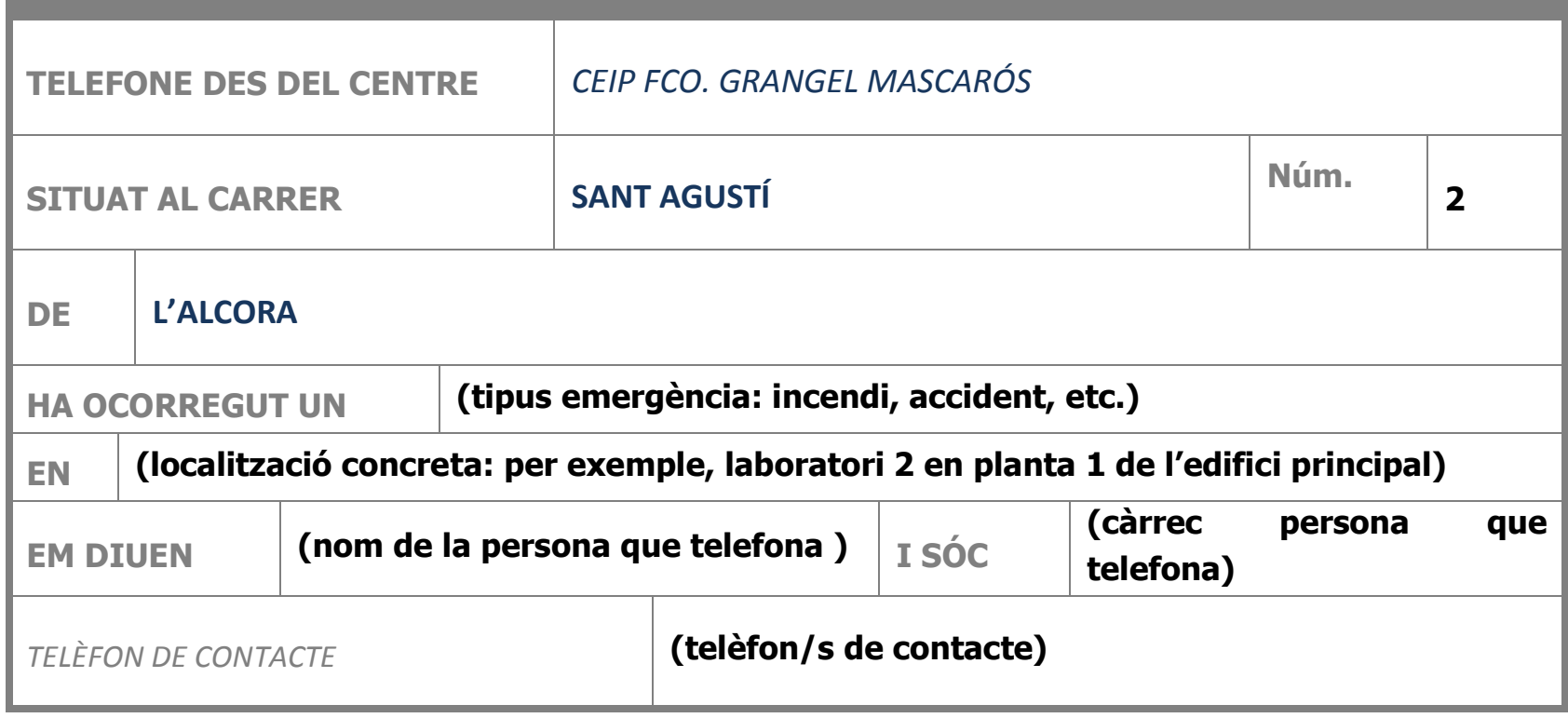

EN EL CAS QUE S'EVACUE EL CENTRE

I ESTEM EVACUANT EL CENTRE, EN EL QUAL TENIM

281 ALUMNES 


\begin{tabular}{|l|l|l|}
\hline HI HA & (Nre.) & FERITS \\
\hline QUE PRESENTEN & (valoració inicial de les lesions o de l'estat dels ferits) \\
\hline HEM ACTUAT DE LA MANERA SEGÜENT & $\begin{array}{l}\text { (expliqueu actuacions realitzades amb } \\
\text { els ferits) }\end{array}$ \\
\hline QUÈ HEM DE FER FINS QUE ARRIBEU? & \\
\hline
\end{tabular}

\section{INVENTARI ALARMES I MEGAFONIES}

Al centre disposem dels següents recursos acústics:

- Avisadors d'emergència (10 edifici primària + 2 edifici infantil)

- Megafonia utilitzada en el timbre musical

- Megàfon

- Polsadors d'alarma (4 edifici primària +2 edifici infantil)

\section{MISSATGES EN CAS D'EMERGÈNCIA}

\subsection{AVÍS D'UNA EMERGÈNCIA PER MEGAFONIA}

En cas d'emergència el Coordinador General activarà el missatge gravat corresponent o llegirà, fent servir la megafonia del centre, les següents instruccions:

- Simulacre d'incendi: Atenció! Açò és un simulacre d'incendi. Prepareu-vos per anar al punt d'encontre, seguint les instruccions dels professors i dels coordinadors de planta.

- Evacuació per incendi, avís de bomba...: Atenció! Per motius de seguretat s'ha d'evacuar l'edifici. Estigueu atents a les instruccions dels professors i coordinadors de planta.

- Confinament: Atenció! Per motius de seguretat es recomana a professors i alumnes romandre en les seues aules. Estigueu atents a les instruccions dels coordinadors de planta. 


\subsection{MISSATGES E INSTRUCCIONS DEL COORDINADOR DE PLANTA}

Estaran redactats en un sobre a l'aula habitual del coordinador de planta i del seu substitut. Aquest sobre estarà enganxat al plànol general d'evacuació del centre.

\subsection{MISSATGES E INSTRUCCIONS DELS PROFESSORS ALS ALUMNES}

Estaran redactats en un sobre enganxat al plànol general d'evacuació del centre que hi ha en cada aula.

Durant l'evacuació els professors han de transmetre missatges de calma als alumnes i recordar les normes a seguir.

\section{INFORMACIÓ ALS ALUMNES I EVACUACIÓ DEL PERSONAL AMB MOBILITAT REDUÏDA}

A l'inici del curs tots els tutors han d'informar i recordar als alumnes els diferents casos d'emergència possibles i les vies d'evacuació disponibles en cada cas. També se'ls informarà de l'ordre d'eixida i de les pautes a seguir davant alguna emergència.

Tinguen o no alumnes amb mobilitat reduïda, degut a la possibilitat de que qualsevol alumne estiga en aquesta situació en el moment d'una evacuació, els tutors hauran de fer saber a l'alumnat que tots aquells que es troben en aquesta situació esperaran amb el seu tutor per tal d'eixir després dels seus companys de planta.

\begin{tabular}{|c|c|}
\hline $\begin{array}{c}\text { INSTRUCCIÓ } \\
\text { OPERATIVA } \\
\text { MESURES D'EMERGÉNCIA: }\end{array}$ & Núm. \\
\hline INSTRUCCIONS GENERALS PER A L'ALUMNAT & \\
\hline
\end{tabular}

\section{SI DETECTES UNA EMERGĖNCIA}

- Si detectes un incendi o una fuga de gas, MANTÍN LA CALMA I COMUNICA-HO al professor més pròxim.

- Retorna a l'aula com més ràpid millor.

- Si presencies un accident, MANTÍN LA CALMA I COMUNICA-HO al professor més pròxim, que al seu torn ho comunicarà al responsable de primers auxilis. 


\section{EN CAS D’EVACUACIÓ}

- Mantín l'orde i seguix les indicacions del professor.

- Espera l'orde del professor per a eixir de l'aula.

- Quan rebes l'orde del professor, ix de l'aula ordenadament sense córrer i sense espentar.

- Dirigix-te a la via d'evacuació que t'indique el professor i roman en silenci fins que este dóna l'orde d'evacuar.

- Seguix en fila índia al professor de forma ordenada sense eixir-te'n de l’itinerari, fins a arribar al PUNT DE REUNIÓ.

- No et ressagues agafant objectes personals.

- No t'acatxes ni pares per a agafar objectes que hagen caigut.

- Procura no parlar durant l'evacuació perquè tots puguen escoltar les ordes que es donen.

- NO UTILITZES MAI L'ASCENSOR.

- Si el fum no et deixa respirar bé o et dificulta la visió, avança acatxat.

- Roman en el PUNT DE REUNIÓ fins a nova orde.

\section{COMUNICACIÓ INFANTIL - PRIMÀRIA / GRUPS DEL PATI}

\subsection{COMUNICACIÓ INFANTIL - PRIMÀRIA}

En cas d'incendi, es fa necessari un sistema de comunicació d'alarma d'incendi automàtic entre els dos edificis. D'aquesta manera el personal de l'edifici que no està afectat és conscient de l'existència d'un incendi en l'altre. El més adequat seria un avís sonor simultani, es a dir, si es fa sonar l'alarma d'incendi en l'edifici de primària hauria d'haver un avís sonor (conegut per tot el personal) a l'edifici d'infantil i al contrari.

\subsection{COMUNICACIÓ AMB ELS GRUPS DEL PATI}

Al pati hi ha instal'lat un avisador acústic però és insuficient. Caldria revisar-lo i augmentar el seu volum, si fóra possible, o ficar un segon avisador al pati de primària. 
Per una altra banda, s'ha d'intentar que els mestres que estiguen al pati porten sempre un telèfon mòbil per poder comunicar-se amb el Coordinador General en cas d'emergència. Seria interessant comprar un o dos braçalets o cinturons porta-mòbils, especialment destinats als mestres d'Educació Física.

\section{INFORMACIÓ A FACILITAR ALS BOMBERS}

El Coordinador General estarà a disposició dels bombers per tal oferir-los la informació necessària:

- Confirmació de l'evacuació de TOTS els alumnes, mestres i personal no docent del centre.

- Confirmació de la revisió per part del personal de tots els espais o llista dels espais que no s'han pogut revisar.

- Ubicació de l'incendi.

- Tipus del material que possiblement s'està cremant.

- Pla d'emergència del centre.

\section{INFORMACIÓ I MISSATGES EN EL PUNT DE REUNIÓ}

Una vegada en el punt de reunió, els tutors hauran de fer recompte i vore si estan TOTS els alumnes i traslladarà aquesta informació al Coordinador General.

Els alumnes es mantindran asseguts per grups classe en les zones establertes. En cas d'haver evacuat junt a un grup diferent del seu grup classe, els alumnes buscaran reunir-se amb el seu grup i tutor per tal de facilitar el recompte d'alumnes.

Una vegada fet el recompte, els tutors romandran amb el seu grup. Donaran missatges tranquil litzadors i recordaran el procediment a seguir:

- És important estar tots junts i tranquils. 
- Recordeu que no us heu d'alçar fins que els bombers (o Coordinadora General) ens diga que tot està bé.

- Recordeu que els bombers i la policia ens ajuden a tots i hem de fer el que ens diguen.

\section{COMUNICACIÓ FINALITZACIÓ DE L'EMERGÈNCIA}

La Coordinadora General anirà al punt de reunió i informarà al professorat de la finalització de l'emergència i del procediment a seguir (si poden tornar a les aules amb normalitat o no etc.)

Els professors traslladaran aquesta informació als alumnes i seguiran les instruccions donades per la Coord. Gereral.

\section{COMUNICACIÓ EN SITUACIONS GREUS}

Una vegada finalitzada l'emergència, i en cas d'haver algun ferit greu 0 defunció:

\subsection{COMUNICACIÓ AMB FAMILIARS}

La directora avisarà a les famílies corresponents per telèfon i les citarà en el centre. Una vegada allí, se'ls informarà de la situació. 
Seria convenient que estigués present el psicòleg del centre per donar suport a les famílies en cas necessari.

\subsection{COMUNICACIÓ AMB MITJANS DE COMUNICACIÓ}

Amanda

\subsection{COMUNICACIÓ AMB COMPANYS D'ALUMNES O PROFESSORS}

L'encarregada de comunicar aquest tipus de notícies als professors seria la directora recolzada pel psicòleg del centre.

En el cas dels alumnes, serien els tutors (ja que són els mestres que més temps passen amb els xiquets i amb qui tenen major confiànça) amb el psicòleg els encarregats d'informar-los. 
La elaboración del manual por parte del centro conllevó además un ejercicio de autoreflexión que les llevó a introducir cambios prácticos en el desarrollo de los simulacros y en la preparación para emergencias. Además de todo lo que se reflejó en el manual, a partir del examen comunicativo y de la propia revisión de estos elementos por parte del personal del centro se decidieron toda una serie de modificaciones.

Por ejemplo, algunas pautas sobre el comportamiento en evacuaciones fueron ubicadas en forma de cartelería en cada aula, de forma que los profesores tenían acceso rápido a esa información en cuanto la necesitasen.

La maestra de educación física pasó a llevarse el teléfono móvil a sus clases de gimnasia, para ser avisada en caso de una emergencia en el centro y a la espera de una solución más definitiva sobre un problema de alcance sonoro de la alarma y megafonía, que no llegaba a todas las zonas del recinto. Ahora sabían que existía este problema, y que requería una solución.

El análisis del lenguaje no verbal de la zona de concentración de personas evacuadas, que había revelado una gran excitación y algarabía entre los alumnos en caso de quedarse de pie y sin filas, introdujo alguno de los cambios más significativos.

En una primera medida, se decidió para próximas ocasiones balizar la zona acotada para los evacuados, que debían permanecer sentados y sin ponerse en riesgo a sí mismos o a los organismos de emergencia. Este primer paso cambiaba significativamente la situación.

Los cambios todavía iban más allá, ya que tras esta primera medida, que ya implicaba mejoras sustanciales, todavía se adoptó otra más contundente: se iba a cambiar la ubicación del punto de reunión de forma que este quedaba definitivamente fuera de la zona próxima al trabajo de los bomberos, y sin necesidad de balizamiento se eliminaba completamente la posibilidad de sufrir ningún tipo de percance, ni siquiera por descuido. Además la nueva zona preservaba más la intimidad de los evacuados, ya que la primera ubicación quedaba a vistas de todo el vecindario.

Estas modificaciones significaban mucho: la revisión de los aspectos comunicativos había llegado a transformar la ubicación física del punto de reunión. 


\subsubsection{Sesión de trabajo con el personal del centro}

Las sesiones de trabajo consistieron en reuniones con la dirección de la emergencia y la responsable de los temas de prevención del centro educativo, con el fin de repasar todos los aspectos comunicativos abordados y planificar acciones futuras. En un principio, se consideró la posibilidad de realizar una charla divulgativa entre todo el claustro escolar, pero finalmente se optó por trasladar esa información a las personas directamente encargadas de los temas de autoprotección para que posteriormente a su vez fueran estas las responsables de trasladar esa información al resto de personal, como responsables de evacuación de planta o tutores y a partir de ahí, a los alumnos.
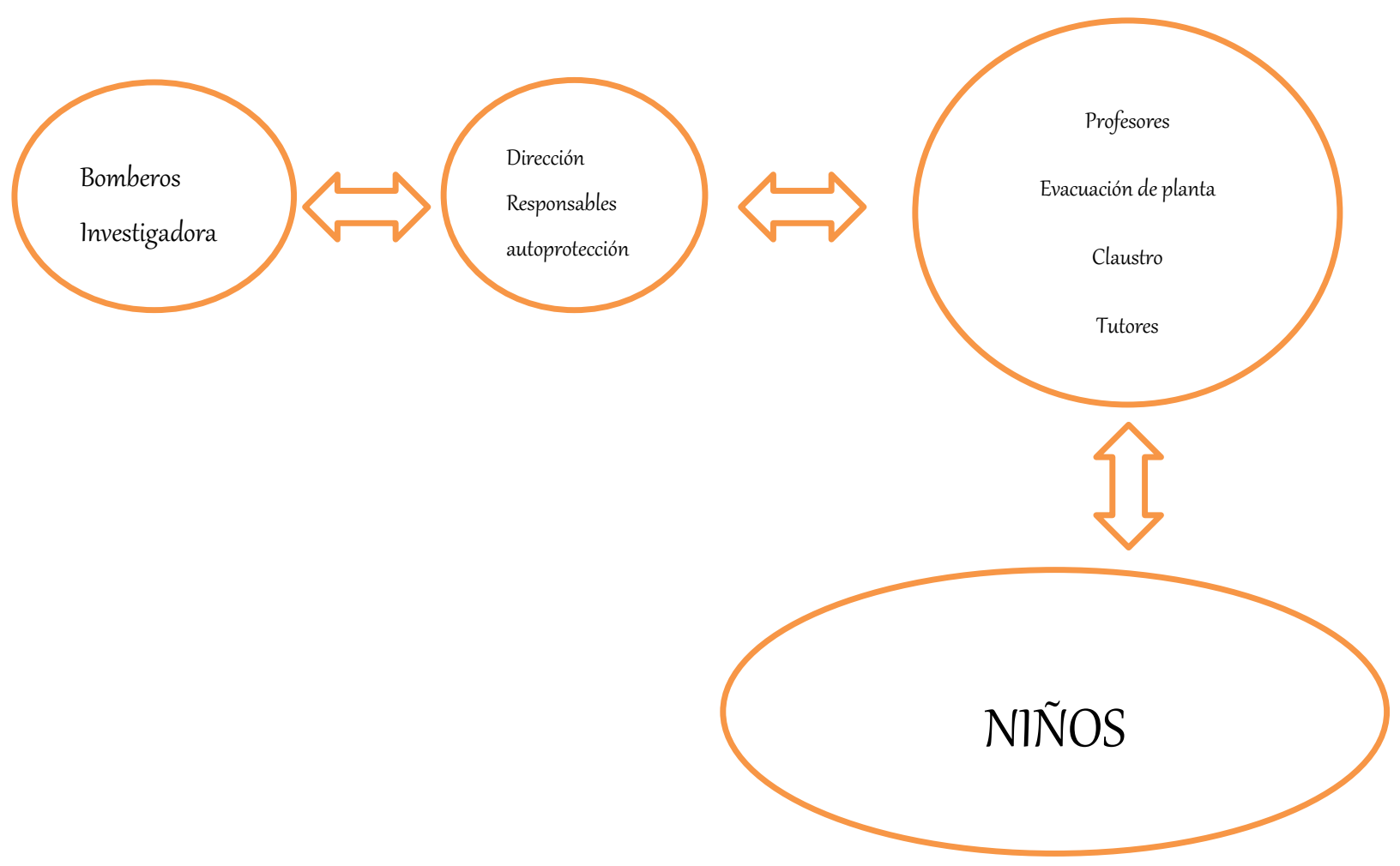

De esta forma, esa información pasaba a ser un tema directamente gestionado por el centro, y no únicamente por expertos externos, pudiendo existir una comunicación más fluida y adaptada a las características del propio centro y abordada en el conjunto de la comunidad educativa. 


\subsubsection{Actividades con los niños}

Uno de los puntos propuestos era trabajar en alguna actividad dedicada a los niños. Se llevó a cabo en una doble vertiente. Por una parte, dado que en el periodo en el que se realizó esta investigación en el centro, los alumnos de infantil no habían participado en los simulacros del colegio, se decidió que debía realizarse alguna actividad que introdujese a los niños y niñas en el universo de las emergencias y la prevención.

Por otra parte, desde el Consorcio de Bomberos de Castellón se había solicitado a la Fundación MAPFRE la participación en la Semana de la Prevención de Incendios. Como se ha explicado en el apartado dedicado a las entrevistas en profundidad, se trata de una campaña en la que esta fundación se coordina con servicios de bomberos de toda España para preparar actividades sobre prevención de incendios, en este caso dedicado al ámbito escolar. La Fundación suministra algunos materiales, como cuadernos o vídeos, y los respectivos cuerpos de bomberos diseñan y programan las distintas actividades que desarrollaran en los colegios para que los niños se formen en temas de prevención y autoprotección. En su semana de la prevención, realizada en otoño de 2014, el Consorcio de Bomberos de Castellón realizó actividades para unos 1.700 participantes de distintos centros escolares, entre ellos, el CP Grangel Mascarós. Esto nos permitía observar en primera línea una actividad diseñada en conjunto entre una fundación, un servicio de bomberos y un centro escolar, existiendo por tanto una aproximación multilateral a la formación escolar que encajaba totalmente con las recomendaciones de las distintas investigaciones vistas en los capítulos anteriores.

Exponemos a continuación el desarrollo y las conclusiones tanto de las actividades para el ciclo de infantil como de la Semana de la Prevención de Incendios.

\subsection{Actividades del Ciclo de Infantil}

El ciclo de infantil no había participado en el simulacro, dado que este se había desarrollado en otro edificio, el de primaria. Así que se estudió la posibilidad de diseñar algún tipo de actividad especialmente pensada para ese ciclo. Teniendo en cuenta su corta edad, se valoró que debía tratarse de algún tipo de actividad participativa, lúdica y que supusiese una primera toma de contacto con el mundo de las emergencias. Se valoró la utilización de manualidades, juegos, marionetas... 
aunque la decisión final fue la preparación de una representación teatral a desarrollar durante el festival de navidad.

¿Cuál podría ser el tema de la obra? Las estadísticas de prevención de incendios arrojan cifras claras sobre cuándo se produce un mayor incendio de viviendas. Es en los meses de invierno, cuando el frío obliga a un gran uso de chimeneas y distintos tipos de calefacción, provocando fuegos o malas combustiones con efectos letales. Pero además, en diciembre se produce un tipo de incendios que solo puede darse entonces: los incendios originados en árboles de Navidad. Tener este elemento decorativo en casa nos aporta un ambiente muy agradable.. pero también puede ser foco de problemas.

Así que desde la investigación se sugirió que el tema de la obra fuese un incendio en el árbol de Navidad. El colegio asumió el reto de preparar esta obra teatral, y a partir de ahí se decidieron una serie de pautas que debían estar presentes, dada la corta edad de los participantes. Así, en la obra debía quedar claro que el fuego se había iniciado por algún tipo de problema relacionado con el árbol de Navidad

Además, los alumnos adoptarían multitud de roles que reflejasen la situación de emergencia y que además permitiesen la participación de todos los alumnos: unos podían ser el fuego, otros el agua, unos los bomberos....

A partir de aquí, la maquinaria de creatividad y organización que caracteriza a los centros escolares se puso en marcha. La dirección y la responsable de prevención consiguieron implicar a maestros y alumnos en la dirección que marcaba la obra. Se empezó a diseñar su estructura, los disfraces de cada participante comenzaron a tomar forma, e incluso se preparó una canción para formar parte de la representación. Llegaron los ensayos y los preparativos, y el día del festival de Navidad la obra se estrenó con éxito para todos los alumnos, padres y profesores.

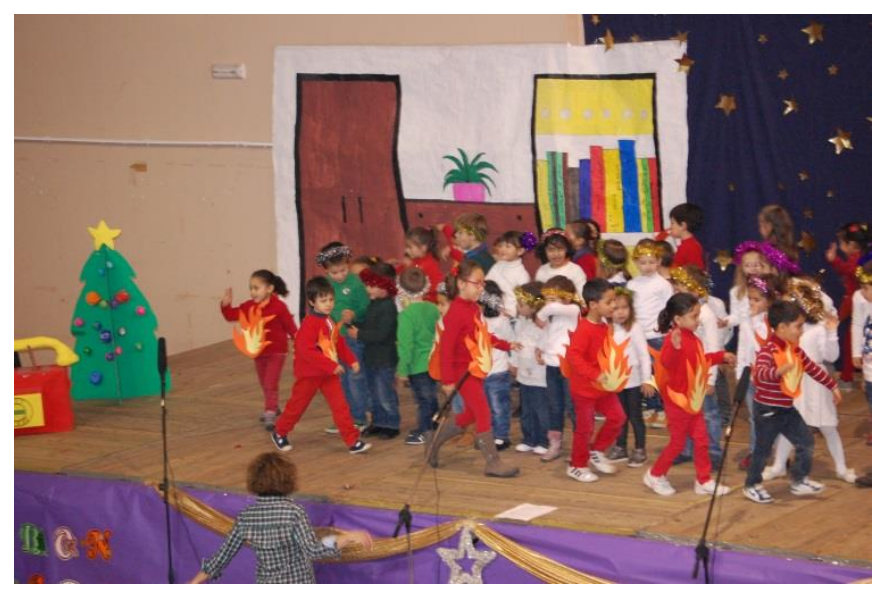



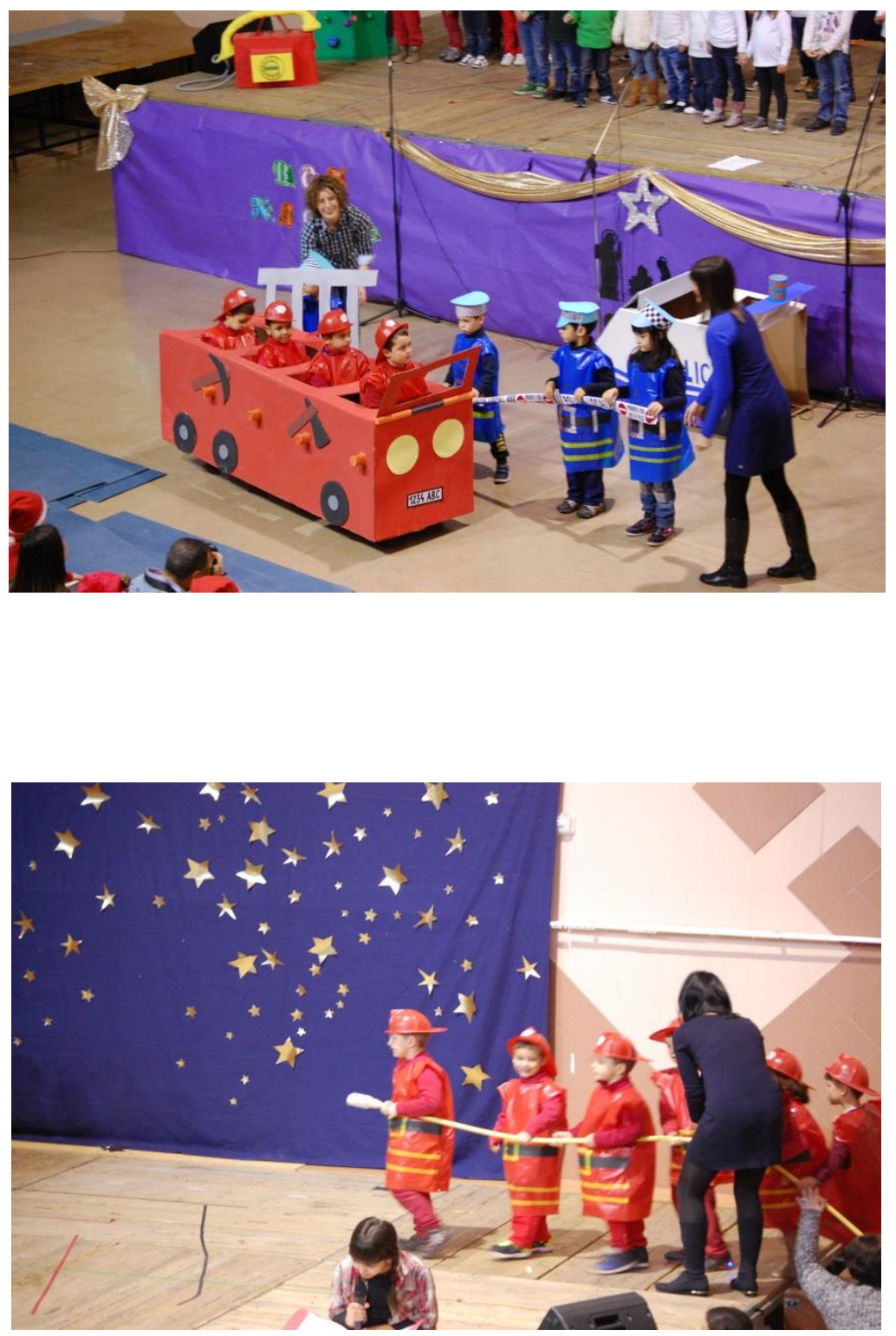

Tras esta experiencia consideramos que integrar los temas de prevención y autoprotección dentro del festival de Navidad comporta varias ventajas, sobre todo en edades tempranas como el ciclo de infantil, pero también puede resultar útil para cursos superiores.

En primer lugar, es fácil de integrar en los tiempos y periodos del colegio, que siempre destinan una época del año a planificar y preparar el festival de Navidad.

Se trabajan los contenidos vinculados a la prevención desde un aspecto lúdico, que consigue llegar a los niños más pequeños. 
Como se ha visto en capítulos anteriores, los niños y niñas son valiososo canales de transmisión de conocimientos y concienciación, y este tipo de actividades, en las que ellos son los verdaderos protagonistas, les situa en el centro de ese proceso transformador.

Finalmente, también resulta importante que la actividad alcanza visibilidad social al realizarse frente a un nutrido auditorio, tanto de alumnos como de profesores, e incluso de medios de comunicación locales. De esta forma, las actividades de difusión de la prevención salen de su círculo de actores especializados para alcanzar a distintos públicos. A través de la infancia, se alcanza a otros actores de la sociedad.

\subsection{Actividades de la Semana de Prevención en las instalaciones del CP Grangel} Mascarós.

Como se vio con anterioridad, esta actividad está planteada de forma que la fundación MAPFRE, como actor impulsor de cambios sociales, implica a los distintos cuerpos de bomberos de España en su Semana de la Prevención. Los bomberos, como expertos, preparan las actividades y difunden los conocimientos en materia de autoprotección a diversos públicos y, en el caso de los escolares, han de llevar a cabo un auténtico proceso de adaptación para llegar al público infantil.

A continuación se ofrece el informe y las conclusiones de cómo se llevaron a cabo estas actividades en el centro objeto del presente estudio.

\section{INFORME:}

Lugar: Colegio Grangel Mascarós y local Bancaixa (frente al colegio)

Fecha y hora: 27 de octubre de 2014 de $09 \mathrm{~h}$ a $17 \mathrm{~h}$

Cuerpo de bomberos participantes: Consorcio Bomberos Castellón, a través de su Jefe de Bomberos Voluntarios, Jefe de Parque de Bomberos Voluntarios de l'Alcalatén, 5 bomberos voluntarios del citado parque.

\section{Actividades realizadas:}

\section{Actividades previas a la Semana de la Prevención}

-Los alumnos y profesores han trabajado en el aula los cuadernos educativos editados por Mapfre, donde hay explicaciones, actividades, juegos, etc.

-Se ha hecho llegar a los padres un escrito con los objetivos y programación de la jornada de actividades. 
TIPOS DE ACTIVIDADES DESARROLLADAS

\section{CHARLAS}
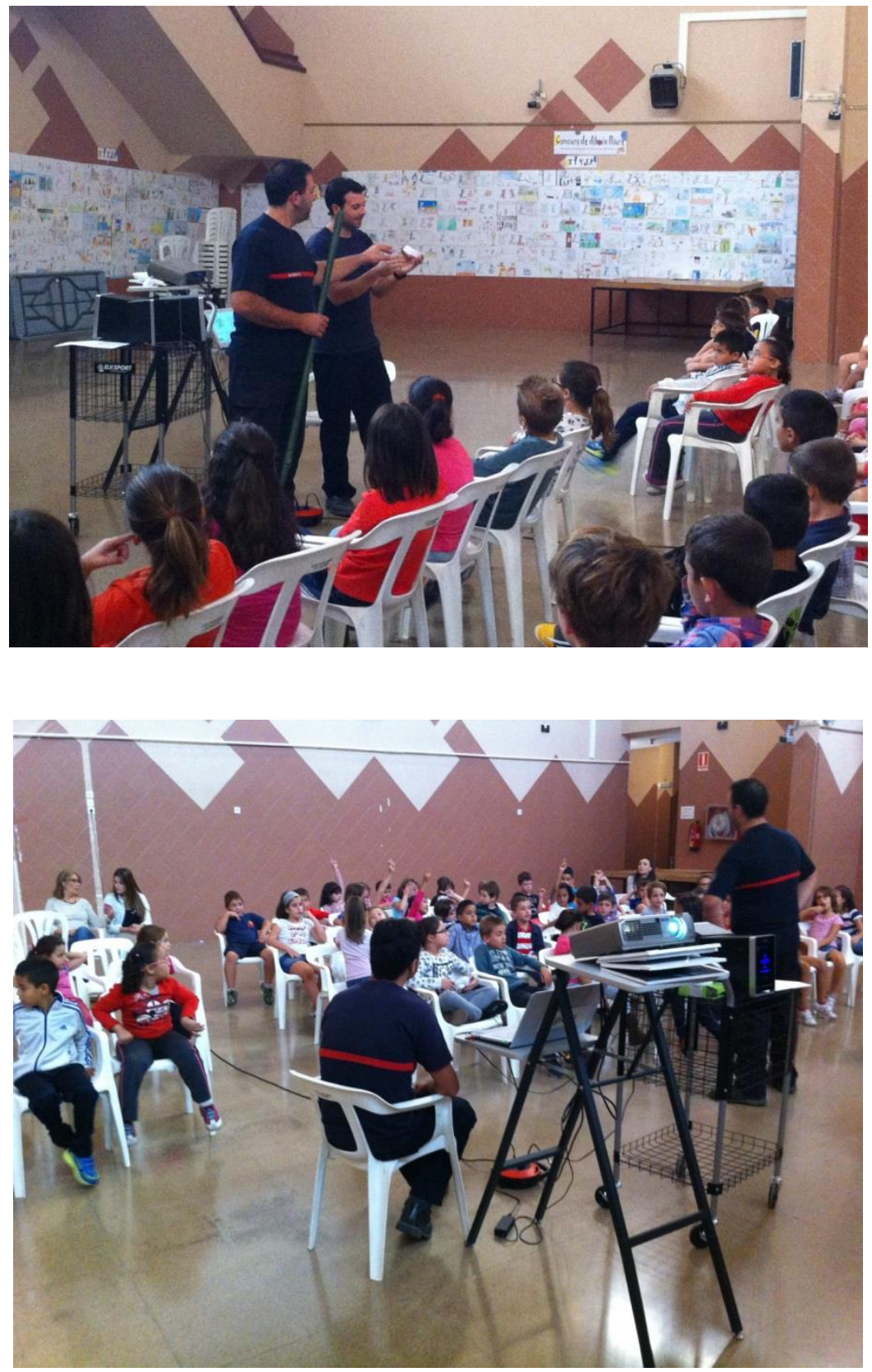
Están realizadas por dos bomberos. Las características de estas charlas son las siguientes:

a) Desarrollo:

*Uso de proyecciones, que recogen parte de los contenidos de los cuadernos educativos facilitados por la fundación: peligros, el triángulo del fuego etc.

*Exhibición de cómo funciona un detector de humos

*Explicaciones del bombero. Para generar más dinámica, se les pregunta mucho a los ninos sobre si alguna vez "han visto...", "han tocado..", "en su casa hay...." "sus hermanos hacen...", para animarles a participar.

*Vídeos. Se usan distintos vídeos de 2 minutos de duración cada uno en los que aparece un bombero que va explicando y mostrando diferentes riesgos.

b) Participación de los niños:

${ }^{*}$ Realizan muchas preguntas al bombero que realiza la charla, levantando contínuamente el brazo para preguntar o contar vivencias personales relacionadas con la explicación.

*Como dato relevante, todos responden correctamente a la vez sobre "¿cuál es el número de teléfono que se ha de marcar para emergencias?": "1-1-2". Tienen un conocimiento total sobre este número.

*Realizan preguntas de todo tipo, algunas difíciles de responder: “¿Qué hago si hay un incendio en mi casa, no tengo teléfono, y estoy encerrado en una habitación sin ventanas? (pregunta realizada por un niño de segundo de primaria).

*Si se les pregunta si han hecho alguna vez algo como "poner los dedos en un enchufe", "ver una sartén incendiarse" etc., siempre responden que "Si" o que conocen a alguien (hermano, padres, amigo, etc.) a quien sí le ha pasado. Cuentan vivencias personales y quieren participar de las historias que allí se cuentan.

*Los niños más pequeños preguntan más que los más mayores. Participan tanto, que no da tiempo de poner todos los vídeos.

*Durante el proyectado de los vídeos, el lenguaje no verbal de bastantes niños parece reflejar un menor interés que con las actividades precedentes: no miran la pantalla, se revuelven en su asiento, se giran a mirar a los compañeros, hablan entre ellos, etc. 
Podría resumirse en que muchos "desconectan", y vuelven a concentrarse una vez el bombero que estab ofreciéndoles la charla retoma la palabra.

Tras consultar con el profesorado del centro su opinión sobre este punto, concluímos que quizá viene motivado porque los vídeos no están adaptados a un lenguaje audiovisual infantil que les resulte más atractivo (no hay niños protagonistas, no hay un entorno infantil como colegios o no se usan recursos como dibujos animados).

\section{CAMINAR POR CIRCUITO CON MALA VISIBILIDAD}

Los alumnos han de desplazarse por los ojos vendados por un laberinto de madera, como si tuviesen que hacerlo por un lugar afectado por humo que les impidiese ver.

-Los niños se esfuerzan por realizarlo bien.

-Lenguaje no verbal: las explicaciones las hace un bombero muy alto que opta por agacharse para estar a la altura de los ojos de los niños, facilitando la comunicación.

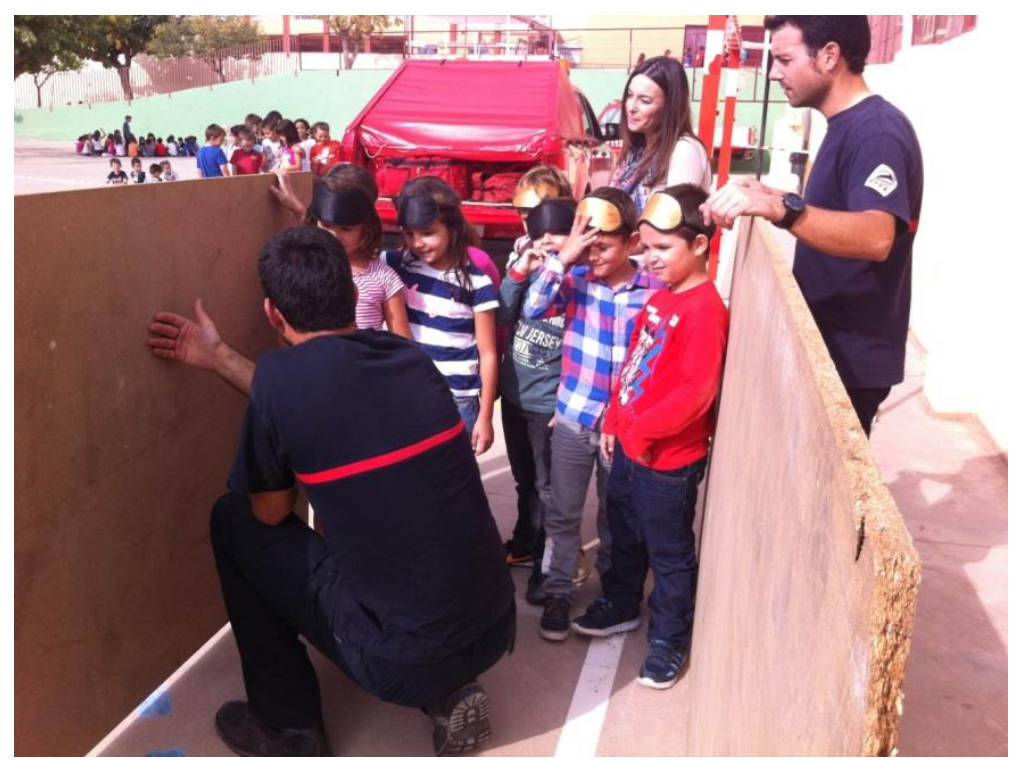




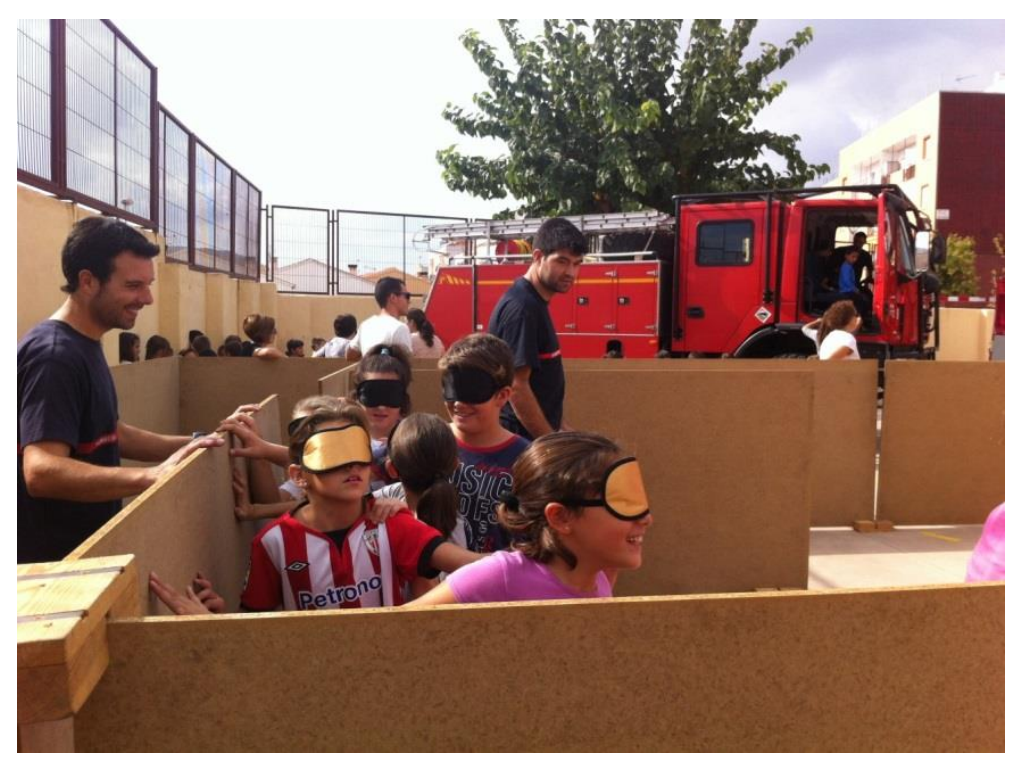

\section{SUBIR A UN CAMIÓN BOMBEROS}

-Se les explica cómo es el camión por dentro.

-Se les permite utilizar la megafonía

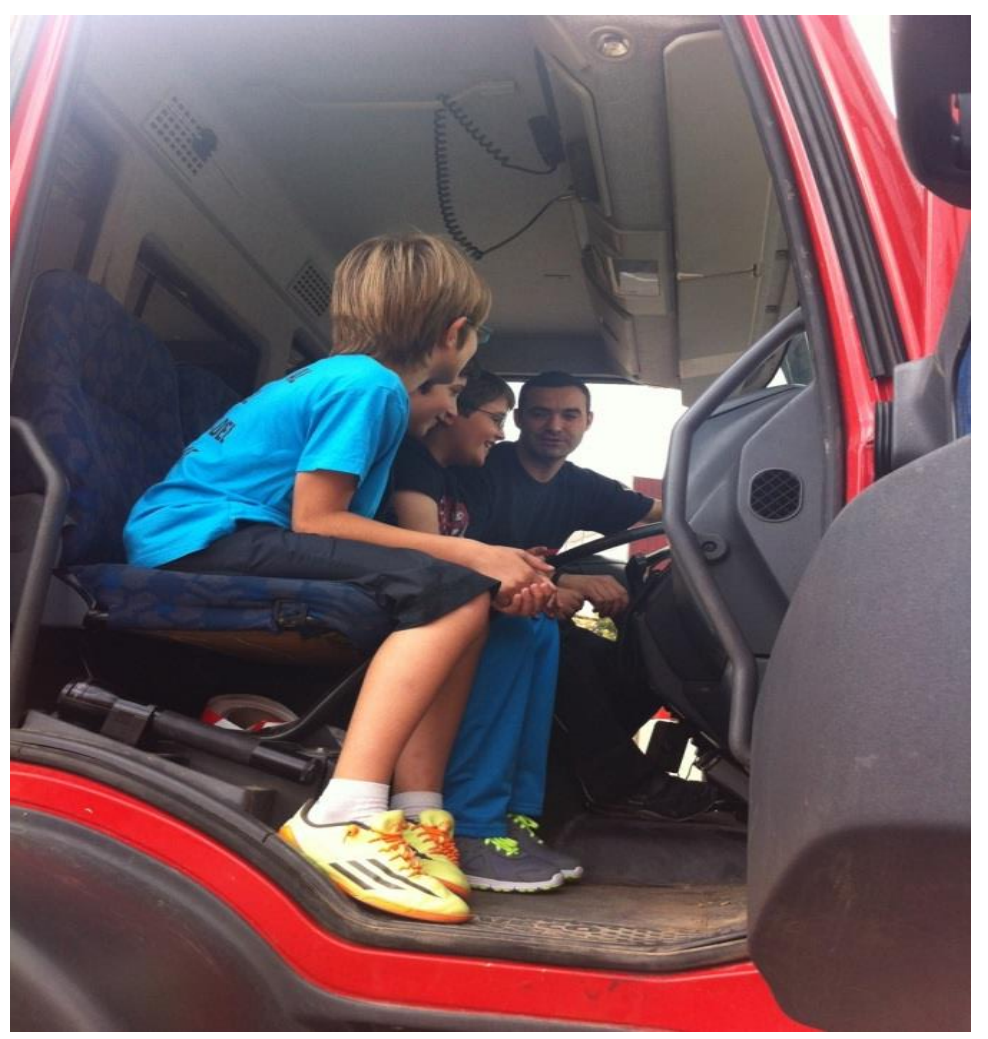




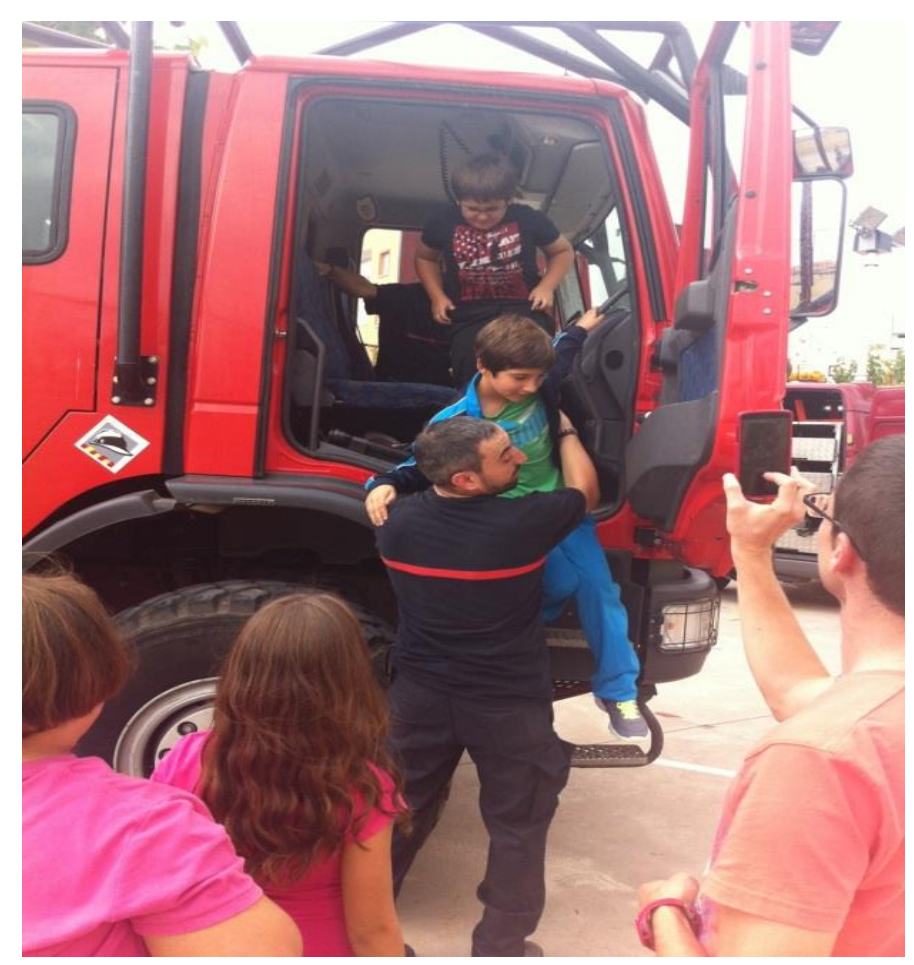

\section{EXHIBICIÓN DE MATERIALES}

- Se les explica a los niños para qué se usan algunos materiales y herramientas de los bomberos, realizando alguna demostración práctica. También se les permite probarse cascos y chaquetas.

-Leguaje no verbal:

*Bomberos de pie y niños sentados en círculo

*Durante las explicaciones sobre el manejo de herramientas, los niños están sentados escuchando. Cuando se les permite tocar materiales: todo el grupo se mueve más, hay gritos y peticiones de ser voluntario para probar las herramientas, hay un mayor nerviosismo y excitación general. Llega un punto en que muchos niños se levantan y hay que volverles a sentar. 

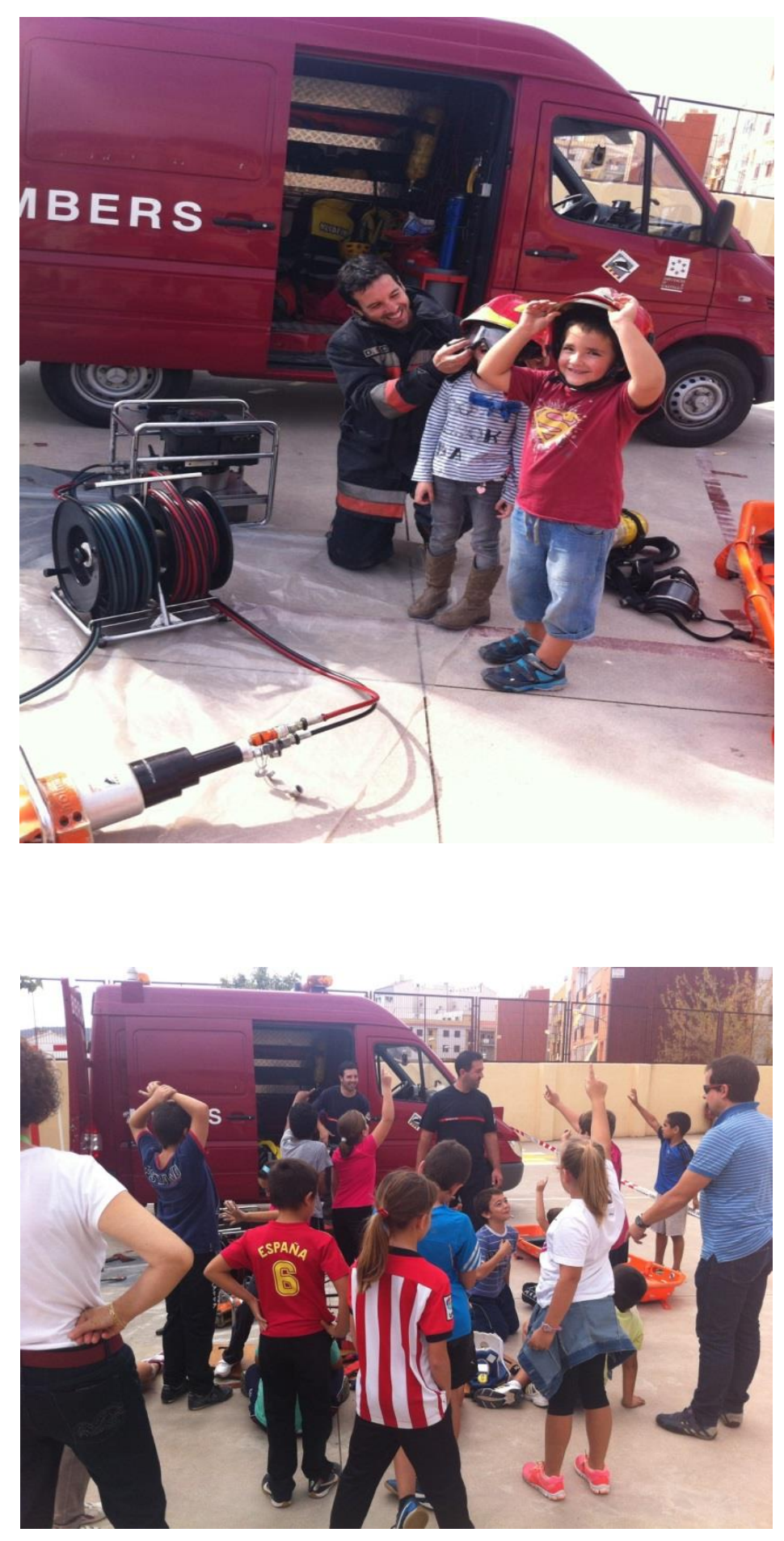
TRASLADOS EN CAMILLA
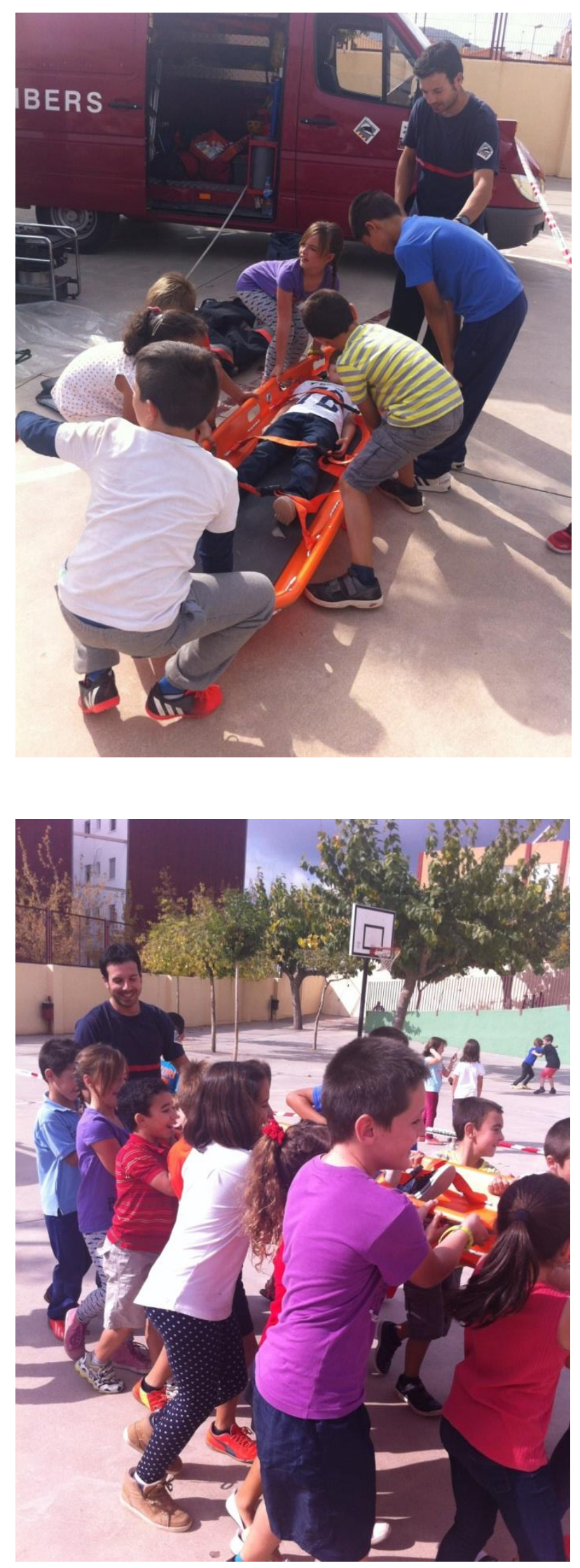
-Se les enseña a trabajar en grupo para poner a un herido en camilla y trasladarlo levantando la camilla del suelo.

-Todos quieren participar, reacción similar a la de exhibición de materiales (muchos niños pidiendo a la vez ser voluntarios etc.).

Claramente las actividades de exhibición de materiales y traslados en camilla, en la que los niños pueden "tocar", "hacer", "probar" y adoptar el rol de un bombero o rescatador, provocan un clima de mayor excitación entre los participantes y un incremento de las ganas de participar.

\section{EXHIBICIÓN Y PRÁCTICAS DE MANEJO DE EXTINTORES}

-Se enseña a algunos profesores y alumnos cómo manejar un extintor para apagar el fuego. Se les equipa con chaqueta y casco, y un bombero les explica de uno en uno cómo utilizarlo, y les acompaña a usar el extintor.

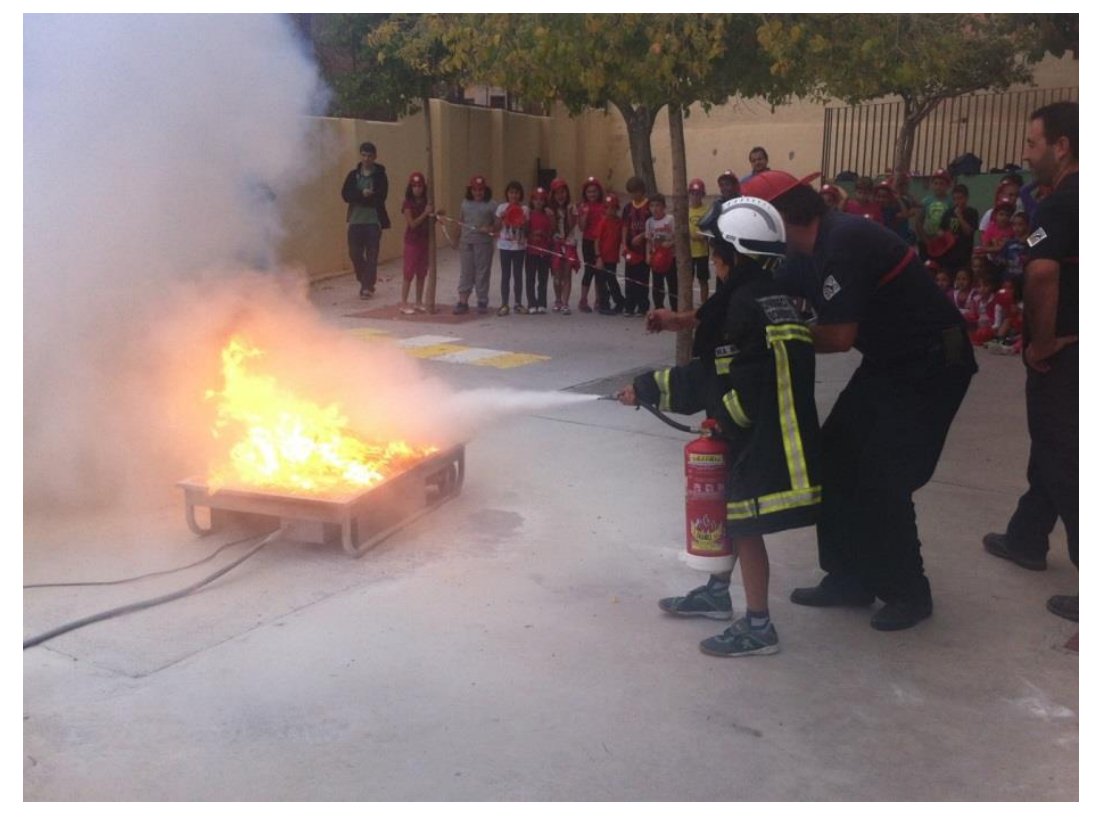




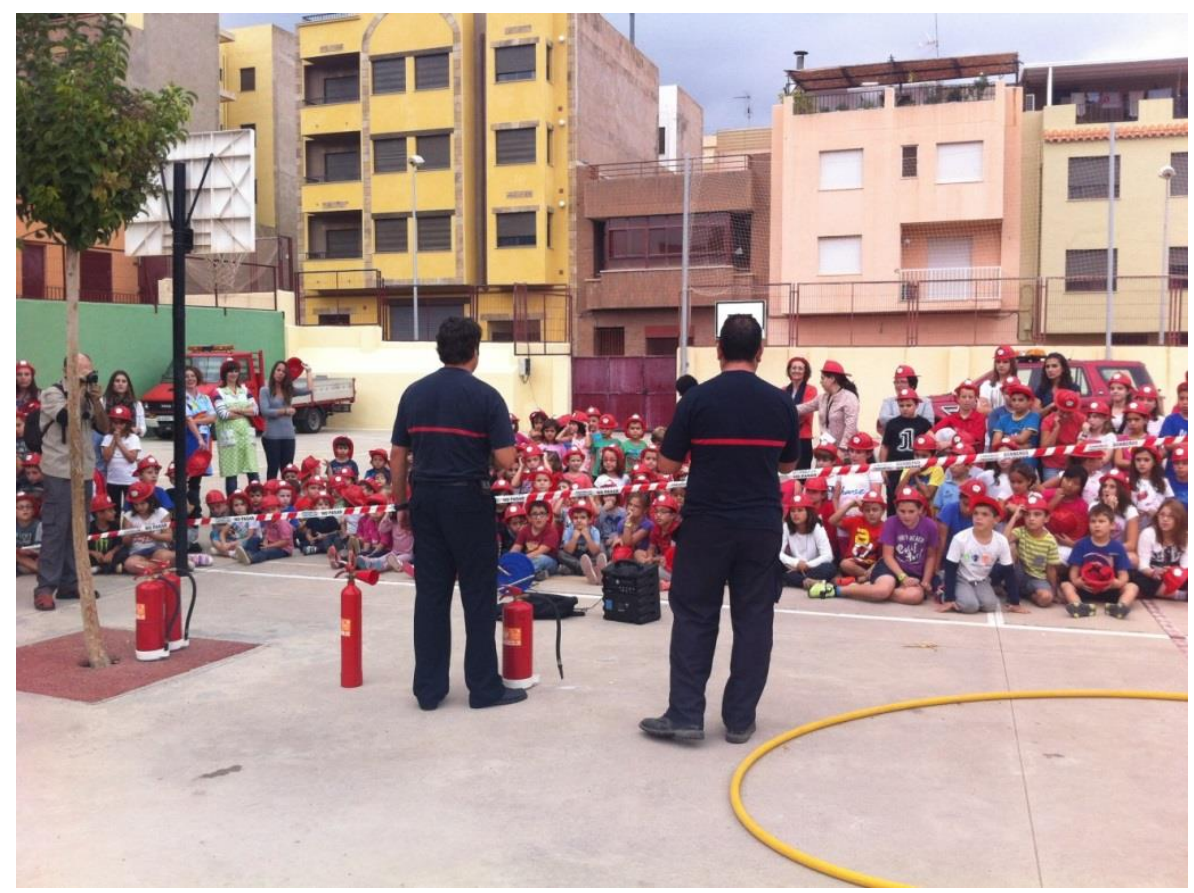

-Para verlo, el resto de asistentes se sienta en el suelo. Los niños viven esta actividad como un espectáculo:

*Aplauden en diversos momentos: la primera vez que el bombero muestra el extintor; a cada práctica que realiza un profesor o alumno; etc.

*Lanzan gritos y jalean a los participantes, animándoles como si fuese un evento deportivo.

Tras la realización de esta jornada, se difunden las actividades realizadas, a través del blog de la maestra Eder Górriz. De esta forma se hace partícipe de las mismas a toda la comunidad educativa, padres, etc. Consideramos muy importante esta vertiente porque contribuye a hacer de los temas escolares y en este caso de los temas en prevención de emergencias un asunto que incumbe al conjunto de la sociedad.

\subsubsection{Vídeo}

Entre las propuestas de actividades de esta segunda fase, de observación participante, se encontraba la realización de un vídeo que permitiese reflejar el funcionamiento de un simulacro, y en el que no se primase de forma exclusiva la voz del experto, sino que mostrase el conjunto de participantes de este tipo de ejercicios de preparación ante emergencias: profesores, alumnos, cuerpos de bomberos... 
Uno de los objetivos de la realización del vídeo era la creación de un documento audiovisual que pudiese alcanzar a un mayor número de personas que por otras vías.

Finalmente, se optó por realizar una cobertura mediática de una televisión de ámbito autonómico de la Comunidad Valenciana. La investigadora se encargaría de la faceta periodística, dado que tenía funciones laborales en dicho medio de comunicación.

Por su parte, los participantes en el simulacro serían filmados mientras éste se llevaba a cabo, y posteriormente se realizarían algunas entrevistas en las que se pusiese de manifiesto su labor y participación en el ejercicio.

Con la realización de este vídeo, pretendíamos demostrar entre otras cosas que los temas de prevención pueden ser tratados informativamente, y llegar a grandes audiencias a través de un soporte y formato televisivo. Ya habíamos detectado en el apartado de esta investigación dedicado al rol de los medios de comunicación, que los temas vinculados a la prevención se enfrentaban a algunos aspectos que en ocasiones dificultaban su cabida en la agenda mediática: no respondían a los criterios periodísticos de actualidad y noticiabilidad, no siempre eran fácilmente reflejables en imágenes, no hacían referencia a hechos recientemente acontecidos... Pero tambien vimos que un ajuste deliberado a estos criterios, podía dotar de una mayor cabida mediática a estos temas de prevención.

Consideramos que los simulacros pueden tener cabida en la agenda mediática dado que pueden ser inseribles en su narrativa. Hay varias razones para ello: los temas de prevención sí son en ese caso reflejables en imágenes, suele participar mucha gente y por tanto hay acceso a distintos puntos de vista y opiniones que enriquecen el relato audiovisual, participan cuerpos de emergencia que aportan vistosas acciones... Y acaban llegando a miles de espectadores, siendo una de las vías donde se logra una mayor difusión, ya sea través de la audiencia televisiva o de internet, donde suelen compartirse muchos de estos contenidos a través de las redes sociales.

Por todo ello se valoró que elaborar una noticia alrededor de otro simulacro programado para este colegio podía colaborar a esa de difusión de la prevención, ya que una actividad protagonizada por niños tenía repercusión en el mundo de los adultos.

Se transcribe a continuación el texto y las declaraciones, en valenciano en el original. 
"OFF PERIODISTA: Suena la alarma de incendio en el Colegio Grangel Mascarós de Alcora, y rápidamente comienza la evacuación. Niños y maestros salen en orden de las clases en dirección a las escaleras. Han estado preparándose durante el primer trimestre $y$ todos saben lo que tienen que hacer.

NIÑA:Tendremos que ponernos detrás del maestro $y$ dejar todas las cosas, $y$ levantarnos y hacer una fila con el maestro. Después iremos por las escaleras y bajaremos hasta la calle. Ahí vendrán los bomberos y apagarán el fuego.

OFF PERIODISTA: En pocos minutos llegan los bomberos del Consorcio de Castellón, desde el Parque del Alcalatén. Les avisan de que faltan por salir dos niños, así que los bomberos tienen que inspeccionar bien el edificio, afectado por el humo

BOMBERO: Establecimos que haríamos el ejercicio planteado con dos niños que simularían ser víctimas, afectados por el incendio. Para ello lo que hacemos es llenar una aula, la que determinemos, la llenamos de humo con una máquina que es humo respirable, el humo típico de los conciertos.

NIÑO: Me ha tocado ponerme debajo de una mesa para hacer como si estuviese atrapado.

OFF PERIODISTA: Finalmente, los bomberos localizan a los niños y consiguen rescatarlos. Desde el centro consideran fundamental realizar estos simulacros periódicamente

DIRECTORA: Porque así tanto el personal docente como el personal no docente y los niños se conciencian y actúan con tranquilidad y eficacia frente a una situación de riesgo.

OFF PERIODISTA: En total 192 niños y 16 maestros han participado en este simulacro. Una actividad que les ayudará a estar más preparado frente a un hipotético incendio. Una preparación que sin duda ayuda a tener unos colegios más seguros.

Ests son algunas de las imágenes extraídas del vídeo emitido en televisión.

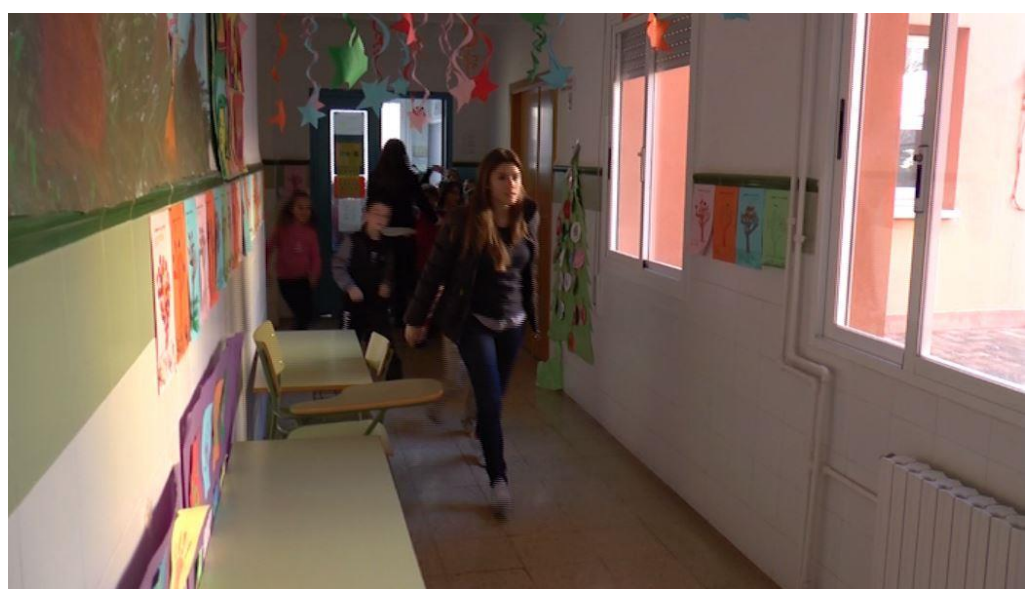



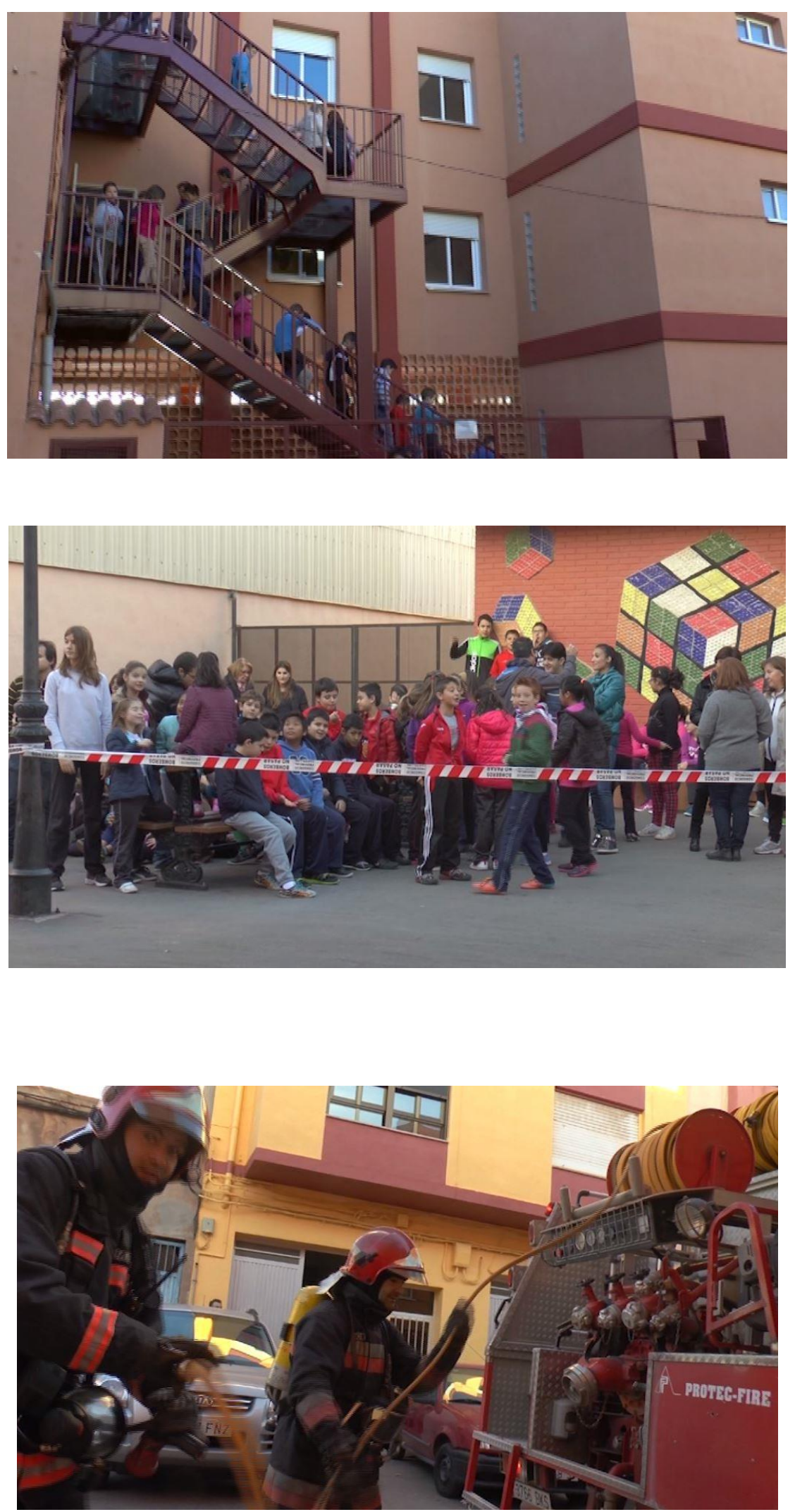

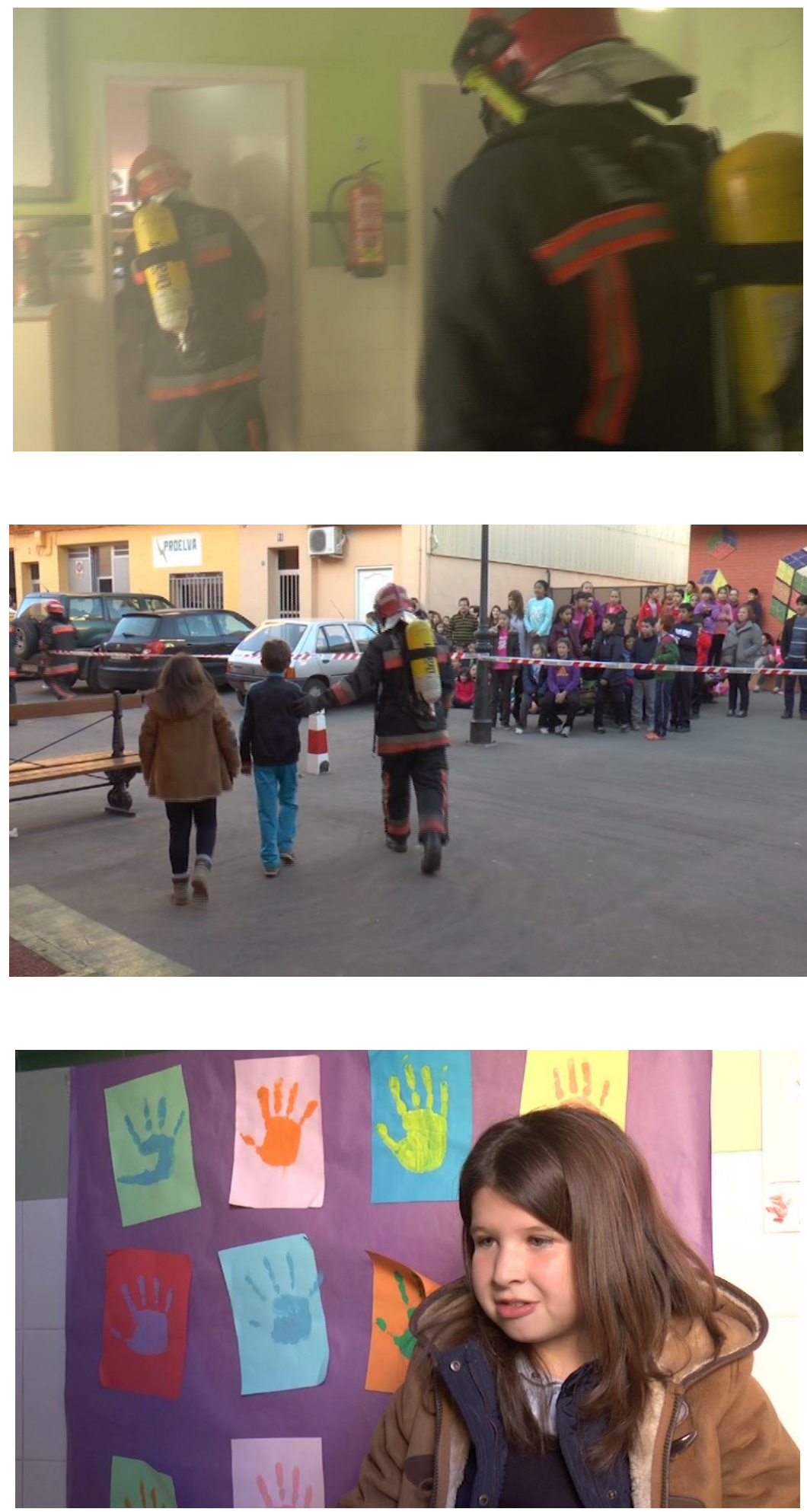

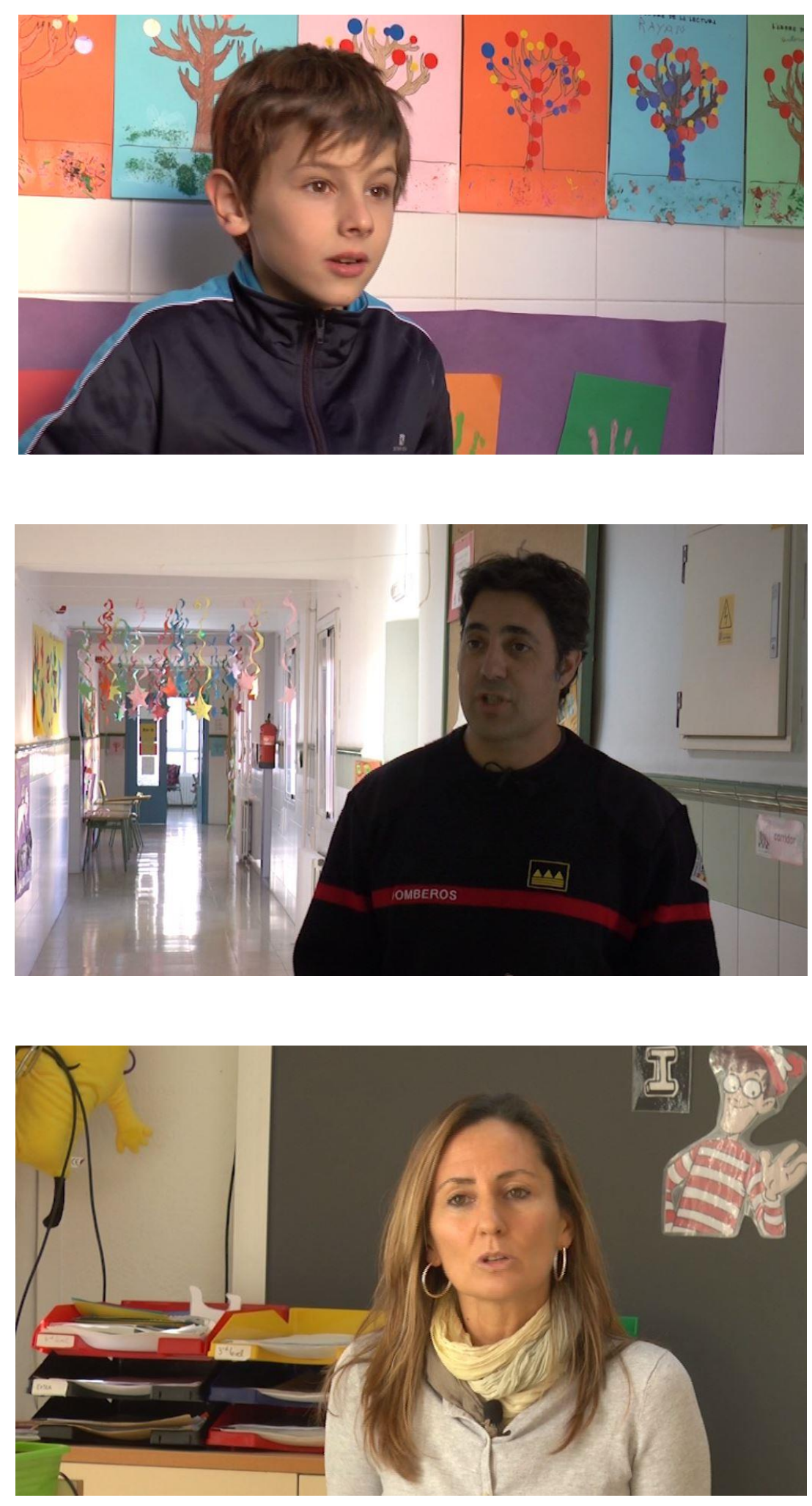


\subsubsection{OTRAS ACTIVIDADES}

El centro educativo objeto de análisis, tras finalizarse esta fase de investigación, ha continuado desarrollando por su parte actividades vinculadas a la prevención y autoprotección en el centro escolar.

\section{Simulacro de infantil}

Los alumnos de infantil han realizado un simulacro sin ayudas externas, para familiarizarse con la ruta de evacuación y practicar los pasos a seguir. Dada su corta edad, la maestra encargada de la realización del simulacro y que había participado en la totalidad de la fase de investigación-acción (Eder Gorriz) ideó un juego mediante el cual los niños pudiesen participar en la evacuación de una forma que a ellos les resultara natural y familiar. Así, les planteó el siguiente juego:

"Un día vendré al colegio vestida de llama de fuego, con tres llamitas en mi mano. Nadie podrá tocarme o se quemará. El primer niño que me vea tiene que ir rápido a avisar a su maestra". A todos se les explicó cómo debían salir del edificio.

Un día, esta maestra llegó al edificio de infantil vestida de llama, y un niño la vio y aviso a su maestra. Los alumnos reaccionaron adecuadamente: salieron en orden, concentrados en lo que hacían, se dirigieron al punto de reunión, se sentaron en el suelo.. y todo en el plazo previsto de dos minutos.

La creatividad en la educación en prevención de emergencias es un factor determinante, y que contribuye a implicar a todos los participantes.

\section{Stop-motion}

No es ese el único ejemplo de actividad creada desde este colegio, ya que tras su paso por ese proyecto investigador han continuado con el objetivo de difundir los temas de prevención de otras innovadoras formas.

En el curso 2014-2015 han integrado también estos temas en el proyecto global del curso, destinado al cine y denominado "3-2-1 Cámara y acción”.

Eran diversos los objetivos y contenidos que debían interrelacionar en esta ocasión. Por un parte, al tratarse de una de los principales municipios cerámicos y azulejeros de España, los alumnos debían participar en actividades desarrolladas en el Museo de la Cerámica de la localidad. Por otro, había que vincular esta actividad al proyecto 
global del curso, el cine. Finalmente, el centro decidió que de todo ello debía formar parte de forma transversal la prevención en emergencias.

El resultado final fue una película rodada mediante la técnica del stop-motion, con figuras fabricadas por los alumnos en el museo. En una de las escenas, los personajes ven una obra de teatro de Navidad que resultaba ser la obra de teatro representada en el colegio, en la vida real, con motivo de los incendios de árboles decorativos, como ya hemos explicado en los apartados anteriores. En ella se veía como el árbol de Navidad se veía afectado por un incendio.

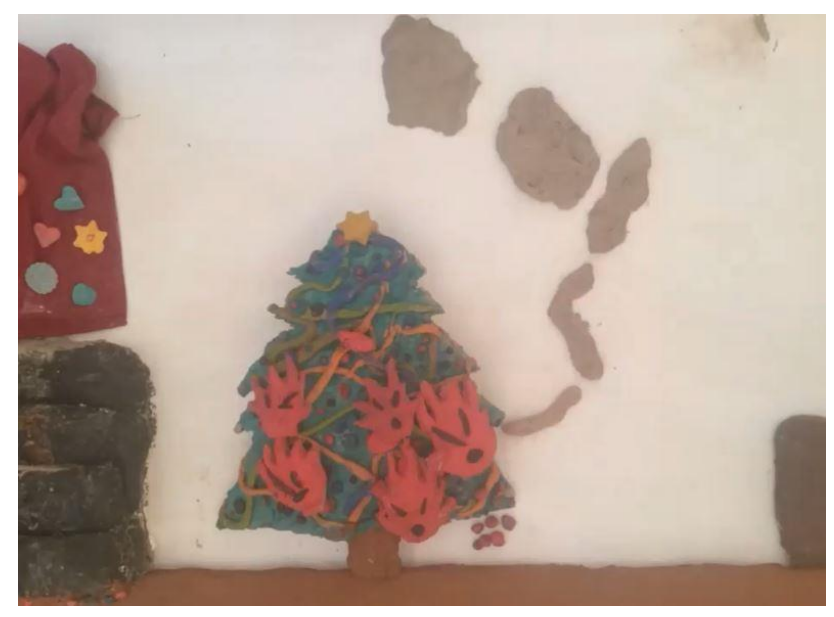

La película recuperaba el guión original de la obra de teatro, en el que se destacaban algunas ideas como la necesidad de llamar al 1-1-2 si se detecta un fuego o de evacuar de la zona en riesgo. También se mostraba el trabajo de extinción de los bomberos (fueron caracterizados como los correspondientes al Parque de l'Alcalatén, que eran con quien los alumnos habían realizado sus actividades de simulacro y de semana de la prevención) y como posteriormente la situación regresaba a la normalidad.

Llamada al 1-1-2

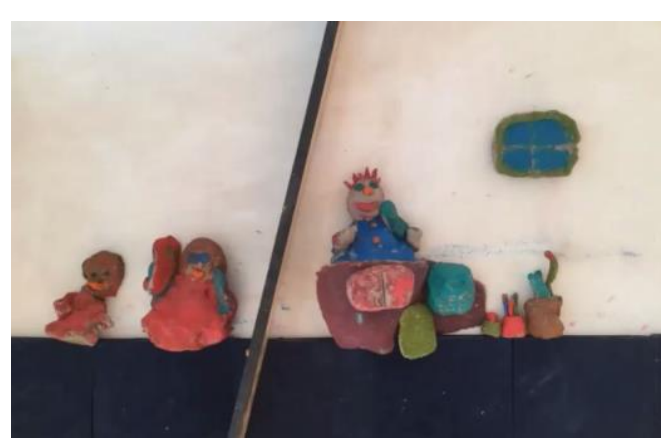


Llegada de los bomberos al colegio

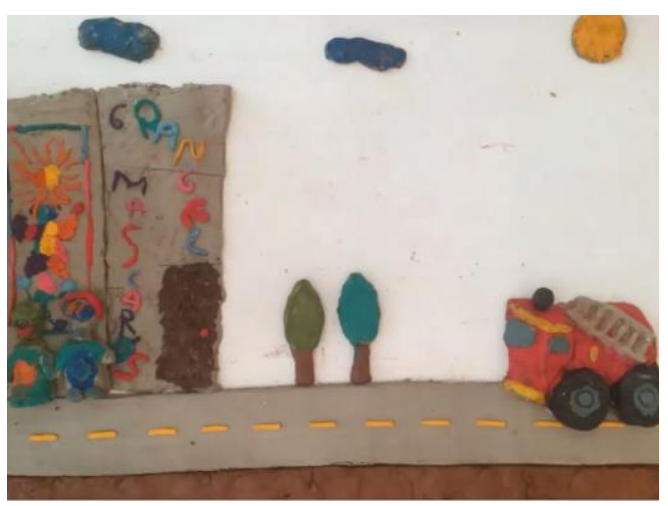

Bomberos apagan el fuego

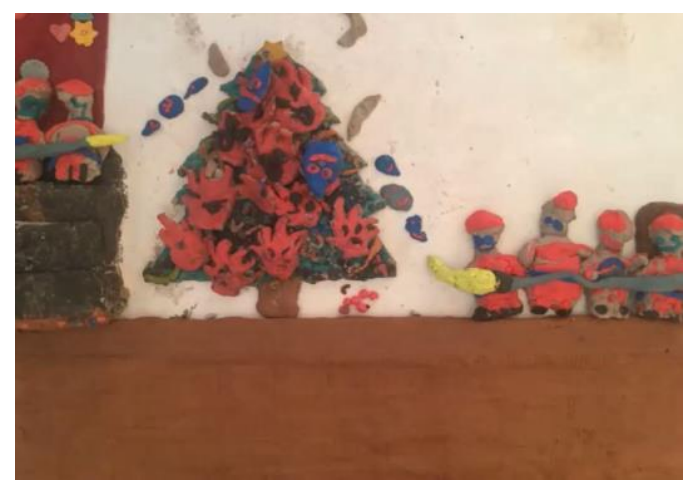

La situación recobra la normalidad

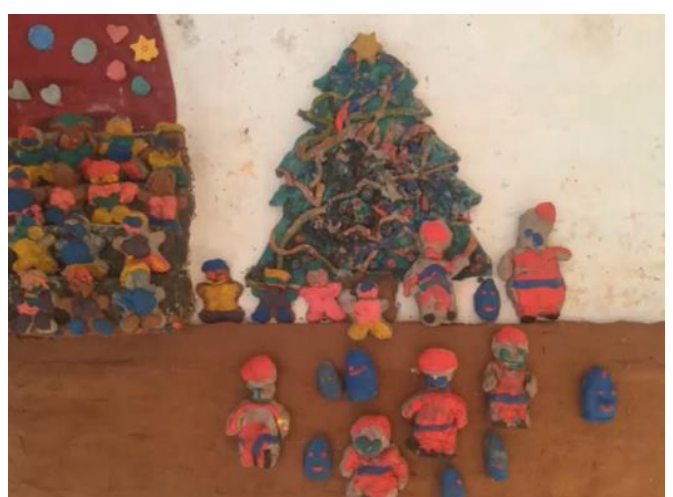


Making off: los niños en el taller preparando las figuras de la película stop-motion

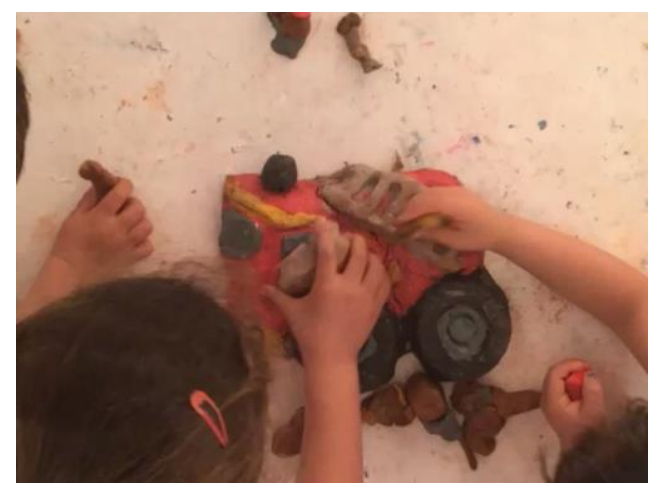

De esta forma, cine, cerámica y prevención de incendios, tres temas aparentemente muy desconectados entre sí, quedaron integrados en un mismo proyecto. Fue una muestra de que la semilla de la prevención puede extenderse por toda la cultura del colegio. 


\section{CAPÍTULO 4. CONCLUSIONES Y PROPUESTAS}

\subsection{LIMITACIONES Y CUMPLIMIENTO DE OBJETIVOS}

Antes de pasar a profundizar en las conclusiones y propuestas surgidas de esta investigación, nos gustaría también repasar algunas de las limitaciones que este proceso investigador ha tenido.

-No se han medido los resultados de los conocimientos o hábitos de los públicos infantiles que participan de estas prácticas comunicativas relacionadas con la prevención. Las técnicas de medición deberían estar totalmente adaptadas al mundo infantil y consideramos que para varias de las prácticas evaluadas sería necesario ampliar mucho más la muestra y extenderla en el tiempo.

No era el objetivo de la presente investigación medir resultados, pero consideramos que disponer de este tipo de datos podría contribuir a lograr una perspectiva todavía más amplia sobre el fenómeno.

-Algunas de las webs analizadas hacían referencia también a la existencia de redes sociales de la institución, pero dichas redes sociales han sido descartadas de la presente investigación. El motivo ha sido, por una parte, la entidad diferenciadora de las redes sociales respecto a otros canales comunicativos, que hacían necesario emplear otros métodos de análisis distintos al resto de los aplicados en el presente estudio. Además, dado que la mayoría de las redes sociales mencionadas en las referidas webs plantean como requisito de uso ser mayor de 14 años, esa circunstancia evidenciaba que no podíamos considerar como destinatario a la mayoría de la infancia y adolescencia a la que sí iban dirigidos otro tipo de contenidos analizados en la presente tesis (simulacros, páginas web etc).

Por estos motivos, se consideró más oportuno que el tema de las redes sociales fuese abordado más adelante a lo largo de las futuras líneas de investigación.

-La práctica de investigación-acción en el centro escolar arrojó resultados muy interesantes. Aún así, estimamos que para poder profundizar en el ámbito del diálogo multidireccional, y una vez que ya se ha hecho una primera experiencia que también haya servido para formar al formador, podrían realizarse futuras investigaciones donde todavía se primase más ese proceso de diálogo. 
Sin olvidar estas limitaciones, debemos por otra parte examinar cómo los resultados de la investigación han ofrecido resultados interesantes a la hora de conocer mejor el panorama del discurso y prácticas comunicativas sobre información preventiva para infancia y adolescencia, y cómo han cumplido con los objetivos que se habían fijado al inicio del proceso investigador.

Por una parte, se trataba de describir el panorama de la información y formación en prevención de emergencias, concretando qué tipo de organizaciones estaban participando de este proceso, que relaciones establecían con el resto de actores y el tipo de prácticas comunicativas que se desarrollaban. Para poder concretar el tipo de organizaciones se ha acudido al marco teórico, así como al análisis de las páginas web y la realización de una serie de entrevistas en profundidad. Todo ello nos ha conducido a dibujar el panorama de instituciones vinculadas a la protección civil que participan de este proceso de adaptación a un público infantil y juvenil.

El segundo de los objetivos consistía en poner en práctica mediante un trabajo de campo las conclusiones más relevantes de las fases anteriores del presente estudio y, para alcanzar este objetivo se ha desarrollado una investigación-acción en un centro educativo.

Por una parte esto ha permitido observar el diálogo entre un centro escolar y un servicio de bomberos y por otra, ha posibilitado poner en práctica las principales conclusiones de la investigación para poder efectuar una intervención que, de forma efectiva, ha logrado implementar los procesos comunicativos de los simulacros de evacuación y de otras actividades vinculadas a la formación en prevención en el entorno escolar.

Finalmente, en tercer lugar, la investigación se proponía como uno de los objetivos proponer un modelo de utilidad para las organizaciones vinculadas a las emergencias que quisiesen incluir a la infancia y adolescencia entre su público prioritario. A lo largo de los diferentes capítulos y apartados se han expuesto las que consideramos las principales líneas que deberían formar parte de este modelo, que será resumido en el apartado 3 del presente capítulo. 


\subsection{CONCLUSIONES}

\subsubsection{EL NIÑO EN EL DISCURSO DE LA PREVENCIÓN}

El desarrollo de la presente investigación nos conduce a reafirmar y confirmar la hipótesis de partida, en la que se apuntaba que los organismos de protección civil, estaban dirigiendo una parte de su comunicación preventiva a informar a los niños y niñas sobre los riesgos existentes y cómo evitarlos. Además planteaba que las prácticas comunicativas generadas se diseñaban teniendo en cuenta ese tipo de público, y contaban con recursos diferentes a los utilizados en la comunicación preventiva orientada al público en general.

Las distintas fases han ido confirmando este planteamiento.

Por una parte, está el discurso expresado por los organismos e instituciones vinculadas a la protección civil, en torno a la cultura preventiva, que destaca de forma expresa la importancia y necesidad de trasladar a la infancia y adolescencia contenidos preventivos. Esta idea central se ha reproducido y se reproduce a través de distintos foros y canales, de forma que podemos concluir que a lo largo de las cuatro últimas décadas, las instituciones dedicadas a la protección civil han situado a los niños en el mapa de públicos de estas organizaciones.

En primer lugar, lo han hecho a través de los textos legislativos, que en repetidas ocasiones han sostenido esta idea. Textos con un gran poder performativo sobre la realidad social, que además de describirla permiten enunciar cómo ha de ser, y facilitan al ciudadano el instrumento legal necesario para reclamar su cumplimiento en caso de que la realidad no se ajuste a lo expuesto.

Estas leyes trazan, por una parte, un panorama en el que las instituciones públicas tienen una labor de concienciación y de información en torno a los riesgos y a una cultura general de prevención, y por otra, dibujan un ciudadano capaz de intervenir en su propio proceso de autoprotección. Con este paisaje de fondo, ponen el acento en la formación e información a la infancia como el pilar sobre el que asentar una cultura general de la prevención. Así, hacen referencia a planes de autoprotección, los simulacros de evacuación, o las actividades de información, prevención y divulgación en materia de protección civil como claves para alcanzar esa cultura.

Para reforzar estos planteamientos y actividades se ha creado en 2015 el Fondo 
Nacional de Prevención de Emergencias, del Ministerio del Interior del Gobierno de España, por lo que las instituciones, organizaciones, ciudadanos y alumnos cuentan desde ahora con un recurso más que podría ofrecer nuevas e interesantes vías a explorar durante los próximos años. La labor de las instancias ministeriales sumada a la de la ciudadanía y organizaciones en general podría conseguir grandes avances si, unos y otros, se implican mediante estas nuevas vías en un trabajo conjunto en el camino de la prevención.

En segundo lugar, el discurso institucional que sitúa a la infancia en el mapa de públicos de las instituciones de la protección civil, procede también de un marco internacional en el que España se circunscribe por pertenecer a la ONU.

Este discurso en torno al papel de la infancia en la prevención de riesgos y desastres remonta sus orígenes a los foros sobre el medio ambiente de los años 70 pero será con las Conferencias Mundiales de Reducción de Desastres y con distintas campañas y estudios específicos dedicados a la infancia donde se intensificará de forma clara.

El punto de inflexión se sitúa en el periodo del año 2000-2006, en el que se producen cuatro hitos en la historia del discurso sobre la infancia y la prevención: la primera campaña mundial para la Reducción de Desastres; la Segunda Conferencia Mundial sobre esta temática (Kobe), que aboga por incluir las nociones en reduccción de riesgo de desastres en los programas de estudios; el estudio Let Our children teach us, que presenta a los niños como un auténtico agente de cambio social y se aproxima a prácticas concretas ya desarrolladas en el seno de la educación formal; y de nuevo otra campaña mundial, que lleva por lema La reducción de desastres comienza en la escuela.

Avanzando en la investigación, hemos observado que las principales líneas del discurso sobre infancia y prevención, se manifiestan, además de en los textos legales y en los foros y documentos internacionales, en las prácticas concretas comunicativas desarrolladas en nuestro país.

Es el caso de las webs analizadas, de carácter autonómico y vinculadas a la protección civil, o las líneas de trabajo y prácticas concretas expuestas por todos los participantes de las entrevistas en profundidad y que muestran el desarrollo de este tipo de actividades.

Sea a través del discurso o de las prácticas concretas en el que se materializa, la representación que se hace del niño, tal como hemos observado, es mayoritariamente el de una persona capaz de adquirir conocimientos y hábitos en torno a determinadas 
pautas de autoprotección, y que puede asumir, adaptadas a sus características y habilidades, responsabilidades en esta materia.

Se destaca también su rol como agente de cambio social, ya que se confía en él como persona capaz de trasladar sus conocimientos a otros, bien sean niños o bien los adultos de su entorno propio, como su familia.

\subsubsection{FORMAS EN QUE SE CONCRETA LA ADAPTACIÓN DE LOS CONTENIDOS DE PREVENCIÓN}

¿Cómo pasan del discurso a la acción las instituciones vinculadas a la protección civil? A lo largo de este estudio, hemos detectado diferentes cauces:

1. Participación en actividades de simulacros escolares, actividades que son de obligado cumplimiento para todos los centros escolares

2. A través de contenidos web, creando secciones específicamente dedicadas para un público infantil

3. Desarrollando actividades de distinta tipología en las que participan conjuntamente fundaciones e instituciones públicas

4. Demandando la incorporación de los contenidos de prevención de riesgos y emergencias al currículo escolar

\section{Los simulacros:}

Consideramos que la realización de simulacros es un escenario ideal para la comunicación de las instituciones de la protección civil (bomberos, policía, sanitarios etc) con sus públicos infantiles. La fase empírica de la investigación así lo ha demostrado.

Por una parte, la institución tiene la oportunidad de familiarizarse con sus públicos, acercándose a sus necesidades y teniendo la ocasión de adaptar mejor sus mensajes y formatos y por otra, sus públicos tienen la posibilidad de adquirir conocimientos, habilidades y lograr un fomento de los hábitos en materia de preparación ante emergencias.

Los simulacros pueden funcionar como llamada de atención hacia diversos problemas estructurales u organizativos que tuviese el centro y que no se hubiera podido detectar previamente, y son un excelente instrumento para medir lo adecuado del Plan de Autoprotección del centro escolar. 
Por otra parte, nuestro enfoque a la hora de evaluar los simulacros desarrollados en la parte empírica ha sido comunicativo. De él surgen a continuación cuatro propuestas:

\section{$\underline{\text { Actividades del tercer sector }}$}

Esta investigación nos ha permitido acercarnos también a actividades desarrolladas conjuntamente entre instituciones de la protección civil y fundaciones vinculadas a la prevención. En el caso que nos ocupó, analizamos la Semana de la Prevención, planificada conjuntamente por el Consorcio de Bomberos de Castellón y la Fundación MAPFRE.

Consideramos que esta fórmula tiene varias ventajas. Existen una serie de materiales preparados por la fundación que son fácilmente adaptables a cualquier centro escolar, y por otra parte, las actividades más prácticas son desarrolladas íntegramente por los servicios de bomberos de cada zona geográfica. La combinación de ambos sistemas da resultados bastante exitosos a tenor del caso evaluado:

-Los materiales (cuadernos, proyecciones) permiten trabajar los contenidos de la Semana de la Prevención tanto con anterioridad como con posterioridad a esta, con lo que se refuerza su memorización

-Las actividades de la Semana de la Prevención son eminentemente prácticas, favoreciéndose una perspectiva experiencial del aprendizaje. Los alumnos se sienten altamente implicados

-Si durante el mismo trimestre se realiza el simulacro de emergencia del colegio y la Semana de la Prevención, los temas de prevención de emergencias (sobre todo en materia de incendios) adquieren un gran peso y presencia en la agenda escolar.

\section{Introducción en el currículo escolar}

El discurso sobre infancia y prevención destaca como uno de los elementos de éxito fundamentales la incorporación al currículo escolar de contenidos vinculados a la protección civil y prevención de riesgos y emergencias. Las instituciones vinculadas a la protección civil así lo expresan a través de legislaciones y estudios, como los realizados a nivel internacional.

En el caso español, esa demanda es en parte recogida por el Ministerio de Educación. En este sentido, el RD 126/2014, de 28 de febrero, del currículo básico de la Educación Primaria, establece la protección ante emergencias y catástrofes como uno 
de los elementos transversales dictados en su artículo 10. También se hace mención al ámbito de educación vial y de forma especial la prevención de accidentes de tráfico.

Por otra parte, otros ejemplos relacionados con la prevención y la protección aparecen el el currículo de la asignatura Valores Sociales y Cívicos (bloque 3), donde entre otras cosas se espera de los alumnos:

-Ser capaz de realizar primeros auxilios y tomar medidas preventivas valorando la importancia de prevenir accidentes domésticos.

-Valorar las normas de seguridad vial, analizando las causas y consecuencias de los accidentes de tráfico

-Investigar sobre la prevención de accidentes de tráfico generando iniciativas y alternativas personales.

Asimismo, también el R.D. 1105/2014, de 26 de diciembre, por el que se establece el currículo básico de la Educación Secundaria Obligatoria y del Bachillerato, señala la protección ante emergencias y catástrofes como parte elemento transversal del currículo.

Posteriormente, una revisión a algunos contenidos concretos de diferentes asignaturas nos ofrecen una cierta presencia de algunos contenidos más relacionados con la prevención: prevención para riesgos sísmico y volcánico (Biología y Geología de 1ํㅡ y

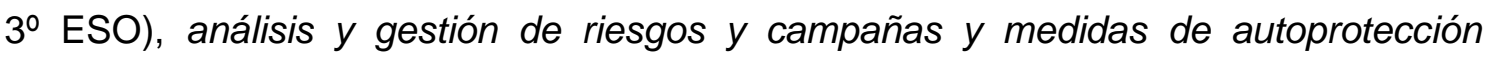
(Geografía de $2^{\circ}$ bachillerato), Protocolos a seguir para activar los servicios de emergencia y de protección del entorno (educación física de 1ํESO), o elaboración de presentación sobre amenazas como desastres medioambientales y desastres naturales (4ํㅡㅇㅡ).

Dado que estos currículos han sido aprobados en 2014, faltará ver como se materializa con el paso de los años esta serie de contenidos. La transversalidad será fundamental, pero será necesario ver cómo se traslada a la práctica durante los próximos cursos, así como evaluar si resulta suficiente.

Recordemos que la ley $17 / 2015$ de Protección Civil de nuestro país señala que:

"La planificación, especialmente los planes de autoprotección, la formación del personal perteneciente al sistema de protección civil y singularmente la inclusión en los currículos escolares de contenidos sobre autoprotección y primeros auxilios, son 
instrumentos poderosísimos de prevención de carácter horizontal que esta ley procura".

Consideramos que será necesario durante los próximos años que las instancias ministeriales competentes al efecto, como el Ministerio del Interior y el Ministerio de Educación, así como los órganos correspondientes a estas áreas en el nivel de la administración autonómica, evalúen si los objetivos educativos de ambas esferas, la de la Protección Civil y la de la Educación, están convenientemente armonizados y alineados.

Por otra parte, consideramos que el éxito de la materialización de estos objetivos responderá en parte al seguimiento de las recomendaciones descritas en los estudios llevados a cabo en colaboración con la ONU a nivel internacional sobre casos ya realizados de introducción de este tipo de contenidos en el currículo escolar.

Entre sus conclusiones, destacan las siguientes:

-Necesidad de formar al formador, que el profesorado pueda contar con los conocimientos y habilidades necesarios para desarrollar estos contenidos

- Formación transversal

- Necesidad de diálogo entre los diferentes sectores interesados: protección civil, educación, comunidad escolar, padres, alumnos

- El niño tiene un rol de agente de cambio social

-La formación experiencial, activa, y práctica ofrece mejores resultados que un enfoque meramente teórico

-Tendencia a una formación chil-to-child, defendida por la ONU, Unesco, y diversas fundaciones, en la que el niño se convierte en formador de otros niños y de otras personas de su entorno social.

\section{Contenidos web}

La mayoría de las webs autonómicas relacionadas con la protección civil sí incluyen contenidos en prevención de emergencias adaptados a un público infantil. Hay similitudes y diferencias con respecto a los contenidos y formatos dirigidos a adultos.

Así, el primer puesto de contenidos tanto para niños como para adultos lo ocupan las pautas de autoprotección, pero a partir de ahí, todo cambia. En el caso de los niños los siguientes contenidos más frecuentes hacen referencia a cómo utilizar el 1-1-2 y cómo desenvolverse en cuestión de autoprotección para el ámbito escolar, mientras que 
para los adultos se trata de explicaciones sobre los distintos tipos de riesgos alertas y avisos sobre situaciones como preemergencias meteorológicas.

Los formatos también varían. En las secciones de niños abundan en primer lugar los formatos resultantes de la combinación de texto e imagen (póster, folleto, tríptico, cuaderno, cuento), y le siguen los juegos, mientras que para los adultos se trata sobre todo de listados, y, seguido con mucha diferencia, la combinación de texto e imagen. Los vídeos son poco utilizados en ambos tipos de públicos, por lo que se trata de un recurso todavía con mucho potencial por descubrir.

En distintos formatos infantiles analizados, como cuentos, folletos o incluso vídeos se aprecian algunos elementos constantes:

-Colores muy vivos

-Poco texto

-Elementos fantásticos propios de la fábula: animales o seres inanimados que adquieren características humanas

-La figura del perro como representación de la prudencia y protección, convirtiéndose en portavoz de los mensajes preventivos de la institución

Se detecta también formatos que hemos venido en llamar de "interfaz pedagógica", porque al igual que los incendios de interfaz urbano-forestal, contienen elementos de ambos tipos de terrenos, en este caso del infantil y del adulto. Se trata de materiales que aparecen en las secciones de adultos, que carecen de algunas características propias del público infantil (historias fantásticas, humor) pero que en cambio sí incoporan otras (poco texto, colores vivos), por lo que consideramos este tipo de material interesante a la hora de poder llegar a los niños a través de una guía adulta.

\subsection{PROPUESTA DE MODELO}

La presente investigación nos permite condensar las principales líneas que deberían formar parte de un modelo de gestión de la información y comunicación preventivas dedicada a la infancia y adolescencia.

Esta propuesta puede ser adoptada por las instituciones vinculadas a la protección civil que tengan entre sus objetivos la difusión de contenidos relacionados con la prevención de riesgos y emergencias para un público infantil y adolescente, especialmente si esa difusión va a realizarse junto a otros actores, como las instituciones educativas. 
Para el caso de la preparación de simulacros conjuntamente entre las instituciones vinculadas a la protección civil y un centro escolar, se propone un modelo que comprende cinco pasos, tal como queda reflejado en el siguiente esquema. Los detalles de cada una de las fases se exponen a continuación.

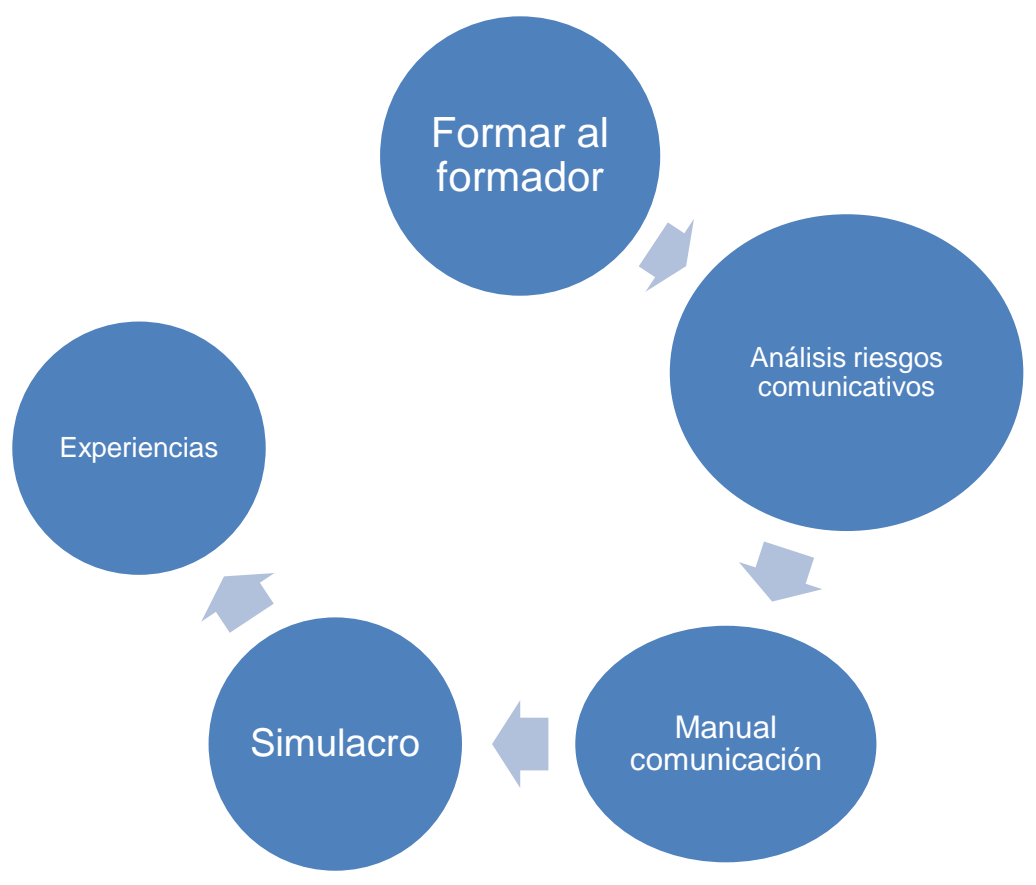

Todos los estudios realizados con motivo de la incorporación de la Reducción de Riesgo de Desastres al currículo escolar han coincidido en destacar la importancia de formar al formador a la hora de que éste pueda trasladar a sus alumnos este tipo de contenidos educativos. Consideramos que también en materia de simulacros puede realizarse esta tarea inicial por parte de las instituciones vinculadas a la protección civil de formar al formador (al personal del centro educativo) con el fin de que adquiera, complemente o perfeccione los conocimientos acerca de la gestión de un simulacro y de la preparación frente a hipotéticas emergencias en un centro escolar.

El segundo paso de este modelo sería el análisis de los "riesgos comunicativos" de ese centro escolar en concreto, un análisis que debería realizarse y supervisarse conjuntamente entre la institución de protección civil y el centro educativo.

De esta forma, a la hora de confeccionar el Plan de Autoprotección del centro escolar, convendría evaluar esos riesgos comunicativos, esto es, factores que por sus 
características podrían entorpercer las labores comunicativas durante una hipotética situación de emergencia. Se trata por ejemplo, de zonas del edificio donde no se escuchen bien las alarmas de incendio o la megafonía. Al igual que otro tipo de riesgos, entendemos que debería quedar claramente remarcado en la documentación del centro para estudiar su siguiente subsanación.

El tercer paso sería, desde una perspectiva global de comunicación, que el centro escolar redactase su propio Manual de Comunicación para situaciones de Emergencia.

En el caso que hemos analizado (CP Grangel Mascarós de l'Alcora), el centro analizado lo ha incluido como un anexo en su documento de Plan de Autoprotección. Incorpora todos los aspectos globales de comunicación a tener en cuenta durante las evacuaciones y además añade aspectos relativos a situaciones extremas como la comunicación de malas noticias a familiares de alumnos.

El cuarto paso es la realización de un simulacro en el que, que como ya habíamos señalado en el capítulo 7, se evalúe su desarrollo comunicativo en base a seis aspectos. Como ya han sido ampliamente abordados en el correspondiente capítulo, no los desarrollaremos de nuevo aquí, sino que nos remitimos a la exposición allí realizada y que se refería a una revisión de los aspectos de: megafonía y acústica, información al 1-1-2, información a ayudas externas, pautas de evacuación, comunicación en el punto de reunión, comunicación para casos específicos. Reproducimos de nuevo aquí el cuadro correspondiente, a modo de recordatorio.

\begin{tabular}{|c|c|}
\hline OBJETIVO DE ANÁLISIS COMUNICATIVO & ELEMENTOS A ANALIZAR \\
\hline MEGAFONIA Y ACÚSTICA & $\begin{array}{l}\text { Inventario de recursos acústicos, funcionamiento, } \\
\text { mensajes grabados }\end{array}$ \\
\hline INFORMACIÓN AL 1-1-2 & $\begin{array}{l}\text { Estructura de la llamada, información importante } \\
\text { facilitada }\end{array}$ \\
\hline INFORMACION A AYUDAS EXTERNAS & $\begin{array}{l}\text { Información facilitada a bomberos, sanitarios etc } \\
\text { que ayude a resolver la emergencia y no la agrave }\end{array}$ \\
\hline PAUTAS DE EVACUACIÓN & Instrucciones para evacuar adecuadamente \\
\hline COMUNICACIÓN EN PUNTO DE REUNIÓN & $\begin{array}{l}\text { Información y actitud para una espera responsable, } \\
\text { paciente e informada }\end{array}$ \\
\hline COMUNICACIÓN PARA CASOS ESPECÍFICOS & $\begin{array}{l}\text { Recomendaciones para llevar a cabo la } \\
\text { evacuación de personas con problemas de } \\
\text { movilidad, así como otras situaciones que doten de } \\
\text { mayor complejidad a su evacuación }\end{array}$ \\
\hline
\end{tabular}


Finalmente, el quinto paso de este modelo es la puesta en marcha, las semanas alrededor del simulacro, de otro tipos de actividades que refuercen los conocimientos y habilidades relacionados con la prevención, y que estén basadas en un aprendizaje de carácter experiencial y práctico.

El simulacro puede ser el punto de partida para organizar toda una serie de actividades centradas en este tipo de aprendizaje. Así, en el colegio analizado durante la fase empírica, por ejemplo, se ha llevado a cabo una obra de teatro, una película en stop motion y un simulacro especial para los alumnos de infantil. La práctica ha confirmado que una visión global de la prevención a lo largo de los disintos cursos y actividades contribuyen a fomentar una cultura preventiva en el centro y a que toda comunidad escolar se sienta más implicada.

Por otra parte, otra de las propuestas que se realizan desde la presente investigación tiene que ver con las webs que pretendan difundir contenidos de prevención entre la infancia y la adolescencia. En este caso, y tras el análisis realizado a las diecisete webs españolas y el caso de Estados Unidos, consideramos que una web, para ser lo más completa posible y adaptada a su público concreto de infancia y adolescencia, debería contener los siguientes elementos:

a) Una sección específicamente dedicada a ese tipo de públicos, detallando expresamente que está dirigida a ellos.

b) Contenidos clasificados por edades. Aunque muchas de las webs no tenían una clasificación definida, entendemos que adaptar los contenidos no sólo a infancia y adolescencia de forma genérica sino clasificarlos según grupos de edad todavía más concretos, ayudará a mejorar todavaía más la adaptación de contenidos y formatos.

c) Incluir en la sección infantil contenidos para padres y formadores, que les ayuden a tratar este tipo de temas en el hogar o en clase. De igual forma, incluir contenidos de interfaz pedagógica, en este caso material formativo para adultos pero que contenga características de diseño y contenido que le permitan al adulto compartirlo con los niños y adolescentes. El objetivo es que la sección infantil sea lugar de destino tanto de niños como de adultos, fomentando el diálogo en el aula o en casa en torno a los contenidos y actividades allí reflejados.

d) Manejar diferentes tipos de recursos, evitando los listados largos de información y optando en su lugar por juegos, actividades, rompecabezas o recortables. 
e) Para la infancia, ha de primar el uso de ilustraciones llamativas con poco contenido textual pero muy claro, así como figuras propias del universo infantil como las mascotas. Para la adolescencia, uno de los recursos más versátiles es el cómic, que permite introducir más información, reflejar los estilos de vida de los adolescentes, incorporar su propio lenguaje y hacer uso de imágenes llamativas y dinámicas.

f) El vídeo es un recurso poco explotado hasta la fecha pero que consideramos muy recomendable también debido a su gran versatilidad y adaptabilidad a diferentes tipos de público.

\subsection{FUTURAS LÍNEAS DE INVESTIGACIÓN}

El proceso investigador ha abierto nuevos interrogantes que merecerán ser analizados a lo largo de futuros estudios.

En primer lugar, una de las futuras líneas de investigación deberá ser la presencia en las redes sociales de información preventiva dirigida a adolescentes, o bien dirigida a adultos pero centrada en cómo proteger y formar a la infancia. Se tratará de ver qué representación se realiza en las redes de estos grupos específicos de edad, y qué tipo de recursos y contenidos se están manejando.

Recuérdese que no buscaremos contenido específicamente dedicado a menores de 14 años porque, en principio, este tipo de públicos no está autorizado para los destinatarios de la mayoría de redes sociales.

Por otra parte, otro reto investigador es el análisis de si los recursos ofrecidos en las webs para niños y adolescentes pueden tener una vertiente todavía más participativa, en la que se fomente un aprendizaje activo y no pasivo, ya que este último factor era uno de los riesgos detectados respecto al uso de las nuevas tecnologías. Estas son una herramienta extraordinaria e ineludible hoy en día en la formación de los más jóvenes, así que se habrá de analizar como puede fomentarse a través de ellas un carácter todavía más experiencial en la formación sobre prevención de riesgos y emergencias.

Otra de las líneas de investigación que resultan vitales es el análisis de cómo las instituciones de la protección civil interactúan con otros públicos especiales, concretamente los mayores y los colectivos de personas discapacitadas, y cómo adaptan en estos casos los contenidos y formatos de contenidos preventivos. 
Ya hemos visto que cada vez más las instituciones de protección civil ajustan sus mensajes a las características sociodemográficas y culturales de sus destinatarios, así que se tratará de analizar cómo están realizando ese proceso de ajuste respecto a esos dos grupos que consideramos prioritarios junto a la infancia y adolescencia.

Finalmente, será también importante realizar estudios de caso sobre los contenidos de prevención difundidos en los medios de comunicación, tanto para un público infantil y adolescente como adulto. Resultará especialmente interesante analizar aquellos casos en los que una institución y un medio de comunicación hayan trabajado conjuntamente, e incluso en colaboración con otros actores, para el diseño de contenidos y formatos sobre temas divulgativos de prevención de riesgos y emergencias. Ya hemos señalado en capítulos anteriores la insuficiente presencia de este tipo de temas en la agenda mediática, pero dado el importante papel que pueden jugar los medios de comunicación en el proceso de concienciación sobre riesgos, emergencias y desastres, detectar casos de buenas prácticas en este sentido puede resultar útil a la hora de obtener conclusiones sobre como posibilitar una mayor presencia mediática.

\subsection{TENDENCIAS DE FUTURO}

Las tendencias de futuro en cuanto al discurso y prácticas comunicativas adaptadas a la infancia por parte de las instituciones vinculadas a la protección civil, consideramos que estarán relacionadas con cuatro áreas.

En primer lugar, respecto a los contenidos web, puede producirse un incremento todavía mayor de la presencia de contenidos relacionados con la prevención. Teniendo en cuenta que el discurso internacional sobre la importancia de la difusión de estos contenidos para la infancia tiene su principal arranque en torno al año 2000, y que en 2015 la mayoría de webs españolas ya tienen contenidos adaptados, consideramos que la progresión puede ser relativamente rápida y seguir extendiéndose en pocos años al conjunto de todas las webs.

En segundo lugar, podría producirse una mayor inclusión de los contenidos sobre prevención en el currículo escolar y una mayor concienciación en los centros escolares acerca de la realización de los simulacros. Ese fenómeno estará vinculado a procesos de diálogo entre instancias educativas, protección civil, fundaciones y expertos. 
La mayor o menor capacidad de diálogo repercutirá en que la cultura preventiva de los centros escolares se intensifique o no.

Por otra parte, como se ha comentado con anterioridad, el papel de los medios de comunicación en todo este proceso está todavía por ampliar y potenciar. Puede ser un recurso muy importante, que hoy en día está siendo reivindicado desde el marco legislativo y desde las sucesivas cumbres mundiales de la prevención, pero que hoy en día todavía no parece haberse materializado en líneas claras. En este sentido, el diálogo y los esfuerzos del sector de la protección civil por adaptar sus contenidos a las necesidades de la lógica mediática pueden ser fundamentales.

Las nuevas tecnologías jugarán cada vez un papel más importante, convirtiéndose en herramientas muy útiles para los niños y adolescentes y de forma muy especial para distintos colectivos (por ejemplo personas discapacitadas). La gran baza de las tecnologías será su capacidad de mostrar formatos atractivos para los más jóvenes, mientras que el reto a evitar será que se convierta en un recurso de aprendizaje demasiado pasivo, en comparación con otras herramientas más prácticas y experienciales.

En cualquiera de estos foros y canales de difusión de contenidos preventivos, la adaptación a las características de los distintos actores, en este caso la infancia y la adolescencia, resultará fundamental. Una adaptación que tenga en cuenta sus peculiaridades y las peculiaridades locales de su entorno, y que le ayude tanto a formarse a él como a ser agente de cambio para la sociedad en la que vive.

Va a ser necesario. Considerar que los riesgos, las emergencias o los desastres es algo que les pasa a otros, o que los servicios de emergencia expertos son los únicos que se encargarán de la situación si algo sucede, no nos ayudará. Contribuir a que el conjunto de la sociedad, incluídos los niños, adquieran conocimientos y adopten pautas de actuación acordes a una cultura preventiva, sí puede cambiar las cosas. Para lograrlo habrá que estar dispuestos a ver cosas invisibles: el éxito de esta cultura preventiva, parafraseando a Kofi Annan, serán los desastres que no ocurrirán. 


\section{BIBLIOGRAFÍA}

ACINAS, Maㅡ Patricia (2004). Habilidades de comunicación y estrategias asistenciales en el ámbito sanitario (I). Alcalà la Real: Formación Alcalà

ACINAS, Ma Patricia (2004). Habilidades de comunicación y estrategias asistenciales en el ámbito sanitario (II).

AGUILÓ, Vicente, BENITO, Marina, CREMADES, Tomás, MARTíNEZ, Gerardo, MOLLÀ, Miguel y YAGÜE, Marcelino (2005). La gestión de las emergencias. Valencia: Alfa Delta Digital.

ÁLVAREZ-GAYOU, Juan Luis (2003). Cómo hacer investigación-cualitativa. Fundamentos y metodología. México, D.F., etc: Paidós.

ANTÓN, Franciso, DUTOR, Natalia, ORENGO, Carmen y SOLER Juan Ignacio (2005). Riesgos antrópicos. Valencia: Alfa Delta Digital

ARMENGOT, Rafael, GINER, José Juan, LA ROCA, Neus y SEGURA Francesca (2005). Riesgos naturales. Valencia: Alfa Delta Digital.

AUF DER HEIDE, Erik.(1989). Disaster response: Principles of Preparation and coordination. Mosby

BAKER, E.J (1979). Predicting response to hurricane warnings: A reanalysis of data from four studies. Mass emergencies, 4,9-24

CAPRIOTTI, Paul

*(1999). Planificación estratégica de la imagen corporativa. Editorial Ariel Comunicación

*(2009). Branding corporativo. Fundamentos para la gestión estratégica de la identidad corporativa. Santiago, Chile: Colección de libros de la empresa

CASTERFORS, K., SVEDIN, L. (2001). Crisis communication:Learning from the 1998 LPG near miss in Stockholm. Journal of hazardous materials, 88, 235-254

CATALÁ, Alexandre y SOLER, Margarita (2005). Marco legal de la protección civil en España. Valencia: Alfa Delta Digital.

COHEN R.E., AHEARN F.L.(1980). Handbook for menthal health care of disasters victims. Baltimore, MD. John Hopkins University Press.

COSTA, Joan (1977). La imagen de empresa. Métodos de comunicación integral. Madrid: Ibérico-Europea de Ediciones 
CUESTA, Ubaldo, UGARTE, Aitor y MENÉNDEZ, Tania, coord. (2008). Comunicación y salud. Avances y modelos en estrategias de intervención. Madrid: Editorial Complutense.

DEL RÍO, Olga (2011). El proceso de investigación: etapas y planificación de la investigación. En L.Vilches ( coord) La investigación en comunicación. Métodos y técnicas en la era digital. Barcelona: editorial Gedisa.

\section{DIRECCIÓN GENERAL DE PROTECCIÓN CIVIL Y EMERGENCIAS}

-(1992). Análisis de la demanda de información y elaboración de un modelo de respuesta.

-(2006). Autoprotección en centros escolares. En: Programa para centros escolares. Guía didáctica para profesores. [s.I.] Ministerio del Interior, Secretaría General Técnica.

- (2006). Riesgo incendios forestales. En: Programa para centros escolares. Guía didáctica para profesores. [s.I.] Ministerio del Interior, Secretaría General Técnica.

DRABEK, T.E., STEPHENSON, J.S.(1971). When disaster strikes. Journal of applied social psychology, 1, pp.187-203

DRABEK, T.E., McENTIRE, D.A.(2002). Emergent phenomena and multiorganizational coordination in disasters: Lessons from research literature. International Journal of Mass Emergencies and Disasters, 20, 197-224

DYNES, Russell, QUARANTELLI, Enrico, RODRÍGUEZ, Havidán (2006). Handbook of disaster research. Springer

ESPLUGA, Josep (2004). "Conflictes socioambientals i estudi de la percepció social del risc“En: Papers, Revista de Sociologia. №72 (pp.145-162)

FARRÉ, Jordi y FERNÁNDEZ, Josep (eds.) (2007). Comunicació i risc petroquímic a Tarragona. De les definicions a les pràctiques institucionals. Tarragona: Publicacions de la Universitat Rovira i Virgili.

FARRÉ, Jordi y GONZALO, Juan Luis (2011). Teoría de la comunicación de riesgo. Barcelona: Editorial UOC.

FITZPATRICK, C.M, MILETI, D.S.(1994). Public risk communication. En: Dynes, R.P, Tierney, K.J.( eds) Disasters, collective behavior, and social organization. Newark, N.J: University of Delaware Press: $71-84$

FRITZ, C.E. (1961) "Disasters", en MERTON, R.K. y R. A. NISBET (eds) (1961). Contemporary Social Problems. New York: Hacourt 
FOUCE, J.G, C.HERNÁNDEZ-CORONADO, M.NEVADO, R.M.MARTÍNEZ, D. LOSADA y A.LILLO (1998). "Intervención psicológica en situaciones de emergencia", ponencia presentada en el II Congreso Iberoamericano de Psicología, Madrid 13-17 julio.

GAITÁN, Juan A., y PIÑUEL, Jose L. (1998). Técnicas de investigación en comunicación social. Elaboración y registro de datos. Madrid: Editorial Síntesis

GIDDENS, Anthony (1993). Consecuencias de la modernidad. Madrid:Alianza

GIL, Enrique (2003). El miedo es el mensaje: riesgo, incertidumbre y medios de comunicación. Madrid: Alianza

HUMANES, Maria Luisa e IGARTUA, Juan José (2004). Teoría e investigación en comunicación social. Madrid: Editorial Síntesis.

LINDELL, M.K., PERRY, R.W.(1992). Behavioral foundations of community emergency planning. Washington DC: Hemisphere

LINDELL, M.K., PERRY, R.W.(2004). Communicating environmental risk in multiethnic communities. Thousand Oaks, CA: SAGE

LÓPEZ, Alfonso, PILES, Inmaculada, SOLER, Juan Ignacio y VILLANUEVA, Jaime (2005). Fases de la emergencia. Valencia: Alfa Delta Digital.

LÓPEZ, Ángel (1996). Escritura e información. La estructura del lenguaje periodístico.Madrid: Cátedra.

LOSADA, José Carlos (2010). Comunicación en la gestión de la crisis. Barcelona: Editorial UOC.

McENTIRE, David (2006) Local Emergency managament organizations. En: En Dynes, R, Quarantelli, H., Rodriguez, H ( eds). Handbook of Disaster Research Springer.

MILETI, D., SORENSEN, J.(1988). Planning and implementing warning systems. En: M.Lystad(ed), Mental health and care in mass emergencies: Theory and practice (pp.321-345). New York: Brunner/Mazel.

MILETI, D., SORENSEN, J.(1990). Communication of emergency public warnings: a social science perspective and the state-of-the-art-assessment, ORNL-6609. Oak Ridge, TN: Oak Ridge National Laboratory, Department of Energy

MINISTERIO DEL INTERIOR (2008). Percepción social del riesgo en España.

NIGG, J.M.(1995). Risk communication and warning systems, En: Horlick-Jones, T., Amendola A., Casale R. (Eds.) Natural risk and civil protection (pp.369-382) London:E \&FN Spon 
ORENGO, Ma del Carmen, PILES, Inmaculada y VILLANUEVA, Jaime (2005). Riesgos tecnológicos. Valencia: Alfa Delta Digital.

ORTí, Alfons (2000). El centre d'emergències 1-1-2. En: REQUENA, Jesús y CAMPINS, Mar, (coords). De las catástrofes ambientales a la cotidianidad urbana. Barcelona: Publicacions de la Universitat de Barcelona.

PERRY, R., LINDELL, M., GREENE M.(1981).Evacuation planning in emergency management. Lexington, MA: Lexington Books.

PONT, Carles (2009):Comunicació i crisi. La gestió de la comunicació pública en episodis d'emergència. Barcelona: Editorial UOC.

QUARANTELLI, Enrico ( 2005). A social science research agenda for the disasters of the 21st century. En Perry R.W, Quarantelli, E.L ( eds) What is a disaster? New answers to old questions (pp.325-396).Philadelphia:Xlibris

QUARANTELLI, E.L, LAGADEC, P., BOIN, A (2006). "A Heuristic Approach to Future Disasters and Crises: New, Old and In-Between Types". En Dynes, R, Quarantelli, H., Rodriguez, H ( eds). Handbook of Disaster Research (pp.16-41), Springer.

RENEDO, M., GIL J.M., VALERO, M . (2007). Psicología y desastres: aspectos psicosociales. Castellón: Publicacions de la Universitat Jaume I.

RODRÍGUEZ, H., DÍAZ, W., SANTOS, J., AGUIRRE, B.(2006) Communication risk and uncertainty: science, technology, and disasters at the crossroads. En En Dynes, R, Quarantelli, H., Rodriguez, H ( eds). Handbook of Disaster Research (pp.476-488), Springer.

SORENSEN, John H., VOGT, Barbara (2006). Community processes: warning and evacuation. En Dynes, R, Quarantelli, H., Rodriguez, H ( eds). Handbook of Disaster Research (pp.185-199), Springer.

TIERNEY, Kathleen (2006). Recent developments in U.S. Homeland Security Policies and their implications for the management of extreme events. En En Dynes, R, Quarantelli, H., Rodriguez, H ( eds). Handbook of Disaster Research (pp.405-412), Springer

TURNER, Ralph H.(1983). "Waiting for disasters:changing reactions to earthquake forecasts in souther California". International Journal of Mass Emergencies and disasters, 1(august):307:334

UNISDR (2009). Terminología sobre reducción del riesgo de desastres. Ginebra: Estrategia Internacional para la Reducción de Desastres de las Naciones Unidas.

VILCHES, Lorenzo (coord.) (2011). La investigación en comunicación. Métodos y técnicas en la era digital. Barcelona: Editorial Gedisa. 
VILLANUEVA, Tomás (2005). La planificación de la protección civil. Valencia: Alfa Delta Digital.

WAHLBERG, Anders y SJÖBERG, Lennart (2000). Risk perception and the media. Journal of Risk Research, volume 3 (number 1), pp.31-50

\section{ESTUDIOS}

EUROPEAN AGENCY FOR SAFETY AND HEALTH AT WORK (2009). OSH in the school curriculum: requirements and activities in the EU Member States. Luxembourg: Office for Official Publications of the European Communities

ISDR (2006). Let our children teach us. A review of the role of the education and knowledge in disaster risk reduction. Bangalore, India: Books for change

ISDR (2007). Towards a culture of prevention. Disaster risk reduction begins at school. Geneve:UN/ISDR

Regional Consultative Committe on Disaster Management, RCC (2007). Integrating Disaster Risk Reduction into School Curriculum

UNESCO (2007). Natural Disaster Preparedness and Education for Sustainable Development. Bangkok

UNESCO Word Conference on Education for Sustainable Development (2009) Workshop 4. EDS and disaster risk reduction: building disaster-resilient societies. Bonn.

UNICEF-UNISDR (2011). "Children and disasters: building resiliencie through education"

Unicef (2012). Disaster Risk Reduction in the School Curricula: Case Studies from Thirty Countries. Paris.

\section{DECLARACIONES E INFORMES DE LA ONU}

Declaración de la Conferencia de las Naciones Unidas sobre el Medio Humano. Estocolmo. Junio 1972

Informe de la Conferencia de las Naciones Unidas sobre el Medio Ambiente y el Desarrollo. Junio 1992. A/CONF.151/26 (Vol. I)

Informe de la Conferencia Mundial sobre la Reducción de Desastres. Kobe, Hyogo, enero 2005. A/CONF.206/6 
Informe de la Conferencia Mundial sobre la Reducción de los Desastres Naturales, Yokohama mayo 1994. A/CONF.172/9

Informe de la Tercera Conferencia Mundial sobre la Reducción del Riesgo de Desastres. Sendai, Marzo, 2015

\section{ARTÍCULOS DE REVISTAS}

ESPLUGA, Josep (2004). Conflictes sociambientals i estudi de la percepció social del risc. En: Papers, Revista de Sociología, núm. 72. Barcelona: Universitat Autònoma de Barcelona. Servei de Publicacions. pgs. 145-162

GALIANA, Luis (2012). Las interfaces urbano-forestales. Un nuevo territorio de riesgo en España. En: Boletín de la Asociación de geógrafos españoles. №58. Madrid: Asociación de Geógrafos Españoles. pgs. 205-226

GREENWOOD, Davyd (2000). De la observación a la investigación-acción participativa: una visión crítica de las prácticas antropológicas. En Revista de Antropología Social, no 9:27-49

MAPFRE Seguridad (2005). Iniciativas para educar en colegios sobre seguridad y prevención. MAPFRE Seguridad, nํ100, 4ํㅡㄴ trimestre 2005, pp. 49-51

SACO CID, Antonio (1983). Una solución educativa ante el incendio en la escuela. Salud y trabajo. Madrid, no 38, julio-agosto 1983. pp.45- 52

TALAYERO, F. y ARAGONÉS, J.I. (1997). La conducta humana en los incendios. En: Papeles del psicólogo. № 68.

\section{RECURSOS ELECTRÓNICOS}

Dirección General de Protección Civil y Emergencias (año desconocido): Programa para centros escolares. Guía didáctica para profesores. Recuperado el 17/04/ 12 de: http://www.proteccioncivil.org/publicaciones-catalogo

Dirección General de Protección Civil. Definición de riesgo http://www.proteccioncivil.es/web/dgpcye/riesgos

Fidalgo Vega, Manuel (año desconocido): La conducta humana ante situaciones de emergencia: la conducta colectiva. Documentación NTP 395, recuperado el 14/04/12 de:

http://www.insht.es/InshtWeb/Contenidos/Documentacion/FichasTecnicas/NTP/Fichero s/301a400/ntp_395.pdf 
FOG, Agner.(2002)“Mass media and democracy crisis. The suposed and the real role of mass media in modern democracy“

Disponible (agosto 2015) en: http://www.agner.org/cultsel/mediacrisis.pdf

GENERALITAT VALENCIA. CONSELLERIA DE JUSTÍCIA I ADMINISTRACIONS PÚBLIQUES. Guía para la redacción de un plan de autoprotección. En: Planes de autoprotección de edificios. Recuperado de: www.juntadeandalucia.es/.../GuiaAutoproteccionValencia/11400920

GENERALITAT VALENCIANA. CONSELLERIA D'EDUCACIÓ. Formación en Medidas de Emergencia de Centros docentes 2010-2011. [s.I.] Recuperado de: www.cefe.gva.es/per/.../Medidas_Emergencias/Formacio2009_es.pdf

VALERO VALERO, M: Comportamiento y reacciones de la población en desastres. Recuperado el 17/04/12 de: https://aulavirtual.uji.es/mod/resource/view.php?id=1086075

Vañó Mayor, A.M. (2007) Elementos básicos para la elaboración de una herramienta pedagógica para niños y adolescentes. Recuperado el 14/04/12 de : http://www.mapfre.com/documentacion/publico/i18n/consulta/resultados ocr.cmd

\section{LEGISLACIÓN CONSULTADA}

-Ley 2/1985, de 21 de enero, sobre protección civil (BOE núm.22, de 25 de enero de 1985)

-Ley 17/2015, de 9 de julio, del Sistema Nacional de Protección Civil (BOE núm.164, de 10 de julio de 2015)

-Real Decreto 407/1992, de 24 de abril, por el que se aprueba la Norma Básica de Protección Civil (BOE núm.105, de 1 de mayo de 1992).

-Real Decreto 393/2007, de 23 de marzo, por el que se aprueba la Norma Básica de Autoprotección de los centros, establecimientos y dependencias dedicados a actividades que puedan dar origen a situaciones de emergencia.

-Decreto 83/2008 del Consell, de 6 de junio, por el que se crea el Registro Autonómico de planes de Autoprotección

-Acuerdo de Consejo de Ministros de 31 de marzo de 1995, que aprueba el Plan Estatal de Protección Civil para emergencias por incendios forestales

-Orden de 2 de abril de 1993, por la que se publica el Acuerdo del Consejo de Ministros que aprueba la Directriz Básica de Planificación de Protección Civil de Emergencia por Incendios Forestales (BOE núm.90, de 15 de abril de 1993). 
- Ley 9/2002, de 12 de diciembre, de Protección Civil y Gestión de Emergencias de la Generalitat Valenciana.

-Ley 13/2010, de 23 de noviembre, de Protección Civil y Gestión de Emergencias de la Generalitat.

-Decreto 163/1998, de 6 de octubre, del Gobierno Valenciano, por el que se aprueba el Plan Especial frente al Riesgo de Incendios Forestales de la Comunidad Valenciana.

-Orden de 31 de enero de 1995, de la Conselleria de Educación y Ciencia, sobre Autoprotección de centros de Educación Infantil, Primaria, secundaria, y Enseñanzas de Régimen Especial, dependientes de la Generalitat Valenciana (DOGV 04-05-95, pgs: 6130-6132)

-Orden 27/2012, de 18 de junio, de la Conselleria de Educación, Formación y Empleo, sobre planes de autoprotección o medidas de emergencia de los centros educativos no universitarios de la Comunidad Valenciana [2012/6296]. 


\section{ANEXO. ENTREVISTAS EN PROFUNDIDAD}

\section{ENTREVISTA A Da ESTHER GORJÓN}

Enfermera de emergencias y portavoz del proyecto "Educación Civil en Emergencias" EdCivEmerg

\section{BLOQUE 1. EXPERIENCIA DE LA INSTITUCIÓN/ COMPAÑÍA/ PROYECTO AL QUE REPRESENTA EL ENTREVISTADO}

\section{1. ¿En qué consiste la actividad que llevan ustedes a cabo para el público infantil?}

Nuestro objetivo principal es conseguir que la formación en primeros auxilios, emergencias, protección civil y educación vial formen parte del currículo escolar de manera obligatoria. Nuestra actividad ha ido más encaminada a conseguir este objetivo mediante la difusión de la iniciativa, conseguir apoyos políticos y entrevistarnos con el Ministerio que de cara al público infantil. No obstante, hemos aprovechado la iniciativa para difundir también primeros auxilios, actuación ante incendios y seguridad vial en redes sociales y de forma presencial, con actividades extraescolares y la formación de 1800 niños de 6ํㅜ de Educación Primaria en Alcorcón, como parte previa a una Jornada divulgativa que organizamos en aquel municipio.

\section{2. ¿Por qué han elegido esta modalidad pedagógica y no otra?}

Al tratarse de un proyecto piloto, se optó por unas sesiones cortas de cada uno de los bloques, lo más prácticas posibles. Se hizo así teniendo en cuenta que la práctica creemos que ayuda a fijar mejor los conocimientos que sólo la teoría y que además a los niños es necesario estimularles para que presten atención. EL hecho de que las clases fueran cortas también se debe a esa misma necesidad de mantener la atención de los alumnos.

3. ¿Hay diálogo y feedback con el público infantil o es una comunicación más unidireccional?

Yo creo que eso depende mucho de varios aspectos. De lo atractivo que lo presente el profesor/instructor y de la edad de los niños. Intentar recibir un feedback de niños muy 
pequeños es sumamente complicado, ya que si les das opción a hablar, les preguntas para que levanten la mano y contesten corres el riesgo de que se te vayan por las ramas y luego es complicado reconducir la situación.

4. ¿Ha participado algún otro actor social en el desarrollo o puesta en marcha de su actividad? (organismos públicos, comunidad educativa, fundaciones, etc.). ¿Cuál?

Se han implicado sociedades científicas, ONG, cuerpos de Bomberos y Policía Local, profesionales sanitarios. Los profesores y directores también quisieron recibir la formación y mostraron su apoyo a la iniciativa.

5. ¿Se han medido alguna vez los resultados de su actividad? ¿De qué manera y con qué resultados?

No se llegaron a medir. Cuando quisimos recoger datos ya era demasiado tarde y apenas teníamos tiempo para hacerlo.

BLOQUE 2. CÓMO COMUNICAR PREVENCIÓN DE EMERGENCIAS EN LA INFANCIA

1. ¿Cuáles piensa que deberían ser los contenidos básicos que se habrían de trasladar a los niños en materia de prevención de emergencias? ¿Hay algún tipo de contenido a evitar? ¿Por qué?

Creo que deberían ir introduciéndose los conceptos y habilidades de forma gradual, a lo largo de todo el ciclo educativo. Todo lo referente a Primeros Auxilios, actuación ante emergencias (tecnológicas, naturales, accidentes de tráfico, incendios...), conocimientos generales de protección civil, prevención de accidentes, prevención de enfermedades cardiovasculares, prevención de incendios y educación vial.

2. Por favor indique si está más de acuerdo con a) o con b), y por qué motivo.

La educación sobre los riesgos y cómo evitarlos (por ejemplo: incendios de vivienda):

a ) Debe adaptarse a las características locales del entorno conocido por el niño, como las condiciones geográficas, culturales, etc. 
b) No debe tener en cuenta las características locales, sino ser una explicación universal susceptible de ser comprensible en cualquier lugar de un país o del mundo.

Creo que más bien la b. La situación actual parece indicar que existe una gran movilidad geográfica. Si queremos que esos niños sean ciudadanos responsables, sea donde sea que se encuentren, deberían estar formados de manera que puedan actuar correctamente sea donde sea que se encuentren, aunque quizá habría que hacer hincapié en los riesgos más frecuentes de su entorno.

\section{3. ¿Qué fórmulas considera más idóneas para acercar el mundo de la prevención} de emergencias a los niños?

Como ya he dicho antes, empezar desde muy pequeños, con cuestiones básicas, y aprovechar cada año para reforzar lo aprendido y ampliar los conocimientos y habilidades, de acuerdo a su edad. Todo de manera práctica y, cuanto más pequeños los niños, de manera asociada al juego.

4. ¿Dónde piensa que se han de abordar estos temas?: ¿casa, colegio, televisión, la red, instalaciones y dependencias de servicios de emergencias, fundaciones, empresa privada?, etc. ¿Por qué?

Creo que debe ser una estrategia global. La administración pública puede hacer mucho más de lo que hace. Los padres deberían preocuparse de que sus hijos aprendan. En la escuela debería ser obligatorio, y los servicios de emergencias, TV etc pueden ayudar a potenciar su difusión. Las acciones puntuales llegan a poca gente y, si no se repiten o se recuerdan, se olvidan. Debe ser un aprendizaje presente a lo largo de toda la vida.

5. ¿Cuál ha de ser el rol del niño en este proceso? ¿De qué forma puede incrementarse su participación?

Debe enseñársele la gran responsabilidad que tiene como ciudadano de actuar correctamente en caso de emergencia. Debe ser un rol activo y participativo. Se le puede animar a que él mismo enseñe a otros niños más pequeños para que se sienta más responsable y que vea lo importante que es. 
6. ¿Piensa que las nuevas tecnologías abren nuevas formas de comunicarse con la infancia en estos temas? ¿Por qué?

Sin ninguna duda. Internet está presente en sus vidas desde su nacimiento. Son nativos digitales y como tal hay que usar las herramientas que ellos usan y manejan con tanta destreza para fomentar su interés y participación en el tema.

\section{BLOQUE 3. ACTORES SOCIALES EN LA COMUNICACIÓN DE PREVENCIÓN DE EMERGENCIAS}

1. ¿Qué tipo de instituciones piensa que están más implicadas en la difusión de temas de prevención de emergencias entre los niños? (organismos de emergencias, instituciones educativas, compañías, etc.) ¿Por qué sucede así?

Sin ninguna duda los propios organismos de emergencias, que son al fin y al cabo los que han detectado y ven las consecuencias que produce la falta de conocimientos en estos temas. Las instituciones educativas creo que lo ven necesario, pero creen que no son capaces de dar ese tipo de formación, por lo que están a expensas de la disponibilidad de los bomberos, emergencistas, voluntarios, etc.

2. ¿Cree que hay diálogo entre los diferentes actores sociales o cada uno funciona de forma independiente a los demás?

Creo que gracias a nuestra iniciativa ha empezado a haber un consenso entre muchos (no todos) de los actores implicados. Aun así, falta mucho camino por recorrer.

3.¿Piensa que se implican más las instituciones de carácter local, autonómico, nacional o internacional? ¿Por qué?

Las de carácter local y autonómico. Supongo que a nivel nacional no es tema que preocupe especialmente ya que lo desconocen, y es necesario que desde las administraciones locales y regionales se les inste a que conozcan el tema y se preocupen por él.

\section{BLOQUE 4. EL NIÑO EN LA SOCIEDAD}

1. Diga si está de acuerdo o no con estas afirmaciones y por qué: 
- El niño formado en prevención de emergencias es capaz de trasladar esa información a los adultos

- Un niño formado en prevención de emergencias será en el futuro un trabajador más seguro

Totalmente de acuerdo.

Los niños son unos vectores de difusión de conocimientos excepcionales y pueden enseñar a un adulto todos estos conocimientos, 0 , al menos, hacer que el adulto tome conciencia de su propio desconocimiento y que se preocupe por aprender.

Un niño formado en prevención de emergencias será un adulto más seguro, en general, y eso se aplica tanto al ámbito personal como al profesional.

2. ¿Considera que en nuestra sociedad estamos preocupados ante riesgos crónicos como aquellos relacionados con la alimentación o la contaminación? ¿Considera que en nuestra sociedad estamos preocupados ante riesgos agudos como una inundación en nuestro municipio o un incendio en un colegio? ¿ Por qué?

En nuestra sociedad nos preocupamos cuando vemos las orejas al lobo, como suele decirse. Nos bombardean con el tema de alimentación desde muchos ámbitos y aun así seguimos sin llevar una alimentación adecuada, y eso se lo trasladamos a nuestros hijos. Mucho menos sensibilizados estamos con los riesgos agudos. Pensamos que eso no nos va a pasar o que para eso ya están los servicios de emergencias, cuando realmente la vida de un apersona puede depender de cómo actúe en esos primeros minutos, cuando aún los servicios de emergencia no han llegado al lugar del suceso.

\section{BLOQUE 5. TENDENCIAS}

1. ¿Qué tendencia piensa que seguirá la comunicación en prevención de emergencias e infancia en los próximos diez años? ¿ Por qué?

Espero que gracias a nuestra iniciativa consigamos que los niños se formen en el colegio de manera obligatoria y eso haga que los adultos que ya no tienen acceso a esos conocimientos se preocupen por formarse o soliciten en su empresa, gimnasio, club o comunidad de vecinos que se les forme en esos aspectos. Las redes sociales ayudarán a que la gente se forme (aunque sea de manera básica) en estos temas. 
2. Puede añadir aquí las consideraciones adicionales que desee, si algún tema de interés para usted no se ha abordado en las preguntas anteriores. Ninguna. Me parece una entrevista muy completa. 


\section{ENTREVISTA A Da MONTSERRAT RODRÍGUEZ.}

Técnico de Protección Civil de la Generalitat Valenciana. Dirección General de prevención, Extinción de Incendios y Emergencias.

\section{BLOQUE 1. EXPERIENCIA DE LA INSTITUCIÓN/COMPAÑIIA/PROYECTO AL QUE REPRESENTA EL ENTREVISTADO}

1. ¿En qué consiste la actividad que llevan ustedes a cabo para el público infantil?

La implantación de los Planes de Autoprotección; por supuesto, haciendo partícipes a los ocupantes de los centros, entre los que se encuentra el público infantil.

2. ¿Por qué han elegido esta modalidad pedagógica y no otra?

Los códigos de buenas prácticas, se interiorizan practicando - Es el mejor método de concienciación.

3. ¿Hay diálogo y feedback con el público infantil o es una comunicación más unidireccional?

Sí hay diálogo; y además, este diálogo se lo llevan a su vida fuera del centro

4. ¿Ha participado algún otro actor social en el desarrollo o puesta en marcha de su actividad? (organismos públicos, comunidad educativa, fundaciones, etc.). ¿Cuál?

Todos los relacionados con el tipo de centro donde se esté implantando el Plan.

5. ¿Se han medido alguna vez los resultados de su actividad? ¿De qué manera y con qué resultados?

Sí. Resultados estadísticos y encuestas poblacionales. Los resultados han sido satisfactorios respecto del conocimiento de lo aprendido por parte del alumnado; y no 
tan satisfactorio por parte de los organismos públicos, al tener que subsanar deficiencias - Esto está en función del nivel de concienciación de los directores de los centros.

\section{BLOQUE 2. CÓMO COMUNICAR PREVENCIÓN DE EMERGENCIAS EN LA INFANCIA}

1. ¿Cuáles piensa que deberían ser los contenidos básicos que se habrían de trasladar a los niños en materia de prevención de emergencias? ¿Hay algún tipo de contenido a evitar? ¿Por qué?

Todos aquellos contenidos que hagan de la prevención su forma de vida - ejem: riesgo de incendio, riesgos sanitarios, seguridad en las instalaciones...

En general, para niños, todo tipo de información cargada de negativismo. $Y$ en general, sabiendo al público al que se dirige la información, ésta no ha de ser traumática. Ejem: para niños con discapacidad física motora, se evitaría cualquier información que les hiciera sentir culpables de su deficiencia.

2. Por favor indique si está más de acuerdo con a) o con b), y por qué motivo.

La educación sobre los riesgos y cómo evitarlos (por ejemplo: incendios de vivienda):

a ) Debe adaptarse a las características locales del entorno conocido por el niño, como las condiciones geográficas, culturales, etc.

b) No debe tener en cuenta las características locales, sino ser una explicación universal susceptible de ser comprensible en cualquier lugar de un país o del mundo.

De acuerdo con la a); puesto que los riesgos son diferentes para cada entorno; luego hay que adaptarse a la realidad del entorno en el que se desarrollen.

3. ¿Qué fórmulas considera más idóneas para acercar el mundo de la prevención de emergencias a los niños?

Actividades formativas en los centros escolares, comenzando desde el momento de su escolarización. 
4. ¿Dónde piensa que se han de abordar estos temas?: ¿casa, colegio, televisión, la red, instalaciones y dependencias de servicios de emergencias, fundaciones, empresa privada?, etc. ¿Por qué?

La prevención es tarea de todos, a aplicar en todos los ámbitos de la sociedad; por tanto, se ha de abordar en todo tipo de actividad dentro y fuera de casa.

5. ¿Cuál ha de ser el rol del niño en este proceso? ¿De qué forma puede incrementarse su participación?

El niño, tendrá el mismo rol que tenga en su vida cotidiana; y sobre todo participativo.

Su participación se incrementaría haciéndole sentirse protagonista.

6. ¿Piensa que las nuevas tecnologías abren nuevas formas de comunicarse con la infancia en estos temas? ¿Por qué?

Sí. A través del desarrollo de vídeojuegos, se les puede transmitir información de forma rápida, asequible y divertida; y sobre todo adaptada a su demanda.

BLOQUE 3. ACTORES SOCIALES EN LA COMUNICACIÓN DE PREVENCIÓN DE EMERGENCIAS

1. ¿Qué tipo de instituciones piensa que están más implicadas en la difusión de temas de prevención de emergencias entre los niños? (organismos de emergencias, instituciones educativas, compañías, etc.) ¿Por qué sucede así?

Organismos de emergencias. Están más implicados en la difusión de temas de prevención; porque están más concienciados. Ven probadamente que una mayor prevención conlleva a disminuir el número de emergencias y en su caso a aminorar sus consecuencias.

2. ¿Cree que hay diálogo entre los diferentes actores sociales o cada uno funciona de forma independiente a los demás? 
No todos funcionan totalmente independientes; ahora bien, se requeriría de una mayor coordinación para rentabilizar el trabajo de todos.

3.¿Piensa que se implican más las instituciones de carácter local, autonómico, nacional o internacional? ¿Por qué?

No podría decir qué institución se implica más. En más de 20 años de experiencia, he llegado a la conclusión que el nivel de implicación está en función del responsable a cargo de la institución.

\section{BLOQUE 4. EL NIÑO EN LA SOCIEDAD}

1. Diga si está de acuerdo o no con estas afirmaciones y por qué:

- El niño formado en prevención de emergencias es capaz de trasladar esa información a los adultos

Totalmente de acuerdo en la actualidad; ya que hasta hace no mucho, esta materia sólo se trataba en foros profesionales y no en todos los ámbitos de la vida; luego el nivel de concienciación entre nuestros adultos es bajo.

- Un niño formado en prevención de emergencias será en el futuro un trabajador más seguro

Sí. Tendrá interiorizado hábitos de conducta preventiva.

2. ¿Considera que en nuestra sociedad estamos preocupados ante riesgos crónicos como aquellos relacionados con la alimentación o la contaminación? ¿Considera que en nuestra sociedad estamos preocupados ante riesgos agudos como una inundación en nuestro municipio o un incendio en un colegio? ¿Por qué?

Quizá estemos más preparados por los riesgos de contaminación, porque la sociedad en general se ve sin armas para que, actuando con prevención, se pueda combatir una contaminación, o en su caso minorar sus consecuencias.. Por otra parte, existen muchos menos estudios, métodos de análisis de riesgos medioambientales, por lo que 
es más difícil el saber qué medidas preventivas (con rigor) se han de adoptar para combatirlo.

\section{BLOQUE 5. TENDENCIAS}

1. ¿Qué tendencia piensa que seguirá la comunicación en prevención de emergencias e infancia en los próximos diez años? ¿Por qué?

En solo diez años, creo que la tendencia será de crecimiento en cuanto a actividades desarrolladas desde los organismos de emergencias, con el colectivo infantil. Pero, debido al incremento rápido de falta de recursos en las instituciones, puede haber un desfase entre la información que se imparta con la realidad del entorno- por las dificultades en llevar a cabo un buen mantenimiento (tanto de infraestructuras y recursos, como de planificación).

2. Puede añadir aquí las consideraciones adicionales que desee, si algún tema de interés para usted no se ha abordado en las preguntas anteriores.

Creo que sería interesante, y así demostrarían nuestros dirigentes su alto nivel de concienciación, incluir dentro de los planes académicos (a todos los niveles), la prevención de riesgos; ya que vivimos en una sociedad del riesgo, para los que debemos estar preparados a afrontarlos. Este sería el nuevo modelo de gestión de riesgos. 


\section{ENTREVISTA A D”a ELENA PUERTAS}

Psicóloga. Dirección General de Protección Civil y Emergencias. Subdirección General de Planificación, Operaciones y Emergencias. Grupo de Psicología de Catástrofes

\section{BLOQUE 1. EXPERIENCIA DE LA INSTITUCIÓN/COMPAÑÍA/PROYECTO AL QUE REPRESENTA EL ENTREVISTADO}

\section{1. ¿En qué consiste la actividad que llevan ustedes a cabo para el público infantil?}

La DGP dentro de sus competencias tiene el tema de la autoprotección escolar y la educación para la prevención. Este objetivo lo ha llevado a cabo a través de diversas acciones. La primera de ellas, que es bastante fundamental, es que ha elaborado un conjunto de guía didácticas para profesores de todos los riesgos en los que tenemos competencia la protección civil. Estas guías didácticas lo que contemplan es que los niños aprendan pautas de autoprotección y de prevención en relación a esos riesgos, tanto en el entorno escolar como en el entorno familiar. Entonces tenemos guías didácticas de riesgo de inundaciones, de riesgo volcánico, sísmico, incendios forestales... tenemos una de autoprotección escolar en general, tenemos una que estamos elaborando actualmente sobre riesgo nuclear, de accidente en centrales nucleares, tenemos una de tsunamis. Estas guías tienen el objetivo de que los profesores implanten a lo largo del curso, una serie de actividades y de juegos para que los niños se vayan concienciando y vayan aprendiendo esa cultura de la prevención de forma transversal. De tal manera que en primaria por ejemplo puedan incluirlo en Lenguaje con determinados términos, en Dibujo, dibujando algunos de los fenómenos de la naturaleza de los que se tratan los riesgos y demás. Y luego en secundaria se ampliaría un poco más a las Matemáticas, a la Física y demás.

También en estas guías se contempla una serie de orientaciones y actividades pedagógicas dirigidas a los profesores, para que la implantación de la guía a ellos les resulte más fácil, porque ellos no son especialistas en los riesgos.

Por otra parte, también hay una serie de directrices de apoyo psicológico a los niños cuando viven una emergencia. $Y$ en la guía de autoprotección general está incluido otro riesgo también, el bullying, como riesgo social y psicológico en lo que es el propio centro escolar.

Por otro lado, lo que se viene haciendo desde hace bastante tiempo, desde hace 9 ó 10 años, es que a través de un convenio entre el Ministerio de Educación y el 
Ministerio del Interior celebramos el certamen de unos premios para la seguridad y la protección en colegios de toda España, de tal manera que incentivamos que los colegios trabajen el tema de la seguridad y de la protección, y se puedan presentar a este concurso. Hay un jurado que otorga los premios a los mejores trabajos de los colegios que se hayan presentado. $Y$ esto se ha hecho ya durante bastantes años.

Otra de las cosas que hacemos es una semana entera de la prevención en la escuela, que se llama La Prevención empieza en la Escuela, siguiendo el lema de la propia Estrategia Internacional para la Reducción de Desastres, y lo que se hace es que la Escuela Nacional de Protección Civil, en Rivas (Madrid), está abierta a una serie de colegios de la zona, en la que se les entrena en distintas pautas de prevención y autoprotección. Por ejemplo hay un taller de primeros auxilios, en los que se les enseña las nociones más básicas de primeros auxilios, se trabaja también la seguridad vial y hay un taller en el que tenemos bicicletas, cochecitos para el uso del cinturón de seguridad, del casco, y se les enseñan normas básicas de seguridad vial. También hay un taller de autoprotección en accidentes aéreos, donde también se trabaja el tema de la solidaridad y de la cooperación con los demás. Hay también otro de incendios en el que se les enseña el funcionamiento básico de un extintor, como prevenir algunos incendios, qué comportamientos son peligrosos a la hora del fuego y demás.

El año pasado también editamos un video que se llamaba "Autoprotección de centros escolares", fundamentalmente para el riesgo de incendios en los centros escolares, que se rodó en un colegio de la Comunidad de Madrid (en Sevilla la Nueva), y también contamos con ello en el Centro de Documentación. Y en la feria de Aula, en el IFEMA, siempre tenemos un stand en el que siempre llevamos todos estos materiales. Este video ha gustado mucho y nos han hecho muchas peticiones.

Otra cosa que hacemos es en todos los programas de Información a la Población con los que colaboramos, ofertamos la posibilidad de la implantación de las guías didácticas, y algunos de los documentos divulgativos que tenemos también específicos para niños.

Esas guías didácticas todas llevan un CD interactivo de juegos y actividades con los niños.

Actualmente estamos preparando la realización de un simulacro internacional de accidente nuclear en la central nuclear de Almaraz, en Cáceres, y en todo el programa 
de información preventiva a la población hemos incluido a la población infantil, y hemos elaborado un video, rodado un video en uno de los colegios de la zona, sobre los comportamientos a seguir por parte de los niños en caso de que un accidente nuclear ocurriera en horario escolar.

También tenemos la web infantil, unas actividades básicas, explicaciones y recomendaciones, en relación a los distintos riesgos, para que desde las distintas instituciones y la gente que visite nuestra página, también comprenda la importancia de que los niños puedan ya tener desde las primeras etapas evolutivas este tipo de entrenamiento y este tipo de información.

\section{2. ¿Por qué han elegido esta modalidad pedagógica y no otra?}

Es una metodología muy participativa, que lo que pretende es que sea transversal, y no solamente que conciencie y prepare para la respuesta preventiva ante determinados riesgos. Se ha comprobado que algunos programas preventivos sobre determinados riesgos tienen una eficacia indirecta $o$ dan a conocer otros riesgos también. Entonces concebimos que la metodología debía ser de una implantación transversal a través de los profesores para que realmente las actitudes preventivas formen parte de la cultura y de la educación de estos niños, no solamente en los riesgos que nos competen sino en todos los riesgos de uso social que puede haber, por ejemplo en drogadicción, en alcoholismo, en tabaquismo, en seguridad vial, en salud pública etc etc.

\section{3. ¿Hay diálogo y feedback con el público infantil o es una comunicación más unidireccional?}

En otros ámbitos, por ejemplo los Bomberos o Policía, van a los colegios a dar información preventiva por ejemplo sobre el uso de las redes sociales, o sobre el fuego, etc., y esto es el experto o el representante directamente con los niños. Nosotros no, nosotros hemos descansado en la figura del profesor para que lo trabaje a lo largo de todo el curso, y además siempre con una metodología participativa por parte del niño, fundamentado no solamente en el conocimiento técnico y teórico de lo que es el riesgo, sino también en actitudes sociales y en comportamientos preventivos. Es decir, que realmente en la guía didáctica los contenidos son técnicos pero con el apoyo de las orientaciones pedagógicas lo que facilita es que haya una integración entre las tres dimensiones, la cognitiva, la comportamental y la afectiva. $Y$ que los 
niños efectivamente trabajen el riesgo y trabajen la prevención desde los distintos ámbitos de su crecimiento, no solamente desde la teoría del riesgo.

\section{4. ¿Ha participado algún otro actor social en el desarrollo o puesta en marcha de} su actividad? (organismos públicos, comunidad educativa, fundaciones, etc.). ¿Cuál?

La comunidad educativa, y por ejemplo en el tema nuclear también los Ayuntamientos de municipios que tienen centrales nucleares y que están en el área de la planificación. Apoyan y aporta medios por ejemplo si hay que realizar una evacuación.

\section{5. ¿Se han medido alguna vez los resultados de su actividad? ¿De qué manera y con qué resultados?}

Una medición sistemática y estructurada como tal no. Este es una de las asignaturas pendientes de los estudios de prevención. Se evalúa muy poco. Muchas veces se valora el impacto del programa en sí, el impacto emocional casi, pero realmente no hay una estructura de medición que mida los resultados a medio o largo plazo. Quizá en este sector infantil tengan que pasar años para saber si realmente han interiorizado este tipo de actitudes. Aunque sí que parece que en relación a generaciones anteriores son niños que sí que se ponen el cinturón de seguridad, que tienen una clara actitud para reciclar en relación al cuidado del medio ambiente, que son actitudes preventivas. Pero también dependiendo de las zonas en las que se viva y de los riesgos... Por ejemplo en el Mediterráneo que hay más inundaciones tendrán más cultura de inundaciones que de volcanes, que hay mucho menos. $O$ en zonas que son un poco más sísmicas, a lo mejor ellos no han sentido directamente el sismo, pero hay memoria histórica y lo han escuchado en casa o lo han escuchado a adultos, entonces hay más sensibilización en relación al comportamiento preventivo en este tipo de riesgos que en otros. Entonces yo creo que todavía no tenemos parámetros que nos indiquen la eficacia o no de estos programas. Cabe entenderse que al menos en algunos de los comportamientos sociales cotidianos, estos niños sí que están siendo preventivos. Con el tema de fumar, pues dicen "papá no fumes", digamos que la pauta negativa la entienden mucho mejor porque no ha habido que disuadirles. No es como a nosotros que a lo mejor nos han tenido que disuadir del fumar, o del reciclar, o del correr en el coche. Nosotros a ellos les estamos persuadiendo y es mucho más fácil que disuadir de algo que ya tienes interiorizado. Pero vamos, parámetros de 
evaluación sistemáticos y estructurados como tal, desde luego no creo que haya demasiados.

BLOQUE 2. CÓMO COMUNICAR PREVENCIÓN DE EMERGENCIAS EN LA INFANCIA

1. ¿Cuáles piensa que deberían ser los contenidos básicos que se habrían de trasladar a los niños en materia de prevención de emergencias? ¿Hay algún tipo de contenido a evitar? ¿Por qué?

Contenidos básicos, todos aquellos de los riesgos que la sociedad actual de hoy en día no puede evitar, empezando por los de la naturaleza, siguiendo por los de la propia convivencia humana y colectiva, e incluso riesgos psicosociales como el de bullying. Incluyendo desde luego todos los temas de salud pública. Hay que dar información preventiva dependiendo del nivel educativo. Por ejemplo en temas de drogas, alcohol, de sexo... Los programas preventivos tienen una eficacia indirecta en otros programas preventivos, por tanto cuanto más extensión hagamos de la prevención, independientemente del riesgo, mayor comportamiento preventivo obtendremos en la persona. ¿Cuál no debemos de incluir? No se me ocurre ninguno. Los niños dependiendo de su nivel educativo y de su edad cronológica sí deben conocer los riesgos. Hombre, a un niño de cuatro años no le vas a hablar del riesgo del alcohol a lo mejor, o del riesgo de un embarazo no deseado, pero si vive en una zona sísmica sí que le tienes que decir donde se tiene que meter cuando la tierra le tiemble. $Y$ a lo mejor a un niño de ocho años pues también ya le puedes ir introduciendo en cosas de seguridad vial, de salud pública, pero también dependiendo del entendimiento. ¿Suprimir? No se me ocurre ninguno. En principio me parece que la prevención de todos los riesgos que tenemos que vivir es buena. No significa que tengamos que bombardear a los niños continuamente con la prevención de los riesgos o que les tengamos que asustar, pero que intentemos desarrollar en estas generaciones una cultura de la prevención, yo creo que sí. Porque eso va siempre a favor de su propia seguridad y de su entorno.

2. Por favor indique si está más de acuerdo con a) o con b), y por qué motivo.

La educación sobre los riesgos y cómo evitarlos (por ejemplo: incendios de vivienda): 
a ) Debe adaptarse a las características locales del entorno conocido por el niño, como las condiciones geográficas, culturales, etc.

b) No debe tener en cuenta las características locales, sino ser una explicación universal susceptible de ser comprensible en cualquier lugar de un país o del mundo.

Parece que la primera es más lógica, dado que los niños se van a mover más en ese nivel. Pero que sea universal, y que pueda ser entendible, y que pueda ser asumida, o asimilada para cualquier parte del mundo también me parece importante, porque el niño puede trasladarse, y puede encontrarse en distintos lugares del mundo. Ya conoces el caso emblemático de la niña inglesa que en el tsunami asiático salvó la vida de varias personas, porque identificó que el mar retrocedía y que este fenómeno precedía al tsunami, aunque en Inglaterra no haya tsunamis. Sin embargo, la niña tenía pautas de comportamiento preventivo en este riesgo, y contribuyó a que hubiera menos víctimas, y a salvarse a ella y a su familia.

3. ¿Qué fórmulas considera más idóneas para acercar el mundo de la prevención de emergencias a los niños?

El juego, la participación, el debate, y todas las fórmulas que hemos visto antes.

4. ¿Dónde piensa que se han de abordar estos temas?: ¿casa, colegio, televisión, la red, instalaciones y dependencias de servicios de emergencias, fundaciones, empresa privada?, etc. ¿Por qué?

Pienso que debe haber una función transversal. Quizá que pudiera estar promovida por los organismos de emergencias, pero trabajado desde la familia, en el colegio y en los distintos ámbitos de relación del niño.

5. ¿Cuál ha de ser el rol del niño en este proceso? ¿De qué forma puede incrementarse su participación?

Participativo. Él aprende, pero a través de su aprendizaje y de su propia experiencia, está transmitiendo también el conocimiento dentro de su entorno. A lo mejor a sus compañeros, o incluso en familia lo puede comentar. Lo que no significa que el niño 
tenga que ser el agente socializador para los adultos, no. Pero es verdad que también puede ser transmisor de una serie de conocimientos.

6. ¿Piensa que las nuevas tecnologías abren nuevas formas de comunicarse con la infancia en estos temas? ¿Por qué?

Todas. Porque así como en nuestras generaciones las nuevas tecnologías nos están dando mucho, pero no nos llegan tanto, quizá porque tenemos otros hábitos de búsqueda, para ellos todo. Las nuevas tecnologías con juegos interactivos, video juegos, etc., eso es fundamental.

\section{BLOQUE 3. ACTORES SOCIALES EN LA COMUNICACIÓN DE PREVENCIÓN DE EMERGENCIAS}

1. ¿Qué tipo de instituciones piensa que están más implicadas en la difusión de temas de prevención de emergencias entre los niños? (organismos de emergencias, instituciones educativas, compañías, etc.) ¿Por qué sucede así?

No podemos excluir. Creo que en la justa medida de la responsabilidad que tenemos cada uno, así estamos. Supongo que habrá comunidades autónomas más sensibilizadas que otras, habrá directores generales de la administración general del estado más interesados que otros, habrá personal docente más interesado que otro dependiendo del colegio, habrá colegios que les den mucha importancia a estos temas y habrá otros que no, dependiendo también de la zona, de la experiencia que tengan con las emergencias, etc. Entonces yo no creo que sea una respuesta única, es decir, supongo que todos los sectores que estamos implicados estamos interesados y de ahí en función de las circunstancias pues la aplicación de estos programas en épocas será de una manera y en épocas será de otra.

\section{2. ¿Cree que hay diálogo entre los diferentes actores sociales o cada uno funciona de forma independiente a los demás?}

A veces sí y a veces no. Por ejemplo en el caso del tema nuclear, estamos en contacto con el Gobierno de Extremadura, y con los colegios, que es un actor fundamental, pues también, cuando vienen a la Escuela Nacional de Protección Civil. 
Con el Ministerio de Educación hemos tenido muchas reuniones para incluir en el área curricular algún tema de estos, y parece que han incluido algún tema de protección civil, etc. Es decir, diálogo hay porque no puede ser de otra forma. Todos estamos implicados porque tenemos responsabilidad. Pero insisto, somos demasiados actores como para poder resumir. ¿Hay diálogo o no hay diálogo? Lo hay, a veces muy fluido y muy bien, y a veces peor.

\section{3.¿Piensa que se implican más las instituciones de carácter local, autonómico, nacional o internacional? ¿Por qué?}

A nivel internacional, la Estrategia Internacional para la Reducción de Desastres tiene el norte puesto en el tema de la prevención, y concretamente en el tema de los niños. Desde que la Estrategia Internacional recomienda a los gobiernos de todos los países que realmente se invierta y se apoye la educación para la prevención, pues es una palanca importantísima a nivel internacional.

Hemos hecho dos congresos internacionales de Educación y Formación para la Prevención, en relación a la Estrategia Internacional para la Reducción de Desastres, en los años 2003 y 2006, en la Escuela Nacional de Protección Civil. También se incluyó el área del estudio de la prevención y la gestión de riesgo de desastres en universidades, centros de trabajo, etc.

A nivel nacional, nosotros y el Ministerio de Educación también estamos interesados y en la medida de lo posible llevamos a cabo diversas acciones. A nivel autonómico sí que te diré que muchos de los temas de los riesgos están transferidos a las comunidades autónomas, y hay algunas que realmente trabajan fenomenal con los colegios. Pero otras no, otras trabajan muy poco.

Otra cosa que hemos hecho, fue en el año 2006 me parece, hicimos una experiencia de formación de formadores con muchos docentes de todas las provincias españolas, para que ellos formaran a los chicos y chicas de secundaria en la prevención de incendios forestales en el verano. $\mathrm{Y}$ de ahí todas las Comunidades Autónomas, a través de las Subdelegaciones del Gobierno, colaboraron.

Respecto a los Ayuntamientos, pues igual. El Ayuntamiento de Madrid tiene muchos materiales de prevención, y hay muchos ayuntamientos más pequeños, por ejemplo el de Lorca ( Murcia), que también está intentando trabajar. Muchas veces el tema del dinero condiciona mucho. El Ayuntamiento de Lorca está intentando trabajar mucho el tema de los terremotos. El País Vasco trabaja fenomenal, Cataluña también trabaja muy bien. 
1. Diga si está de acuerdo o no con estas afirmaciones y por qué:

- El niño formado en prevención de emergencias es capaz de trasladar esa información a los adultos

- Un niño formado en prevención de emergencias será en el futuro un trabajador más seguro

Estoy de acuerdo con las dos.

2. ¿Considera que en nuestra sociedad estamos preocupados ante riesgos crónicos como aquellos relacionados con la alimentación o la contaminación? ¿Considera que en nuestra sociedad estamos preocupados ante riesgos agudos como una inundación en nuestro municipio o un incendio en un colegio? ¿Por qué?

A lo largo de los años hemos hecho algunos estudios sobre percepción de riesgos en España, el último fue en el 2007. De los primeros riesgos que percibían los españoles era el tema del terrorismo, y luego pues ya dependía de la zona. Por ejemplo inundaciones también era un riesgo relativamente percibido, y por ejemplo en Canarias pues más el volcánico, y dependiendo un poco del riesgo histórico que tenga la comunidad, se percibe con mayor precisión.

El tema de la contaminación, quizá aprendemos que es un riesgo, pero no creo que los españoles en general tomemos medidas efectivas para no contaminar. Bueno, es una percepción mía subjetiva, realmente no lo sé. Pero no creo que estemos tan concienciados de la contaminación como una persona que haya vivido inundaciones, por ejemplo.

\section{BLOQUE 5. TENDENCIAS}

1. ¿Qué tendencia piensa que seguirá la comunicación en prevención de emergencias e infancia en los próximos diez años? ¿Por qué?

Pienso que mejorará. Par empezar la legislación, por ejemplo en prevención de riesgos laborales, está inculcando en otros niveles de la sociedad la importancia de la prevención por ejemplo en los centros de trabajo, en las comunidades de vecinos. Por 
otra parte, pienso que en el colegio, con determinadas actividades y con el tema de redes sociales, de prevención de drogadicciones, de tabaquismo, etc., cada vez se irá ganando en prevención, por lo menos en estos riesgos actuales que tenemos ahora, claro. No sabemos si dentro de diez años habrá algunos otros riesgos para los cuales no estemos preparados y no tengamos prevención que valga. También es un poco aventurado el pensar que será que sí, porque vete a saber, a lo mejor vamos mejor en los de ahora, pero no sabemos qué tal en los futuros.

2. Puede añadir aquí las consideraciones adicionales que desee, si algún tema de interés para usted no se ha abordado en las preguntas anteriores. 


\section{ENTREVISTA: D.LUIS CARMENA}

Director Fundación Fuego para la Seguridad contra Incendios y Emergencias; y

Director Técnico Fundación Fuego.

\section{BLOQUE 1. EXPERIENCIA DE LA INSTITUCIÓN/COMPAÑÍA/PROYECTO AL QUE REPRESENTA EL ENTREVISTADO}

\section{1. ¿En qué consiste la actividad que llevan ustedes a cabo para el público infantil?}

La primera es campamentos infantiles de emergencias. Lo que hemos creído fundamental es que los chicos deberían tener una formación básica en lo que son las emergencias, y cómo prevenirlas. Una buena edad en la que pueden tener un buen entendimiento a la hora de comprender qué es una emergencia, es entre los 5 y los 12 años. Era una buen edad para empezar a aprender.

Los chicos realizan cinco actividades distintas, que son cinco emergencias que creemos que se pueden dar en lo que es el día a día de las familias, del colegio y de su entorno en general.

La primera es conocer cuáles son las emergencias más inmediatas. Lo que van a hacer es enfrentarse a una situación de fuego, en la que les van a indicar cómo salir sin mayores problemas. Es una formación que se da con profesionales de las emergencias, concretamente bomberos, en este caso de la Comunidad de Madrid.

El segundo día lo que van a aprender son emergencias médicas, cómo enfrentarse a una situación si han tenido un accidente, un incendio, una emergencia sanitaria, una herida, un corte, intoxicados por humo, etc., ver de qué manera pueden solucionar eso. Ellos han visto por ejemplo cómo inmovilizar un brazo o una pierna, cómo solucionar un corte de manera inmediata sin tener medios, o cómo utilizar la llamada al 1-1-2 de emergencia.

También otras cosas cómo qué es lo que tienen que hacer en caso de quemadura, si por ejemplo se queman en su casa. En definitiva, ven cómo hacer el primer paso antes de llamar a los servicios de emergencia.

El tercero es cómo hacer rescates acuáticos, saber qué puede pasar si estamos jugando por ejemplo en una piscina, qué hacer y qué no hacer, qué ocurre si encuentran un niño que no sabe nadar. Ellos son capaces de realizar una reanimación cardiopulmonar. Fueron practicando todos los niños, en una rueda y mediante unos desfibriladores todos masajearon a tiempo correcto. Aprendieron a atender las instrucciones de la máquina: indicaciones de cuándo parar, de continuar masajeando, 
de ver si respira. Los niños paran, escuchan, miran si sigue respirando, etc. Ellos entienden perfectamente el lenguaje, éste siempre debe ser muy cercano a ellos. Son capaces de absorber muchos conceptos, y luego saben ponerlos en práctica.

La cuarta actividad que hacíamos era sobre incendios forestales: cómo evitar un incendio, qué tienes que hacer si se produce, qué hacemos si nos encontramos con un animal durante el incendio. Aprenden ideas cómo no encender cerillas, no colocar cristales al sol, aprenden a ver de dónde venía el fuego y el viento, por qué se produjo así. Siempre se finaliza con la llamada al 1-1-2. Ellos saben que esa es una consigna básica, que se ha de finalizar con el aviso a emergencias.

La última es rescate a animales, esto se hace en conjunto con una asociación. Lo que se busca es que ellos tengan una relación con el medio ambiente, que lo cuiden, etc. Por ejemplo, si salen con sus padres a hacer marcha, o estamos en el campo en casa de los abuelos, siempre nos podemos encontrar con algún animal que se ha caído o está herido, hay que ver qué podemos hacer, cómo podemos cuidarles, y finalmente como siempre, ver cómo acudimos al 1-1-2.

\section{2. ¿Por qué han elegido esta modalidad pedagógica y no otra?}

Pensamos que es una manera muy directa de aprender además de muy divertida. No solamente vamos a facilitar una serie de conceptos básicos, sino que van a ponerlos en práctica, y siempre mediante el juego. Primeramente van a aprender los conceptos, y en segundo lugar pues se hacen cosas como ginkanas, donde se van a poner en práctica todas las actividades. Durante las mañanas se transmiten los conceptos, y las tardes son prácticas.

\section{3. ¿Hay diálogo y feedback con el público infantil o es una comunicación más unidireccional?}

Es difícil que sea unidireccional. Los niños bien sea a través de los medios, de su cole, de un amigo, de alguien que le ha pasado, del abuelo que se puso malo, etc., tienen ya ciertos conceptos. Ellos tienen además esa capacidad de corregirte si es que piensan que te han de corregir, de hecho tienen más conocimientos de los que nosotros pensamos. Lo que hay que hacer es tratar de dirigir esos conocimientos, modificarlo y adaptarlo a la realidad. Hay conceptos que todavía están muy en el aire. Del 1-1-2 sí que tienen nociones, no sé si será gracias al colegio. 


\section{4. ¿Ha participado algún otro actor social en el desarrollo o puesta en marcha de}

su actividad? (organismos públicos, comunidad educativa, fundaciones, etc.). ¿Cuál?

De momento no. Esta ha sido nuestra primera actividad. Para el año que, ya tenemos programada pasar esta formación a colegios, porque pensamos que ha de formar parte de lo que es la actividad diaria del cole, que forme parte de las asignaturas. Nosotros participamos también con la iniciativa de Educación Civil para las Emergencias, y nos parece que es fundamental que se dé formación en el colegio.

\section{5. ¿Se han medido alguna vez los resultados de su actividad? ¿De qué manera y con qué resultados?}

En la última edición que hicimos del campamento, se realizó una valoración por parte de los monitores. Se comprobó que se lograban fijar los conceptos aprendidos, se les hacían preguntas a los niños tras las actividades y veías que sí que eran capaces de responder sin ningún problema.

Algunos de nuestros hijos participaron. Eso nos permitió hacerles una encuesta directa. A lo largo del tiempo esos conceptos que aprendieron han quedado. También ves qué son templados, con "sangre fría", incluso los niños más activos. Esto tiene para ellos mucha importancia, ver que pueden ayudar, que pueden salir de una situación... Les hace sentirse importantes, porque se ponen a la altura de un bombero, de un médico, etc.

BLOQUE 2. CÓMO COMUNICAR PREVENCIÓN DE EMERGENCIAS EN LA INFANCIA

1. ¿Cuáles piensa que deberían ser los contenidos básicos que se habrían de trasladar a los niños en materia de prevención de emergencias? ¿Hay algún tipo de contenido a evitar? ¿Por qué?

Nosotros tenemos claro que los contenidos han de ir en función de la edad. Los conceptos han de estar siempre adaptados a la edad. Por ejemplo a los cincos años se intenta adaptar al aprendizaje que ya van teniendo de ciencias naturales, a su 
capacidad de aprender...Ha de ir enlazado su edad, su conocimiento y su capacidad de aprendizaje con la formación que nosotros le demos.

¿Excluir algún concepto? Ninguno. Porque los niños tienen una capacidad tremenda, hay un gran potencial. Lo que sí que hay que enseñarles siempre es a ser prudentes, hasta qué límite tienen que llegar, cómo tienen que hace las cosas. Ellos siempre tienen que hacer las cosas en el entorno de una persona mayor, y si esta no está, han de llamar al 1-1-2.

\section{Por favor indique si está más de acuerdo con a) o con b), y por qué motivo.}

La educación sobre los riesgos y cómo evitarlos (por ejemplo: incendios de vivienda):

a ) Debe adaptarse a las características locales del entorno conocido por el niño, como las condiciones geográficas, culturales, etc.

b) No debe tener en cuenta las características locales, sino ser una explicación universal susceptible de ser comprensible en cualquier lugar de un país o del mundo.

Tiene que ser universal. Porque acotar esa formación significa que tú has educado a un chico para una situación concreta. Lo que has de hacer es dar una formación con la que ellos puedan actuar en cualquier momento. Por ejemplo, si ellos viven en una vivienda en altura, y ellos se trasladan a vivir a una vivienda de una sola planta, no deja de ser una vivienda... Ellos deben saber enfrentarse en cualquier situación, ha de ser universal.

3. ¿Qué fórmulas considera más idóneas para acercar el mundo de la prevención de emergencias a los niños?

Hay muchas alternativas. A nosotros nos pareció una buena idea tener un campamento porque se sale de lo tradicional, es dar formación de una manera divertida, donde ellos participan de manera activa.

Lo que sí es bueno es que esta formación se diera de una forma habitual en los colegios, que ha de haber consejos de prevención, que todos deberíamos tener formación en nuestras casas, etc. Pero habitualmente esto no sucede. Y una manera de empezar es a través de los chicos, ellos van a ser el futuro, se empieza por ellos, y 
ellos a su vez formarán a sus hijos y así sucesivamente. Ha de ser una formación general.

La idea es que ellos empiecen jugando con esto, y a medida que van creciendo, que la formación sea un poco más desarrollada. Que empiecen jugando y que tengan en cuenta que esto pasa, que cuanto más cuidado tengan mejor, y que han de tener respeto. Que sepan también que los medios que tienen muchas veces no son suficientes, y que para eso están los bomberos y los servicios de emergencia en general.

Les ha de interesar y que el niño no vea que simplemente se les va a hacer un examen y se acabó.

Que ellos formen parte de esta formación, que ellos no vean esto como "tengo que estudiar mates", "tengo que estudiar lengua", sino que ellos lo vean como una cosa normal del día a día, que vean que va a ser una formación muy válida para ellos, que van a saber enfrentarse al fuego, que no han de tener miedo pero sí respeto. $O$ al fuego o a cualquier tipo de emergencia.

4. ¿Dónde piensa que se han de abordar estos temas?: ¿casa, colegio, televisión, la red, instalaciones y dependencias de servicios de emergencias, fundaciones, empresa privada?, etc. ¿Por qué?

En primer lugar los servicios de emergencia. El mensaje que les llega de un bombero, de un parque, los niños lo recuerdan. ( Dado que no pueden estar todos los días en el parque )Luego esto tiene que estar reforzado en el colegio. Y también en casa, pero no sólo de padres a hijos, sino también al revés.

Respecto a televisión, siempre hay campañas, pero para edades pequeñas a no ser que des con un personaje muy característico y que se desarrolle a lo mejor en forma de serie o algo así, las campañas a los niños no les llegan.

Entre las instalaciones de emergencia, el colegio y la casa, es donde creo que debe estar el $90 \%$ de todo esto.

Tiene que ser complementario en realidad.

5. ¿Cuál ha de ser el rol del niño en este proceso? ¿De qué forma puede incrementarse su participación? 
Como en toda la educación, el rol ha de ser activo. $\mathrm{Y}$ en esta educación especialmente, él ha de hacer cosas. Si viene alguien y te hace un sermón de media hora, pues bueno, pero si además es práctica, se va a implicar más... Además han de ver que si en un futuro ellos quieren ser voluntarios. Habría que buscar algo de forma que, igual que a esas edades se puede ser boy-scoutt, pues que si ellos quieren implicarse en algo relacionado con las emergencias, pues que puedan. Y si ya cuando son mayores quieren implicarse en voluntariado de Protección Civil, Cruz Roja, o convertirse en bombero o médico pues que sean. Pero hay que intentar implicarles desde el principio.

\section{6. ¿Piensa que las nuevas tecnologías abren nuevas formas de comunicarse con la infancia en estos temas? ¿Por qué?}

Sí pero con cuidado. Que no tenga carácter sustitutivo. Que no sólo sea por nuevas tecnologías, pero está claro que como recordatorio, como un juego, o aplicaciones, pues claro que sí, pero no sustitutivo.

Muchos de los niños, con discapacidad, son capaces de saber qué es una emergencia y cómo atenderla: existen unas aplicaciones con unos conceptos muy básicos, a través de pictogramas, con las que saben identificar una situación de emergencia. $O$ sea que sí, pero dependiendo: para estos chicos es fundamental esta forma de aprendizaje, pero para los chicos que tienen la capacidad de ser más autónomos, sí, pero siempre de forma complementaria.

BLOQUE 3. ACTORES SOCIALES EN LA COMUNICACIÓN DE PREVENCIÓN DE EMERGENCIAS

1. ¿Qué tipo de instituciones piensa que están más implicadas en la difusión de temas de prevención de emergencias entre los niños? (organismos de emergencias, instituciones educativas, compañías, etc.) ¿Por qué sucede así?

Instituciones educativas, poco. Se les está diciendo desde hace un año que incluyan los contenidos de emergencias y no lo meten, por lo general no lo meten. (Se refiere a la iniciativa de apoyo a la educación escolar en emergencias). Tienen actividades 
como visitas a parques, y no todos, como actividades no obligatorias sino complementarias.

Y luego respecto a los organismos de emergencia tampoco puedes generalizar. Unos se implican mucho, otros menos y otros nada. La respuesta de un organismo de emergencia cuando le proponen algo suele ser buena, pero hay que proponérselo.

Hay campañas de todo tipo en todas las Comunidades Autónomas: de ascensores, de calderas, de ventanas, pero no hay una campaña sobre esto. Entonces dices, ¿por qué? No lo sabemos. A lo mejor ni se lo han planteado, o creen que no hace falta, o que no es lo suficientemente mediático, o que es muy cara... Pero no hay ninguna campaña pública sobre esto. Como mucho está la Semana de la Prevención, que hace la Fundación MAPFRE, pero realmente no deja de ser algo privado. Cuenta muchas veces con los recursos públicos, pero no parte de ellos. $Y$ respecto a empresas con una labor social bestial, ninguna dedica un poquito a esto especialmente.

\section{2. ¿Cree que hay diálogo entre los diferentes actores sociales o cada uno funciona de forma independiente a los demás?}

No hay. Cada uno hace lo que le parece bien. $Y$ luego pues si se unen algunos como en la iniciativa de la Educación Cívica, bien, pero por lo general no hay. Salvo excepciones.

La conclusión es que la prevención de cara a la opinión pública vende muy poco, porque no se ve. En cambio, si cuando ha pasado algo, dices que vas a recaudar dinero para los afectados, pues eso ya vende más. Pero tú haces prevención y nadie lo ve, entonces el problema es ese. Hay que cambiar un poco el chip.

\section{3.¿Piensa que se implican más las instituciones de carácter local, autonómico, nacional o internacional? ¿Por qué?}

Hablando de emergencias, la implicación local es mil veces mayor que la autonómica, mil veces mayor que la central, y la internacional no lo sé. Pero la implicación nacional hablando de emergencias no existe. La autonómica, pues depende de cada comunidad, y la local sí, hay Ayuntamientos muy muy implicados, pero muchísimo. 
1. Diga si está de acuerdo o no con estas afirmaciones y por qué:

- El niño formado en prevención de emergencias es capaz de trasladar esa información a los adultos

- Un niño formado en prevención de emergencias será en el futuro un trabajador más seguro

Yo creo que las dos son así. Ellos son capaces de decir "esto no lo tienes que hacer", "esto sí lo tienes que hacer", y son capaces de decirte a ti que lo que estás haciendo está mal. Si ellos se han implicado, conocen el valor de lo que están haciendo, si saben que lo que pueden hacer puede salvar una vida, efectivamente ellos sí son capaces de formar a un mayor, y de hecho llegar a ser un trabajador seguro.

2. ¿Considera que en nuestra sociedad estamos preocupados ante riesgos crónicos como aquellos relacionados con la alimentación o la contaminación? ¿Considera que en nuestra sociedad estamos preocupados ante riesgos agudos como una inundación en nuestro municipio o un incendio en un colegio? ¿Por qué?

Respecto a los riesgos crónicos, sí estás más preocupado porque te afecta a ti. Es decir, la alimentación afecta a cada uno, la contaminación también. Ese tipo de riesgos te influyen directamente a ti. ¿El resto, como inundaciones o incendios? Hasta que no pasa no te afecta, entonces no te preocupas. Ante un incendio todo el mundo dice "si ocurriera un incendio qué horror", pero ya está. Incluso pasa un incendio a tres manzanas tuyas y dices "qué horror", pero tú sigues haciendo lo mismo. Y sigues sin interesarte por la prevención, no decir en el colegio que quieres que tu hijo tenga formación en prevención, o alguna actividad que esté relacionada con los servicios de emergencias. Eso sí, cuando te pasa, pues depende: si te afecta directamente, si se quema tu colegio y tu niño está en peligro, pues claro que cambias la mentalidad. Si no, pues siempre hay un periodo de que "esto no puede volver a pasar", pero luego se relaja. Un ejemplo es lo que ha pasado ahora: ocho meses después del Madrid Arena ha vuelto a pasar, en los San Fermines, pero exactamente lo mismo, sin fallecidos, pero ha vuelto a pasar. Por muchos San Fermines que sean, eso ha de tener unas medidas, y si no caben más de 300 corredores, pues no caben más. $Y$ los incendios forestales, hubo uno hace poco aquí en Valdemorillo. No se sabe exactamente, pero 
parece ser que el origen serían unos trabajos en una obra, y hace poco nos llamaron que se quemó un edificio porque un señor con una radial se le había caído y había cortado unos cables. Seguirá pasando todo el tiempo, a no ser que te afecte a ti pero que te afecte muy directamente, no al vecino, sino a ti.

Los riesgos que nos afectan, como imagen, bienestar, etc., sí que estamos preocupados, pero aquellos riesgos que puede ocurrir pero tampoco los tienes muy en cuenta, hasta que no te pasa no te das cuenta de que realmente podrías haber hecho mucho.

Y si te toca algún simulacro en algún lado, y encima como que te molesta.

Por ejemplo estás en tu oficina, y piensas "estoy en mi horario laboral, no voy a perder tiempo en estas cosas", o en el supermercado.

Sin embargo cuantas veces preguntan "y este móvil que me ha dado la empresa, ¿no me causará a mí un tumor, no?" En cambio le dices "como sigas gastando ese enchufe te vas a quemar" y te contestan "eso no pasa, hombre". La diferencia es esa, que no tienes en la cabeza que te puede pasar. $Y$ un incendio puede ser fatal.

\section{BLOQUE 5. TENDENCIAS}

\section{1. ¿Qué tendencia piensa que seguirá la comunicación en prevención de emergencias e infancia en los próximos diez años? ¿Por qué?}

Desgraciadamente esto va ligado a los sistemas educativos. Como sigamos cada cuatro, cada cinco, cada seis años, cambiando de sistema educativo, o que se llamen las mismas cosas de distinta forma, pones o quitas asignaturas... $O$ las administraciones locales y autonómica logran implicar a las centrales, y no me refiero al ministerio, sino a la Dirección General de Protección Civil, o si no esto será dando bandazos.

La iniciativa sobre Educación el Ministerio no la ha metido en los nuevos planes. Acabas de hacer una reforma, y decían que tenían interés, ¿cómo es posible que no la incluyas?

Dentro de $X$ años cambiará otra vez todo el sistema educativo, llamarán a una cosa otra, pero seguirá igual. A no ser que toque una persona que le ha pasado algo, y está preocupado con esto, o a no ser que las entidades de ámbito más local, autonómico y junto con la acción de las entidades privadas, pues lo desarrollen por su cuenta, no en forma de materia reglada pero sí con campamentos, charlas, etc. Actividades que los niños se les vayan metiendo poco a poco el gusanillo, incluso con programas de 
voluntariado para jóvenes. O llega una persona muy implicada con esto, o nosotros creemos que al menos desde el punto de vista oficial, esto seguirá igual.

Ahora queremos hacer una campaña, que de hecho se ha debatido ahora con una propuesta no de Ley en el Congreso, se ha presentado una campaña de detectores de humo para viviendas, para personas mayores, discapacitados, pisos tutelados. Se ha aprobado en general, menos por un partido. Lo triste de esto es que para poder llevarlo a cabo hay que hacer campañas para que la gente aporte económicamente, porque el Gobierno no se hace cargo de ello.

La idea es que el Congreso inste al Gobierno a hacer campañas, que ya es un paso.

La idea es que ahora todo el mundo vea normal tener una alarma en casa. Aunque nunca te hayan robado, ni te vayan a robar, la pones. Ahora es raro ver una casa que no tenga alarma. Entonces, ¿por qué es raro ver una casa que tenga, no te digo ya un extintor, sino por ejemplo una manta apagafuegos o un detector? ¿Por qué no podemos conseguir eso? Hay que ver qué han hecho las compañías de seguridad, y yo creo que el Ministerio, para que la gente lo vea normal. Porque hace veinte o treinta años no era normal tener una alarma en casa.

La idea es que la gente vea que este riesgo existe, que te puede pasar a ti, que lo vea con respeto, pero que vea que hay cuatro cosas que puede hacer que permite solucionarlo. Pero es complicado porque uno solo no lo puede hacer: ni las empresas privadas por su cuenta, ni los servicios de emergencia por su cuenta, las administraciones sí pero no están por la labor... Mientras no nos pongamos todos de acuerdo, o la mayoría, va a estar complicado.

\section{Puede añadir aquí las consideraciones adicionales que desee, si algún tema de interés para usted no se ha abordado en las preguntas anteriores.}

Los usuarios han de tomarse en serio la autoprotección. Primero los usuarios, luego los técnicos que lo hacen, y luego las administraciones que digan si está bien o mal. Mientras esto no pase, en sitios públicos, la seguridad de esta gente estará en entredicho, porque no sabrán responder. O la autoprotección nos la tomamos en serio, o esto avanzará todavía más despacio.

Pero bueno, llegaremos, llegaremos. O el 26 o el 27 de septiembre haremos una Jornada aquí en Madrid de Seguridad y Autismo. La idea es crear unos procedimientos no universales, pero sí generales, de forma que todas las personas 
relacionadas con el autismo, puedan aplicar esos procedimientos en sus centros. Luego queremos continuar con lesión medular. Luego creo que la ONCE tiene procedimientos para ciegos bastante avanzados.

El objetivo es ir avanzando en procedimientos que puedan servir a esta gente.

Habrá cosas en común de unas discapacidades a otras pero otras cosas no tendrán nada que ver.

Luego te encuentras con planes en los que aparece escrito que eso "es inevacuable". Esto ha pasado con un plan que hemos visto de una residencia, donde hay una persona con mucha discapacidad, y se decía "inevacuables", también hablaba de situaciones "inorganizables"... ¿Pero qué estás escribiendo y que se está firmando? ¿La administración qué está firmando? A partir de ahí nos activamos más. El único mensaje es que los planes los hagan bien. En las jornadas se hablará un poco. 


\section{ENTREVISTA A Da RAQUEL MANJÓN}

Responsable de Prevención del Instituto de Prevención, Salud, y Medio Ambiente de la Fundación MAPFRE

\section{BLOQUE 1. EXPERIENCIA DE LA INSTITUCIÓN/COMPAÑÍA/PROYECTO AL QUE REPRESENTA EL ENTREVISTADO}

\section{1. ¿En qué consiste la actividad que llevan ustedes a cabo para el público infantil?}

En el Instituto de Prevención al que yo pertenezco, casi todas las campañas que van dirigidas al público en general, nos dirigimos también al público infantil. También tocamos al resto de colectivos, adultos y personas mayores, pero fundamentalmente van dirigidas al público infantil, porque consideramos que son los ciudadanos del futuro y es donde tienes que inculcarles hábitos y conductas seguras, y hábitos de vida saludables.

Tocamos desde hábitos de vida saludable y ejercicio físico, y por otro lado está el tema de la prevención de accidentes.

En hábitos de vida saludable está la campaña Vivir en Salud. Normalmente nos dirigimos a Primaria. ¿El futuro cuál es? Pues dirigirnos incluso a niños de Infantil, y a adolescentes. Ya sabemos que para los adolescentes se requiere un esfuerzo especial, porque tienes que dirigirte de distinta forma, y ahora mismo estamos en ese proceso.

También tenemos la campaña de prevención de accidentes, que es Cuidadosos, y luego tenemos la Semana de Prevención de Incendios. Es una campaña que normalmente se realiza en colaboración con los cuerpos de bomberos de las distintas Comunidades Autónomas o Ayuntamientos. Conjuntamente elaboramos material, y hay una semana en concreto que se hacen normalmente entre septiembre y diciembre. Presencialmente durante una semana se hacen eventos. Quien lo hace son los cuerpos de bomberos. Nosotros lo que hacemos es que participamos también pero digamos que quien lo dirige y lo lidera son los cuerpos de bomberos. Él detecta en su comunidad cuáles son las necesidades que tiene y adecúa la Semana de la Prevención de Incendios en base a eso. 


\section{2. ¿Por qué han elegido esta modalidad pedagógica y no otra?}

Vivir en Salud y CuidadoSOS siguen exactamente la misma línea pedagógica. Sin embargo, la Semana de Prevención de Incendios, es diferente. Tanto Vivir en Salud como CuidadoSOS lo hacemos a través de las escuelas. En primer lugar nos dirigimos a la Consejería de Educación de la comunidad autónoma pertinente, allí presentamos lo que son los programas. Los programas están adaptados pedagógicamente a la edad de los niños y a todo lo que son los ciclos de primaria (primero, segundo y tercero). El material siempre lo hacemos bilingüe para que sea más fácil de implementar curricularmente por aquellos colegios que sean bilingües. ¿Cómo es el material? Está compuesto por un material de lectura, y un cuaderno de actividades. Y hay un cuaderno del profesor que es el de apoyo, se le amplían ciertos conocimientos teóricos para que el profesor sea capaz de implantarlo, muy resumidos. ¿Cuál es la idea, por qué utilizamos la lectura? Ahora mismo para entrar en el colegio, el currículum escolar está saturado. Entonces incrementar horas lectivas a estas materias lo consideramos que es complicado. Entonces, hay que hacerlo de forma lúdica. Nosotros les damos un material para que de forma divertida esté leyendo, y que le esté enseñando qué peligros puede tener en la casa, o cómo tengo que evacuar mi colegio. El niño lee un contenido y trabaja las actividades que se proponen en el cuaderno. ¿Qué hacen esas actividades? Reflexionar sobre la lectura, para que el niño interiorice y entienda lo que está leyendo. Nosotros incentivamos a que el profesor utilice el material, porque así como tienen que dedicarle semanalmente $x$ horas la lectura, pues se lo estamos poniendo fácil. En vez de leer otra cosa, pues lee esto que aparte te está aportando unos conocimientos y unos hábitos de autoprotección al niño, que en el futuro le será positivo.

\section{3. ¿Hay diálogo y feedback con el público infantil o es una comunicación más unidireccional?}

Normalmente todo el material, cuando vamos a una Comunidad Autónoma, lo apoyamos con un taller presencial, adecuado a la edad del niño.

La de CuidadoSOS por ejemplo son tres talleres, uno para cada ciclo escolar. El colegio que está interesado en la implantación del programa, nosotros vamos allí y le damos los talleres a los niños. Los monitores son profesionales, o bien bomberos 0 personal que trabaja en SAMU, no son monitores de tiempo libre. Los de primero de 
primaria tocan accidentes en el hogar, y la mitad del taller es un circuito de evacuación. Les ponemos el humo y un circuito en el que hay una puerta. ¿Qué tienes que hacer primero? Lo primeo que hace el niño es abrir la puerta, pero se les enseña que antes de abrirla, tienes que tocar la puerta, antes de entrar tienes que avisar al 1 $1-2$.

Nos encontramos casos de niños que no saben ni lo que es el 1-1-2.

$Y$ lo cierto es que un niño a los tres años ya sabe llamar por teléfono y el 1-1-2 lo puede conocer perfectamente.

Tampoco a veces saben cuál es su dirección de casa. "Estoy aquí", pero no sabe más. Entonces ahí ya se les enseña, a los niños de 6 años, que tienen que conocer dónde están, si están en el colegio cómo se llama el colegio, en qué calle, o si están en casa, saber dónde viven. Y esto un niño de 6 años lo puede saber de memoria.

A los niños se les dice que se tienen que agachar, que no tienen que pasar por arriba, pasan el circuito, se les dice que en caso de que se quemen, tienen que rodar, etc. Hay también una parte teórica en la cual se les da prevención de accidentes, y la segunda parte es de evacuación.

Luego en segundo ciclo de primaria, lo que hacemos es trabajar una parte teórica, en la cual les enseñamos más lo que son los elementos de protección contra incendios, que conozca qué es un extintor, qué es una alarma de incendios, qué es un pulsador, y les enseñamos también las señales de evacuación. Que cuando ellos vayan a un centro de pública concurrencia, que sepan en caso de que ocurra cualquier emergencia, que ellos sepan qué es lo que tienen que buscar. Se les muestra también un video con el que se les enseña cómo es la evacuación en un centro escolar, cómo tienen que comportarse, y hacemos también el circuito de evacuación.

En el taller del tercer ciclo, lo que hacemos es darles un breve recordatorio de las nociones de lo que es una evacuación, y por último ya se les da nociones de primeros auxilios. Ya son niños autónomos que ya hacen campamentos, ya hacen salidas solos, entonces se les da nociones en caso de que tengan cualquier percance, pues que conozcan el 1-1-2, que sepan la posición lateral de seguridad... No les enseñamos una RCP, pero sí que les enseñamos a mantener abertura de vías respiratorias, y posición lateral de seguridad, para que mantengan con vida a la persona herida. 


\section{4. ¿Ha participado algún otro actor social en el desarrollo o puesta en marcha de su actividad? (organismos públicos, comunidad educativa, fundaciones, etc.). ¿Cuál?}

Nosotros siempre vamos de la mano de las Comunidades Autónomas. CuidadoSOS se ha impartido en Castilla La Mancha, en Cantabria, en Andalucía, en Aragón, en septiembre estaremos en Madrid, y ahora mismo estamos en conversaciones con otras comunidades para de cara al año que viene.

En el caso de la Semana de la Prevención, con los cuerpos de bomberos. Eso ya es más local, y hay incluso campañas que se lleva a Ayuntamientos. Pero siempre solemos ir de la mano de algún organismo oficial porque en los colegios ahora mismo, ir privadamente es muy difícil entrar. Lo primero que piensan es que les vas a vender un seguro. Cuando se les explica que es una acción sin ánimo de lucro. Evidentemente a mí quien me da el dinero es MAPFRE, pero hay que entender que yo en ningún momento les voy a vender un seguro ni nada.

\section{5. ¿Se han medido alguna vez los resultados de su actividad? ¿De qué manera y con qué resultados?}

Todo es medible. No hacemos ninguna acción que no midamos. Se hacen entrevistas, cuestionario de opinión... El colegio valora la actividad, nos dice qué cosas le gustan, qué cosas no, cuáles son mejorables, todo lo tenemos cuantificado.

La respuesta es muy positiva. Por ejemplo en el último análisis, con valoración de 1 a 5 , pues todo lo valoran a cuatro.

Al principio los profesores son muy reacios, pero una vez que estás allí, luego lo valoran muy positivamente. Pero lo que cuesta es llegar. Muchos profesores prefieren que la actividad sea fuera, porque así ellos van y se despreocupan, aunque no es así en la mayoría de los profesores. Pero nosotros vamos allí, por lo que necesitamos un apoyo del centro, necesitamos un lugar donde poder hacerlo... Los profesores tienen que estar, porque está el monitor, pero el monitor está haciendo una actividad, entonces pues siempre tienes niños más activos o lo que sea, y el profesor tiene que estar también allí controlando. 


\section{BLOQUE 2. CÓMO COMUNICAR PREVENCIÓN DE EMERGENCIAS EN LA INFANCIA}

1. ¿Cuáles piensa que deberían ser los contenidos básicos que se habrían de trasladar a los niños en materia de prevención de emergencias? ¿Hay algún tipo de contenido a evitar? ¿Por qué?

Adecuando pedagógicamente y psicológicamente el material, yo creo que se les puede hablar a los niños de todo. No creo que haya que ocultarles nada. Si tú tienes un incendio hay un peligro, y es real, y no hay que ocultarlo. Yo creo que tendemos tanto a sobreproteger a los niños, que nos les estamos informando muchas veces de la realidad. $\mathrm{Y}$ yo creo que hay que decírsela. Evidentemente adaptada a su edad.

Cuando haces un simulacro, no es un juego, y se lo toman como que un simulacro es un juego. "Es que tenemos simulacro, ese día es fiesta", perdona pero no. No es fiesta, es algo muy peligroso. A veces no se cuenta algo porque si no "es negativo". Estamos hablando de algo peligroso, y se lo has de hacer ver al niño como algo peligroso.

\section{Por favor indique si está más de acuerdo con a) o con b), y por qué motivo.}

La educación sobre los riesgos y cómo evitarlos (por ejemplo: incendios de vivienda):

a ) Debe adaptarse a las características locales del entorno conocido por el niño, como las condiciones geográficas, culturales, etc.

b) No debe tener en cuenta las características locales, sino ser una explicación universal susceptible de ser comprensible en cualquier lugar de un país o del mundo.

Nosotros los programas que llevamos los exportamos a Latinoamérica. Sí que es verdad que tienes que hacer siempre una pequeña adaptación. Simplemente el lenguaje, aunque estamos hablando del castellano, es distinto. Nosotros estamos adaptando CuidadoSOS sin ningún tipo de problema. Lingüísticamente lo has de adaptar, pero tienes que hablar de una forma universal. Ahora mismo, y con la globalización que hay, el niño no se va a mover en un entorno local. En principio sí, pero los riesgos son universales. Es más generar un hábito de autoprotección en el niño, que éste sepa que en su entorno hay unos riesgos, que debe conocerlos, y cómo debo reaccionar ante ellos. No creo que haya que buscar más cosas raras. 


\section{3. ¿Qué fórmulas considera más idóneas para acercar el mundo de la prevención de emergencias a los niños?}

Hoy por hoy lo más sencillo es a través de las escuelas, porque el niño está allí el $80 \%$ de su tiempo. $Y$ respecto a los padres y los fines de semana, a lo mejor de forma puntual mediante alguna representación teatral, que nosotros lo hemos hecho... pero no les puedes exigir... La gente los fines de semana los utiliza más para su ocio, tiempo libre.

Mi experiencia es que estos programas que estamos llevando a cabo no ocupan tanto tiempo, es como un día de excursión, y el profesor las actividades las va haciendo paulatinamente a lo largo del curso. Trimestralmente va poniendo una o dos fichas, que es comprensión lectora, lo que están haciendo, o sea que están trabajando el curriculum. No les supone ninguna carga. $Y$ ya estás trabajando unos contenidos que no están metidos ahora mismo en materia escolar. No veo otra forma. ¿Las redes sociales? Creo que son útiles. El problema es que estos niños de primaria... ¿vas a dejar a tu hijo solo, con redes sociales? Cuando estamos viendo la problemática que hay ahora mismo con las adicciones al móvil... Creo que puedes hacer juegos, interactivos... Por ejemplo, los cuadernos de actividades que estamos trabajando ahora pues se digitalizan para que los niños en la pizarra digital puedan realizarlas presencialmente en el aula de informática. Estamos facilitando unos recursos para que los profesores los puedan utilizar en el aula.

Yo creo que hoy en día las redes sociales están más enfocadas a dar a conocer el programa, fomentarlo, hacerlo público, para profesores y adultos, equipo directivo de los centros escolares, etc. Pero con el niño yo iría más a juegos lúdicos, etc., yo creo que las redes sociales hay que tocarlas con cierto cuidado.

\section{4. ¿Dónde piensa que se han de abordar estos temas?: ¿casa, colegio, televisión, la red, instalaciones y dependencias de servicios de emergencias, fundaciones, empresa privada?, etc. ¿Por qué?}

Para los niños has de hacerlo de forma integral: familia, escuela, niños... El niño se mueve en un entorno que es la familia y el colegio, y creo que se ha de trabajar en ambos. Nosotros también tenemos un "Manual de la familia"...

Aunque el mejor interlocutor es el niño. Es como en el fumar, y el "papá no fumes": quien no le deja fumar es el niño que se lo dice al padre. El canal es el niño. Llega a 
casa y dice "hoy me han enseñado que es un simulacro, que si ocurre algo debo saber dónde estoy, que tengo que llamar al 1-1-2". El canal es el niño, pero debemos dirigirnos a todos: colegio, familia y niños. No podemos dejar un eje sin tocar.

\section{5. ¿Cuál ha de ser el rol del niño en este proceso? ¿De qué forma puede incrementarse su participación?}

Los niños, y más entre los seis y los doce años, son muy receptivos. El problema está en cómo llegar entre los trece y los dieciocho años. Pero si hemos sido capaces con un programa de seis a doce de generar el hábito, ya es trabajo que tienes hecho para que cuando ese niño llegue a los trece años, ya tengas hecho un trabajo. Hoy en día tenemos un vacío en los chavales de entre catorce y dieciocho años que no llegamos. En eso estamos trabajando. ¿Cómo llegar? Es muy complicado, porque su realidad ahora mismo es otra.

\section{6. ¿Piensa que las nuevas tecnologías abren nuevas formas de comunicarse con la infancia en estos temas? ¿Por qué?}

Yo creo que sí que puede aportar. Sólo que hay que hacerlo midiendo y cuidando mucho lo que pretendes. Ahora está muy de moda el decir "hay que estar en Facebook", y "hay que estar en Twitter", y hay que estar porque hay que estar. Vamos a ver, vamos a estar sabiendo dónde queremos estar: vamos a estructurar, vamos a planificar, qué queremos, qué pretendemos conseguir... Estar por estar yo creo que es un error. Tienes que ver cuáles son tus objetivos, qué quieres comunicar, y qué respuesta pretendes obtener con ello.

BLOQUE 3. ACTORES SOCIALES EN LA COMUNICACIÓN DE PREVENCIÓN DE EMERGENCIAS

1. ¿Qué tipo de instituciones piensa que están más implicadas en la difusión de temas de prevención de emergencias entre los niños? (organismos de emergencias, instituciones educativas, compañías, etc.) ¿Por qué sucede así?

Yo creo que los organismos de emergencia: bomberos, SAMU, Protección Civil... Las instituciones educativas hoy por hoy no lo consideran algo prioritario. Hay tal 
problemática en la educación, que lo que menos les preocupa ahora mismo son las emergencias. Lo ven algo colateral, muy bonito, pero no le prestan el mínimo interés.

En nuestro caso respecto a la Fundación MAPFRE, tradicionalmente el seguro es la prevención de accidentes. Tenemos 5 institutos, y uno de ellos se dedica a Prevención, Salud y Medio Ambiente, porque originalmente la prevención de accidentes, la medioambiental, etc., está en la propia estrategia del grupo, es innata. Por eso sentimos esa línea. Lo que la Fundación MAPFRE pretende con sus acciones es cubrir las carencias que ahora mismo la sociedad tiene. Trabajar sobre contenidos o materias que son una carencia en la sociedad. Por ejemplo en materia de prevención en este país, tanto en niños como en otros ámbitos sabemos que hoy en día hay una carencia. Lo que queremos es, con nuestra pequeña contribución, intentar inculcar a los niños para que nuestros futuros ciudadanos tengan unas conductas responsables para beneficio de la sociedad.

\section{2. ¿Cree que hay diálogo entre los diferentes actores sociales o cada uno funciona de forma independiente a los demás?}

Las iniciativas se impulsan individualmente. Fundación MAPFRE a nivel individual es la que se dirige a una Consejería, contacta, estudian el programa, si se ve adecuado por lo implantan, pero creo que ahora mismo, y más con la crisis, cada uno hace la guerra por su cuenta.

3.¿Piensa que se implican más las instituciones de carácter local, autonómico, nacional o internacional? ¿Por qué?

En estos temas de prevención, influye mucho la persona. Si es un Consejero que está mentalizado, lo tienes fácil. Con áreas locales, de Ayuntamiento, pasa lo mismo. Pero va más por percepción personal, no es porque institucionalmente vean esa estrategia, no, en absoluto: es la acción personal de una persona en concreto.

\section{BLOQUE 4. EL NIÑO EN LA SOCIEDAD}

1. Diga si está de acuerdo o no con estas afirmaciones y por qué:

- El niño formado en prevención de emergencias es capaz de trasladar esa información a los adultos 


\section{- Un niño formado en prevención de emergencias será en el futuro un trabajador más seguro}

Ambas son correctas. Que el canal para trasladar esto a los adultos es el niño, eso lo sabemos todos. El niño que va al colegio y luego a casa con "hoy he aprendido que si nos pasa algo el 1-1-2..." se lo va a contar a sus padres, sí o sí.

Respecto a la segunda afirmación, lo que estamos generando con esto son hábitos de autoprotección. Eso es extensible al futuro trabajador. Si tú a un niño le estás inculcando que cuando vaya a un local sepa cuál es el recorrido de evacuación, cuando sea mayor va a utilizar los EPIS, va a ver cuál es el recorrido de evacuación, va a ver qué conducta es preventiva, va a conocer los riesgos de su puesto de trabajo, etc. De lo que hemos de ser capaces es de generar hábitos de autoprotección en el niño. Que el niño identifique riesgos y sepa cómo enfrentarse a ellos, cómo evitarlos.

2. ¿Considera que en nuestra sociedad estamos preocupados ante riesgos crónicos como aquellos relacionados con la alimentación o la contaminación? ¿Considera que en nuestra sociedad estamos preocupados ante riesgos agudos como una inundación en nuestro municipio o un incendio en un colegio? ¿ Por qué?

Antes veíamos que sí que había un cierto movimiento social en el que la gente se preocupaba: cuidar el medio ambiente, hábitos de autoprotección, generar hábitos de vida saludable, ejercicio físico, etc. De cinco años hacia acá, con el tema de la crisis yo creo que todo eso yo creo que se ha olvidado, ha pasado a un segundo plano. Ahora mismo el reciclar o no reciclar... yo creo que en la mayoría de los sitios ya está muy inculcado, pero no es realmente que se preocupen. Hemos realizado una encuesta de percepción del cambio climático, que la hacemos cada dos años, y antes la preocupación por el medio ambiente estaba en el cuarto lugar, y ahora ha pasado al décimo. $Y$ no hemos hecho ninguna de prevención de accidentes, pero estoy totalmente segura de que todo esto ha pasado a un segundo nivel. Ahora mismo la gente no se preocupa ni del medio ambiente, ni de la prevención de accidentes... Si se lo das, lo ve muy positivo, pero en su día a día no es su preocupación. 


\section{BLOQUE 5. TENDENCIAS}

1. ¿Qué tendencia piensa que seguirá la comunicación en prevención de emergencias e infancia en los próximos diez años? ¿Por qué?

Con las nuevas tecnologías se podrán generar nuevos canales de comunicación, creo que todo es positivo. Pero no creo que todo lo que se innove hay que implantarlo porque sí. Pienso que la lectura, siempre va a ser así, porque los niños tienen que aprender a leer y tienen que hacer comprensión lectora, etc. Innovaremos en nuevas tecnologías y en nuevos recursos pedagógicos, a lo mejor surgen otro tipo de talleres, pero realmente poco se va a ir cambiando.

2. Puede añadir aquí las consideraciones adicionales que desee, si algún tema de interés para usted no se ha abordado en las preguntas anteriores. 
